REVISTA ESPAÑOLA DE DISCAPACIDAD
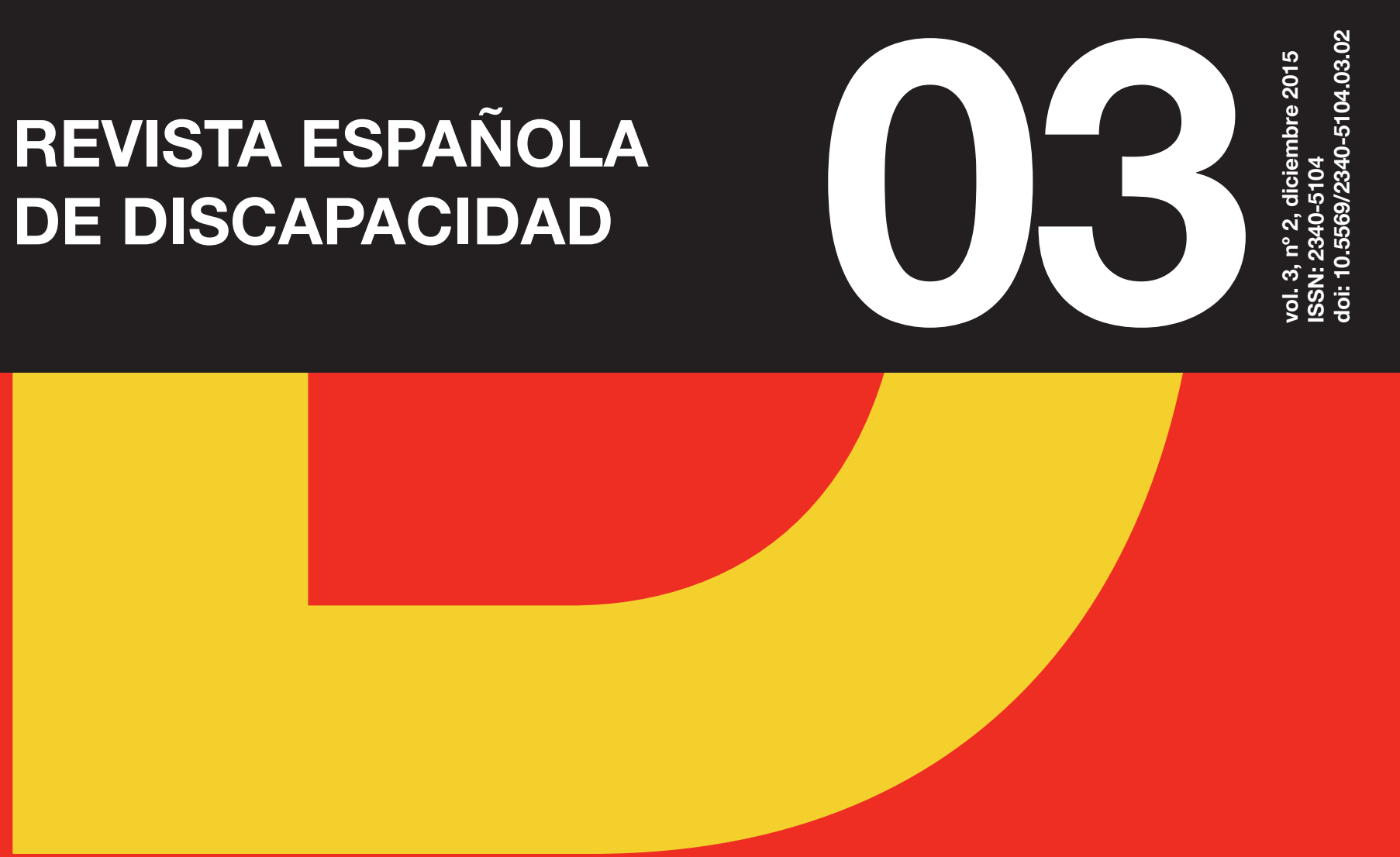
La Revista Española de Discapacidad (REDIS) es una revista electrónica de carácter científico, orientada a la publicación de artículos de investigación y/o de reflexión académica, científica y profesional en el ámbito de la discapacidad, desde una perspectiva multidisciplinar y en consonancia con el modelo social de la discapacidad y la visión de ésta como una cuestión de derechos humanos.

Es una revista de acceso abierto, revisada por pares y dirigida a todas las personas y entidades que trabajan e investigan en el campo de la discapacidad. Su periodicidad es semestral.

\section{Edita}

Centro Español de Documentación sobre Discapacidad (CEDD)

Fundación Eguía Careaga - SIIS Centro de Documentación y Estudios

Real Patronato sobre Discapacidad

C/ Serrano, 140. 28006 Madrid

Tel. 917452449

cedd@cedd.net

\section{Director}

Ignacio Tremiño Gómez (Director del Real Patronato sobre Discapacidad, Director General de Políticas de Apoyo a la Discapacidad,

Ministerio de Sanidad, Servicios Sociales e Igualdad)

\section{Secretario de redacción}

Eduardo Díaz Velázquez (Centro Español de Documentación sobre Discapacidad, CEDD)

\section{Consejo de redacción}

Antonio Jiménez Lara (Consultor social independiente)

Emiliano Díez Villoria (Servicio de Información sobre Discapacidad - SID; Universidad de Salamanca)

Joseba Zalakain Hernández (SIIS-Centro de Documentación y Estudios, Fundación Eguía Careaga)

Juan Antonio Ledesma (Comité Español de Representantes de Personas con Discapacidad, CERMI)

Ma Ángeles Aguado Sánchez (Subdirectora General de Gestión, Instituto de Mayores y Servicios Sociales, IMSERSO)

Mercedes Jaraba Sánchez (Subdirectora General de Coordinación y Ordenación, Dirección General de Políticas de Apoyo a la Discapacidad,

Ministerio de Sanidad, Servicios Sociales e Igualdad)

Rafael de Muslera Maesso (Consejero Técnico - Coordinador, Real Patronato sobre Discapacidad)

\section{Consejo asesor}

Agustín Huete García (Universidad de Salamanca/ Intersocial)

Agustina Palacios Rizzo (Universidad Nacional de Mar del Plata)

Ángel Calle Montero (Instituto de Mayores y Servicios Sociales, IMSERSO)

Antonio León Aguado Díaz (Universidad de Oviedo SAPRE, Sociedad Asturiana de Psicología de la Rehabilitación)

Belén Ruiz Mezcua (Universidad Carlos III de Madrid-Centro Español del Subtitulado y de la Audiodescripción, CESyA)

Carolina Ferrante (Universidad Católica del Norte, Chile)

Clarisa Ramos Feijóo (Universidad de Alicante)

Claudia Grau Rubio (Universidad de Valencia)

Climent Giné y Giné (Universidad Ramón Llull)

Demetrio Casado Pérez (Seminario de Intervención y Políticas Sociales, SIPOSO)

Fernando Fantova Azcoaga (Consultor social independiente)

Francisco Alcantud Marín (Universidad de Valencia)

Gerardo Echeita Sarrionandia (Universidad Autónoma de Madrid)

Gregorio Rodríguez Cabrero (Universidad de Alcalá de Henares)

Javier Tamarit Cuadrado (Plena inclusión)

Jesús Hernández Galán (Fundación ONCE)

Juan Luis Quincoces Soler (Centro Nacional de Tecnologías de la Accesibilidad, CENTAC)

Leonor Lidón Herás (Comité Español de Representantes de Personas con Discapacidad, CERMI)

Liliana Pantano (Universidad Católica Argentina / Consejo Nacional de Investigaciones Científicas y Técnicas, CONICET)

Manuel López Risco (Universidad de Extremadura)

María López González (Universidad de Córdoba)

María Luz Esteban Saiz (Centro de Normalización Lingüística de la Lengua de Signos Española, CNLSE)

Mario Toboso Martín (Consejo Superior de Investigaciones Científicas, CCHS-CSIC)

Miguel A. V. Ferreira (Universidad Complutense de Madrid)

Miguel Ángel Verdugo Alonso (Universidad de Salamanca)

Natxo Martínez Rueda (Universidad de Deusto)

Paulino Azúa Berra (Instituto para la Calidad de las ONGs, ICONG)

Unai Martín Roncero (Universidad del País Vasco)

Xavier Etxeberria Mauleón (Universidad de Deusto)

Yolanda María De la Fuente Robles (Universidad de Jaén)

\section{Diseño}

Estudio Lanzagorta

Maquetación

Concetta Probanza

ISSN: $2340-5104$

DOI: <http://dx.doi.org/10.5569/2340-5104.03.02>

NIPO: 689-15-006-1

Indexada en:

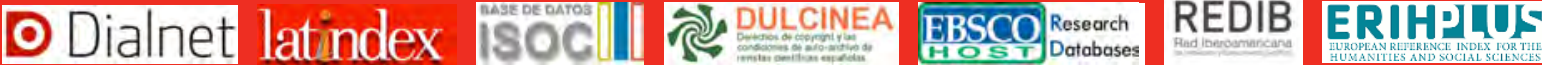

REDIS tiene una licencia Creative Commons: Reconocimiento - NoComercial - SinObraDerivada (BY-NC-ND). No se permite un uso comercial de la obra original ni la generación de obras derivadas. Está permitida la reproducción total o parcial por cualquier medio de los artículos de la revista, siempre que se cite la fuente y el autor o auto-res de los mismos. 


\section{Índice}

\section{ARTículos}

7 Herramientas de cribado para la detección de retrasos o trastornos en el desarrollo: Una revisión sistemática de la literatura

Francisco Alcantud Marín Yurena Alonso Esteban Darío Rico Bañón

27 Estrategias psicosociales utilizadas para el cambio de actitud hacia personas discriminadas por su discapacidad o trastorno mental

Jesús Armando Delgado Meza

41 Necesidades afectivosexuales en personas con discapacidad intelectual. Claves para construir propuestas formativas desde la experiencia subjetiva

Susana Rojas Pernia Ignacio Haya Salmón Susana Lázaro Visa

55 Interpelaciones desde la diversidad funcional. La (in) justa medida de la capacidad en Chile

Ana María Valenzuela Rabi

79 Significados y prácticas de mediación orientada a la inclusión en el contexto mexicano

Úrsula Palos Toscano

María Luisa Avalos Latorre

Roberto Montes Delgado

\section{TRIBUNAS}

101 Personas con Trastorno del Espectro del Autismo con necesidades intensas y generalizadas de apoyo: estrategias para mejorar su calidad de vida

Ruth Vidriales Fernández

José Luis Cuesta Gómez

Marta Plaza Sanz

Cristina Hernández Layna

117 Modelos, pseudomodelos y "burbujas terapéuticas" en Atención Temprana

Juan Carlos Belda Oriola

125 Arte y salud social. Programas de participación sociocultural para personas con diversidad funcional

María Martínez Lemos Jesús Rodríguez López

133 La sordera: una oportunidad para descubrir la música

Liliana Elizabeth Otero

Caicedo

139 ASPAYM Córdoba a fondo Esther Carrasco Rivero 


\section{RESEÑAS}

147 Gregorio Rodríguez, Julia Montserrat Codorniu y Vicente Marbán (2015): Los beneficios de la inclusión social de las personas con discapacidad. Madrid: Grupo Editorial Cinca

SIIS Centro de Documentación y Estudios

151 Amparo Cano, Eduardo Díaz, Susana Rodríguez, Mario Toboso y Miguel A. V. Ferreira (2015): Discapacidad y políticas públicas. La experiencia real de los jóvenes con discapacidad en España. Madrid: Los Libros de la Catarata

SIIS Centro de Documentación y Estudios

\section{BREVES RESEÑAS} BIOGRÁFICAS 


\section{ARTículos}





\section{Herramientas de cribado para la detección de retrasos o trastornos en el desarrollo: Una revisión sistemática de la literatura}

\section{Screening tools for detection of delays or developmental disorders: a systematic review of the literature}

\begin{abstract}
Resumen
El objetivo del artículo es analizar

los diferentes instrumentos de

detección de trastornos o retraso en el desarrollo para valorar la calidad y aplicabilidad de los mismos. Se realiza una revisión sistemática de las publicaciones científicas publicadas en los últimos 25 años (I990-20I4) e indexadas en bases de datos internacionales disponibles en línea. El estudio se limita a herramientas de detección basadas en cuestionarios, tests o sistemas de observación de la conducta del niño. Las herramientas o sistemas analizados son valorados según una escala de calidad construida "ad hoc". Los resultados demuestran una gran variabilidad de herramientas y sistemas de detección, muchos de ellos son cuestionarios de investigación, otros son herramientas de diagnóstico utilizadas con fines de detección. Se pueden clasificar en dos grandes bloques, los construidos en base a los hitos evolutivos cuyo incumplimiento temporal puede significar un retraso en el desarrollo y aquellos otros que, asumiendo el primer principio han seleccionado los hitos que pueden ser precursores de trastornos del desarrollo.

En las conclusiones se realizan recomendaciones para la validación de los sistemas de detección en España y la construcción de nuevos.
\end{abstract}

\section{Palabras clave}

Revisión sistemática, detección, trastornos del desarrollo, retraso en el desarrollo.

\begin{abstract}
The goal of this article is to analyze the quality and applicability screening instruments aimed at detecting developmental delays or disorders. A systematic review of the scientific literature published during the last 25 years (I990-20I4) retrieved from different databases is carried out. The study is limited to detection systems based on questionnaires, tests or observation of children`s behavior. The analyzed systems are rated on a scale of quality built "ad hoc". The results show a high variability of tools and detection systems, many of which are research questionnaires, while others are diagnostic tools used for screening purposes. They can be classified in two large groups of instruments: I), the ones based on developmental milestones whose temporary failure can mean a delay in the development and 2), those who, assuming the first principle, have identified the milestones that can be precursors of developmental disorders. In the conclusions, recommendations are offered regarding the validation of screening systems in Spain and for the construction of new ones.
\end{abstract}

\section{Keywords}

Systematic review, screening, developmental disorders, developmental delay.

\section{Francisco Alcantud Marín <francisco.alcantud@uv.es>}

Universitat de València, Catedrático de Psicología Evolutiva y de la Educación. Director del Centro Universitario de Diagnóstico y Atención Temprana de la Universitat de València

\section{Yurena Alonso Esteban \\ <yurena.alonso@uv.es>}

Departamento de Psicología Evolutiva y de la Educación de la Universitat de Valencia

\section{Darío Rico Bañón \\ <dario.rico@uv.es>}

Centro Universitario de Diagnóstico y Atención Temprana de la Universitat de Valencia

Para citar:

Alcantud Marín, F. et al. (2015):

"Herramientas de cribado para la detección de retrasos o trastornos en el desarrollo: Una revisión sistemática de la literatura", Revista Española de Discapacidad, 3 (2): 7-26.

Doi: <http://dx.doi.org/IO.5569/23405 IO4.03.02.0I>

Fecha de recepción: 29-09-20I 5 Fecha de aceptación: 09-I2-20I 5 


\section{Declaración de conflicto de intereses}

Los autores afirman no tener conflicto de intereses aun siendo los autores del Sistema de Detección Precoz de Trastornos del Desarrollo (SDPTD), puesto que el contenido de este artículo (aunque en la versión publicada este actualizado hasta diciembre del 20I4), fue desarrollado antes del desarrollo del SDPTD y como fase previa del proyecto de investigación. Aun así, para evitar conflictos, se ha excluido expresamente del análisis el sistema del que ellos son autores.

\section{Introducción}

Desde hace ya tiempo se ha puesto de manifiesto la necesidad de desarrollar sistemas de cribado del desarrollo infantil (Shonkoff et al. I979). Los llamados "cribados del desarrollo infantil" son sistemas desarrollados con el objetivo de detectar algún tipo de retraso o trastorno en el desarrollo infantil (motor, cognitivo, socio-emocional, etc.). Se trata en general de cuestionarios o listas de chequeo que facilitan la observación y seguimiento del desarrollo por el profesional. Otros son listados de síntomas o conductas que han manifestado evidencias de relacionarse con trastornos diagnosticados con posterioridad. Los resultados de su uso han demostrado, no solo que los sistemas de cribado del desarrollo son una medida preventiva (Hix-Small et al. 2006), sino que si se acompañan de programas de atención temprana aplicados de forma precoz, producen beneficios en la familia y en el niño/a a largo plazo. La rentabilidad social y económica es incuestionable (Arruabarrena y de Paul, 20I2; Rydz et al. 2006).

Según la Sociedad de Neurología Infantil (Filipek et al. 2000), el Instituto de Salud Carlos III (Muñoz Yunta et al. 2006) y otras instituciones e investigadores, las herramientas de cribado pueden clasificarse en tres niveles:
- $\quad$ Nivel I: Corresponde a los sistemas de vigilancia del desarrollo, por tanto, de aplicación universal. Se suelen aplicar en las consultas de pediatría o en las aulas del primer ciclo de educación infantil (o-3 años). Su objetivo es detectar si el niño/a evaluado/a presenta riesgo de algún trastorno del desarrollo. El síntoma buscado es el retraso en la adquisición de determinados hitos evolutivos que se consideran clave en el desarrollo del niño/a. La herramienta de cribado de primer nivel más frecuente, suele ser el juicio diagnóstico del profesional apoyado de algún tipo de lista de chequeo. Estas listas de chequeo pueden ser administradas por los propios profesionales o contestadas por los padres/madres o cuidadores del niño/a y contrastadas posteriormente por los/as profesionales.

- Nivel II: Corresponde a instrumentos que tienen como objetivo identificar sobre los/ as niños/as de la población detectada con riesgo de desarrollo atípico en el nivel I, si específicamente tienen riesgo de padecer un trastorno o una patología concreta. Las herramientas de cribado de segundo nivel pueden confundirse con las herramientas de diagnóstico (Coonrod y Stone, 2005; Lord y Corsello, 2005). Normalmente requieren mayor tiempo y entrenamiento que las de primer nivel y pueden ser utilizadas como parte de la evaluación inicial en el proceso diagnóstico aunque no como herramienta única del mismo (Johnson y Myers, 2007).

- $\quad$ Nivel III: Corresponde a los instrumentos utilizados para la confirmación diagnóstica. Suelen ser instrumentos específicos que evalúan una o varias áreas o subáreas del desarrollo. Su administración es realizada por profesionales con entrenamiento específico en cada uno de los instrumentos utilizados. Existen escalas del desarrollo con formas breves, a modo de screening, como la Bayley (Bayley, 2006) o la Battelle (Newborg, 2005). Estas formas breves no se suelen utilizar como sistemas de detección de nivel I aunque su objetivo sea la detección del retraso en el desarrollo como síntoma de un posible trastorno. 
Figura 1. Niveles de detección

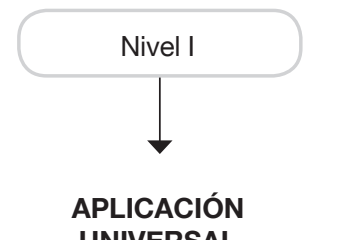

UNIVERSAL

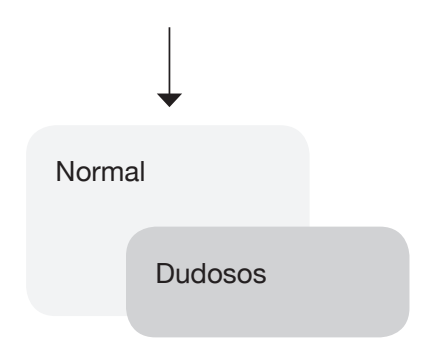

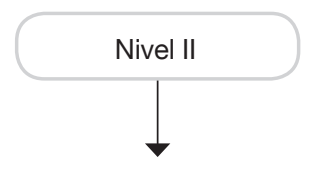

APLICACIÓN POBLACIÓN DE RIESGO

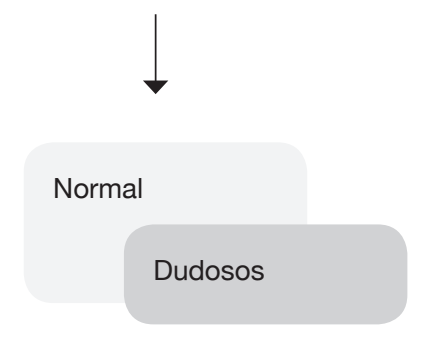

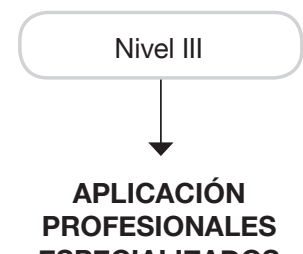

ESPECIALIZADOS

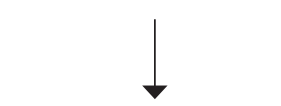

Normal

Patológicos

Fuente: Elaboración propia.

El diagnóstico confiable de los trastornos del desarrollo de etiología idiopática no se realiza hasta los 24-36 meses de vida o incluso, según los casos, posteriormente. Otros, por el contrario, conocida su etiología y sus marcadores biológicos, pueden ser diagnosticados en el mismo momento del nacimiento. Por ejemplo, en el caso de los TEA el diagnóstico puede establecerse sobre los 20-24 meses (Cox et al. I999; Dawson et al. 2000; Bryson et al. 2008; Kleinman et al. 2008). Otros trastornos del desarrollo como el déficit cognitivo o el retraso mental serán mucho más tardíos al requerir una evaluación formal de las competencias cognitivas mediante una prueba psicométrica de inteligencia. La detección precoz permite, aunque no se tenga un diagnóstico formal, la intervención temprana (GAT, 2000). Por este motivo el suelo de un sistema de detección debe ser muy bajo en edad. Por otra parte, es conocido que el diagnóstico ya es posible en algunos casos sobre los 36-48 meses de vida, este debería ser el techo puesto a esa edad. Ante la sospecha, se puede aplicar instrumentos diagnósticos directamente sin necesidad de utilizar previamente instrumentos de detección. Por otra parte, el incremento de la prevalencia de algunos trastornos del neurodesarrollo y la evidencia de la eficacia de los programas de intervención temprana cuando se inician antes de los dos años, ha generado que instrumentos de detección específicos de nivel II se recomienden aplicar de forma universal, es decir, como si se tratara de nivel I. Esta forma de uso ha hecho que se incremente la confusión sobre cuál es el sentido de los niveles de detección.

Éste artículo se centra en el estudio de las herramientas de detección de los trastornos o retrasos del desarrollo. El término "retraso en el desarrollo" es utilizado en muchas ocasiones para identificar a los/as niños/as que no alcanzan los hitos evolutivos en el momento en que lo alcanza el promedio de la población de su edad. Este hecho, tradicionalmente se ha considerado como una señal de alerta de un posible trastorno del desarrollo. Sin embargo, en la literatura científica no existe un consenso sobre el significado del término ni de cuando utilizarlo (Kube et al. ı988). El significado más común ha sido el de retraso mental (trastorno del desarrollo intelectual). También se utiliza en ocasiones para referirse a 
los/as niños/as que obtienen puntuaciones bajas en las escalas de desarrollo o para identificar a los/as niños/as nacidos pretérmino sanos que obtienen puntuaciones más bajas en las escalas de desarrollo que sus iguales nacidos a término (dentro de un desarrollo normativo). Se ha utilizado también como equivalente al término "retraso psicomotor" (Fenichel, I988). En general, es aceptado como un diagnóstico provisional, utilizado hasta que el niño/a tiene la edad suficiente para ser evaluado con pruebas psicométricas formales. En general, el retraso en el desarrollo es un concepto que está siendo reemplazado por el de "trastornos en el desarrollo”. La razón fundamental es que el primero de ellos traslada la idea de poca gravedad y en ocasiones induce a la espera en la intervención. Hoy en día podría referirse a ellos como "trastornos del neurodesarrollo". Es decir, aquellas alteraciones en el desarrollo de funciones vinculadas a la maduración del sistema nervioso central que se inician antes de que finalice el proceso de maduración del mismo y siguen un curso evolutivo estable (ArtigasPallarés, 20I I). Sin embargo, cuando sólo se tienen evidencias de un retraso en el desarrollo sin conocer las causas, y sin tener un diagnóstico específico, se suele mantener el término genérico de "trastornos del desarrollo".

En este artículo se revisa la literatura científica sobre el uso y desarrollo de herramientas de cribado o detección de los trastornos o retrasos del desarrollo de nivel I, es decir, de posible aplicación universal con el objetivo de valorar la calidad de los sistemas de detección, su aplicabilidad y las características que los hacen más adecuados. Para ello, se realiza una revisión sistemática de las publicaciones indexadas en las bases de datos científicas afines a las áreas de conocimiento con competencia (medicina, psicología, educación). El objetivo de esta revisión es detectar todas las posibles herramientas de detección de aplicación universal (nivel I) de trastornos o retrasos en el desarrollo infantil con la finalidad de valorar su calidad analizando sus fortalezas y debilidades. Esta revisión se realiza en el marco de una investigación de mayor nivel que tuvo como objetivo la construcción de un nuevo sistema de detección de los trastornos del desarrollo (Alcantud et al. 2015). Los resultados de revisión que se presentan en esta publicación han sido actualizados hasta diciembre del 2014.

\section{Método y procedimiento}

Se ha desarrollado una revisión de la literatura utilizando principios sistemáticos de búsqueda y selección ${ }^{\mathrm{I}}$. El objetivo es seleccionar artículos de revistas científicas (que incorporen evaluación por pares, sin criterio de tiempo) que permitan identificar las herramientas de cribado para detectar niños/as menores de tres años con riesgo de presentar trastornos del desarrollo. Para ello se realizó la búsqueda utilizando en primer lugar la base de datos en línea Proquest Psychology Journals-PPJ, accediendo mediante la plataforma TROBES del Servicio de Bibliotecas y Documentación de la Universitat de València. En principio se ensayaron búsquedas con diferentes palabras como "Early detection", "Screening tools", etc., determinando que las palabras o frases que más se ajustaban al objetivo de búsqueda eran "Developmental Screening test" o "Developmental Screening Tools" y que podrían aparecen en cualquier campo de la ficha del documento indexado (incluyendo los resúmenes o “abstracts” en inglés para los documentos escritos en otro idioma). El trabajo más antiguo detectado es del año I975 (Barnes y Stark, I975) y se trata de la publicación del estudio normativo del test de screening de Denver. Dado el gran volumen de información obtenida, se optó por limitar el periodo de búsqueda a los documentos publicados en los últimos 25 años (I990-20I4), encontrándose en total 250 artículos. Una vez realizada la búsqueda en esta primera base de datos, se extendió a otras bases de datos en línea de la misma plataforma que tuvieran actualizaciones permanentes (mínimo

I. NHS Centre for Reviews and Dissemination: Systematic reviews. CRD's guidance for undertaking reviews in health care University of York; 2008 [http://www.york.ac.uk/inst/crd/ pdf/Systematic_Reviews.pdf]. 
mensual) y dado el carácter multidisciplinar de la temática de estudio, consideradas de interés por cubrir áreas de conocimiento afines. Las bases de datos consultadas fueron: Medicina+ (PubMed MEDLINE), Educación (ProQuest ERIC) y test psicológicos en general (ProQuest PsycTESTC).

\subsection{Criterios de Inclusión-Exclusión}

Aunque la selección de las bases de datos se realizó cubriendo diferentes áreas de conocimiento como la psicología, educación y medicina, se detectaron un gran número de artículos duplicados. Todos los artículos fueron copiados sobre RefWorks, desde donde se realizó la eliminación de los duplicados y un primer análisis cualitativo de los artículos preseleccionados mediante la lectura de los resúmenes, verificando el cumplimiento de los criterios de inclusión (estudios psicométricos de herramientas de detección de trastornos del desarrollo de nivel I, aplicaciones comunitarias de las mismas, adaptaciones transculturales y lingüísticas, etc.). Fueron excluidos aquellos que cumplían alguno de los siguientes criterios de exclusión: estudios de prevalencia, estudios en poblaciones superiores a tres años, estudios de intervención, técnicas no psicométricas u observacionales de detección, estudios de

\section{Figura 2. Flujo del proceso de búsqueda documental}

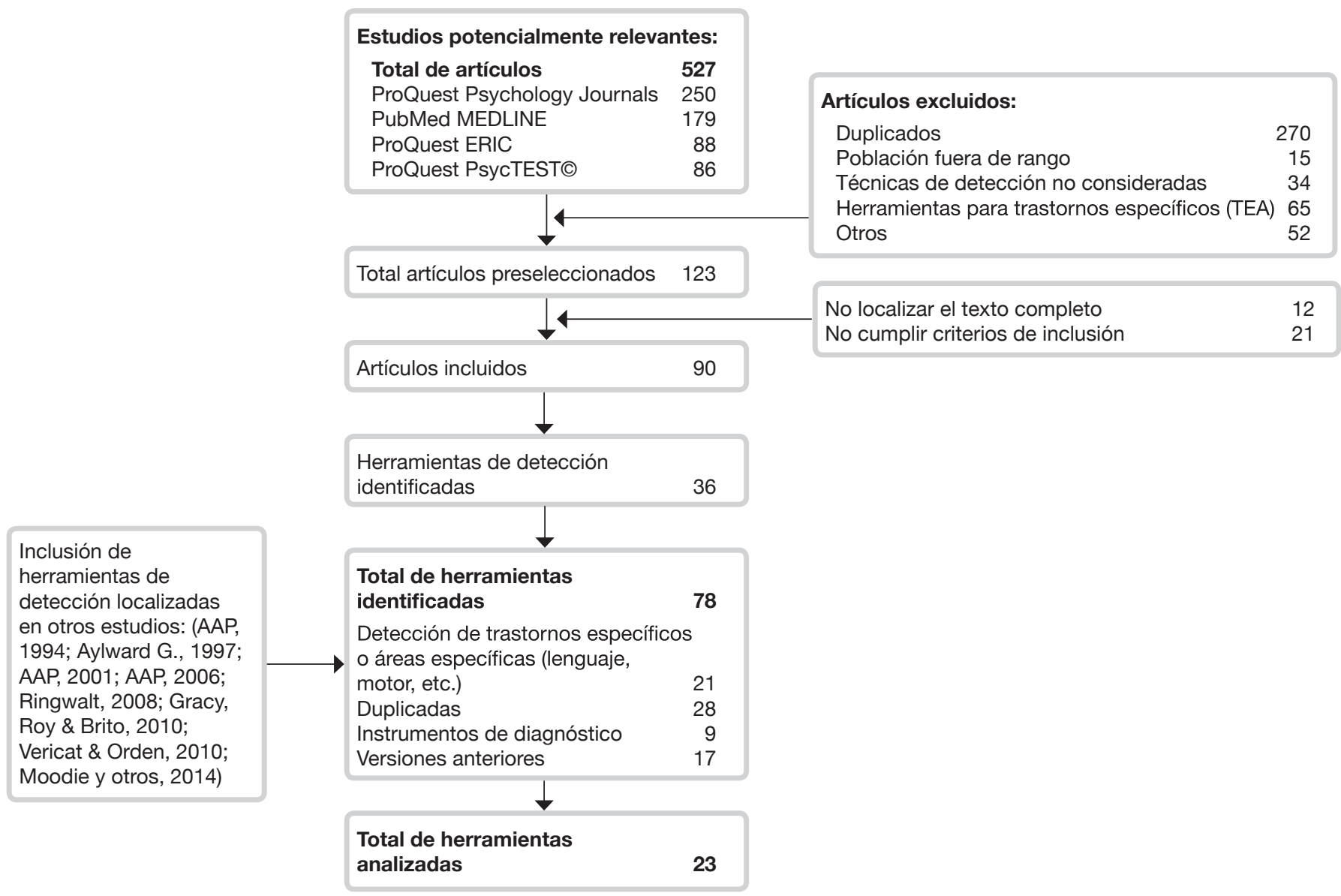

Fuente: Elaboración propia. 
biomarcadores, herramientas de diagnóstico, cribados específicos en áreas concretas de desarrollo (motor, comunicación y lenguaje, desarrollo socio-emocional) o sobre patologías concretas (TEA, TDAH, etc.). Del total de artículos se pre-seleccionaron por cumplir los criterios de búsqueda un total de $\mathbf{2} 3$ artículos.

Se aplicó un segundo análisis cualitativo de los artículos mediante la lectura en su versión completa. Ambos análisis fueron realizados inicialmente por una persona y chequeados por un segundo juez. En este proceso se exclouyeron I 2 artículos por no ser accesible el texto completo y 2 I por incumplir alguno de los criterios de inclusión-exclusión. En total se analizan los 90 artículos incluidos en la revisión. De este conjunto de artículos se detectan un total de 36 herramientas o sistemas de detección.

Entre todos los artículos se detectaron también estudios de revisión previos de los que se vaciaron todas las herramientas de detección (Aylward, I997; AAP, I994; AAP, 200Ia; AAP, 200Ib; AAP, 2006; Moodie et al. 20I4; Gracy et al. 2010; Ringwalt, 2008; Bedford et al. 2013). Entre estas revisiones destacamos la de Vericat y Orden (2010) dado que aporta información de pruebas desarrolladas en español, sin embargo, no han sido incluidas la mayoría de ellas al no estar accesible o ser ilocalizable la información psicométrica de las mismas.

Se listaron todas las herramientas de detección referenciadas en todos los documentos eliminándose las duplicadas, las versiones obsoletas, las herramientas de diagnóstico utilizadas como screening o las herramientas de detección específicas de un tipo de trastorno o un área de desarrollo en particular (lenguaje, desarrollo emocional, motor, etc.), quedando definitivamente el listado formado por 23 herramientas o sistemas de detección.

A continuación, la búsqueda se amplió utilizando los nombres de las herramientas de detección como elemento de búsqueda en "Proquest Psychology Journals". Se organizó la información de todos los artículos donde se referenciaba el uso o estudio de cada una de las diferentes herramientas según el tipo de estudio: adaptaciones culturales o traducciones a otras lenguas, validación con otros instrumentos de cribado, estudios psicométricos, aplicaciones comunitarias, etc. Estas herramientas se presentan en la tabla I donde se incluye una breve descripción de las mismas y las propiedades psicométricas más relevantes.

\begin{tabular}{|c|c|c|c|c|c|c|}
\hline \multirow[b]{2}{*}{ Nombre } & \multirow[b]{2}{*}{ Autor/es } & \multirow[b]{2}{*}{ Descripción: } & \multicolumn{2}{|c|}{ Edad } & \multirow{2}{*}{ 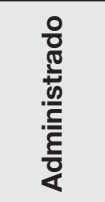 } & \multirow{2}{*}{ 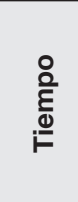 } \\
\hline & & & $\begin{array}{l}\frac{\circ}{0} \\
\stackrel{\vec{D}}{0}\end{array}$ & 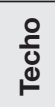 & & \\
\hline $\begin{array}{l}\text { 1.- Ages } \\
\text { and Stages } \\
\text { Questionnaires } \\
\text { (ASQ-3). }\end{array}$ & $\begin{array}{l}\text { (Squires et } \\
\text { al.1997; } \\
\text { Squires et al. } \\
\text { 1998). }\end{array}$ & $\begin{array}{l}\text { Existen diferentes versiones, la más actual (ASQ- } \\
\text { 3), está integrada por } 21 \text { cuestionarios. Está } \\
\text { diseñado para ser contestado por los/as padres/ } \\
\text { madres y posteriormente puntuados por los/ } \\
\text { as profesionales. Evalúa diferentes áreas del } \\
\text { desarrollo (lenguaje, socio-emocional, motricidad } \\
\text { y cognición) en cada edad. Existen versiones } \\
\text { para respuesta cara a cara, por correo y "online". }\end{array}$ & 1 & 66 & Padres & $10-15$ \\
\hline $\begin{array}{l}\text { 2.- Battelle } \\
\text { Developmental } \\
\text { Inventory } \\
\text { Screening Test, } \\
2^{\text {nd }} \text { ed.(BDI-ST). }\end{array}$ & $\begin{array}{l}\text { (Newborg, } \\
2005 \text { ). }\end{array}$ & $\begin{array}{l}\text { Consiste en } 100 \text { ítems ( } 20 \text { para cada dominio o } \\
\text { área evaluada) en diez niveles de edad. Evalúa } \\
\text { las áreas de lenguaje expresivo y receptivo, } \\
\text { motora gruesa y fina, adaptativa, personal-social } \\
\text { y área cognitiva/académica. }\end{array}$ & 0 & 96 & Prof. & 20 \\
\hline
\end{tabular}




\begin{tabular}{|c|c|c|c|c|c|c|}
\hline \multirow{2}{*}{ Nombre } & \multirow{2}{*}{ Autor/es } & \multirow{2}{*}{ Descripción: } & \multicolumn{2}{|c|}{ Edad } & \multirow{2}{*}{ 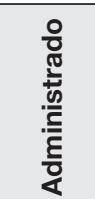 } & \multirow{2}{*}{$\frac{\circ}{\varrho_{0}^{\circ}}$} \\
\hline & & & 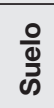 & 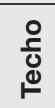 & & \\
\hline $\begin{array}{l}\text { 3.- Bayley III } \\
\text { Screening Test, } \\
\text { (BINS). }\end{array}$ & (Bayley, 2006). & $\begin{array}{l}\text { Herramienta de administración directa. } \\
\text { Compuesta de series de } 6 \text { ítems que evalúan } \\
\text { funciones neurológicas básicas, funciones } \\
\text { receptivas (input visual, táctil y auditivo), } \\
\text { funciones expresivas (habilidades orales, motoras } \\
\text { finas y gruesas) y procesos cognitivos. Los } \\
\text { resultados se expresan en riesgo bajo, moderado } \\
\text { o alto. }\end{array}$ & 1 & 42 & Mixta & $15-25$ \\
\hline $\begin{array}{l}\text { 4.- Brigance } \\
\text { Early Childhood } \\
\text { Screens. }\end{array}$ & $\begin{array}{l}\text { (Brigance y } \\
\text { Glascoe, 2002). }\end{array}$ & $\begin{array}{l}\text { Es una reconfiguración de los otros dos } \\
\text { instrumentos anteriores (earlier Infant and } \\
\text { Toddler Screen-II y Early Preschool Screen-II). } \\
\text { Herramientas de administración directa que } \\
\text { evalúa conocimiento general y comprensión, } \\
\text { lenguaje expresivo, habilidades motoras } \\
\text { gruesas y finas, conocimientos pre-académicos, } \\
\text { habilidades socio-emocionales y autoayuda. }\end{array}$ & 0 & 35 & Prof. & 15 \\
\hline $\begin{array}{l}\text { 5.- Child } \\
\text { Development } \\
\text { Inventory. }\end{array}$ & $\begin{array}{l}\text { (Ireton,1992; } \\
\text { Ireton y } \\
\text { Glascoe, 1995). }\end{array}$ & $\begin{array}{l}\text { Cuestionario para detectar problemas en el } \\
\text { desarrollo social, motor, lenguaje, auto-ayuda, } \\
\text { inicio de la lecto-escritura y numeración y en } \\
\text { general síntomas de problemas conductuales. } \\
\text { Incluye una escala de desarrollo general que } \\
\text { contestan los/as padres/madres. }\end{array}$ & 12 & 72 & Mixta & $30-50$ \\
\hline $\begin{array}{l}\text { 6.- Child } \\
\text { Development } \\
\text { Review. }\end{array}$ & (Ireton, 2004). & $\begin{array}{l}\text { Está dividido en dos secciones "Parent } \\
\text { Questionaire (CDR-PQ) y el "Child Development } \\
\text { Chart". El primero lo contestan los/as padres/ } \\
\text { madres y el segundo los/las profesionales. Evalúa } \\
\text { habilidades de auto-ayuda, motoras, sociales y } \\
\text { de lenguaje. }\end{array}$ & 18 & 60 & Mixta & $10-20$ \\
\hline $\begin{array}{l}\text { 7.- Cognitive } \\
\text { Abilities Scale } \\
\text { 2nd ed. } \\
\text { (CAS-2). }\end{array}$ & $\begin{array}{l}\text { (Johnson } \\
\text { y Bradley- } \\
\text { Johnson,2002; } \\
\text { Bradley- } \\
\text { Johnson y } \\
\text { Johnson, 2001). }\end{array}$ & $\begin{array}{l}\text { Herramienta de evaluación diseñada para la } \\
\text { identificación temprana de niños/as con retrasos } \\
\text { cognitivos. Hay dos formas, infantil (79ítems) y } \\
\text { Preescolar ( } 88 \text { ítems). La forma infantil se divide } \\
\text { en tres secciones: la exploración de los objetos, } \\
\text { de comunicación, de iniciación y de imitación } \\
\text { de actividades. El formulario de pre-escolar } \\
\text { se divide en cinco secciones: el lenguaje oral, } \\
\text { la lectura, matemáticas, escritura y facilitar } \\
\text { comportamientos. }\end{array}$ & 3 & 47 & Prof. & $20-30$ \\
\hline $\begin{array}{l}\text { 8.- } \\
\text { Developmental } \\
\text { Activities } \\
\text { Screening } \\
\text { Inventory-II } \\
\text { (DASI-II). }\end{array}$ & $\begin{array}{l}\text { (Fewell y } \\
\text { Langley, 1984). }\end{array}$ & $\begin{array}{l}\text { Diseñado para la detección temprana de retraso } \\
\text { en el desarrollo, con especial énfasis en los/as } \\
\text { niños/as pequeños con trastorno del lenguaje } \\
\text { cuyas habilidades cognitivas no pueden ser } \\
\text { examinadas con precisión con una herramienta } \\
\text { que requiere que el niño/a siga las instrucciones } \\
\text { habladas. Instrucciones DASI-II puede ser verbal } \\
\text { o visual. Hay } 67 \text { elementos que se pueden } \\
\text { administrar en una o dos configuraciones. } \\
\text { Las tareas se organizan en } 15 \text { categorías de } \\
\text { habilidades que incluyen insensibilidad sensorial, } \\
\text { relaciones de causa-efecto, la causalidad, la } \\
\text { memoria y el razonamiento. }\end{array}$ & 1 & 66 & Prof. & $25-30$ \\
\hline
\end{tabular}




\begin{tabular}{|c|c|c|c|c|c|c|}
\hline \multirow{2}{*}{ Nombre } & \multirow{2}{*}{ Autor/es } & \multirow{2}{*}{ Descripción: } & \multicolumn{2}{|c|}{ Edad } & \multirow{2}{*}{ 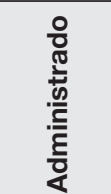 } & \multirow{2}{*}{ 을 } \\
\hline & & & $\frac{\circ}{\stackrel{0}{J}}$ & 응 & & \\
\hline $\begin{array}{l}\text { 9.- } \\
\text { Developmental } \\
\text { Assessment of } \\
\text { Young Children, } \\
\text { 2nd ed. (DAYC- } \\
\text { 2). }\end{array}$ & $\begin{array}{l}\text { (Voress y } \\
\text { Maddox, 1998). }\end{array}$ & $\begin{array}{l}\text { Administrada individualmente en la primera } \\
\text { infancia .Tiene como objetivos principales ayudar } \\
\text { a identificar a los/as niños/as en el área cognitiva, } \\
\text { comunicativa o social-emocional, físico, } \\
\text { habilidades de conducta adaptativa. También } \\
\text { puede utilizarse como seguimiento de programas } \\
\text { de intervención. }\end{array}$ & 0 & 71 & Prof. & $10-20$ \\
\hline $\begin{array}{l}\text { 10- Denver } \\
\text { Developmental } \\
\text { Screening Test II } \\
\text { (DDST-II). }\end{array}$ & $\begin{array}{l}\text { (Frankenburg } \\
\text { et al.1971; } \\
\text { Frankenburg y } \\
\text { Dodds,1967). }\end{array}$ & $\begin{array}{l}\text { Esta herramienta consta de } 125 \text { ítems que } \\
\text { evalúa } 4 \text { áreas del funcionamiento del niño/a: } \\
\text { motora, adaptativa, personal-social y habilidades } \\
\text { comunicativas. }\end{array}$ & 0 & 72 & Prof. & $20-30$ \\
\hline $\begin{array}{l}\text { 11.- } \\
\text { Developmental } \\
\text { Observation } \\
\text { Checklist } \\
\text { System (DOCS). }\end{array}$ & $\begin{array}{l}\text { (Hresko et al. } \\
\text { 1994). }\end{array}$ & $\begin{array}{l}\text { El instrumento es completado principalmente por } \\
\text { el profesional aunque existe una parte que es } \\
\text { completada por la familia. Consta de } 540 \text { ítems } \\
\text { en total pero dependiendo de la edad del niño/a } \\
\text { se completa una cantidad específica. Evalúa } \\
\text { desarrollo general (lenguaje, motor, social y } \\
\text { desarrollo cognitivo), comportamiento del niño/a } \\
\text { y apoyo y estrés de los/as padres/madres. }\end{array}$ & 0 & 72 & Mixta & 30 \\
\hline $\begin{array}{l}\text { 12.- } \\
\text { Developmental } \\
\text { Profile } 3 \text { (DP-3). }\end{array}$ & (Alpern, 2007). & $\begin{array}{l}\text { Permite evaluar de forma rápida las cinco } \\
\text { principales áreas del desarrollo infantil } \\
\text { (Cognición, Motricidad, Socioemocional, } \\
\text { Comunicación y Conducta adaptativa) y ofrece } \\
\text { un índice global de desarrollo del niño/a. Dispone } \\
\text { de dos formas de aplicación alternativas: } \\
\text { mediante entrevista a los/as padres/madres o } \\
\text { mediante un cuestionario que responden estos } \\
\text { de forma independiente. }\end{array}$ & 0 & 155 & Padres & $20-40$ \\
\hline $\begin{array}{l}\text { 13.- Early } \\
\text { Learning } \\
\text { Accomplishment } \\
\text { Profile (E-LAP). }\end{array}$ & $\begin{array}{l}\text { (Hardin y } \\
\text { Peisner, 2001). }\end{array}$ & $\begin{array}{l}\text { El E-LAP es una herramienta de evaluación } \\
\text { referida a criterios. Se puede utilizar para } \\
\text { identificar a los/as niños/as pequeños que } \\
\text { necesitan una remisión para una evaluación del } \\
\text { desarrollo. Los ítems provienen de una amplia } \\
\text { gama de instrumentos de detección y evaluación } \\
\text { estandarizados. El sistema LAP se centra en } \\
\text { las cinco áreas del desarrollo principales: motor } \\
\text { (grueso-fino), auto-ayuda (adaptación), lenguaje } \\
\text { (comunicación), cognitivos y de funcionamiento } \\
\text { socio-emocional. }\end{array}$ & 0 & 36 & Prof. & $12-15$ \\
\hline $\begin{array}{l}\text { 14.- First Step: } \\
\text { Screening Test } \\
\text { for Evaluating } \\
\text { Preschoolers. }\end{array}$ & $\begin{array}{l}\text { (Roxswell,1993; } \\
\text { Miler, 1993). }\end{array}$ & $\begin{array}{l}\text { Instrumento que evalúa directamente las áreas: } \\
\text { cognitivo, comunicación y motor. Se compone } \\
\text { también de dos "checklists", una de ítems socio- } \\
\text { emocionales basadas en las observaciones del } \\
\text { examinador y otra, que completan los padres } \\
\text { sobre el comportamiento adaptativo de su hijo/a. }\end{array}$ & 33 & 74 & Mixto & $15-20$ \\
\hline $\begin{array}{l}\text { 15.- Infant } \\
\text { Development } \\
\text { Inventory (IDI). }\end{array}$ & $\begin{array}{l}\text { (Creighton y } \\
\text { Sauve, 1988). }\end{array}$ & $\begin{array}{l}\text { Cuestionario que completan los/as padres/ } \\
\text { madres o cuidadores que evalúa el desarrollo a } \\
\text { través de las áreas: social, autoayuda, motora, y } \\
\text { habilidades de la comunicación y el lenguaje. }\end{array}$ & 0 & 18 & Padres & $5-10$ \\
\hline
\end{tabular}




\begin{tabular}{|c|c|c|c|c|c|c|}
\hline \multirow[b]{2}{*}{ Nombre } & \multirow[b]{2}{*}{ Autor/es } & \multirow[b]{2}{*}{ Descripción: } & \multicolumn{2}{|c|}{ Edad } & \multirow{2}{*}{ 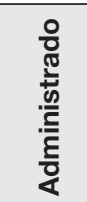 } & \multirow{2}{*}{$\frac{\stackrel{\circ}{\varepsilon}}{\stackrel{\varrho}{\varrho}}$} \\
\hline & & & $\frac{\circ}{\frac{0}{\varrho}}$ & 응 & & \\
\hline $\begin{array}{l}\text { 16.- Individual } \\
\text { Growth and } \\
\text { Development } \\
\text { Indicators } \\
\text { (GDIs). }\end{array}$ & $\begin{array}{l}\text { (Greenwood et } \\
\text { al. 2005). }\end{array}$ & $\begin{array}{l}\text { Conjunto de medidas diseñadas y validadas } \\
\text { para su uso por profesionales. Evalúa las áreas: } \\
\text { comunicación, movimiento, resolución de } \\
\text { problemas, la interacción social. A diferencia de } \\
\text { las pruebas estandarizadas que se administran } \\
\text { con poca frecuencia, IGDI de están diseñados } \\
\text { para ser utilizado en varias ocasiones por los } \\
\text { médicos para estimar la "tasa de crecimiento" de } \\
\text { cada niño/a a través del tiempo. }\end{array}$ & 0 & 36 & Prof. & 40 \\
\hline $\begin{array}{l}\text { 17.-Infant- } \\
\text { Toddler } \\
\text { Developmental } \\
\text { Assessment } \\
\text { (IDA). }\end{array}$ & (Erikson, 1996). & $\begin{array}{l}\text { Este instrumento realiza un cribado del } \\
\text { funcionamiento del desarrollo del niño/a en } \\
\text { varias áreas: motricidad fina y gruesa, relación } \\
\text { con los objetos inanimados (cognitiva), lenguaje/ } \\
\text { comunicación, autoayuda, relaciones con las } \\
\text { personas, emociones, sentimientos e imitación. }\end{array}$ & 0 & 42 & Prof. & - \\
\hline $\begin{array}{l}\text { 18.- Infant- } \\
\text { Toddler } \\
\text { and Family } \\
\text { Instrument (ITFI). }\end{array}$ & $\begin{array}{l}\text { (Provence y } \\
\text { Apfel, 2001). }\end{array}$ & $\begin{array}{l}\text { ITFI permite a los proveedores de servicios } \\
\text { familiares reunir información e impresiones } \\
\text { acerca de un niño/a y la familia y su entorno } \\
\text { familiar, ayudando a los proveedores a decidir } \\
\text { si se necesitan más referencias y servicios. } \\
\text { Evalúa las siguientes áreas: motricidad gruesa } \\
\text { y fina, social y emocional, del lenguaje, de } \\
\text { afrontamiento y auto-ayuda. }\end{array}$ & 6 & 36 & Prof. & - \\
\hline $\begin{array}{l}\text { 19.- Kent } \\
\text { Inventory of } \\
\text { Developmental } \\
\text { Skills-3rd } \\
\text { ed.(KIDS). }\end{array}$ & $\begin{array}{l}\text { (Reuter et al. } \\
\text { 1996; Reuter y } \\
\text { Gruber, 2000). }\end{array}$ & $\begin{array}{l}\text { Cuestionario que se completa por la familia o el } \\
\text { cuidador principal, basado en las observaciones } \\
\text { de comportamiento en diferente rango de } \\
\text { condiciones. Consta de } 252 \text { ítems, dirigidos a } \\
\text { evaluar las áreas: motoras, autoayuda, cognitivo, } \\
\text { comunicación y habilidades sociales. }\end{array}$ & 0 & 15 & Prof. & 45 \\
\hline $\begin{array}{l}\text { 20.-Minnesota } \\
\text { Child } \\
\text { Development } \\
\text { Inventory } \\
\text { (MCDI). }\end{array}$ & $\begin{array}{l}\text { (Ireton et al. } \\
\text { 1977). }\end{array}$ & $\begin{array}{l}\text { MCDI: Esta escala es un cuestionario de padres/ } \\
\text { madres, está compuesta por } 320 \text { ítems. Evalúa } \\
\text { las siguientes áreas: desarrollo general, la } \\
\text { motricidad gruesa, motricidad fina, lenguaje } \\
\text { expresivo, comprensión conceptual, situación de } \\
\text { comprensión, de autoayuda, y personal-social. } \\
\text { Esta prueba está diseñada para complementar } \\
\text { una entrevista con los padres cuando se han } \\
\text { planteado cuestiones de retraso en el desarrollo. }\end{array}$ & 12 & 72 & Prof. & $30-50$ \\
\hline $\begin{array}{l}\text { 21.-Prueba } \\
\text { Nacional de } \\
\text { Pesquisa } \\
\text { (PRUNAPE). }\end{array}$ & $\begin{array}{l}\text { (Leiarraga et al., } \\
\text { 2005). }\end{array}$ & $\begin{array}{l}\text { Es una prueba desarrollada en Argentina. La } \\
\text { prueba consta de setenta y nueve pautas } \\
\text { madurativas pertenecientes a las siguientes } \\
\text { áreas: motricidad fina y gruesa, lenguaje y } \\
\text { personal-social. La prueba consiste en solicitar } \\
\text { al niño/a que realice una serie de ejercicios con } \\
\text { papel y lápiz, cubos, tarjetas dibujadas, que } \\
\text { varían según la edad. }\end{array}$ & 0 & 72 & Prof. & 15 \\
\hline
\end{tabular}




\begin{tabular}{|c|c|c|c|c|c|c|}
\hline \multirow{2}{*}{ Nombre } & \multirow{2}{*}{ Autor/es } & \multirow{2}{*}{ Descripción: } & \multicolumn{2}{|c|}{ Edad } & \multirow{2}{*}{ 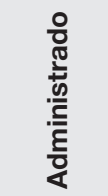 } & \multirow{2}{*}{ 을 } \\
\hline & & & $\begin{array}{l}\frac{0}{0} \\
\stackrel{\varpi}{\partial}\end{array}$ & 옹 & & \\
\hline $\begin{array}{l}\text { 22.- Parents' } \\
\text { Evaluation of } \\
\text { Developmental } \\
\text { Status (PEDS). }\end{array}$ & (Glascoe, 1998). & $\begin{array}{l}\text { Cuestionarios para padres/madres que a través } \\
\text { de } 10 \text { ítems pregunta sobre las preocupaciones } \\
\text { de los padres y evalúa el área cognitiva, lenguaje } \\
\text { expresivo y receptivo, habilidades motoras fina } \\
\text { y gruesa, comportamiento y habilidades socio- } \\
\text { emocionales. }\end{array}$ & 0 & 96 & Padres & 5 \\
\hline $\begin{array}{l}\text { 23.- Parents' } \\
\text { Evaluation of } \\
\text { Developmental } \\
\text { Status } \\
\text { Developmental } \\
\text { Milestones } \\
\text { (PEDS-DM). }\end{array}$ & $\begin{array}{l}\text { (Brothers et al. } \\
\text { 2008). }\end{array}$ & $\begin{array}{l}\text { Herramienta para detectar el retraso en el } \\
\text { desarrollo. Sustituye la lista de chequeo } \\
\text { convencional. Intenta monitorizar el progreso } \\
\text { del niño/a a lo largo de la infancia. El PEDS-DM } \\
\text { contempla un total de } 20 \text { grupos de edad para } \\
\text { cada uno dispone de un cuestionario diferente. }\end{array}$ & 0 & 96 & Padres & $15-20$ \\
\hline
\end{tabular}

Fuente: Elaboración propia.

\section{Evaluación de la calidad de las herramientas}

Entre las herramientas y pruebas detectadas se encontraron gran diversidad de tipos y formas de administración. Desde cuestionarios de investigación hasta herramientas diagnósticas aplicadas con fines de detección. En este sentido, es de destacar que se está generalizando la práctica de los autoinformes sobre el desarrollo de los/as niños/as ofrecido por los/as padres/ madres. Esta práctica es más general, cuanto más bajo es el suelo de aplicación y cuanto menos observable es la conducta sobre la que se hace la evaluación, demostrando su eficacia como "screening” sobre todo en niños/ as pequeños y sobre el desarrollo inmediato (Glascoe, I997).

El criterio de calidad para estos test o cuestionarios se basa en la fiabilidad, validez, sensibilidad y especificidad y en medidas derivadas de estas (Camp, 2006; Johnson y Marlow, 2006). No obstante, existen otros datos que aunque menos objetivos pueden hacer que un sistema sea mejor valorado que otro. Así, la simplicidad y brevedad de administración, el bajo coste de la misma, la interoperabilidad de los resultados, la accesibilidad a los sistemas, la adaptación a otras lenguas y culturas, son otros datos que deben tenerse en cuenta a la hora de seleccionar un instrumento u otro.

Con la finalidad de evaluar los instrumentos analizados se construyó una tabla con la valoración de los diferentes criterios de calidad, teniendo en cuenta tanto las características de las normas de administración como de los resultados psicométricos recogidos en diferentes publicaciones, siguiendo en este sentido las recomendaciones del SAC ${ }^{2}$ y otros (Terwee et al. 2007).

La evaluación de calidad se realizó aplicando los criterios descritos en la Tabla 2. Se sumaron todas las puntuaciones obteniendo una puntuación total.

2. SAC: Scientific Advisory Committee of the Medical Outcomes Trust (Aaronson et al., 2002) 


\begin{tabular}{|c|c|c|}
\hline INDICADOR & DEFINICIÓN & CRITERIO DE CALIDAD \\
\hline \multicolumn{3}{|l|}{ 1. Suelo y Techo } \\
\hline Suelo & Edad mínima de aplicación & $\begin{array}{l}\text { 3: Aplicación por debajo de los tres primeros meses de vida. } \\
\text { 2: Aplicación desde los seis meses de vida. } \\
\text { 1: Aplicación desde el año de vida. } \\
\text { 0: Aplicación después del primer año de vida. }\end{array}$ \\
\hline Techo & Edad máxima de aplicación & $\begin{array}{l}\text { No se valora ningún techo específico. Aunque por la naturaleza } \\
\text { de la información no debería ser superior a los } 36-48 \text { meses. }\end{array}$ \\
\hline \multicolumn{3}{|l|}{ 2. Fiabilidad } \\
\hline Consistencia Interna & $\begin{array}{l}\text { Grado en que los diferentes ítems } \\
\text { o sub-pruebas miden el mismo } \\
\text { constructo. Generalmente se } \\
\text { evalúa mediante el coeficiente } \\
\text { Alpha de Cronbach (correlación } \\
\text { pares-impares) }\end{array}$ & $\begin{array}{l}\text { 3: Alfa entre } 0,70 \text { y } 0,95 \text {. } \\
\text { 2: Alfa menor a } 0,70 \text { a pesar de diseño y método adecuado. } \\
\text { 1: Diseño dudoso sin resultados significativos. } \\
\text { 0: Información no encontrada. }\end{array}$ \\
\hline $\begin{array}{l}\text { Estabilidad de la } \\
\text { medida (Test-Retest) }\end{array}$ & $\begin{array}{l}\text { Grado en que las puntuaciones } \\
\text { de medidas repetidas son } \\
\text { semejantes o consistentes. Se } \\
\text { evalúa mediante Correlación de } \\
\text { Pearson. }\end{array}$ & $\begin{array}{l}\text { 3: Coeficiente entre } 0,70 \text { y } 0,95 \text {. } \\
\text { 2: Coeficiente menor a } 0,70 \text { a pesar de diseño y método } \\
\text { adecuado. } \\
\text { 1: Diseño dudoso sin resultados significativos. } \\
\text { 0: Información no encontrada. }\end{array}$ \\
\hline \multicolumn{3}{|l|}{ 3. Validez } \\
\hline $\begin{array}{l}\text { Validez de Criterio o } \\
\text { Concurrente }\end{array}$ & $\begin{array}{l}\text { Grado de ajuste entre la } \\
\text { puntuación del cuestionario y un } \\
\text { Gold Standard. }\end{array}$ & $\begin{array}{l}\text { 3: Correlación con la Gold Standard superiores a } 0,70 . \\
\text { 2: Correlación con Gold Standard menor a } 0,70 \text { a pesar de } \\
\text { diseño y método adecuado. } \\
\text { 1: No hay argumentos convincentes sobre la adecuación de la } \\
\text { Gold Standard o el diseño o el método es dudoso. } \\
\text { 0: Información no encontrada. }\end{array}$ \\
\hline \multicolumn{3}{|c|}{ 4. Capacidad diagnóstica } \\
\hline Sensibilidad & $\begin{array}{l}\text { Proporción de sujetos evaluados } \\
\text { mediante la herramienta de } \\
\text { cribado con resultado positivo } \\
\text { que finalmente se confirma su } \\
\text { diagnóstico. }\end{array}$ & $\begin{array}{l}\text { 3: Entre } 0,70 \text { y } 0,95 . \\
\text { 2: Menor a } 0,70 \text { a pesar de diseño y método adecuado. } \\
\text { 1: Diseño dudoso sin datos explícitos. } \\
0: \text { Información no encontrada. }\end{array}$ \\
\hline Especificidad & $\begin{array}{l}\text { Proporción de sujetos evaluados } \\
\text { mediante la herramienta de } \\
\text { cribado con resultado negativo } \\
\text { que finalmente se descarta el } \\
\text { diagnóstico. }\end{array}$ & $\begin{array}{l}\text { 3: Entre } 0,70 \text { y } 0,95 . \\
\text { 2: Menor a } 0,70 \text { a pesar de diseño y método adecuado. } \\
\text { 1: Diseño dudoso sin datos explícitos. } \\
\text { 0: Información no encontrada. }\end{array}$ \\
\hline \multicolumn{3}{|l|}{ 5.- Otros } \\
\hline Otros & $\begin{array}{l}\text { Facilidad de uso, interpretabilidad } \\
\text { de los resultados, accesibilidad } \\
\text { de la herramienta, existe versión } \\
\text { en castellano. }\end{array}$ & $\begin{array}{l}\text { 3: Existe versión en castellano y resulta fácil de administrar, } \\
\text { interpretable y accesible. } \\
\text { 2: Cumple solo parcialmente alguno de los diferentes criterios. } \\
\text { 1: Cumple de forma dudosa alguno de los criterios. } \\
\text { 0: No cumple ningún criterio. }\end{array}$ \\
\hline
\end{tabular}

Fuente: Elaboración propia. 


\section{Resultados}

En la Tabla 3 se presentan los resultados de aplicar los criterios de calidad a los 23 instrumentos de cribado detectados en el proceso de revisión. Es de destacar la falta de información psicométrica en general. En particular, la referente a la validez y al valor diagnóstico (sensibilidad, especificidad y valores predictivos positivos y negativos), cuando no un excesivo número de estudios con valores diferentes en función del criterio diagnóstico, tamaño de la muestra, tiempo de la aplicación, etc.

Con respecto al primer criterio (suelo de la prueba) como se trata de uno de los criterios de inclusión en la búsqueda sistemática, se observa que todas las herramientas tienen una puntuación alta. Respecto a la fiabilidad como consistencia interna es el dato psicométrico más frecuente, la valoración obtenida cuando se aporta este dato suele ser alta. De la misma forma ocurre con la fiabilidad como estabilidad de la medida (test-retest), que aunque son muy pocas las pruebas en las que se han encontrado resultados, cuando se han localizado suelen ser medio o medio-alto. No se ha hallado información sobre la fiabilidad inter-jueces de los instrumentos.

El punto más débil en las herramientas analizadas, es la poca o ninguna información que se aporta sobre su validez. Son estudios a posteriori comparando resultados de diferentes instrumentos los que aportan, en todo caso, la información sobre la validez. En este sentido, los datos hacen referencia exclusivamente a la validez de criterio o validez concurrente. Se entiende que, para determinar la validez de constructo o valor predictivo de los ítems en la detección de trastornos concretos, se hacen necesarios estudios longitudinales con muestras muy elevadas y consecuentemente con un alto coste económico.

Al ordenar esta puntuación total se observa que existen tres pruebas que se encuentran dentro del primer cuartil y ocho más en el segundo cuartil (ver Tabla 3). Se trata de las formas cortas o screening de las escalas Bayley (Bayley III Screening Test) y Battelle (Battelle Developmental Inventory Screening Test) y del sistema de detección Ages and Stages Questionnaires (ASQ-3).

La primera de ellas, Bayley III Screening Test (Bayley, 2006) utiliza una forma de administración mixta, parte de los ítems se observan directamente sobre el niño/a y parte, se recoge la información mediante autoinforme de los/as padres/madres. Los resultados permiten clasificar a los/as niños/as como "competente", "emergente" o "de riesgo". Estas categorías se determinaron en base a la puntuación alcanzada por los/as niños/as en la aplicación de la BSID$\mathrm{III}^{3}$. Aunque existen versiones en castellano, la traducción se ha realizado para población hispana norteamericana y se hace necesaria una adaptación al castellano de España. Por otra parte, no existe estudio de tipificación de la BSTIII ${ }^{4}$ en población española.

La segunda prueba, Ages and Stages Questionnaires (ASQ-3), es un sistema de detección compuesto por 2 I cuestionarios, uno específico para cada corte de edad desde los 2 meses hasta los 60 meses. Los cuestionarios pueden ser cumplimentados directamente por los/as padres/madres durante la revisión pediátrica, enviados por correo u "online". Cada cuestionario cuenta con unos pequeños datos demográficos y treinta preguntas sobre el desarrollo del niño/a dividido en cinco dominios. Si la puntuación obtenida es inferior a un punto de corte significa que es necesaria una evaluación más especializada. La validación de este sistema de detección se realizó con las escalas Battelle Developmental Inventory II y Bayley BSID-II obteniendo muy buenos resultados (Gollenberg et al. 2010). Este sistema ha sido adaptado a numerosos países aunque en muy pocos estudios de adaptación se han re-examinado sus propiedades psicométricas (Kerstjems et al. 2009). La versión española ha

\footnotetext{
3. Bayley Scales of Infant and Toddler Development. Edition III.

4. Bayley Screening Test III.
} 


\begin{tabular}{|c|c|c|c|c|c|c|c|c|c|}
\hline \multirow{2}{*}{\multicolumn{2}{|c|}{ Instrumentos }} & \multirow{3}{*}{$\begin{array}{l}\text { Edad } \\
\text { Suelo } \\
3,00 \\
\end{array}$} & \multicolumn{2}{|c|}{ Fiabilidad } & \multirow{3}{*}{\begin{tabular}{c|} 
Validez \\
2,00 \\
\end{tabular}} & \multicolumn{2}{|c|}{ Diagnóstico } & \multirow{3}{*}{$\begin{array}{l}\text { Otros } \\
3,00 \\
\end{array}$} & \multirow{3}{*}{$\begin{array}{l}\text { Total } \\
20,00\end{array}$} \\
\hline & & & \multirow{2}{*}{$\begin{array}{c}\text { Consistencia } \\
3,00 \\
\end{array}$} & \multirow{2}{*}{$\begin{array}{l}\text { Re- } \\
\text { Test } \\
3,00\end{array}$} & & \multirow{2}{*}{$\begin{array}{c}\text { Sensibilidad } \\
3,00\end{array}$} & \multirow{2}{*}{$\begin{array}{c}\text { Especificidad } \\
3,00 \\
\end{array}$} & & \\
\hline & 3.- Bayley III Screening Test. & & & & & & & & \\
\hline 孛 & 1.- Ages and Stages Questionnaires. & 3,00 & 3,00 & 3,00 & 3,00 & 2,00 & 2,00 & 3,00 & 19,00 \\
\hline$\stackrel{\circ}{\circ}$ & $\begin{array}{l}\text { 2.- Battelle Developmental Inventory } \\
\text { Screening Test. }\end{array}$ & 3,00 & 3,00 & & 3,00 & 3,00 & 3,00 & 3,00 & 18,00 \\
\hline \multirow{8}{*}{ 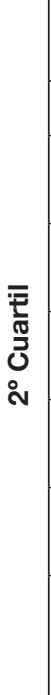 } & $\begin{array}{l}\text { 14.- First STEp: Screening Test for } \\
\text { Evaluating Preschoolers. }\end{array}$ & 3,00 & 3,00 & & 3,00 & 2,00 & 2,00 & 2,00 & 15,00 \\
\hline & 5.- Child Development Inventory. & 2,00 & 3,00 & & 2,00 & 2,00 & 3,00 & 2,00 & 14,00 \\
\hline & $\begin{array}{l}\text { 13.- Early Learning Accomplishment } \\
\text { Profile. }\end{array}$ & 3,00 & 3,00 & & 2,00 & 3,00 & 2,00 & 1,00 & 14,00 \\
\hline & $\begin{array}{l}\text { 19.- Kent Inventory of Developmental } \\
\text { Skills. }\end{array}$ & 3,00 & 3,00 & 3,00 & 3,00 & & & 2,00 & 14,00 \\
\hline & $\begin{array}{l}\text { 22.- Parents' Evaluation of } \\
\text { Developmental Status. } \\
\end{array}$ & 3,00 & 3,00 & & 1,00 & 2,00 & 2,00 & 3,00 & 14,00 \\
\hline & $\begin{array}{l}\text { 4.- Brigance Early Childhood } \\
\text { Screens. }\end{array}$ & 3,00 & 2,00 & & 2,00 & 2,00 & 2,00 & 2,00 & 13,00 \\
\hline & $\begin{array}{l}\text { 8.- Developmental Activities } \\
\text { Screening Inventory-II. }\end{array}$ & 3,00 & 3,00 & 3,00 & 2,00 & & & 1,00 & 12,00 \\
\hline & $\begin{array}{l}\text { 23.- Parents' Evaluation } \\
\text { of Developmental Status } \\
\text { Developmental Milestones. }\end{array}$ & 3,00 & & & 1,00 & 2,00 & 3,00 & 2,00 & 11,00 \\
\hline \multirow{7}{*}{ 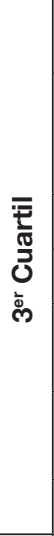 } & $\begin{array}{l}\text { 11.- Developmental Observation } \\
\text { Checklist System. }\end{array}$ & 3,00 & 3,00 & & 2,00 & & & 2,00 & 10,00 \\
\hline & $\begin{array}{l}\text { 16.- Individual Growth and } \\
\text { Development Indicators (IGDIs) for } \\
\text { Infants and Toddlers. }\end{array}$ & 3,00 & 3,00 & & 2,00 & & & 2,00 & 10,00 \\
\hline & 21.- Prueba Nacional de Pesquisa. & 3,00 & & & & 2,00 & 3,00 & 2,00 & 10,00 \\
\hline & 15.- Infant Development Inventory. & 3,00 & & & & 2,00 & 2,00 & 2,00 & 9,00 \\
\hline & $\begin{array}{l}\text { 20.- Minnesota Child Development } \\
\text { Inventory. }\end{array}$ & 1,00 & & & & 3,00 & 3,00 & 2,00 & 9,00 \\
\hline & $\begin{array}{l}\text { 10.- Denver Developmental } \\
\text { Screening Test. }\end{array}$ & 3,00 & & & & 2,00 & 1,00 & 2,00 & 8,00 \\
\hline & 6.- Child Development Review. & 2,00 & & & & 1,00 & 2,00 & 2,00 & 7,00 \\
\hline \multirow{5}{*}{ 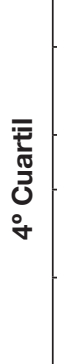 } & 7.- Cognitive Abilities Scale. & 2,00 & & & 2,00 & & & 1,00 & 5,00 \\
\hline & $\begin{array}{l}\text { 9.- Developmental Assessment of } \\
\text { Young Children. }\end{array}$ & 3,00 & & & & & & 1,00 & 4,00 \\
\hline & 12.- Developmental Profile 3. & 3,00 & & & & & & 1,00 & 4,00 \\
\hline & $\begin{array}{l}\text { 17.- Infant-Toddler Developmental } \\
\text { Assessment. }\end{array}$ & 3,00 & & & & & & 1,00 & 4,00 \\
\hline & $\begin{array}{l}\text { 18.- Infant-Toddler and Family } \\
\text { Instrument. }\end{array}$ & 2,00 & & & & & & 1,00 & 3,00 \\
\hline
\end{tabular}


sido traducida para la población hispana de USA y solo disponemos de datos psicométricos de la adaptación de los cuestionarios de 9, I 8 y 30 meses (Pomés, 20I2).

La tercera de ellas, Battelle Developmental Inventory Screening Test (BDIST), (Newborg, 2005), consiste en 96 ítems extraídos de la BDI-II. Evalúa las áreas de desarrollo motor fino y grueso, conducta adaptativa, socioemocional, lenguaje comprensivo y expresivo y estilos cognitivos. El tiempo de administración oscila entre los Io minutos en los/as niños/ as más pequeños y los 30 en los/as niños/as mayores. Existe cierta preocupación sobre las propiedades psicométricas dado que en origen no formaba parte del estudio de normalización de la prueba completa (Bliss y Newborg, 2007). Las normas de aplicación son las mismas que en la escala general por lo que se puede considerar como una forma breve de la BDI-II diseñada exclusivamente para detectar a los/as niños/as que precisan una evaluación de mayor amplitud y profundidad.

Con respecto a las ocho pruebas que quedan ordenadas en el segundo cuartil destacamos, Parents' Evaluation of Developmental Status (PEDS), (Glascoe, I998) y el Parents' Evaluation of Developmental Status Developmental Milestones (PEDS-DM), (Easterbrooks y Goldberg, I984; Brothers et al., 2008) por la originalidad de la idea de detectar el trastorno por medio de la preocupación de los propios padres (PEDS) o por el conocimiento de los hitos evolutivos (PEDS-DM). El primero ha sido comparado con numerosos sistemas de detección (CDI, Brigance Screens, BDIST, etc) con buenos resultados (Halle et al. 20II). En la actualidad ya existe versión electrónica que clasifica a los/as niños/as como de alto, moderado o bajo riesgo. El PEDS-DM puede utilizarse, de forma independiente o complementaria, para realizar un seguimiento longitudinal a lo largo del desarrollo del niño/a. Consiste en 20 cuestionarios distribuidos por edad desde el nacimiento hasta los 8 años aproximadamente.

El Child Development Inventory (CDI) es un cuestionario para la detección y evaluación de niños/as en los que existe preocupación por su desarrollo. Consiste en 300 ítems que los padres/ madres pueden observar en sus hijos/as en situaciones cotidianas. La puntuación obtenida se traslada a un perfil donde se contrasta con la puntuación promedio de su edad. Se considera problemática una puntuación por debajo de 2 desviaciones de la media de su edad. El CDI es el resultado de 30 años de investigación y experiencia clínica con el Inventario Minnesota Desarrollo Infantil (MCDI), (Ireton y Glascoe, I995).

Por último, destacar también que el test de Denver, prueba clásica, obtiene una puntuación baja quedando en el tercer cuartil. Su puntuación se justifica por la falta de estudios de validez, tanto de constructo como diagnóstico, desconociendo datos de su sensibilidad y especificidad (Frankenburg et al. I992). Otros estudios han demostrado que la escala tiene una buena sensibilidad pero baja especificidad (Glascoe et al. I992; Hamilton, 2006).

\section{Discusión y Conclusión}

El cribado del desarrollo es un procedimiento de evaluación breve diseñado para identificar a niños que deberían recibir una evaluación más exhaustiva (Meisels y Provence, I989). Para poder obtener una aplicación universal se debería conseguir un instrumento que suponga bajo coste en su aplicación. Para ello, se ha demostrado que los cuestionarios de autoinformes de los/as padres/madres tienen suficiente validez y fiabilidad como para ser considerados como sistemas de nivel I. El uso de herramientas de cribado por los padres, aunque claramente reduce coste, genera una preocupación general sobre la fiabilidad de las respuestas de los padres respecto al desarrollo de sus hijos (Sheehan, I988). Esta preocupación dio pie a muchas investigaciones alrededor de su validez. En la mayoría de las investigaciones se informa de un acuerdo consistente entre las evaluaciones de profesionales y padres, en 
particular cuando estos últimos respondían a cuestiones sobre el desarrollo actual (Squires et al. I998). Otra ventaja práctica que se les atribuye a este tipo de cuestionarios es que las madres están más preocupadas por el comportamiento y desarrollo de su hijo que por las cuestiones médicas y, sin embargo, muy pocas discuten con su pediatra estas preocupaciones (Hickson et al. 1983). Este sistema de cuestionarios contestados por las familias (cuidadores principales) aporta también como ventaja la inclusión de información de difícil observación directa en el proceso de evaluación (cribado entre otras). Además, los cuidadores (padres/madres) son reforzados como una parte muy importante en todo el proceso, promoviendo así su papel activo en la implementación de estrategias posteriores de intervención.

En cuanto al contenido de los cuestionarios, aunque deben ser simples en sus planteamientos, deberían tener suficientes ítems de cada área del desarrollo (motor, lenguaje comprensivo y expresivo, desarrollo socio-emocional, cognitivo, etc.) como para, en caso de puntuaciones bajas en una de estas áreas, poder orientar al evaluador hacia qué área evaluar con un screening de nivel II. En general la selección de las habilidades a evaluar se establecen siguiendo dos criterios: a) los hitos evolutivos más significativos y b) conductas significativas en la sintomatología de un trastorno. El primer criterio de selección permitirá valorar el nivel de retraso en el desarrollo si es que existe. Mientras que el segundo permitirá el ajuste de la conducta manifiesta sobre unos síntomas potencialmente alarmantes. Una combinación de ambos mejoraría la sensibilidad y la especificidad del instrumento de detección.

Una detección basada en una única prueba no tiene en cuenta la naturaleza dinámica del desarrollo del niño/a. El resultado de un test de desarrollo en un momento determinado en el tiempo puede estar influenciado por diversos factores. El desarrollo es un proceso dinámico no lineal, se caracteriza por rachas, mesetas y hasta regresiones. Una sola instantánea en un punto en el tiempo, no proporciona información sobre la trayectoria de desarrollo del niño/a. Esta reflexión nos lleva a diferenciar entre los test de cribado y los sistemas de vigilancia.

Los tests de detección de nivel I, se aplican o deben aplicarse a toda la población, y su objetivo es distinguir entre aquellas personas que tienen más riesgo de padecer algunos trastornos de aquellas otras de riesgo menor. El sistema de cribado del desarrollo ideal sería aquel que cubriera todas las áreas del desarrollo, en diferentes momentos a lo largo de la primera infancia, formando así un sistema de vigilancia del desarrollo. En este sentido, se podrían y deberían combinar diferentes herramientas tanto de desarrollo general (nivel I) como de patologías específicas (Nivel II) (Drotar et al. 2008).

Teniendo en cuenta la revisión realizada, se observa que la mayoría de los instrumentos de cribado generales encontrados están en inglés, solo algunos de ellos están traducidos al castellano (se entiende que es debido a la presión y/o necesidad de población hispana que reside en Estados Unidos), pero son muy pocos los que están validados en España. Las revisiones o estudios normativos, cuando existen, suelen adolecer de un estudio psicométrico profundo. Sería deseable poder confirmar el porcentaje de respuesta de los ítems cuando estos reflejan hitos evolutivos, con la finalidad de determinar la adecuación del hito a la edad para la que ha sido seleccionado como representante típico. Con respecto al cálculo de la fiabilidad, en general, los resultados manifiestan un nivel medio-alto de fiabilidad. No obstante, se hace notar que la medida de fiabilidad utilizada en la mayoría de las ocasiones hace referencia a la consistencia interna. Este indicador, sin embargo, no garantiza que el instrumento proporcione una medida estable. La fiabilidad como estabilidad de la medida suele medirse mediante el test re-test. Este procedimiento, sin embargo, no es el utilizado en la mayoría de los estudios consultados, posiblemente debido al coste que supone la doble aplicación. Otra medida de fiabilidad ausente que debería tenerse en cuenta en estos casos hace referencia a la consistencia entre jueces. Este indicador se 
hace especialmente relevante en los sistemas y cuestionarios diseñados para que los contesten los/as padres/madres. Un mismo niño/a es observado por varios jueces y sus puntuaciones deberían ser las mismas si las instrucciones y el objeto de observación están bien definidos.

Con respecto a la validez de los sistemas de detección en general se toma como contraste el resultado sobre el mismo individuo de escalas del desarrollo como la Battelle o la Bayley. Siendo adecuado este contraste, no es suficiente sobre todo cuando hablamos de validez de diagnóstico. En este sentido se hace necesario valorar adecuadamente el criterio de contraste. Lo adecuado es conseguir el diagnóstico definitivo, aunque ello obligue en muchos casos a realizar o estudios clínicos o estudios de seguimiento a lo largo del desarrollo del niño/a.

Por último, se deben destacar las ventajas aportadas por las nuevas tecnologías, en particular por la distribución de la información por la red. Existen muchas pruebas con versiones electrónicas o bien que se distribuyen con software de corrección, facilitando la aplicación de los instrumentos. En este sentido, la integración de las facilidades multimedia de la red podrá permitir que las familias con niveles más bajos de comprensión lectora puedan cumplimentar los cuestionarios con menos problemas. A su vez, un sistema electrónico de agenda puede hacer que las familias reciban los avisos oportunos para que cumplimenten los cuestionarios en el momento adecuado según la edad de los/as niños/as.

En definitiva, aunque hay un gran camino ya recorrido y el número de cuestionarios y sistemas de detección es considerable, existe la necesidad en nuestro país de realizar los estudios de validación y normalización necesarios o el desarrollo de sistemas propios. 
AAP (I994): "Committee on Children with Disabilities. Screening infantas and young children for developmental disabilities”. Pediatrics, 93: 863-865.

AAP (200Ia): "Committee on Children with Disabilities. Developmental surveillance and screening of infants an youn children". Pediatrics, г08: 192-196.

AAP (200Ib): Developmental surveillance and screening of infants and young children. Committe on children with disabilities. American Academy of Pediatrics.

AAP (2006): "Identifying Infants and Young Children With Developmental Disorders in the Medical Home: An Algorithm for Developmental Surveillance and Screening”. Pediatrics, I: 405-420.

Aaronson, N. et al. (2002): "Assessing health status and quality-of-life instruments: Attributes and review criteria". Quality of Life Research, I I: 193-202.

Alcantud, F. et al. (2015): Sistema de Detección Precoz de Trastornos del Desarrollo (SDPTD): Construcción, validación y manual de uso (Versión I.o). Madrid: Real Patronato sobre Discapacidad.

Alpern, G. (2007): Developmental Profile. Los Angeles California: Western Psychological Services.

Arruabarrena, I. y de Paul, J. (2OI2): "Early Intervention Programs for Children and Families: Theoretical and EMpirical Bases Supporting their Social And Economic Efficiency". Psychosocial Intervention, 2 (2I): I I 7-I 27 .

Artigas-Pallarés, J. (20I I): “Trastornos del neurodesarrollo: Conceptos básicos, en ArtigasPallarés, J. y Narbona, J.: Trastornos del Neurodesarrollo. Barcelona: Viguera Ediciones.

Aylward, G. (I997): "Conceptual issues in developmental screening and assessment".
Journal of Developmental and Behavioral Pediatrics, I 8: 340-349.

Barnes, K. y Stark, A. (I975): “The Denver Development screening test". American Journal of Public Health: 363-369.

Bayley, N. (2006): Bayley scales of infant and toddler development. 3 rd Edn Screening test Manual. San Antonio Texas: Pearson Education Inc.

Bedford, H. et al. (2013): Measures of child development: A review. Centre for Paediatric Epidemiology and Biostatistics.

Bliss, S. y Newborg, J. (2007): "Battelle Developmental Inventory Sencon Edition”. Journal of Psychoeducational Assessment, 25 (4): 409-4I 5 .

Bradley-Johnson, S. y Johnson, C. (200I): Cognitive abilities scale ( 2 nd ed). Austin Texas: Pro-Ed.

Brigance, A. y Glascoe, F. (2002): Brigance Infant and Toddler Screen, Massachusetts: Hawker Brownlow Education.

Brothers, K. et al. (2008): "PEDS: Developmental Milestones- An Accurate Brief Tool for Surveillance and Screening”. Clinical Pediatrics, 47 (3): 27I-279.

Bryson, S. et al. (2008): "The autism Observation Scale for Infants: Scale development and reliability data". Journal of Autism Developmental Disorders, 38 (4): 73 I-738.

Camp, B. W. (2006): "What the clinician really needs to know: Questioning the clinical usefulness of sensitivity and specificity in studies of screening test". Journal of Developmental and Behavioral Pediatrics, 27: 226-230.

Coonrod, E. y Stone, W. (2005): "Screening for autism in young children", en Volkmar, F. et al.: Handbook of Autism and Pervasive Developmental Disorders. Hoboken NJ: John Wiley \& Sons. 
Cox, A. et al. (I999): “Autism spectrum disorders at 20 and 42 months of age: stability of clinical and ADI-R diagnosis". Journal of Child Psychology ans Psychiatry ans Allied Disciplines, 40 (5): 719-732.

Creighton, D. y Sauve, R. (I988): “The Minnesota Infant Development Inventory in the developmental screening of high-risk infants at 8 months". Journal of Behavior Sciences, 20 : 424-433.

Dawson, S. et al. (2000): "Case study of the development of an infant with autism from birth to two years of age". Journal of Applied Developmental Psychology, 2 I: 299-3 I 3 .

Drotar, D. et al. (2008): Pediatric developmental screening: understanding and selecting instruments. Nueva York: Commonwealth Fund.

Easterbrooks, M. y Goldberg, W. ( I984): “Toddler development in the family: Impact of father involvement and parenting characteristics". Child Development, 55 (3): 740-752.

Erikson, J. (I996): The Infant-toddler developmental assessment (IDA): A familycentered transdisciplinary assessment process. Washington DC: Zero to Three: The National Center for Infants, Toddlers and Families.

Fenichel, G. (I988): Clinical pediatric neurology. Philadelphia: WB Saunders.

Fewell, R. y Langley, M. (I984): DASI-II Developmental activities screening inventory. Austin Texas: Pro-Ed.

Filipek, P. et al. (2000): "Practice parameter: screening and diagnosis of autism". Neurology, $4(55): 468-479$.

Frankenburg, W. y Dodds, J. (I967): “The Denver Developmental Screening Test". The Journal of Pediatrics, 7I (2): I8I-I9I.

Frankenburg, W. et al. (I97I): "Validity of Denver developmental screening test". Child Development: 475-485.

Frankenburg, W. et al. (I992): “The Denver II: a major revision and restandardization of the Denver Developmental Screening Test”. Pediatrics, 89 (I): 9I-97.
GAT, Federación Estatal de Asociaciones de Profesionales de Atención Temprana (2000): Libro Blanco de Atención Temprana. Madrid: Real Patronato sobre Discapacidad.

Glascoe, F. (I997): "Parents' concerns about children's development: pre-screening technique or screening test?". Pediatrics, 99: 522-528.

Glascoe, F. (I998): Parent's Evaluation of Developmental status (PEDS). Nashville: Ellsworth \& Vandermeer.

Glascoe, F. et al. (I992): “Accuracy of the DenverII in developmental screening”. Pediatrics, 89 (6): I22I-I 225 .

Gollenberg, A. et al. (2010): “Concurrent validity of the parent-completes Ages and Stages Questionaires. 2nd Ed. with the Bayley Scales of INfant Development II in low-risk sample”. Child: Care, Health \& Development, 36 (4): 485-490.

Gracy, M. et al. (2010): Developmental and SocialEmotional Screening Instruments for Use in Pediatric Primary Care in Infants and Young Children. Nueva York: Children's Health Fundation.

Greenwood, C. et al. (2005): "Individual growth and development indicators (IGDIs): Tools for assessing intervention results for infants and toddlers". Focus on behavior analysis in education: Achievements, challenges, and opportunities: I03-I 24 .

Halle, T. et al. (20I I): Understanding and choosing Assessments and Developmental Screeners for Young Children Ages 3-5: Profiles of Selected Measures, Washington, DC: Office of Planning, Research, and Evaluation, Administration for CHildren and Families, U.S. Departament of Health and Human Services.

Hamilton, S. (2006): "Screening for developmental delay: reliable, easy-to-use tools". Journal of Family Practice, 55 (5): 4I 5-422.

Hardin, B. y Peisner, E. (200I): The Early Learning Accomplishment Profile (E-LAP). Examiner's manual and Reliability and Validity, Chapel Hill: Training Ourreach Project Inc Kaplan Early Learning Company. 
Hickson, G. et al. (1983): “Concerns of mothers seeking care in private pediatric offices: Opportunities for expanding services".

Pediatrics, 72: 619-624.

Hix-Small, H. et al. (2006): "Impact of implementing Developmental Screening at I 2 and 24 months in a Pediatric Practice". Pediatrics, 2 (I 20): 38 I-388.

Hresko, W. et al. (1994): Developmental Observation Checklist System. Austin Texas: Pro-Ed.

Ireton, H. (I992): Child Development Inventory Manual. Minneapolis: Behavior Science Systems.

Ireton, H. (2004): Child Development Review Manual. Minneapolis: Behavior Science Systems.

Ireton, H. y Glascoe, F. (I995): “Assessin Children's Development Using Parent's Reports: The Child Developmen Inventory". Journal of Clinical Pediatrics, 34 (5): 248-255.

Ireton, H. et al. (I977): “Minnesota Child Development Inventory: Identification of children with developmental disorders". Journal of Pediatric Psychology, 2 (I): I 8-22.

Johnson, C. y Bradley-Johnson, S. (2002): "Construct stability of the cognitive abilities scale for infants and toldders". Journal of Psychoeducational Assessment, 20 (2): I44I 5 I.

Johnson, C. y Myers, S. (2007): "Identification and evaluation of children with autism spectrum disorders". Pediatrics, 5 ( ( 20 ).

Johnson, S. y Marlow, N. (2006): "Developmental screen or developmental testing?”. Early Human Development, 82: I73-183.

Kerstjems, J. et al. (2009): "Support for the global feasibility of the Ages and Stages Questionaire as developmental screener". Early human development, 85 (7): 443-447.

Kleinman, J. et al. (2008): "Diagnostic stability in very young children with Autism Spectrum Disorders". Journal of Autism And Developmental Disorders, 38: 606-6I 5 .
Kube, D. et al. (I988): "Classification of Developmental Delays”. Seminars in Pediatric Neurology, 5 (I): 2-I 4 .

Leiarraga, H. et al. (2005): Prueba Nacional de Pesquisa, PRUNAPE, Manual Técnico, Buenos Aires: Fundación Hospital Garran.

Lord, C. y Corsello, C. (2005): "Diagnostic instruments in autistic spectrum disorders", en Volkmar, F. et al.: Handbook of Autism and Pervasive Developmental Disorders. Hoboken NJ: John Wikey \& Sons.

Meisels, J. y Provence, S. (1989): Guidelines for identifying young disabled and developmentally vulnerable children and ther families.

Washington DC: Bational Center for Clinical Infant Programs.

Miler, L. (I993): FirstSTEP: Screening Test for Evaluating Preschoolers. Manual. San Antonio Texas: Pearson.

Moodie, S. et al. (20I4): Early childhood developmental screening: A compendium of measures for children ages birth to five. Washington: Office of Planning, Research and Evaluation, Administration for Children and Families. US Departament of Health and Human Services.

Muñoz, J. et al. (2006): "Autismo, Identificación e intervención temprana”. Acta de Neurologia Colombiana, 2 (22).

Newborg, J. (2005): Battelle Developmental Inventory. 2nd Edition: Examiner's manual, Itasca IL: Riverside.

Pomés, P. (2012): Examination of the spanish translation of developmental screening instrument, Oregon: University of Oregon.

Provence, S. y Apfel, N. (200I): Ifant-Toddler and Family Instrument (ITFI), Paul H Brookes.

Reuter, J. y Gruber, C. (2000): Kent Inventory of Developmental Skills. Kent, Ohio: Western Psychological Services.

Reuter, J. et al. (1996): Kent Inventory of Developmental Skills (KIDS), Los Angeles: Western Psychological Services.

Ringwalt, S. (2008): Developmental screening and assessment instruments with an emphasis 
on social and emotional development for young children ages birth through five, Chapel Hill: The University of North: FPG Child Development Institute The National Early Childhood Technical Assistance Center.

Roxswell, S. (I993): FirstSPET: Screening test for evaluating preschoolers, Harcourt Brace Javanovich: Psychological Corporation.

Rydz, D. et al. (2006): "Screening for Developmental Delay in the Setting of a Community Pediatric Clinic: A Prospective Assessment of Parent-Report Questionnaires”. Pediatrics, 4 (I I 8).

Sheehan, R. (I988): "Involvement of parents in early childhood assessment", en Wachs T. y Sheehan, R. (Eds): Assessment of young developmentally disabled children, Nueva York: 75-90.

Shonkoff, J. et al. (I979): "Primary care approaches to developmental disabilities”. Pediatrics, 4 (64): 506-5I4.
Squires, J. et al. (I997): "Revision of a ParentCompleted Developmental Screening Tool: Ages and Stages Questionaires". Journal of Pediatric Psychology, 22 (3): 3I3-328.

Squires, J. et al. (I998): "Parent-completed Developmental questionnarires: Effectiveness with low and middke income parents". Early Childhood Research Quaterly: 345-353.

Terwee, C. et al. (2007): “Quality criteria were proposed for measurement properties of health status questionnaires". Journal of Clinical Epidemiology, 60: 34-42.

Vericat, A. y Orden, A. B. (20I0): “Herramientas de Screening del Desarrollo Psicomotor en Latinoamérica". Revista chilena de pediatría, $8 I(5): 39$ I-40I.

Voress, J. y Maddox, T. (1998): Developmental assessment of young children (DAYC-2Ed). Austin Texas: Pro-Ed. 


\section{Estrategias psicosociales utilizadas para el cambio de actitud hacia personas discriminadas por su discapacidad o trastorno mental}

\section{Psychosocial strategies used to change attitudes towards people discriminated against because of their disability or mental disorder}

\section{Resumen}

El presente trabajo permitió realizar una revisión de las estrategias psicosociales relacionadas con el cambio de actitud que suelen ser utilizadas en programas que buscan la modificación actitudinal especialmente en la percepción que tiene la población hacia personas en situación vulnerable de discriminación como suelen ser los discapacitados y los que presentan trastorno mental. Se utilizó la técnica de revisión documental con consultas en bases de datos científicas de Psicología, que arrojó 80 referencias de las cuales 58 hicieron parte del estudio. Los hallazgos encontrados muestran que las estrategias más utilizadas y comunes a los dos tipos de discriminación en programas de reorientación actitudinal son: la educación y el contacto social, que suelen ser combinadas con otros tipos de técnicas.

\section{Palabras clave}

Técnicas psicológicas, cambio de actitud, discriminación, discapacidad y trastorno mental.

\section{Abstract}

This article makes a review of psychosocial strategies related to the change in attitude frequently used in programs aimed at attitudinal changes specifically in the public's perception of persons vulnerable to discrimination many of whom are disabled or have a mental health problem. The method of documentary review was used and scientific psychological databases were searched. The database searches resulted in the retrieval of 80 bibliofraphic references of which 58 were used for the investigation. The findings of the review highlight that the most used strategies in attitudinal reorientation programs, addressing both types of discrimination, are: education and social contact in combination with other techniques.
\end{abstract}

\section{Keywords}

Psychological techniques, change of attitude, discrimination, disability and mental health problems.

\section{Jesús Armando Delgado \\ Meza \\ <jesus.delgado@udi.edu.co> \\ Corporación Universitaria de Investigación y Desarrollo}

Para citar:

Delgado, A. (2015): "Estrategias psicosociales para el cambio de actitud hacia personas discriminadas por su discapacidad o trastorno mental", Revista Española de Discapacidad, $3(2): 27-39$.

Doi: <http://dx.doi.org/IO.5569/23405 I04.03.02.02>

Fecha de recepción: 09-09-20I 5 Fecha de aceptación: O3-I2-20I 5 
Introducción

Diversos programas de intervención psicosocial encaminados a la búsqueda de la reformulación de estereotipos sociales e ideas estigmatizantes han hecho uso de estrategias basadas en distintos paradigmas sobre el cambio de actitudes. El interés por revisar las estrategias de intervención psicológica eficaces para la modificación de actitudes hacia la población de personas discapacitadas (Serrano et al., 20I3) o con trastorno mental (Alvarez y Almeida, 2008) se debe a que se han presentado pocas modificaciones en la percepción que se tiene sobre este tipo de personas, llevando por ende a los sujetos que la poseen a un inadecuado autoconcepto y alteraciones en su socialización, ya que la utilización continua de actitudes negativas se convierten en obstáculos que impiden la integración social de estos dos colectivos. Se trata de una situación en la que fácilmente se ven vulnerados los Derechos Humanos fundamentales, lo que ha llevado a que ésta sea afrontada por diferentes organizaciones internacionales como por ejemplo las Naciones unidas, la Organización Mundial de la Salud, distintas naciones individualmente, grupo de pacientes y de familiares que han visto la necesidad de proponer desde normativas hasta acciones que busquen la oportuna y adecuada integración social de este tipo de personas.

$\mathrm{Y}$ es que la persistencia de prejuicios y actos de discriminación se convierten en una evidencia fehaciente de que la inclusión de personas con discapacidad y/o con trastorno mental a actividades sociales no han mostrado los mejores resultados, tanto en participación, especialmente en lo que tiene que ver con relaciones interpersonales y autoestima por el hecho de enfrentar el riesgo al rechazo, como en aportación social (Palacios, 2008; Hilarion y Koatz, 20I2). Por otra parte, la conservación de actitudes erróneas y conceptualizaciones equívocas están relacionadas con la negación a cambios, resistencias y hasta retrocesos frente a la visión de discapacidad o enfermedad mental (Hernández et al., 2009). Esto se debe particularmente a que ciertos valores y principios de la sociedad se encuentran viciados, lo que requiere que se asuman cambios de actitudes de orden social que permitan abrir espacios, generar más participación y oportunidades de convivencia social.

Precisamente, tratar el tema de los cambios actitudinales refiere retomar el soporte teórico acerca de las actitudes el cual describe que en su estructura según Katz y Stotland (I959), Krech et al. (I962) se destacan tres componentes: el cognitivo, cuyo contenido son creencias y conocimiento del objeto, el afectivo que viene acompañado de la emoción y que suele ser difícil de cambiar y el componente conductual correspondiente a la tendencia o predisposición a actuar. Tanto en la discapacidad como en la enfermedad mental, la estigmatización se ha visto permeada por la influencia de estos tres componentes gracias a la acción de creencias sociales, desafectos y conductas asociadas a la rotulación que la sociedad hace a este grupo de personas, lo cual ha dificultado el desarrollo de los programas de salud mental y la promulgación de sus derechos. Redefinir la idea de inhabilidad y anormalidad en el caso de la discapacidad, y locura y peligrosidad en el caso del trastorno mental serían algunos pasos para combatir este estigma.

La forma como se ha venido actuando para cambiar creencias, afectos y discriminación hacia las personas discapacitadas (Universidad Internacional de Andalucía, 20I4) y/o con trastorno mental (López et al., 2008) ha sido a través de programas basados en la teoría del cambio de actitud que utilizan diversas estrategias ya sea de forma particular o combinada, siendo las más frecuentes el contacto con este tipo de personas, la información sobre temas relacionados con dichas poblaciones y el entrenamiento en habilidades sociales, entre otras.

Es por ello que a través del presente trabajo, se hará una revisión documental que permita escudriñar los procedimientos en cuanto a la utilización de estrategias que inciden sustancialmente en programas sociales e 
intervenciones psicosociales que buscan la modificación en la percepción o el cambio de actitudes en las personas hacia dos sectores poblacionales sensiblemente discriminados: las personas con discapacidad y las personas que presentan algún tipo de trastorno mental.

\section{Metodología}

Este trabajo corresponde a una investigación de tipo cualitativa en la que se utilizó la técnica de revisión bibliográfica o documental con búsqueda en bases de datos científicas de Ciencias Sociales y Humanas tales como Ebsco, Proquest, Psicodoc, Redalyc, Science Direct, PsycInfo, Sociological Abstract y en los índices bibliográficos nacionales y latinoamericanos Publindex y Latindex, la cual arrojó 80 referencias directas e indirectas sobre el tema estrategias para el cambio de actitudes en población adulta que han sido publicadas desde el año I96I hasta el 20I4 tanto en el idioma inglés como en español. Éstas se sometieron a examen de pertinencia quedando 58 , de las cuales, a su vez, las más directamente de orden psicosocial fueron solo 40 . Se definieron a su vez las unidades de estudio, entendidas éstas como los criterios básicos para la creación de fichas de clasificación de la información base de estudio. Estas fueron: título, autores, año de publicación, tema central del documento, ideas relevantes encontradas en el documento y datos a considerar que aportan al objetivo de la investigación; al interior de cada unidad se realizó una categorización con fines de realizar la revisión sistemática.

Finalmente, el estudio documental se desarrolló en cuatro fases: la primera fase, de búsqueda y registro descriptivo de la información de las fuentes; la segunda, interpretativa; la tercera, de sinopsis e integración de los hallazgos y la última fase, de redacción del documento.

Se consideraron como criterios de inclusión de artículos vinculados a la investigación el que se tratase de publicaciones cuyos temas centrales fuesen la exposición de estrategias sobre cambio de actitudes y la utilización de estas en programas orientados a hacer cambiar la visión estereotipada frente a poblaciones discriminadas como son las personas discapacitadas y personas con trastornos mentales, a las cuales se pudiese tener acceso virtual o físico por medio de las bases de datos mencionadas con anterioridad, y cuyas temáticas de análisis correspondan a alguna de las unidades de estudio.

\section{Resultados, análisis y discusión}

Dentro de los estudios encontrados sobre programas propuestos contra la discriminación se evidencia que un número significativo de ellos aplica estrategias de cambio de actitudes que buscan fomentar una percepción saludable y que ayudan a entender la situación de vulnerabilidad en la que se encuentran personas en condición de discapacidad y trastorno mental, permitiendo comprender la importante contribución que pueden llegar a ofrecer a la sociedad así como, también, promover autonomía y calidad de vida estimulando la aceptación y la normalización por parte de las personas objeto de discriminación.

\section{Investigaciones de aplicación de programas de cambio de actitudes hacia la discapacidad}

En el caso de las actitudes colectivas hacia las personas con discapacidad, éstas vienen caracterizadas por un cierto sentido negativo, falsamente mitificadas y cargadas de prejuicios sociales generados en torno a ellas, que conducen a una falsa creencia de que son seres inferiores, incompetentes, ineficaces para enfrentarse a la sociedad, lo que hace que estos estereotipos y prejuicios justifiquen la persistencia de ciertas actitudes hacia las personas con discapacidad (Soto y Vasco, 2008). En ciertos casos, dicha discriminación puede llegar al extremo de que estas personas 
pueden ser excluidas por otras y, de esta forma, negarles sus derechos y una participación activa en la sociedad (Luque y Luque-Rojas, 20II), negándoles el reconocimiento de su condición como parte de las diversidades que compone el mundo y de sus derechos, y el que sean vistas desde su discapacidad y no desde sus múltiples competencias, lo que conlleva a que no se les aproveche para el desarrollo social y económico en una sociedad.

La investigación, propuesta y ejecución de programas de cambio de actitudes hacia la discapacidad viene siendo abordado desde hace más de 20 años y ha sido objeto de estudios específicos (Aguado et al., 2003, 2004; Aguado et al., 2008; Aguado et al., 2006). Sus trabajos han sido basados en la aplicación de técnicas de cambio de actitudes hacia la discapacidad, brindando información directa e indirecta a grupos de personas sobre la discapacidad, estableciendo contacto físico con personas que la presentan y utilizando además ayudas técnicas en sesiones interactivas con discusión guiada, asequible y de fácil realización, que mostraron eficacia y un cierto mantenimiento temporal ya que las actitudes positivas suelen tener un decaimiento estadísticamente significativo. Según estos autores, el contacto estructurado y la información permiten tener un acercamiento a la realidad de la discapacidad, llevando a generar expectativas más ajustadas y a eliminar barreras y prejuicios, afirmación similar a lo encontrado por Gartrell (I986) y Dengra et al. (I99I), quienes adujeron que entre los factores necesarios para producir cambios en las actitudes hacia los sujetos con discapacidad se encuentran la representación de papeles de la condición de discapacidad, el contacto directo con sujetos con discapacidad, el contacto indirecto a través de videos, películas y el trabajo y discusiones en grupo, estas dos últimas de orden informativo.

Más adelante, en un estudio igualmente de Flórez et al. (2009) se realizó una revisión analítica de programas de cambio de actitudes hacia personas con discapacidad, refiriendo que una gran parte de ellos utilizan, bien de forma independiente o combinada distintas estrategias, siendo las más constantes el contacto con personas con discapacidad, la simulación de discapacidades, la información sobre temas relacionados con dicha población, los equipos de trabajo colaborativo, las experiencias en pequeños grupos, los programas de tutoría y el entrenamiento en habilidades interpersonales. Los resultados de la revisión hecha en este estudio muestran que el contacto e información, así como los equipos de trabajo colaborativo, son las técnicas más eficaces para el cambio hacia actitudes más positivas y más aún cuando actúan juntas, tal y como lo enuncian Navas et al. (2004) y Nikolaraizi et al. (2005) al referir que el contacto con personas con discapacidad, sin más, no facilita un cambio de actitudes. La mejora va asociada a un mayor conocimiento de la discapacidad.

El acompañamiento de cualquier técnica tal y como es revelada en los distintos resultados de investigaciones sobre el tema, acentúa la importancia de la educación como el paso inicial en la promoción de las actitudes positivas hacia las personas con discapacidad (Lockhart et al., I998; Shannon et al., 2009).

Por otra parte, teniendo presente que el componente cognitivo no es el único que se considera importante analizar en el cambio de actitudes, el componente afectivo también tiene una incidencia destacable ya que en muchas de las investigaciones la condición de empatía y acercamiento emocional es, sin duda, un aspecto que se observa en programas de intervención, cuyos resultados coinciden con diversos trabajos sobre el tema (Asensio, 2002; Avramidis y Norwich, 2002). Así, el contacto con las personas con discapacidad aumenta las actitudes positivas y se constituye en una variable clave en la configuración de las actitudes hacia ellas (Strohmer et al., I984). Investigaciones como las realizadas por Gómez e Infante (2004) y Newberry y Parish (1987) ratifican que el contacto directo con el discapacitado es un factor que condiciona las actitudes hacia éste, sobre todo cuando existen familiares que la poseen. Las actitudes positivas encontradas en estos estudios estuvieron relacionadas con un contacto cercano y profundo con la persona 
con discapacidad, algo característico y habitual en las relaciones familiares. En este sentido, el grado de vinculación y experiencias con la persona que sufre la discapacidad influye en la percepción, la valoración hacia la discapacidad y el alcanzar concepciones integrales con respecto a los mismos (García y Hernandez, 20I I; Moreno et al., 2006; Novo-Corti et al., 20I I; Wash et al., 2008).

La razón por la cual el contacto y la exposición con personas con discapacidad permiten un cambio en la percepción es porque esto facilita el descubrimiento de los atributos positivos de las personas discapacitadas y desarrollaría una mayor aceptación y entendimiento de las mismas, pudiéndose hacer de forma directa o indirecta y estructurada o no estructurada. Algunos estudios refieren en sus resultados que haciendo uso de contactos no estructurados, la sola interacción produciría el cambio de actitudes (Friedman, I975; Rapier et al., I972); sin embargo, otras investigaciones refieren resultados no significativos o negativos con este tipo de contacto (Stager y Young, I981; Donaldson, I980), las cuales describen que existen factores específicos que contribuyen a cambios actitudinales significativos positivos que no están controlados en las experiencias no estructuradas, existiendo la posibilidad de que se refuercen los estereotipos que las personas "normales" tienen sobre las discapacitadas (Strauch,I970), mientras que en el uso de las interacciones estructuradas con personas discapacitadas, se da lugar a la proporción de imágenes no estereotipadas (Gottlieb, I980) en el que se garantiza la practicidad de las actividades diseñadas, ofreciendo con ello resultados positivos (Bailard et al., I977; Evans, I976; Kierscht, I978; Langer et al., I976; Sedlick y Penta, I975); esto lleva a considerar esta estrategia como una de las más exitosas para producir cambios en la actitudes (Verdugo y Arias, I99I).

García (I997) haciendo uso de una de las técnicas mencionadas por Flórez et al. (2009) puso en práctica un programa de entrenamiento en habilidades interpersonales con un grupo de niños cuya edad estaba dentro del rango de I I-I 5 años. A través de la promoción de habilidades cognitivas de solución de problemas interpersonales se pretendió fomentar la aceptación de la integración de niños ciegos en un ciclo escolar, así como promover la disminución del rechazo a tal integración utilizando como referente un grupo control de niños de condiciones similares al grupo experimental, observándose que tras un programa de entrenamiento, las actitudes hacia la integración se modificaron en la dirección prevista y deseada, evidenciándose la conveniencia de utilizar este tipo de intervenciones con niños pre-adolescentes para incentivar la integración de personas discapacitadas, así como la necesidad de incluir este tipo de actuaciones dentro de los currículos escolares. Años más adelante, Pelechano (2003) utilizó dos programas de habilidades interpersonales orientadas a disminuir las actitudes negativas, concluyendo que las actitudes positivas hacia la integración de las personas con discapacidad son más fáciles de modificar hasta los 30 años y que la autoimplicación desempeña un papel importante en esas actitudes. Esta última afirmación había sido enunciada también por Zabalza (I998) quien señaló que en las nuevas generaciones la minoría de edad y la mayor escolarización son variables para el desarrollo de actitudes positivas hacia las personas que presentan una discapacidad.

Otra evidencia de la variedad de técnicas utilizadas en la búsqueda del cambio de actitud es la simulación como medio de conocimiento bastante directo, profundo y "vivo" sobre la discapacidad, en el sentido de ser experimentada personalmente. La experiencia de aplicación de esta técnica fue efectuada por Verdugo et al. (I994) en un grupo de estudiantes de tercero de secundaria, quienes llegaron a concluir que los tipos de intervención en donde mejor se aplica la afectación sobre los tres componentes de la actitud son: el contacto directo con personas con discapacidad, el conocimiento objetivo de la discapacidad incluyendo por supuesto la simulación o vivencia de la misma. Posteriormente López y López (I997) pretendieron promover una modificación de actitudes que proviniera de la reflexión 
producida por el enfrentamiento entre la actitud previa y la realidad que se le presenta a través de la exposición de las capacidades de las personas con discapacidad y la información sobre la misma, así como también de la simulación de algunas de ellas y el mayor conocimiento sobre las personas que la poseen.

Finalmente, la estrategia contacto social, tal y como se evidenció en descripciones anteriores, así como también en las investigaciones realizadas por Gómez e Infante (2004) y Newberry y Parish (I987), pone de manifiesto que esta forma de interacción efectuada con el discapacitado es un factor que condiciona las actitudes. En el estudio realizado, las actitudes positivas encontradas estarían relacionadas con un contacto cercano y profundo con la persona discapacitada, algo característico y habitual que suele presentarse en las relaciones familiares. En este sentido, el grado de vinculación y experiencias con la persona que sufre la discapacidad influiría en la percepción y valoración personal hacia la discapacidad. Los contextos o ambientes de interacción con personas que presentan discapacidad permiten favorecer el conocimiento sobre estas personas, sus características de discapacidad y la convivencia, evitando con ello exclusiones y desigualdades y haciendo que se produzca un desarrollo justo y solidario que facilite mejores procesos de enseñanza-aprendizaje y valores como el respeto y la tolerancia. Así lo refiere Luque y Luque-Rojas (20II) quien concluye que la discapacidad no es una limitación, ya que el contacto personal refuerza la interacción persona-situación, lo que incrementa o refuerza la sensibilidad social, convirtiéndose en la mejor arma para el desarrollo de actitudes y los valores en una comunidad.

\section{Investigaciones de aplicación de programas de} cambio de actitudes hacia el trastorno mental

De acuerdo a la Organización Mundial de la Salud (2013) debido a la discriminación y estigmatización, las personas con trastornos mentales también sufren violaciones de los derechos humanos, negación de derechos sociales, culturales y económicos, pocas oportunidades de participación en la vida pública y falta de atención a prácticas terapéuticas adecuadas en los centros sanitarios, convirtiéndose en un problema para el desarrollo de programas de salud mental que buscan mejorar los derechos humanos de los enfermos mentales (Guimón, 2004).

La promoción y aplicación de programas sobre el cambio de actitud hacia el trastorno mental como estereotipo social en general, sin recurrir a una clasificación por enfermedad (Eaton et al., 2008), se han extendido debido a la implicación social del tema, a los comportamientos discriminatorios hacia este grupo, a sus repercusiones en la reducción de sus posibilidades en la calidad de vida de quienes se encuentran bajo dicha condición, y en general, a las consecuencias de dichas actitudes en la vida y salud mental comunitaria. Desde las ciencias sociales y humanas, especialmente la Psicologia Social y la Sociología, tres estrategias han sido objeto de estudio y han mostrado tanto resultados positivos como negativos: protesta social, educación y contacto social (López et al., 2008).

Angermeyer y Matschinger (I996) comprobaron cómo la divulgación selectiva en los medios refuerza el estereotipo negativo de la enfermedad mental. Es por ello que la primera estrategia denominada "protesta social" ha tenido unos claros efectos a corto plazo en la lucha contra la estigmatización y la discriminación. Acciones como la solicitud de disminución de imágenes negativas basadas en estereotipos hacia las personas estigmatizadas, la supresión de alguna forma específica de discriminación difundida por los medios de comunicación, han mostrado buenos resultados. Sin embargo, su utilidad a largo plazo ha sido cuestionada, dada la poca utilización de imágenes positivas y la resistencia al cambio de los estereotipos sugeridos a través de los medios, lo que ha hecho que no se mantenga una percepción favorable hacia la población con enfermedad mental (Corrigan y Penn, I999; Corrigan, 200I).

Por otra parte, la estrategia "protesta social" ha ido de la mano con la estrategia "educación” lo que ha suscitado la generación de programas a 
largo plazo que han resultado ser útiles cuando se incluyen no sólo la transmisión pasiva de información sino la exposición de casos reales con presencia de personas que viven la discriminación y una discusión alrededor de la problemática (Rusch et al., 2005; Corrigan y Penn, I999; Estroff et al., 2004; Penn y Couture, 2002), concluyendo que la acción de la educación por sí sola no soluciona el problema de la discriminación, aún más cuando no existen datos explícitos de su capacidad para cambiar creencias o actitudes, sino conductas reales.

Diversos programas se han llevado a cabo a través de la ejecución de proyectos como el denominado Changing minds, Every family in the land emprendida por el Royal College of Psychiatrists del Reino Unido e Irlanda entre el año 1998 y 2003 que puso en marcha una serie de actividades para combatir la estigmatización de personas con enfermedad mental, buscando como objetivo incrementar el conocimiento y la comprensión por parte del público en general y de esta manera disminuir el estigma y la discriminación (Muñoz et al., 2009). Durante cinco años de trabajo en dicho proyecto, se desarrolló un abundante material informativo y audiovisual dirigido a receptores específicos como profesionales en salud, las propias personas con enfermedad mental, padres de familia y profesores, entre otros, destacándose entre las acciones de campaña la creación y divulgación de una guía dirigida a profesionales de la comunicación en donde se recopila información sobre la esquizofrenia, su incidencia, causas, síntomas, diagnósticos y tratamiento.

Por otra parte, la Federación Europea de Asociaciones de Familiares de Enfermos Mentales en el año 2004 inició una campaña con el slogan "Zero Estigma" cuya finalidad fue la disminución del predominio de prejuicios, rechazo y miedo e incentivar la aceptación, información y comprensión. Para ello se valieron de una guía para las campañas locales, exponiendo de manera razonada los métodos que pueden utilizar las asociaciones que forman parte de la Federación para llevar a cabo los proyectos.
Otra iniciativa reconocida es la realizada por la Asociación Mundial de Psiquiatría denominada "Open the doors", desarrollada desde el año I997 en distintos países como España, Canadá, India o China, entre otros, con el objetivo también de aumentar la concientización y los conocimientos acerca de la esquizofrenia y las posibilidades de tratamiento mejorando de esta manera la actitud de las personas hacia aquellas que la han padecido y hacia sus familias. En cada uno de esos países se estableció un grupo en el que participan representantes de organizaciones y personajes reconocidos dedicados a combatir la estigmatización y la discriminación.

Algunos estudios posteriores a la ejecución de los programas anteriormente mencionados han evaluado los efectos de estos programas antiestigma, basados en la representación que de la enfermedad mental hacen los medios de comunicación y las actitudes y percepciones que el público tiene. Los resultados muestran que se han producido algunos cambios positivos moderados, como una reducción de términos y expresiones peyorativas, y un aumento del número de reportajes positivos (Wahl et al., 2002).

Al igual que la estrategia "protesta social", la intervención educativa es otra de las estrategias igualmente efectivas que han ofrecido buenos resultados, sobre todo cuando es continua y de larga duración. Esta ha sido de gran utilidad y ha conllevado a mejores resultados cuando el contenido de los mismos versa más sobre el conocimiento de la enfermedad y de los tratamientos médicos que sobre otro tipo de conocimiento y creencias poblacionales (Crisp, 2000; Kadri y Sartorius, 2005). Además, la iniciativa pedagógica utilizada en la intervención educativa combina el abordaje claramente definido para grupos específicos, como por ejemplo profesionales encargados de procesos educativos, sectores poblacionales concretos como empresarios y personas pertenecientes a barrios que promueven diferentes tipos de mensajes sobre la enfermedad mental y los tipos de creencias a modificar como la idea de peligrosidad y la imprevisibilidad en el caso 
de enfermedades o trastornos graves. Sobre este último aspecto, investigaciones como las realizadas por Casco et al. (I987) con el interés de difundir y estructurar la información existente con respecto al tema de la percepción y las actitudes hacia la enfermedad mental, determinaron que las causales de rechazo hacia el enfermo mental estaban dadas por las características de agresión, irresponsabilidad e impredecibilidad del sujeto y que variables como la educación y jerarquía ocupacional permiten una actitud más favorable hacia el enfermo mental. Estos autores finalmente aseguraron que a medida que los sujetos participantes en el estudio tenían más edad se mostraban menos favorables hacia este tipo de personas. Los resultados de diferentes estudios sobre la educación a grupos sobre discapacidad sugieren que las personas que tienen una menor comprensión de la enfermedad mental son menos propensas a la discriminación y estigma de la enfermedad mental (Brockington et al., I993; Link y Cullen, I986; Link, I987; Roman y Floyd, I98I).

Finalmente, la estrategia de exposición o contacto directo con las personas con enfermedad mental se ha considerado desde hace tiempo como un medio efectivo de lucha contra el estigma, sobre todo cuando este se combina con la educación y se siguen las directrices de lo que se denomina contacto óptimo, es decir, de igual a igual, compartiendo objetivos, no competitivo y siendo supervisado por una autoridad competente (Muñoz et al., 2006). Para potenciar el que se comience a producir este contacto, las propuestas incluyen medidas que favorecen la visualización del problema y la exposición a situaciones de contacto igualitario y positivo a través de modelos con capacidad de influencia, como son los personajes de series televisivas o figuras destacadas de distintos ámbitos que frecuentan los medios de comunicación.

Diversos estudios han definido que el contacto personal suele presentarse como una situación que se puede entender en sentido bidireccional ya que presenta beneficios tanto para las personas que suelen discriminar como a los discriminados, ya que en los primeros, el interactuar con personas con trastorno mental los lleva a conocer y comprender la enfermedad y a los segundos a sentir aceptación y autocontrol. Sin duda alguna este tipo de interacción ofrece los mejores resultados en cuanto a su efecto en la reducción de prejuicios entre grupos sociales (Sherif et al., I961; Johnson et al., I984; Desforges et al., I991), a pesar de lo encontrando inicialmente por Perris y Kemali (I985) quienes estimaron que las actitudes públicas hacia la población con trastornos mentales eran negativas incluso después de una convivencia con ellas posterior a seis meses y las hechas por Angermeyer y Matschinger (I996) quienes destacaron en su estudio que un gran número de personas consideraban como "peligrosos" a los pacientes psiquiátricos cuando son desconocidos, llegando a sugerir como medida fundamental el mantenerlos alejados del trato social. Posteriormente en otras investigaciones como las realizadas por Vezzoli et al. (200I) contrastaron lo anteriormente mencionado con los resultados de su estudio, considerando muy importante tener contactos anteriores con los pacientes psiquiátricos ya que las personas que han conocido e interactuado con un paciente psiquiátrico muestran una actitud más positiva, es decir, menos temor, más integración y oportunidades sociales.

\section{Conclusiones}

El estigma y discriminación que afecta a las personas con discapacidad y enfermedad mental se presenta como un fenómeno en términos de causas y repercusiones, lo que implica que sus posibles soluciones necesiten intervención a nivel social. En esos términos, cuando se pretende cambiar actitudes que buscan específicamente la modificación de creencias estigmatizantes, aunque no es posible determinar el grado de efectividad de algunas estrategias utilizadas, dado que estas mismas en los diferentes programas revisados fueron utilizadas de 
manera simultánea en la mayoría de los casos, se confirma que el aumento de la sensibilización hacia las personas con discapacidad y trastorno mental se debe a la utilización de medidas predominantemente informativas, siendo necesario, como suele suceder en todo proceso educativo, el integrar conocimiento, discusión y, por otra parte, estrategias que faciliten el contacto con las personas que son objeto de discriminación. Estas dos medidas permiten adoptar entornos de aprendizaje que fomentan la participación de individuos tanto discapacitados o con trastorno mental, así como coordinar las posibles variables que intervienen en la mejora actitudinal hacia las personas discriminadas con discapacidad o trastorno mental.
Finalmente, se resalta con respecto a la estrategia de educación o formación, como estrategia común en las dos situaciones de discriminación objeto de estudio, el que esta debe efectuarse de manera adecuada asegurando que un proceso de "psicoeducación social" establezca intervenciones con objetivos claramente segmentados y definidos, brindando información correcta, debidamente articulada durante un tiempo prolongado y que se integren a políticas de salud y estrategias más generales. Tanto las estrategias de formación o educación como contacto social en general, ofrecen buenos resultados y su ejecución no es compleja, permitiendo modificar las concepciones negativas y erróneas acerca de la diversidad y la diferencia. 


\section{Referencias bibliográficas}

Aguado, A. et al. (2003): "Un programa de cambio de actitudes hacia personas con discapacidad en entorno escolar". Análisis y Modificación de Conducta, 29 (I 27): 673-704.

Aguado, A. et al. (2004): "Programas de cambio de actitudes ante la discapacidad". Psicothema, I6 (4): $667-673$.

Aguado, A. et al. (2006): "Programa de cambio de actitudes hacia personas con discapacidad en entornos escolares". Comunicación presentada a las VI jornadas cientificas de Investigación sobre personas con Discapacidad. Salamanca, INICO.

Aguado A. et al. (2008): "Cambio de actitudes hacia la discapacidad con escolares de primaria". Psicothema, 20 (4): 697-704.

Alvarez, L. y Almeida, O. (2008): “Actitudes hacia el trastorno mental y la búsqueda de ayuda psicológica profesional en un grupo de adultos intermedios de la ciudad de Bucaramanga”. Rev.Fac.Med 56 (2).

Alcedo, M. et al. (2013): "Eficacia del contacto e información como técnicas de cambio de actitudes hacia personas con discapacidad en niños de educación primaria". Universitas Psychologica, I2 (2): 493-504.

Angermeyer, M. y Matschinger, H. (I996): “The effect of personal experience with mental illness on the attitude towards individuals suffering from mental disorders". Social Psychiatry and Psychiatric Epidemiology. 3I (6): 32 I-326.

Asensio, J. (2002): "Las actitudes en la reforma: un aspecto de la educación emocional”. Revista Española de Pedagogía, 22I, enero-abril: 5I-64

Avramidis, E. y Norwich, B. (2002): “Teachers attitudes toward integration/inclusion: A review of the literature". European Journal of Special Needs Education, I7 (2): I29-I47.

Bailard, M. et al. (I997): "Improving the social status of mainstreamed retarded children". Journal of educational Psychology, 69: 605-6I I.
Brockington, I. et al. (1993): “The community's tolerance of the mentally ill". British Journal of Psychiatry, 162: 93-99.

Casco, M. et al. (1987): "La actitud hacia la enfermedad mental, una revisión de la bibliografía”. Salud mental, Io (2): 4 I-50.

Corrigan, P. (200I): "Three strategies for changing attributions”, Schizophrenia Bulletin, 27: I87I95.

Corrigan, P. y Gelb, B. (2006): “Three programs that use mass approaches to challenge the stigma of mental illness". Psychiatry, serv, 57 (3): 393-398.

Corrigan, P. y Penn, D. (I999): “Lessons from Social Psychology on Discrediting Psychiatric Stigma”, Am Psychol, 54 (9): 765-776.

Crisp, A. et al. (2000): "Stigmatization of people with mental illness". The British Journal of Psychiatry, I77: 4-7.

Dengra, R. et al. (I99I): "Estudio de las variables que afectan a las actitudes de los maestros hacia la integración escolar de niños con necesidades especiales”. Anuario Español e Iberoamericano de Investigación en Educación Especial. Madrid: CEPE, 47-48.

Desforges, D. et al. (I99I): "Effects of structured cooperative contact on changing negative attitudes toward stigmatized social groups". Journal oI Personality and Social Psychology, 60 (4): 53 I- 544 .

Donaldson, J. (I980): "Cambio de actitudes hacia las personas retrasadas”. Siglo cero, I I 2: 39-38.

Eaton, W. et al. (2008): "The burden of mental disorders”. Epidemiology Rev, 30 (I): I-I4.

Elms, A. (I966): "Influence of fantasy ability on attitude change through role playing". Journal of Personality and Social Psychology, 4 (I): 36-43.

Estroff, S. et al. (2004): "From stigma to discrimination: an analysis of community 
efforts to reduce the negative consequences of having a psychiatric disorder and label”. Schizophrenia Bulletin, 30 (3): 493-509.

Evans, J. (I976): “Changing attitudes toward disabled: an experimental study". Rehabilitation counseling bulletin, I9: 572579 .

Flórez, M. et al. (2009): "Revisión y análisis de los programas de cambio de actitudes hacia personas con discapacidad". Armario de Psicología Clínica y de la Salud, 5: 8 5-98.

Friedman, R. (I975): The peer-peer interaction program: a model program for the integration of severely handicapped youngsters with nondisabled peers, Albertson (Nueva York): Human Resources center.

García, L. (I997): "Fomento de la aceptación de la integración de niños ciegos en ESO”. Comunicación presentada al Simposio Cambios de habilidades interpersonales a lo largo del ciclo vital de las II Jornadas Científicas de Investigación sobre Personas con Discapacidad, Salamanca.

García, L. y Hernandez, O. (20I I): "Actitudes hacia la discapacidad de jóvenes y adultos de Chiapas”. Universitas Psychologica, , Iо (3): $817-827$.

Gartell, A. (I986): “Modifying attitudes toward the handicapped: A review of the literature and methodology". En Jojes, R. L. (Comp): Attitudes an attitude change in special Education. Reston (Virginia): The council for exceptional children.

Gómez, V. e Infante, M. (2004): “Actitudes de los estudiantes de educación hacia la integración de las personas con discapacidad y hacia la educación multicultural". Cultura y Educación I 6 (4): 37 I-383.

Gottlieb, J. (I980): "Improving attitudes toward retarded children by using group discussion". Exceptional children, 47: I06-I I I.

Guimon, J. (2004): La discriminación de los pacientes mentales: un reto para los derechos humanos. Bilbao: Publicaciones de la Universidad de Deusto.
Hernández, R. et al. (2009): "La inclusión de discapacitados intelectuales en el mundo laboral: análisis cualitativo. Estudio de un caso". Revista Latinoamericana de Educación Inclusiva. Escuela de Educación Diferencial Facultad de Ciencias de la Educación 2 (3).

Hilarión, P. y Koatz, D. (20I2): Guía para la integración laboral de personas con trastorno mental. Edición obra social "La Caixa" (en línea). <http://www.incorporasaludmental.org/ images/doc/D_CAS_INI+ENT+EMP_DOCU_ GUIA_0047_Guia_Integ_Laboral.pdf>, acceso IO de diciembre de 2015 .

Johnson, D. et al. (I984): "Goal interdependence and interpersonal attraction in heterogeneous classrooms: A meta analysis”, en Miller, N. y Brewer, M. B. (eds): Groups in contact: The psychology of desegregation. Nueva York: Academic Press.

Kadri, N. y Sartorius, N. (2005): The global fight against the stigma of schizophrenia. PLOS Medicine, 2 (7): 597-599.

Katz, D. y Stotland, E. (I959): “A preliminary statement to a theory of attitude structure and change”. En Koch, S. (Ed): Psychology: a study of science. Formulations of the person and the social context, Nueva York: McGraw-Hill.

Kierscht, M. et al. (I978): Children's attitudes about disabled scale. Psychology department: Moorhead state (manuscrito no publicado).

Krech, D. et al. (1962): Individual in Society. New York: McGraw-Hill.

Langer, E. et al. (I976): “Stigma, staring y discomfort: a novel-stimulus hypothesis". Journal of experimental social psychology, I 2: $45 \mathrm{I}-463$.

Link, B. y Cullen, F. (I986): "Contact with the mentally ill and perceptions of how dangerous the are". Journal of Health and Social Behavior, 27: $230-289$

Link, B. (I987): “Understanding labeling effects in the area of mental disorders: An assessment of the effects of expectations of rejection". American Sociological Review, 52 (I): 96-I I 2. 
Lockhart, R. et al. (I998): "Influence of empathy training to modify attitudes of normal children in physical educativon toward peers with physical disabilities”. Clinical Kinesiology, 52 (2): 35-4I.

López, M. et al. (2008): "La lucha contra el estigma y la discriminación en salud mental. Una estrategia compleja basada en la información disponible". Revista de la Asociación Española de Neuropsiquiatría, IOI (28).

López, M. y López, M. (I997): “Simular la discapacidad. Una técnica para conocer las necesidades educativas especiales y modificar actitudes en la formación del profesorado". Revista electrónica interuniversitaria de formación del profesorado, I (o).

Luque, D. y Luque-Rojas, M. (20 I I): "Conocimiento de la discapacidad y relaciones sociales en el aula inclusiva. Sugerencias para la acción tutorial". Revista Iberoamericana de Educación. 54 (6): I-I2.

Moreno, F. et al. (2006): “Actitudes ante la discapacidad en el alumnado universitario matriculado en materias afines". Revista Iberoamericana de Educación, 40 (5): I 5-25.

Muñoz, M. et al. (2006): Informe de propuestas específicas para la reducción del estigma social en las personas con enfermedad mental grave y crónica, Madrid: Facultad de psicología. Universidad Complutense de Madrid.

Muñoz, M. et al. (2009): Estigma y enfermedad mental. Análisis del rechazo social que sufren las personas con enfermedad mental, Madrid: Editorial Complutense.

Muñoz, J. et al. (20I3): “Análisis de las actitudes, de los jóvenes trabajadores del sector textil hacia la discapacidad: diferencias por razón de género". Revista de Investigación Educativa, 3I (I): 93-II 5 .

Navas, L. et al. (2004): "Algunas variables predictoras de las actitudes del alumnado ante la integración escolar”. Revista de Psicología Social, I9 (2): I 59-I7I.

Newberry, M.K. y Parish, T. (I987): “Enhancement of attitudes toward handicapped children through social interactions". Journal of Social Psychology, I 27 (I): 59-62.

Nikolaraizi, M. et al. (2005): “A cross - cultural examination of typical developing children;s attitudes toward individuals with special needs". International Journal of Disability. Development and Education, 52 (2): IOI-I I9.

Novo-Corti, I. et al. (20I I): “Análisis de las actitudes de los jóvenes universitarios hacia la discapacidad: un enfoque desde la teoría de la acción razonada". RELIEVE, 2 (I7).

Organización Mundial de la Salud, OMS (2013): Informe sobre la salud en el mundo 2013: investigaciones para una cobertura sanitaria universal. Luxemburgo (en línea). <http://apps.who.int/iris/ bitstream/I0665/8 5763/I/978924069I223_ spa.pdf $>$, acceso I I de diciembre de 2015 .

Palacios, A. (2008): El modelo social de discapacidad: orígenes, caracterización y plasmación en la convención internacional sobre los derechos de las personas con discapacidad, Madrid: Ediciones Cermi (en línea). <http://www.cermi.es/es-ES/ ColeccionesCermi/Cermi.es/Lists/Coleccion/ Attachments/64/Elmodelosocialdediscapacidad. pdf $>$, acceso I I de diciembre de 20 I 5 .

Pelechano, V. (2003): "El estudio de la discapacidad desde el punto de vista psicosocial”. Análisis y Modificación de conducta, 29 (I25): 327-393.

Penn, D. et al. (I994): "Dispelling the stigma of schizophrenia: what sort of information is best?”. Schizophrenia Bulletin, 20: 567-74.

Penn, D. y Couture, S. (2002): “Strategies for reducing stigma towards persons with mental illness". World Psychiatry, I (I): 20-2I.

Perris, C. y Kemali, D. (1985): "Focus on the Italian psychiatric reform: an introduction". Acta Psychiatr Scand Suppl, 3 16: 9-I4.

Rapier, J. et al. (1972): “Changes in children's attitudes toward the physically handicapped". Exceptional children, 39: 219-223.

Roman, P. y Floyd, H. (I98I): "Social acceptance of psychiatric illness and psychiatric treatment”. Social Psychiatry, I6: I6-2I. 
Rusch, N. et al. (2005): "Mental illness stigma: concepts, consequences and initiatives to reduce stigma”. European Psychiatry, 20: 529-539.

Sedlick, M. y Penta, J. (I975): “Changing nurse attitudes toward quadriplegics through use of television", Rehabilitation literature, 36: 274-278.

Serrano, C. P. et al. (20I3): "Barreras contextuales para la participación de las personas con discapacidad física: Discapacidad y barreras contextuales". Revista de la Universidad Industrial de Santander. Salud, I (45): 4I5I (en línea). <http://www.scielo.org.co/ scielo.php?script=sci_arttext\&pid=So I 2 I 080720I3000I00006\&lng=en\&tlng=es >, acceso I I de diciembre de 2015.

Shannon, C. et al. (2009): "The effect of contact, context, and social power on undergraduate attitudes toward persons with disabilities". Journal of rehabilitation, 75 (4): I I-I 8.

Sherif, M. et al. (196I): The Robbers Cave Experiment: Intergroup Conflict and Cooperation. Norman, Oklahoma: Book Exchange, University of Oklahoma.

Soto, V. y Vasco, E. (2008): "Representaciones sociales y discapacidad". Hologramática, 8 , (VI): 3-22.

Stager, S. y Young, R. (I98I): "Intergroup contact and social outcomes for mainstreamed EMR adolescents", American Journal of mental deficiency, 85:497-503.

Strauch, J. (1970): "Social contact as a variable in the expressed attitudes of normal adolescents toward EMR pupils", Exceptional Children, 36: 495-500.

Strohmer, D. et al. (I984): “Attitudes toward persons with disability: An examination of demographic factors, social context and specific disability". Rehabilitation Psychology, 3 (29):

I 3 I-I 45 .

Universidad Internacional de Andalucía (20I4):

$I^{a}$ Jornada sobre maltrato a las personas con discapacidad, Sevilla: Universidad Internacional de Andalucía (en línea). <http://dspace.unia.es/ bitstream/handle/I0334/337I/Irajornadamalt rato.pdf? sequence $=\mathrm{I}>$, acceso $\mathrm{I} 7$ de diciembre de 2015 .

Verdugo, M. y Arias, B. (I99I): "Evaluación y modificación de las actitudes hacia los minusválidos”. Revista de Psicologia General y Aplicada, 44 (I): 95-IO2.

Verdugo, M. et al. (1994): Actitudes hacia las personas con minusvalía. Madrid: Ministerio de Asuntos sociales.

Vezzoli R. et al. (200I): “Attitude toward psychiatric patients: a pilot study in a northern town”. European Psychiatry, I 6: 45 I-458.

Wahl, O. et al. (2002): "Newspaper coverage of mental illness: is it changing?" Psychiatric Rehabilitation Skills, 6 (I): 9-3I.

Wash, M. et al. (2008): "Attitudes of University Students toward individuals with exceptionalities and inclusive Practices: A Baseline Analysis of students Enrolled in the Introductory Course". NERA conference proceedings, (22).

World Health Organization, WHO (2OII): World report disability (en línea). <http://whqlibdoc. who.int/publications/20I I/97892406852I 5 eng.pdf>, acceso 30 de noviembre de 2015.

Zabalza, M. (I998): "Evaluación de actitudes y valores”. En Medina, A. et al. (Eds.): Evaluación de los procesos y resultados de aprendizaje de los estudiantes. Madrid: Editorial UNED. 



\title{
Necesidades afectivo-sexuales en personas con discapacidad intelectual. Claves para construir propuestas formativas desde la experiencia subjetiva
}

\author{
Affective and sexual needs of persons with intellectual disabilities. \\ Key aspects from the subjective experience to consider when \\ formulating training proposals
}

\section{Resumen}

El objetivo de este trabajo es presentar las necesidades vividas por un grupo de personas con discapacidad intelectual en torno a la esfera afectiva y sexual. Para ello, a través de una entrevista semiestructurada que abarca diferentes áreas vitales, I 6 entrevistados ponen de relieve sus conocimientos y experiencias en torno a la relación de pareja y la intimidad. Sus relatos codificados muestran tres grandes necesidades ilustradas a lo largo del texto: la búsqueda del otro próximo con quien compartir su intimidad emocional y afectiva, la necesidad de ampliar sus conocimientos sobre sexualidad a cuestiones de carácter interpersonal y relacional, y la necesidad de contar con espacios de comunicación donde poder intercambiar dudas, buscar apoyos necesarios. El análisis realizado sugiere una revisión de la educación afectiva y sexual dirigida hacia este colectivo, fundamentada casi siempre en la prevención de riesgos, para poner de relieve la importancia de construir propuestas formativas a partir de sus intereses y dudas, que reconozcan también el derecho a vivir su sexualidad e intimidad de forma satisfactoria.

\section{Palabras clave}

Relaciones afectivo-sexuales, amor, personas con discapacidad intelectual, necesidades formativas.

\begin{abstract}
This work aims to present the affective and sexual needs experienced by a group of persons with intellectual disabilities. Through a semi-structured interview, which covers different vital areas, I 6 persons share their knowledge and experiences about relationships and intimacy. Their coded accounts show three major needs illustrated throughout the text: the search for the other for sharing of emotional and affective intimacy, the need to expand their knowledge on sexual issues of interpersonal and relational character and the need for communication spaces aimed at the presentation of doubts and the seeking of support. The results of the analysis suggest a revision of the emotional and sexual education, based mostly on risk prevention, highlighting the importance of formulating educational proposals that are based on their interests and concerns and that recognize their right to a successful sexuality and intimacy.
\end{abstract}

\section{Keywords}

Affective-sexual relationships, love, people with intellectual disabilities, training needs.

\section{Susana Rojas Pernia \\ <rojass@unican.es>}

Universidad de Cantabria. Doctora por la Universidad Autónoma de Barcelona. Profesora e investigadora en la Universidad de Cantabria

\section{Ignacio Haya Salmón \\ <hayai@unican.es>}

Universidad de Cantabria. Doctor en Educación por la Universidad de Cantabria

\section{Susana Lázaro Visa \\ <lazaros@unican.es>}

Universidad de Cantabria. Doctora en Psicología por la Universidad de Salamanca. Docente e investigadora en la Universidad de Cantabria

Para citar:

Rojas, S. et al. (2015): "Necesidades afectivo-sexuales en personas con discapacidad intelectual. Claves para construir propuestas formativas desde la experiencia subjetiva”, Revista Española de Discapacidad, 3 (2): $4 \mathrm{I}-54$.

Doi: <http://dx.doi.org/IO. $5569 / 234$ O5 I04.03.02.03>

Fecha de recepción: I 5-09-20I 5 Fecha de aceptación: 27-II-2OI 5 


\section{Introducción}

Algunos de los estudios recientes sobre afectividad y sexualidad en personas con discapacidad intelectual reflejan el cambio en la comprensión de las dificultades que encuentran para el desarrollo de esa parte de sus vidas. Se trata, por un lado, de trabajos que han servido para cuestionar las creencias extendidas sobre las personas con discapacidad intelectual tales como su falta de interés afectivo y sexual ("seres asexuales") o su falta de autocontrol en la expresión de sus deseos o necesidades (Shakespeare, I998). Otros han incidido en la necesidad urgente de asegurar espacios que garanticen una información y formación amplia en el ámbito de los afectos y la sexualidad.

Así, bajo el título The sexual politics of disability (Shakespeare et al. 1996) fue posible acceder a las visiones y representaciones de personas con discapacidad, incluyendo a algunas personas con discapacidad intelectual. Las experiencias personales reflejadas incidían en las barreras físicas, sociales, culturales o económicas que encuentran, al tiempo que se abordaban cuestiones como la intimidad, el amor o la diversidad sexual. En la misma dirección, el trabajo publicado unos años antes por Booth y Booth (I994) situaba la mirada sobre el asunto de la maternidad y la paternidad en este colectivo, el origen social de las dificultades vividas y la necesidad de apoyo y guía por parte de los profesionales. La consideración de las diferencias de género (Ann et al. 2003; McCarthy, 200I, 2010; FEAPS ${ }^{\mathrm{I}}$, 20I I; Fitzgerald y Whiters, 20I3), la diversidad afectivo-sexual (Löfgren-Màrtenson, 2009; Tess Vo, 20ıо; Clos y Deulofeu, 20ı4; Parra y Oliva, 20I 5) o el abordaje de asuntos como el uso de servicios sexuales (Jones, 20I2) profundizan y amplían nuestro conocimiento sobre el tema que nos ocupa, poniendo en entredicho mitos

I. FEAPS es la Confederación Española de Organizaciones en favor de las personas con discapacidad intelectual, denominada en la actualidad Plena Inclusión. Más información: http:// www.plenainclusion.org/ como la eterna infancia o la impulsividad descontrolada.

También la creciente preocupación desde la década de los ochenta por evitar situaciones de riesgo ha llevado al desarrollo de programas orientados a la educación sexual de las personas con discapacidad intelectual (López, 2002). Como recoge un trabajo reciente (Morentin et al. 2008), la mayoría de los trabajos sobre sexualidad y personas con discapacidad intelectual han centrado su atención en la salud sexual, en las barreras que encuentran o la educación afectivo-sexual. Concretamente, en algunas propuestas recientes, el desarrollo sexual, la fecundación, las conductas sexuales, las infecciones de transmisión sexual (ITS) o los embarazos no deseados son los contenidos nucleares (McCarthy y Thompson, 2009; Gutiérrez Bermejo, 20Iо; Navarro et al. 20Iо; Garvía, 20I I; López, 20I I).

No obstante, como algunos autores señalan (Schultz, 2009; McCarthy, 2010), en la actualidad la investigación sigue siendo escasa, sobre todo con las personas con discapacidad intelectual que más apoyos necesitan. Además, en nuestro contexto más próximo, algunos estudios hechos desde enfoques disciplinares distintos (psicología, ética, derecho o educación) insisten en la necesidad de reconocer los avances en materia de derechos fundamentales y la distancia con el ejercicio real y efectivo de los mismos (Morentin et al. 2008; Peláez, 2009).

Con todo ello, son necesarios estudios e investigaciones que escuchen las voces de hombres y mujeres con discapacidad intelectual, que trabajen desde sus experiencias y que reconozcan el derecho a estar representados por sí mismos (Nind, 20I4). La enunciación reflexiva puede ser un dispositivo para producir la vida y darle sentido (Booth, I998) y un recurso para incentivar el debate y las buenas prácticas profesionales $\left(\mathrm{GREA}^{2}, 20 \mathrm{I} 3\right.$; FEAPS,

2. Grup de Reflexió d'Ètica Aplicada (GREA) del Consorci de Serveis Socials de Barcelona es un equipo de trabajo que reúne a los responsables de servicios residenciales para personas con discapacidad intelectual que necesitan intensidades de apoyo extensas o generalizadas en el área metropolitana de 
20I I), también en investigación educativa (Loja et al. 2013; Ollerton y Horsfall, 2013; Goodley, 20I4).

Partiendo de este marco, en este artículo se abordan las necesidades relacionadas con la esfera afectiva y sexual que plantea un grupo de 16 personas con discapacidad intelectual. A través de sus relatos, formando parte de una investigación más amplia donde se plantearon temas como la formación, el trabajo o las relaciones de amistad, los participantes en la investigación señalaron algunas cuestiones que para ellos son importantes en la gestión de esa parte de sus vidas y que nos invitan a reflexionar sobre el tipo de respuestas que familias y profesionales venimos dando.

\section{Metodología}

La aproximación metodológica adoptada fue de corte cualitativo. El propósito era conocer las experiencias subjetivas de los participantes y, en particular, explorar con ellos el mundo de los afectos y la sexualidad, lo que sitúa al paradigma cualitativo-hermenéutico de investigación como el más apropiado para el desarrollo del estudio (Denzin y Lincoln, 20I2). Como más adelante se detalla, el proceso se desarrolló mediante entrevistas semiestructuradas. Además se utilizaron algunas imágenes para indagar sobre sus ideas y deseos en torno a la afectividad y la sexualidad. Las decisiones metodológicas adoptadas responden a la necesidad de reconocer a los participantes como individuos que construyen creativamente sus vidas y sus historias, frente a posiciones más tradicionales en la investigación socioeducativa en las que la búsqueda de la generalización incrementa el riesgo de la "desaparición del individuo" (Booth, I998).
Barcelona. Más información: <http://www.cssbcn.cat/serveiAtencioPersonesAmbDiscapacitat.html>.

\section{Elección de los participantes}

La selección de los participantes responde, principalmente, a criterios de conveniencia metodológica en tanto que los objetivos del trabajo de investigación, como se señaló con anterioridad, pasan por acceder a los relatos vitales de personas con discapacidad intelectual. De este modo, las decisiones muestrales suponen la selección de contextos relevantes al problema de investigación (Vallés, I999) como son entidades vinculadas al movimiento de autodefensa de las personas con discapacidad intelectual. Seleccionadas una entidad en cada una de las CCAA, se presentó el proyecto a los profesionales y una vez clarificados los propósitos del estudio, se dio a conocer la investigación a cada una de las personas con discapacidad intelectual, mayores de I 8 años, que manifestara su interés por participar. Para algunas personas, la decisión última estuvo supeditada a la autorización expresa de un tutor legal. Concretamente, el proceso seguido fue:

- $\quad$ El equipo de investigación contactó con dos asociaciones y presentó la investigación: propósito, contenidos, condiciones éticas, compromiso con los participantes.

- Cada una de las entidades informó a algunas de las personas con las que estaban trabajando de la puesta en marcha de la investigación.

- Las entidades contactaron con el equipo de investigación para trasladar el interés de todas las personas con las que habían hablado de formar parte de la investigación.

- El equipo de investigación realizó reuniones grupales e individuales antes del inicio de las entrevistas para a) explicar en mayor detalle la investigación y dudas que los posibles participantes tuvieran y b) garantizar que las personas entendían los propósitos de la investigación y deseaban participar en ella. Para ello se elaboró un documento en lectura fácil (García, 20II) que acompañó la presentación oral y visual de la propuesta de investigación. 
Específicamente, los requisitos para participar en la investigación fueron, en primer lugar, manifestar la adhesión a la investigación de forma voluntaria y contar con la autorización de los tutores legales en el caso de que fuera necesario; en segundo lugar, entender los objetivos de la investigación y el contenido de lo que se iba a abordar y, por último, poder trasladar al investigador su deseo de no responder a determinadas preguntas o a no abordar algunos asuntos si así lo estimaba.

\section{Participantes}

En la investigación participaron un total de I 6 personas con discapacidad intelectual que viven en dos comunidades autónomas. Los Io hombres y las 6 mujeres tenían edades comprendidas entre los I 8 y los 39 años. En el momento en que fueron realizadas las entrevistas, todos estaban en formación o trabajando en centros ocupacionales (CO) o especiales de empleo (CEE), excepto uno de los participantes, en empleo ordinario. Asimismo, la mayoría (I I personas) vivían en el hogar familiar o en alguna alternativa residencial (3 personas) y solo dos personas lo hacían de manera independiente pero sin sus respectivas parejas.

\section{Instrumentos y recogida de datos}

Antes de obtener el consentimiento informado de cada uno de los participantes se explicitó el compromiso de mantener el anonimato si así lo expresaban, retirar las preguntas a las que no deseasen contestar o descartar información si lo valoraran necesario tras la realización de la entrevista ${ }^{3}$.

3. Algunos de los participantes nos pidieron retirar alguna información de las entrevistas y así lo hicimos. Por otro lado y aunque algunas personas expresaron su deseo de aparecer con su nombre en los resultados y en los trabajos que de la investigación se derivaran, el equipo de investigación decidió cambiar los nombres para garantizar la confidencialidad. Esa decisión fue comunicada y argumentada a los participantes en la sesión de devolución.
La técnica empleada para la recogida de datos fue la entrevista semi-estructurada (Kvale, 20II). Las preguntas se agruparon en torno a seis grandes bloques temáticos:

I) Autopresentación; 2) Vivienda; 3) Formación y empleo; 4) Ocio y tiempo libre; 5) Relaciones sociales y, finalmente, 6) Relaciones afectivas/ pareja.

La entrevista fue concebida como un recurso flexible, lo que permitió incorporar las decisiones de los participantes en su desarrollo y garantizar que ninguno quedaba excluido (Rojas et al. 2013). Es importante señalar que se hizo un uso cuidado del lenguaje con el propósito de que las personas sintieran que podían hablar libremente de su orientación del deseo y de sus intereses afectivo-sexuales. Asimismo, la entrevista contemplaba estrategias de adaptación metodológica que promueven que los participantes tengan mayor control sobre el proceso. Se combinó la formulación de preguntas abiertas y cerradas, se concretaron cuestiones abstractas, se dio valor a la comunicación no verbal y se emplearon canales y soportes distintos a la palabra oral -por ejemplo, imágenes e ilustraciones para representar términos abstractos relacionados con la afectividad (Haya et al. 20I4)-. La duración de la entrevista fue, en la mayoría de los casos, de dos horas. Algunas personas solicitaron las entrevistas transcritas y les fueron enviadas. De igual forma, solo uno de los participantes solicitó matizar, cambiar y añadir información a la entrevista original.

El análisis de la información se realizó a partir de un proceso de codificación temática (Gibbs, 20I 2) diferenciando unidades de significado a las que se asignó un código. El catálogo de códigos se elaboró en base a procesos de análisis deductivo-inductivos, esto es, un proceso de ida y vuelta del marco teórico de la investigación a los relatos construidos por los participantes. En la codificación se introdujo también un código a propósito de la reflexión metodológica, con el fin de extraer de los textos fragmentos en los que el investigador o los participantes toman decisiones e introducen cambios ad hoc para asegurar las condiciones éticas de la 
investigación y la participación informada del entrevistado.

Los resultados obtenidos fueron presentados a los participantes. Para ello, se realizaron dos sesiones grupales concebidas como espacios de diálogo en los que conocer, pensar, discutir y valorar la información presentada.

\section{Resultados}

\section{La esfera interpersonal: el valor de la intimidad emocional y afectiva compartida}

“(...) pues principalmente es que yo no me sentiría solo, que no me siento solo porque tengo a mi familia, pero es otro tipo de soledad (...) necesito otro tipo de amor" (Gabriel, 30 años).

Las relaciones amorosas son puestas en valor por todos los participantes aunque no todos habían tenido relaciones afectivas íntimas con otras personas en el momento en el que la entrevista fue realizada. Cuando les preguntamos por tres cuestiones importantes en sus vidas, algunos sitúan entre esas prioridades la pareja, el amor, la posibilidad de construir una familia o de tener hijos:

“Tres cosas importantes: Mi familia en primer lugar, evidentemente. Mi trabajo y, ¡me gustaría encontrar pareja que no tengo!” (Gabriel, 30 años).

“¿Tres cosas importantes?: vivir con mi pareja, que eso va a ser muy difícil... y luego, dedicarme a cuidar niños, que eso me gustaría un montón" (Luna, 37 años).

"Tres cosas importantes: 'estar bien con mi novia, el amor y el aprecio'. Un deseo 'tener un hijo"” (Ismael, 2I años).

Para otras personas es la familia, los amigos, la posibilidad de encontrar un trabajo, formarse bien o tener un lugar en el que vivir lo que ocupa un lugar principal.

“¿Más importantes en mi vida? Pues muchas cosas... mi familia, venir aquí al $\mathrm{T}$. [centro formación ocupacional] con los compañeros e ir a clases de música... voy a clases de música y me llevo muy bien con el profesor, con la gente" (Joan, 29 años).

"Mi familia. Toda. Para mí lo más importante es mi familia" (Rosa, 32 años).

Es importante observar como las trayectorias vitales, las experiencias previas de cada uno de los participantes o las preocupaciones más inmediatas definen lo que es importante: “Tener trabajo, salud y una vivienda" son también la prioridad para Oriol, quién tiene pareja y durante la entrevista expresa su deseo de cambiar una vez más de vivienda, esta vez con ella. No obstante, la posibilidad de no tener un lugar donde vivir es un temor importante que recoge en su discurso.

Las respuestas señaladas reflejan la individualidad, no todos quieren o desean lo mismo al mismo tiempo, si bien las necesidades son compartidas. Para algunos de los participantes, el amor, las relaciones de pareja, tener un compañero o compañera es algo valioso, mientras que para otras personas es algo deseable en un futuro próximo. Por tanto, es una necesidad que forma parte de quiénes son o de quienes desearían ser.

De igual modo, tanto los que mantienen una relación de pareja como quienes no la tienen, aunque lo sienten como una necesidad en ese momento en sus vidas, tienen claro qué tipo de relaciones afectivo-sexuales prefieren.

Sin excepción, todos imaginan una relación de pareja como una relación muy próxima de intimidad compartida. Reconocen que es posible mantener relaciones sexuales con otras personas sin una relación de compromiso, no obstante, prefieren que esa interacción se de en el marco de una relación de pareja porque "cuando tú tienes relaciones sexuales con tu 
pareja compartes con ella algo que no compartes con nadie más” (Gabriel, 30 años), "es como estar más cerca de esa persona, demostrar el cariño que tienes hacia ella" (Zelatan, I 8 años). Para las mujeres participantes, el coito es algo secundario, menos relevante, pero señalan que sí lo es para sus parejas por lo que sienten importante no descuidar esa parte de la relación. De hecho, alguna de las participantes manifiesta en su discurso sentirse satisfecha sólo con una relación física más preliminar, "que me den un beso y un abrazo, con eso me basta” (Rosa, 32 años), aunque para él no sea suficiente.

Para quienes tienen pareja en este momento, hombres y mujeres, la relación de pareja es definida como una relación basada en la confianza, en el respeto mutuo y en el compromiso. Se trata de:

“(...) tener respeto, sensibilidad y ser comprensivo con la otra persona, y no sé, sincero, ser sincero con esa persona" (Javier, 30 años).

“(...) que estemos los dos bien, o sea, que estemos los dos, que nos queramos, que nos queramos como somos" (Luna, 37 años).

Ese esquema se repite para las personas que no han tenido nunca una relación de pareja:

“¿Y cómo te imaginas que sería esa pareja ideal? ¡O tu pareja, vamos!”

"Mi pareja, porque eso de pareja ideal, la verdad que suena un poco... iia cuento!! (...) pues una persona normal, una persona agradable, comprensiva, amable, que te entienda y te valore" (Javier, 30 años).

Saben qué tipo de relación amorosa quieren y lo que es importante para mantenerla aunque, como matizan, a veces no resulte sencillo. Para algunos las dificultades aparecen con terceras personas, en los contextos relacionales más amplios. Rosa ( 32 años) sabe que a su padre no le gusta mucho su pareja actual y eso hace que en ocasiones aparezcan ciertas tensiones. Por su parte, uno de los chicos más jóvenes relata que hasta que su pareja no vio su certificado de discapacidad no supo que tenía una discapacidad intelectual, algo que supuso un problema para la familia de la chica con la que estaba saliendo:

“Conocí a una chica (...) le comencé a gustar (...) y claro, íbamos a estar juntos y se ve que se lo dijo a los padres y los padres le dijeron: "no, es que tiene discapacidad, y puede ser que cuando seáis mayores tú te encargues de él o cuando tengáis hijos, puede ser que salgan tontos" (Zelatan, I 8 años).

La necesidad formativa: el valor de la información y formación afectivo-sexual

“(...) esos talleres me parecen súper importantes porque si no te enseñan nada pues no sabes e imagínate que luego tienes un fallo, la lías tú, la lías supergorda” (Asier, I 8 años).

Excepto tres de los chicos más jóvenes que afirman no haber recibido ninguna charla o sesión informativa en la que se le hablara de afectividad y sexualidad, la mayoría recuerda que en algún momento de su escolarización se les ha hablado de ello.

Pregunta- “¿Tú has recibido alguna vez información y formación sobre sexualidad?”.

Respuesta- "Sí (...) ¡Que hay que utilizar preservativo!, ¡iSí!!”.

Pregunta- “¿Dónde te han dado información?”.

Respuesta- "Pues justamente en el instituto que me estabas comentando tú (...) Sí pero hace tiempo, mira yo acabe en el instituto en el año 99, imagínate si hace tiempo (...) si no recuerdo mal, fue gente que vino de fuera [del instituto], gente que vino de fuera y que nos explicó el tema de que había que utilizar condón y todo eso... cómo evitar el contagio de enfermedades venéreas" (Gabriel, 30 años).

Solo uno de los participantes recuerda que la formación fue extensiva en el tiempo y que 
en ella abordaron cuestiones que ya había trabajado en la escuela Primaria. En esta ocasión los temas que recuerda haber trabajado son los mismos que mencionan otros participantes: “(...) siempre con condón, siempre... algún vídeo que otro de cómo se hacen los hijos" (Zelatan, i 8 años).

Aunque en general los participantes valoran necesaria y suficiente la información recibida, algunas personas creen que sería conveniente recibir más información. María (23 años) cree que disponer de más información podría ayudarles a protegerse mejor, no obstante, no tiene muy claro qué tipo de información precisa.

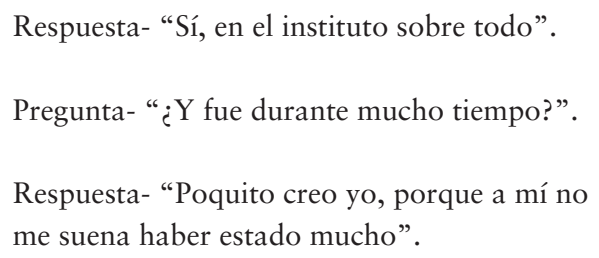

Respuesta- "Sí, yo creo que sí, porque así nos podríamos organizar mejor y todo (...) sabríamos más cosas para cómo protegernos”.

Solo uno de los participantes plantea que en caso de necesitar más información acudiría a un centro de información conocido: “(...) en el que te dicen lo que puedes coger cuando haces relaciones sexuales, y cuando vas te dan por lo menos tres o cuatro gomitas" (Zelatan, I8 años).

Sin embargo para otros hombres y mujeres hay temas que no se abordan y que para ellos son relevantes. La formación en torno al aparato reproductor, las ITS y la prevención de embarazos no deseados es importante pero algunas personas, tal y como se recoge a continuación, señalan que hay otros asuntos relacionados con sus emociones o los sentimientos de los otros y con las formas en las que todo lo anterior se expresa que rara vez se aborda en las sesiones de información/ formación:

Respuesta- "No, en el colegio cuando nos tocaba naturales y aquí (centro formativo al que acude) vino una chica y nos dio una charla (...) de las relaciones sexuales, de las protecciones que os tenéis que poner... iya está! Lo básico, sí. De los reproductores, lo básico del hombre y la mujer”.

Pregunta- "¿Y tú has echado en falta alguna vez algún otro tipo de información?, que tú dijeras, a mí me gustaría que me hablaran...”.

Respuesta- "No, de eso no, yo creo que de eso no, más información no... ¡iAh!! De algunas cosas, sí, sí...”.

Pregunta- “¿Qué echas tú en falta?”

Respuesta- "Pues, cuándo sabes que te gusta alguien de verdad o, por ejemplo, cómo puedes llevar una relación, es que eso no... como no lo he probado no sé... (...) porque a mí esas cosas me cuestan porque no sé si le gusto de verdad a la gente, paso ya...”.

Pregunta- “¿Tú pasas? Conoces a alguien que te gusta...".

Respuesta- "Sí, me gusta, pero ya está. Me gusta pero como no sé, no sé dar el primer paso, pues me quedo ahí, como amigos. Me da mucha vergüenza" (Tesa, 30 años).

El formato audiovisual es, según algunos de los participantes, uno de los medios con los que obtener información aunque no les ayuda a encontrar ciertas respuestas. Como relata Joan, las películas no le han dado claves sobre cómo conocer a otras personas o iniciar y mantener una relación con ellas.

Pregunta- " ¿Y las cosas que sabes sobre sexualidad, dónde las has aprendido?”.

Respuesta- "Pues no sé, la gente de allí (se refiere al taller ocupacional en el que estuvo 
anteriormente), los compañeros, iyo qué sé!, sexología también, y la tele también, se ve en la tele (...) en películas a veces. Sí bueno cuando estaba un amigo, un vecino, él tenía sus películas porno".

“(...) pero sobre eso no sé (se refiere a cómo conquistar a una chica) Debería comprar (un libro de) un chico que sacaron una vez en la tele para ligar, era algo de palabras para decirle a una chica, piropos y eso, para comunicar, tener una novia, pero no lo compré".

No obstante, sí parece que las imágenes y los modelos de belleza que los medios de comunicación ofrecen, contribuyen a elaborar una imagen deficitaria de sí mismo: "No lo sé, para mí, te digo, me da mucha vergüenza decirle a una chica que me gusta y todo esto, y pedirle de salir (...) es más fácil para las personas más guapas, más delgadas, yo lo veo así” (Joan, 29 años). Del mismo modo que lo contrario, da a Zelatan la confianza para iniciar y mantener relaciones íntimas con mujeres sin discapacidad: las chicas "siempre me eligen a mí, ¿sabes?, no sé por qué siempre me eligen a mí”. Como señala repetidamente a lo largo de la entrevista, su discapacidad no es evidente, dándole la oportunidad de vivir como otros chicos de I 8 años:

“(...) bueno yo tengo un $59 \%$ de discapacidad y las personas me dicen que no se me nota nada (...) si se me notara mucho, sería una persona más cerrada (...) como mi madre siempre me dice "tú vas a conseguir lo que tú quieras, no esperes nunca".

A los temas que no se plantean porque no surgen necesariamente en los contextos reglados, se añade la ausencia de tiempos y espacios en los que abordar asuntos que les preocupan personalmente.

La necesidad de espacios y apoyos: el valor de la comunicación con profesionales y familia

“(...) porque es que también están subiendo los monitores porque como solemos tardar, pues nos suben a ver qué estamos haciendo (...) ¡no se puede! (tener relaciones)" (Luna, 37 años).

Luna relata que los educadores conocen a su pareja y saben que toma anticonceptivos pero no hablan del tema, aunque lo ha intentado en alguna ocasión. Concretamente, en un momento de la entrevista afirma que vive con cuatro personas más y que ninguna puede llevar a su pareja a casa porque infringir esa norma supondría perder el privilegio de vivir donde lo hace. De ese modo, es la habitación que su pareja comparte con otro chico uno de los pocos espacios de intimidad de los que disponen en algunas ocasiones y bajo la supervisión de los educadores.

A las dificultades para disponer de un espacio de intimidad, se suma su deseo de vivir con su pareja y de formar una familia. De ese asunto también ha intentado hablar con su padre pero sentencia "que no me cree capaz".

Como hiciera Luna, otras personas describen distintas situaciones a través de las que expresan los obstáculos para encontrar espacios en los que, ya sea con algún familiar o con profesionales, abordar lo que en un momento concreto de sus vidas es importante para ellos. Algunas de las chicas más jóvenes han interiorizado que no deben o pueden mantener relaciones afectivosexuales con otras personas y posponen la idea de conocer a alguien o iniciar una relación de pareja a un futuro aun sin precisar. Concretamente, una de las participantes rechaza la posibilidad de tener pareja en ninguno de los contextos en los que se mueve, excepto en Facebook donde está casada y tiene un hijo:

Respuesta- "En la escuela no se puede tener novio".

Pregunta- "No, pero ahora, ya no estás en esa escuela, ahora estás trabajando".

Respuesta- "Sí”.

Pregunta- "Y ahora que estás trabajando no tienes novio". 
Respuesta- "No, en el trabajo no".

Pregunta- "En el trabajo no y ¿fuera del trabajo?”.

Respuesta- "Tampoco (...) en el Facebook a mi nombre yo era casada y... con cuñados e hijos".

Pregunta- "¿Te has puesto en el Facebook y has dicho que estabas casada y con hijos?".

Respuesta- "Sí” (Mónica, 23 años).

Asimismo, Joan (29 años) afirma que ha podido hablar de sexo en alguna ocasión con sus padres o con algún amigo pero que "no les hace mucha gracia (...) no les gusta que hable de cosas de esas". Su relato expresa continuamente la idea de que es alguien físicamente poco atractivo para las mujeres y que no sabe cómo iniciar una relación.

Para alguno de los entrevistados, formar una familia es un deseo importante y, sin embargo, tras tres años de relación no sabe si su pareja está o no esterilizada.

Pregunta- "Dices que tú te has informado en revistas o que $\mathrm{X}$ (nombra una asociación dirigida a personas con discapacidad intelectual) te ha ayudado, ¿sobre qué tenías tú interés?”.

Respuesta- "Sobre cómo tener una pareja, sobre cómo tener un crío, una familia... si podías tener una familia o no la podía considerar una familia".

Pregunta- "¿Habéis hablado de formar una familia?”.

Respuesta- "Más o menos (...) más o menos sí porque ella... yo le he dicho de que se puede adoptar si ella no, ¡no sé si ella está operada o no está operada! ¿Me entiendes?” (Oriol, 39 años).

Los participantes observan que el amor, el sexo, la intimidad, el erotismo o la idea de familia forma parte de lo que les rodea pero parece que es algo que les pasa a los demás y no a ellos. Se trata de una idea que, como ya se señaló anteriormente, se ve alimentada a través de los modelos y referentes que los medios de comunicación ofrecen continuamente. $\mathrm{La}$ ausencia de espacios desde los que abordar la imagen que construyen de sí mismos en función de los mensajes que reciben del exterior conduce, como se ha descrito a través de algún ejemplo, a una visión deficitaria de sí mismos, de quiénes son o pueden llegar a conseguir.

En este sentido, que algunas cuestiones no se planteen porque parecen no ser importantes o no haya espacios para ello conduce a reforzar y mantener relaciones desiguales entre hombres y mujeres. Como muestran algunos de los siguientes ejemplos, las situaciones se interpretan y justifican desde el modelo masculino tradicionalmente dominante:

Pregunta- "¿Y lo que menos te gusta (de tu pareja)?”.

Respuesta- "Que se enfade. Es que yo a veces me pongo demasiado pesada, o sea, estoy mucho encima de él. Él me dice: "que no te preocupes tanto por mí, que yo en cambio sí me preocupo por ti pues es distinto porque yo soy un hombre, y tu eres una mujer y no tienes que estar siempre preocupándote por mí” (Luna, 37 años).

Pregunta- “¿Tú qué crees que es importante en una relación de pareja?”.

Respuesta- "Para él es el tema de tener relaciones (sexuales). (...) Yo no quiero tener relaciones, las he tenido, de tarde en tarde pero no me gustan... lo hacemos pero no me quedo...” (Rosa, 32 años).

“(...) yo le dije "si tus padres no me conocen, ¿cómo saben cómo soy? (...) a ver es más, eres chica, ella tiene más preocupación siendo una chica, si fuese chico le dejarían un poco más ¿'sabes?, pero si es una chica, yo lo veo normal" (Zelatan, I 8 años). 


\section{Discusión}

Es indudable que experimentamos la sexualidad de forma personal, a través del cuerpo, pero ésta tiene una clara dimensión social. La negación o el control de la sexualidad de las personas con discapacidad intelectual desde distintos contextos (familiar, educativo o religioso) y bajo intereses diferentes (cuidado, protección, regulación o supresión) ha supuesto que durante mucho tiempo las personas con discapacidad intelectual hayan visto cómo una parte fundamental de sí mismos era relegada al olvido (Brown, I994; McConkey y Leavey, 20I3). La desinstitucionalización primero, el movimiento de la inclusión educativa posteriormente o la aprobación reciente de la Convención Internacional de los Derechos de las Personas con Discapacidad ( 13 de diciembre de 2006) son herramientas y al mismo tiempo la expresión de cambios sociales fundamentales que insisten en reconocer a las personas con discapacidad intelectual como seres humanos. No obstante, y como ya se señalara en la introducción, la distancia entre el reconocimiento y el ejercicio efectivo de esos derechos es sin duda importante.

Las dificultades en el acceso a la información o el tipo de formación recibida puede ser un obstáculo para el desarrollo afectivo y sexual de las personas con discapacidad intelectual (McCarthy, 200I; McCarthy y Thompson, 2009; Morentin et al. 2008; Navarro et al. 20I0; López, 20II). Es posible afirmar que los programas y materiales dirigidos a la educación sexual de las personas con discapacidad intelectual se han ido haciendo eco de las críticas recibidas y han ido incorporando temas nuevos que se han ido alejando de planteamientos biológicos y/o con carga moralista (Fitzgerald y Whiters, 20I3).

La mayoría de los participantes en la investigación recuerdan haber asistido a sesiones informativas en las que les hablaron fundamentalmente de fecundación, métodos anticonceptivos e ITS. El hecho de haber tenido acceso a esa información es valorado positivamente, sobre todo desde un enfoque preventivo; $y$, sin excepción, todos consideran que ha sido información suficiente. No obstante, varias cuestiones merecen nuestra atención.

En primer lugar, el hecho de que tres de los dieciséis participantes no hayan tenido acceso nunca a información o formación afectivosexual cuando, además, dos de ellos forman parte del grupo de los más jóvenes (2 I y 23 años respectivamente) $)^{4}$. Cabría pensar que esa situación se diera con los hombres o mujeres de más edad, pero resulta cuanto menos llamativo que sean algunos de los participantes que han salido recientemente de la educación obligatoria los que se encuentren con ese obstáculo. Este dato parece estar en la línea de los resultados obtenidos por algunos trabajos dirigidos al profesorado, como el de Martínez et al. (20I3) quienes señalan que la educación sexual sigue siendo la gran ausente de nuestro sistema educativo.

En segundo lugar, los participantes consideraban que la información que les habían dado era suficiente y que, por tanto, no necesitaban saber más sobre esos contenidos específicos, sobre todo porque hay otras fuentes de información como los medios de comunicación. Concretamente hicieron referencia a algunas series o películas. Sin considerar de momento otros elementos importantes en el análisis de las consecuencias que de ello pueden derivarse, como la ausencia de modelos adecuados en los medios audiovisuales a los que tienen acceso continuado, esas situaciones reflejan la necesidad de atención a esta parte de la vida de las personas con discapacidad intelectual. Obviamente, tener recursos para resolver las necesidades afectivas y sexuales es una prioridad para que las personas puedan situarse como ciudadanos 5 .

En tercer lugar, y a pesar de los cambios que se han ido introduciendo en propuestas y

\footnotetext{
4. La tercera persona es un hombre de 39 años.

5. Siguiendo a Etxeberria (2008), la persona con discapacidad intelectual es sujeto del conjunto de derechos humanos en su vida privada y pública.
} 
programas, algunos de los participantes -sobre todo los que no tienen pareja- reclaman que se aborden otros contenidos distintos a los mencionados, de carácter más interpersonal. Algunas personas plantean que en la formación no se habla de la atracción, el enamoramiento, el cuidado, la seducción o la ética en las relaciones amorosas, ejes en un modelo de educación sexual biográfico-profesional defendido por algunos autores (López, 2005). Estas carencias favorecen algunas de las dificultades que nos muestran, como su sentimiento de inseguridad o la consideración como propias de las dificultades para iniciar y mantener relaciones.

Por otro lado, las experiencias de los participantes insisten en una cuestión fundamental, la necesidad de responder individualizadamente a las personas, acompañándolas en su proyecto personal. Tal y como muestran algunos trabajos recientes, los profesionales son mediadores que deben apoyar decididamente la vida afectiva y sexual que las personas quieran (López, 20I I; FEAPS, 20I I). Como algunos relatos de la investigación muestran, que un tema se evite o se deje "aparcado" tiene consecuencias para las personas con discapacidad intelectual porque la necesidad de hablar de ello no desaparece. Ese tipo de prácticas lanza dos mensajes claros con consecuencias personales y sociales.

La persona con discapacidad intelectual recibe el mensaje que lo que le ocurre es algo que tiene que ver con ella, por ejemplo, el escaso atractivo físico o la falta de recursos para relacionarse con otras personas con y sin discapacidad intelectual. De alguna manera, la ausencia de espacios para hablar de lo que le preocupa y es importante para ellos, les coloca en una situación de "aislamiento" o soledad frente al resto de personas percibidas como capaces de disfrutar de situaciones de intimidad compartidas.

Asimismo, negarse a abordar algunos asuntos le confiere a estos el cariz de inadecuado o prohibido. Algunas personas con discapacidad intelectual tienen pocos espacios de intimidad (McCarthy, 20I0) y encuentran dificultades para hablar sobre sus relaciones afectivo-sexuales con las personas que deben protegerlas y apoyarlas lo que devuelve una idea de esas relaciones como desajustadas o inapropiadas, como mostraran también otros trabajos anteriores (Fitzgerald y Whiters, 20I3).

Todo lo anterior nos lleva necesariamente a pensar en la situación de vulnerabilidad en la quedan algunas personas con discapacidad intelectual (McCarthy, 20Iо; Hollomotz, 20II). Las relaciones de poder desiguales que pueden establecerse entre personas con y sin discapacidad intelectual de distinto género, nivel socioeconómico o cultural pueden conducir a situaciones de abusos o maltrato de distinto tipo. Como señalaba una de las mujeres, todos saben que tiene una relación de pareja desde hace tiempo, sin embargo nadie habla con ella sobre los lugares en los que mantienen relaciones sexuales porque tiene prohibido que su pareja entre en su casa. Tampoco sobre cómo vive ella esas relaciones (satisfacciones, deseos, cambios, dificultades...).

La ausencia de espacios en los que colectiva e individualmente se planteen los temas que preocupan a las personas con discapacidad intelectual en cada momento de sus trayectorias vitales ayuda a mantener creencias y mitos sobre esa dimensión de sus vidas. Es decir, refuerza la idea dominante de unos frente a otros, de una sexualidad válida y de sexualidades disidentes, reforzando un imaginario colectivo deficitario.

Por tanto, es necesario escuchar a las personas con discapacidad intelectual y entender que asuntos tan sensibles como la intimidad o la dignidad deben ser planteados y abordados, desde el conocimiento y con respeto por parte de familias, entidades y profesionales que las apoyan (GREA, 20I3; Clos y Deulofeu, 20I4). 


\section{Conclusiones}

Las necesidades de las personas con discapacidad intelectual, en materia afectiva son las mismas que las de las personas sin discapacidad (Morentin et al. 2008). La complejidad de las relaciones que mantenemos en contextos asimismo complejos nos definen en un devenir constante difícil de atrapar y desde luego estabilizar a través de un diagnóstico. “(...) no todos queremos, deseamos o nos sentimos atraídos por lo mismo, ni de la misma manera ni en el mismo momento" (Clos y Deulofeu, 20I4: I07), tampoco las personas con discapacidad intelectual.
Es necesario que revisemos el tipo de respuestas que damos a las demandas que las personas con discapacidad intelectual nos plantean. Algunas de esas respuestas (prohibición, negación o indiferencia) nos recuerdan en alguna medida las dificultades sociales y culturales que mantenemos aún hoy.

Para finalizar, es importante que los trabajos de investigación escuchen a las personas con discapacidad intelectual y contribuyan a empoderarlas. La explicación reflexiva puede ser un dispositivo para producir la vida, para dar sentido a esa parte del "nos-otros" que viene definida por las relaciones afectivas que mantenemos con otras personas y que nos sitúa en relación con los otros, en el mundo. 
Ann, L. et al. (2003): “'People tell me I can't have sex': women with disabilities share their personal perspectives on health care, sexuality, and reproductive rights". Women and Therapy, $26(3-4): 195-209$.

Booth, T. (I998): "El sonido de las voces acalladas: cuestiones acerca del uso de los métodos narrativos con personas con dificultades de aprendizaje”, en Barton, L. (Comp.): Discapacidad y sociedad, Madrid: Morata.

Booth, T. y Booth, W. (I994): Parenting under pressure: mothers and fathers with learning difficulties, USA: Open University Press.

Brown, H. (I994): “An Ordinary Sexual Life?: A review of the Normalisation Principle as it applies to the sexual options of people with learning disabilities". Disability and Society, 9: I $23-\mathrm{I} 44$.

Clos, C. y Deulofeu, G. (2014): Sensuales. Relatos de sexo y afecto en la discapacidad, Barcelona: Comanegra.

Denzin, N. y Lincoln, I. (20I2): Manual de investigación cualitativa, Barcelona: Gedisa.

Etxeberria, X. (2008): La condición de ciudadanía de las personas con discapacidad intelectual, Bilbao: Universidad de Deusto.

FEAPS (20II): También somos mujeres, [Documental], Madrid: FEAPS.

Fitzgerald, C. y Withers, P. (2OI3): “'I don't know what a proper woman means': what women with intellectual disabilities think about sex, sexuality and themselves". British Journal of Learning Disabilities, 4I: 5-I2.

García, O. (20I I): Lectura fácil: métodos de redacción y evaluación, Madrid: Real Patronato sobre discapacidad.

Garvía, B. (20I I): Relaciones afectivas y sexualidad, Barcelona: Fundació Catalana Síndrome de Down.

Gibbs, G. (20I2): El análisis de datos cualitativos en investigación cualitativa, Madrid: Morata.
Goodley, D. (20I4): Dis/ability studies. Theorising disablism and ableism, Oxon: Routledge.

Grup de Reflexió d'Ética Aplicada, GREA (2013): Diversitat funcional, afectivitat i sexualitat. Algunes qüestions ètiques que plantegen les relacions afectives $i$ sexuals de les persones amb diversitat funcional amb necessitats de suport extens i generalitzat que viuen en residències, Barcelona: Consorci de Serveis SocialsAjuntament de Barcelona.

Gutiérrez Bermejo, B. (2010): Habilidades sociosexuales en personas con discapacidad intelectual, Madrid: Anaya.

Haya, I. et al. (2OI4): "Observaciones metodológicas sobre la investigación inclusiva. 'Me gustaría que sacarais que la personas con discapacidad tiene su propio pensamiento'". Revista de investigación en educación, I 2 (2): I35-I 44 .

Hollomotz, A. (201 I): Learning difficulties and sexual vulnerability. A social approach, London: Kingsley.

Jones, C. (20I2): "Paying for sex; the many obstacles in the way of men with learning disabilities using prostitutes". British Journal of Learning Disabilities, 4I: I 2 I-I 27.

Kvale, S. (20I I): Las entrevistas en investigación cualitativa, Madrid: Morata.

Löfgren-Màrtenson, L. (2009): “The invisibility of Young homosexual women and men with intellectual disabilities". Sexuality and Disability, 27: 21-26.

Loja, E. et al. (2013): "Disability, embodiment and ableism: stories of resistance". Disability and Society, 28 (2): 190-203.

López, F. (20I I): Guía para el desarrollo de la afectividad y de la sexualidad de las personas con discapacidad intelectual, Valladolid: Junta de Castilla y León, Gerencia de Servicios Sociales, Consejería de Familia y Asuntos Sociales. 
López, F. (2005): La educación sexual, Madrid: Biblioteca Nueva.

López, F. (2002): Sexo y afecto en personas con discapacidad, Madrid: Biblioteca Nueva.

Martínez, J. L. et al. (2013): "Educación sexual y formación del profesorado en España: diferencias por sexo, edad, etapa educativa y comunidad autónoma". Magister, 24: 37-47.

McCarthy, M. (20I0): "The sexual lives of women with learning disabilities”, en Grant, G. (ed.): Learning disability: alife cycle approach [2nd edition], Berkshire (Inglaterra): Open University Press.

McCarthy, M. y Thompson, D. (2009): Sex and the ${ }_{3}$ Rs. Rights, Risks and Responsabilities. A sex education pack for working with people with learning disabilities [First edition, I992], Southampton: Pavilion.

McCarthy, M. (200I): "Women with learning disabilities experiencing their sexuality in healthy way". Learning Disability Review, 6 (I): I 6-2I.

McConkey, R. y Leavey, G. (20I3): "Irish attitudes to sexual relationships and people with intellectual disability". British Journal of Learning Disabilities, 4I: I8 I-I 88.

Morentin, R. et al. (2008): "El amor en personas con discapacidad intelectual y su repercusión en el bienestar emocional", en II Edición de los premios de Investigación e Innovación sobre Personas con Discapacidad Intelectual. Manresa: AMPANS.

Navarro, Y. (20I2): "Percepción de la sexualidad y el amor en una muestra de personas con discapacidad intelectual: aportaciones para la elaboración de programas de educación sexual de calidad". Información psicológica, IO3: I 5-30.

Navarro, Y. et al. (2010): "Programa de intervención psicosexual en personas con discapacidad intelectual". Educación y Diversidad, 4 (2): 75-92.
Nind, M. (20I4): What is inclusive research?, London: Bloomsbury.

Ollerton, J. y Horsfall, D. (20I3): "Rights to research: utilising the Convention on the Rights of Persons with Disabilities as an inclusive participatory action research tool”. Disability and Society, 28 (5): 616-630.

ONU (2006). Convención sobre los derechos de las personas con discapacidad, Nueva York: Naciones Unidas.

Parra, N. y Oliva, M. (20I 5): Sexualidades diversas. Manual para la atención de la diversidad sexual en las personas con discapacidad intelectual o del desarrollo, FEAPS Canarias.

Peláez Narváez, A. (coord.) (2009): Maternidad y discapacidad, Madrid: Ediciones CINCA.

Rojas, S. et al. (2013): “'Giving voice' in research processes: an inclusive methodology for researching into social exclusion in Spain". International Journal of Inclusive Education, I7 (2): I 56-I73.

Schultz, S. L. (2009): "Psychological theories of disability and sexuality: a literature review". Journal of Human Behavior in the Social Environment, I9: 58-69.

Shakespeare, T. (I998): "Poder y prejuicio: los temas de género, sexualidad y discapacidad", en Barton, L. (comp): Sociedad y discapacidad. Madrid: Morata.

Shakespeare, T. et al. (1996): Sexual politics of disability: untold desires. London: Cassell.

Strike, R. and McConnell, D. (2002): "Look at me, listen to me. I have something important to say”. Sexuality and Disability, 20 (I): 53-63.

Vo, T. (Dir) (20I0): Our Compass [Documental], Canadá.

Vallés, M. (I999): Técnicas cualitativas de investigación social. Reflexión metodológica y práctica profesional, Madrid: Síntesis. 


\title{
Interpelaciones desde la diversidad funcional. La (in) justa medida de la capacidad en Chile
}

\author{
Interpellations from functional diversity. \\ The (un) fair measure of ability in Chile
}

\section{Resumen}

Este artículo se enmarca en el contexto de la tesis doctoral "Políticas públicas sobre inclusión educativa: lógicas, mecanismos y configuraciones. Los casos de Chile y Estados Unidos”. Se aproxima a la problemática de la efectividad de las políticas de inclusión educativa, desde la sociología del individuo y el enfoque de investigación realista, para dar cuenta de la naturaleza del cambio social que propone, el modo en que los recursos se encadenan para cumplir con el objetivo y las formas en que son ofertados a los sujetos de la política para su interpretación. La evidencia sugiere que la inclusión es puesta en cuestión por los egresados, sea por los modos de identificación utilizados para acceder, el trato social que se debe sobrellevar para mantenerse una vez incluidos y/o por la valoración de los esfuerzos personales que se hacen para cumplir con las distintas exigencias escolares que el sistema educativo les impone.

\section{Palabras Claves}

Justicia, inclusión educativa, evaluación, capacidades.

\begin{abstract}
This article is framed in the context of the doctoral thesis "Public policies of inclusive education: logical mechanisms and settings. The case of Chile and USA". It approaches the effectiveness of education inclusion policies, from the viewpoint of sociology of the individual and adopting a realist research approach. This approach is adopted in order to account for the nature of social change proposed and to describe how resources are linked in furtherance of the objective and the ways in which they are offered for interpretation by the subjects of politics. Evidence suggests that the graduates call inclusion into question, whether by the means of identification used to access, the social treatment to be overcome in order to remain once included or the assessment of personal effort that is made to meet diverse school requirements imposed by the educational system.
\end{abstract}

\section{Keywords}

Justice, inclusive education, assessment, abilities.

\section{Ana María Valenzuela Rabi \\ <anavalenrabi@gmail.com>} <ana.valenzuela.r@usach.cl>

Universidad Santiago de Chile

Para citar:

Valenzuela, A. M. (2015):

"Interpelaciones desde la diversidad funcional. La (in) justa medida de la capacidad en Chile", Revista Española de Discapacidad, 3 (2): 55-77.

Doi: <http://dx.doi.org/IO.5569/2340$5^{\text {I04.03.02.04> }}$

Fecha de recepción: $02-04-2015$

Fecha de aceptación: 24-II-2OI 5 


\section{Introducción}

Las personas que presentan diversidad funcional, según las estadísticas oficiales, son las que están más expuestas a la exclusión social o discriminación. Como consecuencia de esta segregación tienen acceso restringido a servicios de salud y a los edificios que albergan estos servicios (Schkolnik, 20I0); son frecuentemente relegados de los procesos políticos (Stang, 2OII); consiguen menor acceso a la educación (UNESCO, 2009); viven por debajo del umbral de la pobreza, poseen menor participación en la fuerza de trabajo e ingresos sustancialmente menores que los percibidos por personas $\sin$ discapacidad (OMS, 20II).

Una de las soluciones previstas para abordar esta problemática social es la inclusión de este colectivo en distintos niveles del sistema educativo, con el fin de igualar las oportunidades y su participación efectiva en otras esferas de la vida social. Los proyectos de integración escolar dentro del sistema regular de educación representan la herramienta de rango medio sobre la cual se articulan recursos y actividades para incluir a las personas que presentan diversidad funcional ${ }^{\mathrm{I}}$. La iniciativa fue impulsada por el convencimiento de que las escuelas normales, con educación integradora, son el medio más eficaz para combatir actitudes discriminatorias y alcanzar la mejor formación posible (UNESCO, I994), erigiéndose en la sociedad como la teoría dominante que moviliza la política.

\section{Problematización}

Los adelantos más reveladores en materia de inclusión refieren al extenso marco jurídico desarrollado y garantías básicas otorgadas

I. En este estudio, estudiantes con diversidad funcional refiere a todas aquellas personas que requieren de apoyo adicional para acceder, progresar, mantenerse y egresar en sistema regular de educación. durante estas últimas dos décadas, ${ }^{2}$ junto al incremento de la subvención por alumno, el mayor acceso a las escuelas públicas y a servicios de educación especial, así como a la ampliación de la cobertura para personas que presentan distintos tipos de requerimientos adicionales. Sin embargo, pese a todos estos esfuerzos, las distintas evaluaciones ejecutadas en la Encuesta de Caracterización Socioeconómica Nacional (CASEN) exhiben que muy pocos jóvenes pueden graduarse en la escuela, proseguir estudios en la educación superior y menos aún transitar al pleno empleo (Ministerio de Desarrollo Social, 20I I), lo que significa que la acción potencial del programa está en juego. La pregunta que se formula en todos los ámbitos es: ¿Qué impide que la promesa inclusiva se cumpla?

En primera instancia, según los organismos internacionales la problemática se origina en las exiguas y discontinuas acciones evaluativas de las políticas y los escasos seguimientos de programas públicos (CEPAL, 20I0). Cuando éstas se efectúan, existen amplias diferencias entre las definiciones, las normas y las metodologías utilizadas (ONU, 2010), arrojando datos poco rigurosos y no comparables para determinar las condiciones reales a las que están expuestas las personas con discapacidad (OMS, 20I I). Dichos vacíos en los sistemas de información, son un obstáculo significativo para la formulación eficaz de políticas y programas inclusivos, así como para la evaluación de sus progresos y el diseño efectivo de las intervenciones públicas.

En la arena institucional, un problema fundamental para las comunidades educativas es el sistema de control y supervisión que sostienen los departamentos de educación (CEAS, 2003; MINEDUC, 2004; UMCE, 2008; Fundación

2. Dentro de las más relevantes por su impacto en la elaboración de leyes y en la determinación de áreas de intervención, se encuentran las "Normas Uniformes sobre la igualdad de oportunidades para las personas con discapacidad" (I993), la "Convención interamericana para la eliminación de todas las formas de discriminación contra las personas con discapacidad, de la Organización de Estados Americanos" (I999) y la "Convención sobre los derechos de las personas con discapacidad” (2006). 
Chile, 20I3). El reclamo de las instituciones enfatiza que los modelos de fiscalización están más centrados en la conformidad administrativa y reglamentaria que en la mejora de los establecimientos, ahogando la capacidad de las escuelas. Situados entre las riberas del diseño y la implementación de políticas, se advierte la constante controversia y disenso entre quienes diseñan y quienes implementan. Visto desde las políticas hacia las prácticas, se constata la existencia de una brecha entre los principios mandatados, las propuestas curriculares y las prácticas pedagógicas concretas en el aula, que hacen difícil avanzar en el desarrollo de escuelas más inclusivas (Ainscow, 2013). Percibido desde las prácticas hacia las políticas, se insinúa la falta de legitimación y marginación de la masa crítica y de la población usuaria y/o beneficiaria en su implementación. Así como también señales confusas, un abordaje parcial del problema, insuficiente capacitación, disposición de recursos limitados y organización inadecuada desde el nivel central (Opertti, 2009).

Desde la mirada de las familias, la inserción social y educativa desde el nacimiento hasta la educación superior, es un "deambular" incesante en búsqueda de oportunidades, ya sea en el sistema público o privado. A mayor requerimiento de apoyo adicional y más edad, mayor es el grado de discriminación institucional y menor la probabilidad de proseguir estudios y obtener un empleo. Parafraseando a las madres consultadas, la integración escolar "es un camino sin rumbo" más allá de la condición económica, las escuelas a las que hayan asistido y los requerimientos que ellos tengan. Dicha percepción, se expresa en los discursos como un sentimiento de inseguridad profunda sobre el futuro, que reclama a una sociedad insensible y una clase política poco empática con la experiencia vital de quienes día a día deben luchar por un lugar digno en la sociedad para sus hijos(as).

Por último, para los estudiantes, la inclusión se ha convertido en una verdadera prueba que deben rendir para lograr ser tratados como iguales en términos de derechos, consideración y respeto. Identificados como discapacitados desde la entrada, son instituidos como lo no deseado, rechazado $\mathrm{y}$, muchas veces, lo amenazante. Se les trata diferente, porque son vistos como una barrera para aprender y un peligro para la competencia justa. Derivados, expulsados, sacados o autoexcluidos, a temprana edad descubren que "ser igual a los demás", es un atributo o trofeo que se gana en el día a día de las exigencias escolares. Alcanzar esa justicia depende del esfuerzo personal que deben hacer para responder a los estándares comunes, sobreponiéndose al fracaso que siempre se explica por la "insuficiencia de sus rendimientos y las débiles capacidades que poseen”.

Las respuestas al cuestionamiento social son múltiples. Manifiestan un problema en el orden del funcionamiento, así como concepciones técnicas, políticas y morales que expresan significados no consensuados sobre la distribución de la justicia social en el sistema educacional. El discurso oficial del incumplimiento, el reclamo institucional del abuso, las justificaciones docentes sobre las deficiencias estructurales y las interpelaciones sobre un trato social digno, son el reflejo de ese desacuerdo.

\section{Nuevas aproximaciones}

El tema de fondo en la problemática, desde luego, no son los recursos, sino los motivos subyacentes que impulsan la cadena de ejecución de los proyectos. Es decir, la lógica fundamental que moviliza a la política (Donaldson y Lipsey, 2008), el modo en que los recursos (materiales, humanos y actividades) se encadenan para cumplir con el objetivo de interés o teoría del programa (Pawson, 200I, 200Ia, 2006) y las formas en que son ofertados a los sujetos de la política para su interpretación (Araujo, 2009). Bajo esta perspectiva, la Política de inclusión educativa se comprende como la proyección del ideal social de "Igualdad", que supone una concepción del mundo, de las relaciones que emergen y se construyen en él, así como del rol que cumple cada sujeto social en el proceso de transformación pensado. Las ideas, implícitas o explícitas, ofertan distintas representaciones 
al sujeto para su interpretación, así como espacios posibles para su constitución como sujeto social. Sin embargo, "la acción del ideal siempre estará cruzada por lo que la experiencia social aporte" (Araujo, 2009, 2009a, 2009b; Araujo y Martuccelli, 20I0), una experiencia que múltiple y consistentemente, se elabora, decanta y significa, gracias al "cotidiano trabajo del individuo”. Al proceso por el cual el sujeto deconstruye y reconfigura las representaciones sociales, conforme a su vivencia y desde distintos campos cognitivos, valorativos, afectivos, para conducirse en lo social, lo llamaremos configuración.

Este documento sistematiza concepciones, principios y normativas, poniendo en el centro del examen la experiencia vital de los estudiantes. En las primeras secciones revisa algunas discusiones centrales en torno a la noción de discapacidad como medio de identificación. A continuación, pone el acento en la tensión entre la justa igualdad de oportunidades y el principio de no discriminación, para responder a las demandas de justicia de este colectivo en el sistema educativo. Los siguientes apartados presentan lógicas/mecanismos que movilizan a las políticas y el significado que cobra para los estudiantes conforme a su experiencia escolar. Por último, se exploran distintas perspectivas sociológicas para abordar la problemática de inclusión en el contexto del sistema regular de educación. La importancia de este abordaje habla por sí mismo, la política de inclusión educativa constituye la encarnación de un ideal que aspira a sociedades más justas, democráticas y solidarias.

\section{Justicia social y diversidad funcional}

La Política de Inclusión Educativa se inspira en los principios de la justa igualdad de oportunidades y de no discriminación. Mediante los proyectos de integración escolar, ambos se articulan en los espacios educativos, garantizando a los/las estudiantes sin excepción un tratamiento equitativo y provisión apropiada de servicios para lograr su máximo potencial de desarrollo. Los problemas que debe resolver está política son tres: evitar la estigmatización y discriminación, redistribuir con justicia bienes (recursos, posiciones y capacidades) y medir la efectividad de la política. Las principales corrientes teóricas en el campo de la antropología, sociología y psicología social, entregan luces sobre el contenido y alcance de estas decisiones en la experiencia cotidiana.

\section{Concepciones públicas sobre discapacidad}

La identificación, indica David Lehmann (2012), es el pasaporte para un tratamiento especial a las exenciones o beneficios que mantiene a los departamentos sociales entre la presión de no etiquetar y no prejuzgar las características adscriptivas de los postulantes, y la presión de reconocer las desventajas que afectan a una persona derivada de la discriminación o exclusión social. La mayoría de los Estados utilizan la Clasificación Internacional del Funcionamiento de la Discapacidad y de la Salud (CIF, 200I), como criterio político y administrativo para organizar la distribución bienes sociales y habilitar a los beneficiarios como elegibles para impetrar los beneficios. Lo que se busca es una manera neutral "a gran escala, legítima, ecuánime y con bases seguras” para operar los programas y leyes.

La discapacidad, según este organismo, hace referencia a las deficiencias, restricciones o limitaciones, "a nivel de la estructura o funciones corporales; de las actividades a nivel personal y participación en un contexto social”. Desde esta definición, se desprenden dos modelos comprensivos de la discapacidad. Uno médico, que la entiende como un funcionamiento que se desvía de las normas biomédicas, producto de alguna condición individual, y otro social, que promueve la idea de la discapacidad como una situación originada por barreras sociales, actitudinales y/o legales, que resulta de un modo de organización social, por lo que las soluciones en este caso se dirigen 
a eliminar los obstáculos que la sociedad interpone para la participación efectiva de estas personas en las distintas esferas del mundo social.

Tanto el modelo clínico como el social concitan la crítica de distintos sectores. Los defensores de los derechos de las personas con discapacidad reclaman al modelo médico, o rehabilitador, la excesiva focalización en las deficiencias situadas en el individuo, que convierte a las personas con discapacidad en objetos médicos que deben ser modificados (Toboso y Arnau, 2008). Los críticos del modelo social consideran que su fuerte énfasis en las interacciones como generador del cambio y el desconocimiento de la relación causal entre el impedimento y la discapacidad, ocultan una realidad objetiva. A cambio, se propone un modelo interaccional, que promueve una comprensión bicausal de la discapacidad. Es decir, "una compleja combinación entre las características inherentes a una persona y cómo estos rasgos se manifiestan en el entorno en que se encuentran" (Shakespeare, 2006).

A juicio de los miembros del Movimiento de Vida independiente ${ }^{3}$, la discapacidad no es sólo la forma de clasificación de un estado y menos se entiende como una "falla" del llamado orden natural (Soto, 20II). La discapacidad, señala Pérez Bueno (2003), "es el modo en que los individuos se perciben como sujetos" y son llevados a reconocerse como colectivo. Los conceptos utilizados tradicionalmente por la normativa internacional encierran una negatividad colindante con lo peyorativo, $\mathrm{y}$ tienen una significativa influencia en la forma en que las personas con discapacidad son vistas dentro del orden social establecido, incidiendo en la erradicación de la discriminación por razones de diferencias funcionales, tanto físicas

3. Uno de los movimientos que mayor impacto ha tenido en el mundo por su estructura, filosofía y organización en la lucha contra la discriminación en razón de la diversidad funcional es el Movimiento de Vida Independiente. Constituido y representado por personas con diversidad funcional, se funda en Estados Unidos por Ed Roberts hace más de 40 años con representación en países como Suecia, Reino Unido, España, Zimbabwe y Brasil. como mentales y sensoriales (Romañach y Palacios, 2008).

No se puede ignorar la multiplicidad de significados y funciones atribuibles a la idea de discapacidad. En este constructo, coexisten un concepto técnico que corresponde a un enfoque internacional, mediante el cual se describe una condición y situación objetiva que puede tener un individuo a nivel personal y en interacción social (Pantano, 2007); un concepto regulador que, basado en las normas técnicas, prescribe las circunstancias que definen al colectivo discapacidad, para la distribución de beneficios sociales, y una concepción pública de la misma, que expresa una valoración o apreciación de la situación o condición de los sujetos. La noción de discapacidad es una construcción sociocultural en la que convergen modelos mentales, juicios y actuaciones, respecto de individuos o grupos ajenos a los círculos establecidos por otros.

Bajo el sello de la lógica cognitiva, la categoría "discapacidad", sería la resultante de un proceso de normal categorización social. A nivel individual, permitiría simplificar la información para entender la realidad, por medio de un proceso cognitivo de comparación entre semejanzas endogrupales y diferencias exogrupales, que sirven como base para valorar a los miembros de las categorías asignadas. A nivel social, se emplearía para explicar y racionalizar hechos sociales, defender el sistema de valores del individuo, justificar los comportamientos hacia otros grupos y mantener la identidad positiva del propio grupo (Tajfel, 20IO).

Concebida como resultado de un prejuicio, corresponde a un juicio con anterioridad en sociedad, que pone en desventaja, primero simbólica y luego práctica, a grupos sociales específicos (Allport, I954). Apoyados en la identificación de atributos físicos, psicológicos o tribales, percibidos como "defecto, falla o desventaja”, los individuos y grupos sociales construyen teorías sobre la inferioridad de otros, justificando el trato social que se les otorga. Erving Goffman (1963) llama a esta 
identificación “estigma”. Una clase de relación especial entre imputación de identidad social real (rasgos inmodificables) y una identidad social virtual (rasgos atribuidos), que desacredita la imagen pública de los individuos que no cumplen con los estándares socialmente acordados o definidos por los grupos como básicos para lograr la pertenencia.

Richard Jenkins (2008: 40) señala que la identificación es la "síntesis dialéctica entre definiciones externas e internas sobre el orden de lo individual, institucional e interaccional”. En este sentido, la discapacidad puede ser definida como el nombre o etiqueta que reúne una serie de hechos brutos individuales y sociales que le acontecen a cierto tipo de personas, o bien refiere a una construcción virtual donde la identificación nominal adquiere significado, tanto para los sujetos nominados como para los sujetos que nominan, de acuerdo a los contextos en que se desarrollan la experiencia cotidiana y las consecuencias prácticas en su vida. Ambos aspectos forman parte de un mismo proceso, ocupan un espacio similar, están interrelacionados y ocurren simultáneamente.

En consecuencia, los supuestos sobre imparcialidad y carencia de carga deóntica, requieren ser desechados para comprender sus implicaciones para las personas incluidas en el término. En las próximas secciones se vuelve sobre estos asuntos. Basta decir por ahora que la representación técnica sobre discapacidad es un componente central y referencial para definir los cursos de acción de la política de inclusión educativa, es decir, forma parte de la lógica de la política y, por tanto, de la naturaleza del cambio que propone.

\section{Concepciones teóricas sobre justicia}

Con el estatus asignado al sujeto de la política, avanzamos hacia los dilemas que intentan resolver los teóricos de justicia social, tales como distribución, reconocimiento y trato social justo para este colectivo. La justicia social alude a cierta idea de bien común, que debe ser regulada, protegida y asignada en virtud de las características y circunstancias de los individuos. John Rawls es considerado el máximo exponente de esta tradición y su propuesta fundamental es una justicia distributiva, sobre la base de procedimientos institucionales justos que garantizarían las oportunidades, fundamentalmente económicas, para que cada persona lleve a cabo su plan de vida.

La propuesta de Rawls ha concitado la crítica desde diferentes disciplinas. Dentro de las más reiteradas se encuentran aquellas que objetan su concepción restringida de los bienes sociales, debilidad del principio de diferencia para casos que escapan a las desventajas socioeconómicas, indiscriminada responsabilidad otorgada a los sujetos e incapacidad de los principios propuestos para responder a los requerimientos de justicia de las personas con discapacidad, entre otros. Rawls reconoce que la propuesta es incompleta $y$, en rigor, puede no funcionar para grupos con menos capacidad. No obstante, muchos de estos supuestos actualmente orientan los criterios que rigen para la repartición de responsabilidades y beneficios en instituciones sociales como la escuela.

\section{Justa igualdad de oportunidades}

La justicia social, señala John Rawls, "es el modo en que las grandes instituciones sociales distribuyen los derechos y deberes fundamentales y determinan la división de las ventajas provenientes de la cooperación social” (2006:18). La asignación depende de un acuerdo original entre miembros plenamente cooperantes y capaces de la sociedad, a lo largo de una vida completa, quienes a partir de juicios meditados y como resultado de procedimientos equitativos establecen los principios qué limitan o consienten comportamientos y las expectativas que se pueden tener. Los dos principios que concitarían el acuerdo de las partes son la igual oportunidad (política, económica y personal) para el acceso justo a las distintas posiciones sociales y el principio de la diferencia (ventajas 
y acceso), que actuaría como auxiliar para abordar la ineficacia de la justa igualdad de oportunidades, mediante la cual se obtienen ventajas por la posición inicial de los individuos. Ambos de carácter general y universal en su aplicación, imponen un orden que propende al bien, a pesar de las ventajas individuales que se tengan o quieran obtener. Lo justo o injusto está definido por los procedimientos que la estructura social básica utiliza para asignar los bienes sociales valorados por las partes, y que permitirían alcanzar condiciones de igualdad. Si los bienes son distribuidos igualitariamente, se está en presencia de un sistema justo y se cuenta con una referencia para juzgar las mejorías.

En la perspectiva de Ronald Dworkin (I978), el principio de la diferencia sólo prevé transferir recursos (dinero y riquezas) a los sujetos que se encuentran peor situados en términos económicos, ignorando otras desventajas como "aquellos que tienen algún hándicap natural, ya sea físico o mental”. La propuesta que ofrece, también llamada igualdad constitutiva o de resultado, admite e incluso exige la consideración de las diferencias sociales, propiciando la ejecución de medidas de tratamiento diferenciado positivo a favor de los desventajados por circunstancias moralmente arbitrarias. Supone generar resultados sensibles a las responsabilidades individuales e insensibles a las circunstancias que no pueden ser controladas por los individuos, neutralizando, tanto como sea posible, el impacto de la suerte en la vida.

Amartya Sen (I 999) ha optado por un perfeccionamiento de las teorías de la igualdad de oportunidades. Según el economista, la teoría de la "justicia como equidad" de Rawls no considera las dificultades naturales o sociales que una persona puede tener en la "conversión de los bienes primarios" en logros. En su lugar, privilegia la valoración de funcionamientos y capacidades que son constitutivos a la vida humana, como espacio de comparación del bienestar. Se trata de examinar el valor de los funcionamientos, ponderando aquellos acordados como valiosos, que al ser intersectados producirían un “orden de dominancia parcial" o lista prioritaria de capacidades. Igualar por capacidades es, en última instancia, un proceso de expansión de las libertades fundamentales una vez que se hayan eliminado las principales fuentes de privación de libertad (Sen, 2004). El desarrollo de la capacidad permite a los individuos ser competentes, tanto en el ámbito de las decisiones morales como en los demás aspectos de la vida, lo cual, traería como resultado el incremento de la calidad de vida.

Para François Dubet (20I2) la igualdad de oportunidades, por sí misma, no crea situaciones de justicia verdadera. La legislación más que preocuparse por las posiciones, explica, se interesa por las distancias o brechas entre posiciones que organizan la estructura social, otorgando posibilidades de ocupar cualquier posición en función del mérito. En su opinión, la meritocracia se vuelve injusta cuando no se tiene mérito para competir por las posiciones, como también por la asignación arbitraria del mérito que realizan las instituciones. Dubet propone priorizar la igualdad relativa de posiciones sociales, con el fin de reducir las desigualdades de ingreso, de las condiciones de vida, de acceso a los servicios y la seguridad. El modelo de las posiciones, consiste esencialmente en la reasignación de riquezas por medio de impuestos, derechos y políticas de redistribución que equilibren el acceso a los beneficios sociales por medio de la intervención estatal.

Expandiendo las fronteras de la justicia, Martha Nussbaum (2007) afronta directamente lo que ha denominado como los problemas no resueltos en la teoría del contrato social rawlsiano. Sustancialmente, la doctrina del contrato social excluye a las personas que funcionan de un modo distinto, en el diseño de los principios y políticas que fundamentan a la justicia. Bajo la idea sutil de la posición original, el supuesto moral es que los agentes representantes de los ciudadanos deben ser más o menos iguales en capacidad y en productividad para que se beneficien mutuamente. La exclusión de estas personas como electores implica que quedan exceptuados del trato social acordado por los sujetos primarios de la justicia, afectando 
su plena igualdad como ciudadanos. A pesar de la extensa crítica que realiza, la teoría que desarrolla corresponde a una ampliación de la teoría de la justicia de Rawls, en el sentido del respeto a la libertad sustancial de los ciudadanos. Sólo que dicha libertad, "dignidad", no se gana y no requiere ser sacrificada por el bien social general. La dignidad "es atributo de los seres humanos y se constituye en un fin y no un medio para fines de otros” (Ibíd: 83). Igualar oportunidades por capacidades es alcanzar una base mínima de dignidad humana, que se expresa en una lista de diez capacidades donde se especifican las condiciones para que una sociedad sea mínimamente justa ${ }^{4}$.

Existe coincidencia entre los distintos actores del mundo académico y político en que no se trataría de elegir entre un modelo y otro, sino de combinarlos. De acuerdo con Minor Mora et al. (2005), la consideración de las oportunidades como el resultado de un conjunto de factores sociales de carácter estructural y la visión del actor individual como un sujeto activo en la toma de decisiones, son un avance teórico sustantivo que conjuga oportunidad y agencia. No obstante, hoy en día son cada vez más frecuentes las críticas a la justa oportunidad ofertada por la estructura social, sea por las opciones que ofrece a sus miembros para promover su desarrollo, los procedimientos que utiliza para distribuir los bienes acordados, o por los principios que la sustentan para valorar las ventajas o desventajas a nivel individual.

\section{Principio de no discriminación}

Los movimientos de vida independiente a lo largo de todas sus representaciones en el mundo y nuestros estudiantes ponen de relieve dos esferas más que pueden ser llamadas Justicia Relacional y Justicia Participativa (Murillo y Castilla, 20II), es decir, una demanda en términos de redistribución igualitaria de reconocimiento de identidad, diferencias

4. Vida; salud física; integridad física; sentidos, imaginación y pensamiento; emociones; razón práctica; afiliación; otras especies; control sobre el propio entorno. y respeto (Honneth, I992), junto a un procedimiento o proceso participativo (Young, I990), para lograr una justicia distributiva y un reconocimiento político. Todos ellos eventualmente recogidos por el principio de no discriminación, como respuesta afirmativa a la problemática de dichas minorías.

Recogiendo usos comunes como definiciones derivadas del espacio jurídico, Jesús Rodríguez (2006) proporciona una formulación sobre discriminación que describe la situación de la siguiente forma: "la discriminación es una conducta, culturalmente fundada, sistemática y socialmente extendida, de desprecio contra una persona o grupo de personas sobre la base de un prejuicio negativo o un estigma relacionado con una desventaja inmerecida, y que tiene por efecto (intencional o no) dañar sus derechos y libertades fundamentales" (2006: 26). De esta definición se desprende que discriminar es tratar a otros como inferiores, en razón de alguna característica o atributo que no resulta agradable para quien discrimina, y alude a prejuicios negativos (Allport, I954) y estigmas (Goffman, I963) que tienen consecuencias concretas en el sujeto moral o jurídico que sufre la discriminación en razón del daño que produce. Este prejuicio se actualiza en las interacciones sociales y es percibido para quiénes lo viven cotidianamente, como abusos moralmente intolerables, producto de relaciones asimétricas esencialmente verticales y jerárquicas (Araujo, 2013).

Jesús Rodríguez (2006) avanza con una formulación técnica que pretende garantizar y proteger el derecho a un tratamiento igualitario, "La no discriminación es el derecho de toda persona a ser tratada de manera homogénea, sin exclusión, distinción o restricción arbitraria, de tal modo que se le haga posible el aprovechamiento de sus derechos y libertades fundamentales y el libre acceso a las oportunidades socialmente disponibles" (2006: 29). El principio de no discriminación funciona como extensión o reinterpretación del principio de igualdad. El resultado de la discriminación es siempre la limitación de derechos y oportunidades fundamentales, y la no discriminación opera como una palanca para 
la igualdad de oportunidades y la protección y/o promoción de derechos para personas que históricamente han sido discriminadas. Sin embargo, el reconocimiento de su identidad no se traduce en un trato digno y respetuoso, la confirmación del daño no se convierte en mejor calidad de vida o favorables resultados de aprendizaje, y el trato homogéneo no ha logrado habilitar a las personas con diversidad funcional como sujetos de derecho y oportunidades.

Para enmendar el vacío, Rodríguez anexa a la anterior proposición, "siempre y cuando un tratamiento preferencial temporal hacia ella o hacia su grupo de adscripción no sea necesario para responder o compensar el daño histórico y la situación de debilidad y vulnerabilidad actuales causadas por prácticas discriminatorias previas contra su grupo" (2006:29), construyendo una definición compleja de no discriminación. Este segundo complemento pone en tensión el trato igualitario con el trato preferencial, cuestión que contraría el valor de igualdad de la filosofía liberal.

El trato igualitario ignora las diferencias entre las personas (Dworkin, I978) y las influencias externas que las afectan (Loayza, 2005). Este tratar igual resulta en un trato desigual para las personas con diversidad funcional, en particular para aquellos que se encuentran en una posición desfavorable, como es el caso de las personas con capacidad intelectual fuera de los rangos estándares acordados técnicamente. El trato preferencial incluye la idea de medidas compensatorias de carácter especial, promovidas y/o supervisadas y estimuladas por el Estado e implicaría la aceptación de diferencias de trato para favorecer temporalmente a quienes pertenecen a los grupos vulnerados por la discriminación (Dworkin, I978). Sin embargo, muchas de las personas con diversidad funcional requieren de medidas permanentes como la asistencia para llevar una vida lo más "normalizada" posible.

Rodríguez (2006) indica que normativamente la no discriminación se mantiene en el estatus de reconocimiento del daño social, asociado a derechos subjetivos como lo son el estigma y el prejuicio, impidiendo que del concepto de no discriminación se desprenda directamente la obligación normativa de compensación o reparación del daño para los grupos que la han sufrido. La consecuencia de esta definición llana sobre no discriminación, que abunda en las regulaciones, explica, es que el modelo utilizado para abordar el fenómeno parece "una exhortación a los ciudadanos a portarse bien recíprocamente y no considerar a nadie inferior" (Ibíd: 24), que un modelo que se compromete en la lucha contra las discriminaciones.

De manera similar, David Lehmann (2012), expone que las respuestas a la discriminación están más concentradas en el impulso de la identidad o el comportamiento ejemplar que en alcanzar una justicia social. En la primera respuesta, la discriminación se interpreta como incluir a los marginados y se sirve del poder ejecutivo y su generosidad. En la segunda respuesta, se dirige a castigar la mala conducta a través del poder judicial en un contexto como América Latina, donde el castigo de los actos discriminatorios es inusual, sea por prejuicios $\mathrm{o}$ indiferencia de las autoridades, o a causa de factores tales como la impotencia de las víctimas y la dificultad de probar la intención de discriminar.

Hasta aquí se ha intentado ofrecer un panorama general sobre los límites de los principios de la justa igualdad de oportunidades y no discriminación, para abordar la condición y situación particular de las personas que presentan diversidad funcional. En suma, la contrariedad parece encontrarse en el tipo de respuestas hacia la discriminación, que se mantienen entre la paradoja de un reconocimiento económico o redistributivo y un reconocimiento cultural o simbólico que se constituyen en lógicas opuestas (Fraser, I997). Mostrar la relación confusa entre estos principios, puede contribuir a repensar los problemas que debe enfrentar la Política Pública de Inclusión Educativa en los espacios educativos, ya que estos preceptos orientan los contenidos y procesos que se llevan a cabo (o no) para cumplir la promesa de inclusión educativa. 


\section{Los límites de igualdad en la escuela}

En la lógica de la igualdad de oportunidades el esfuerzo se pone al principio, ofreciendo oportunidades fundamentalmente para acceder al sistema. Complementada con la nivelación de las situaciones de vida de diferentes grupos sociales, provee ciertos niveles mínimos de protección y compensación a los individuos que garantizarían el desarrollo de las capacidades de las personas en el trayecto educativo. Igualar oportunidades en la escuela puede ser descrito como distribuir de manera justa recursos para acceder a distintas posiciones sociales en el sistema educativo. Nivelado el campo de juego o satisfecho el primer principio, dicha igualdad dependerá sólo de los talentos individuales y esfuerzo voluntario, garantizando a los individuos retribuciones diferenciales en términos de éxito educativo. Conjetura también, eliminar los obstáculos que impiden la realización del mérito, de manera tal que concurra un aprovechamiento máximo de la estructura de oportunidades existente en una sociedad. El principio de diferencia funcionaría como restricción a la carrera abierta de talentos, para evitar dañar a los menos talentosos. De este modo, el sistema educativo será eficiente o justo si se benefician (aprenden) la mayoría de los/las estudiantes y las desigualdades serán tolerables en la medida que el esfuerzo realizado sea el que le otorgue posiciones relativas.

El Informe sobre Estado Mundial de la infancia (UNICEF, 20I3), para los casos de Chile y Estados Unidos, muestra que las tasas de matriculación entre los años 2006- 20II, bordean el $95 \%$ en el nivel primario. A nivel secundario, la tasa en Chile es de $83 \%$ y Estados Unidos alcanza una tasa de $90 \%$. A pesar del incremento en las tasas de matriculación, los estudiantes con diversidad funcional presentan menores tasas de permanencia, promoción, asistencia, y la transición a niveles de educación más elevados son más bajos (OMS, 20II). Las cifras oficiales indican que, para los estudiantes con diversidad funcional, las posiciones relativas son definitivamente injustas. Una vez más, el trato equitativo, el principio de diferencia, ni las compensaciones por las circunstancias moralmente arbitrarias, están pudiendo rectificar el impacto del mérito en el ámbito educativo.

Retomando las críticas al modelo, acceder a la educación no es garantía de progreso, puesto que la capacidad de conversión de bienes en logro, es menos probable en este grupo y genera desigualdades en curso o minusvalías de conversión (Sen, 2004). En simple, los estudiantes con diversidad funcional están en desventaja con respecto a otros estudiantes aunque tengan la misma dotación inicial de bienes (currículo). Pero el discurso de la igualdad se mantiene en el terreno de postulados de las reglas distributivas generales para todos los ciudadanos (Rodríguez, 2006), sin espacios relevantes para el diseño de los caminos necesarios, para que todos los estudiantes avancen de acuerdo a su ritmo funcional. $\mathrm{La}$ justicia imparcial es indiferente hacia estas contingencias.

El tratamiento preferencial, condicionado a la temporalidad, mérito y provisiones sociales de los individuos, no exige transformaciones sustantivas al sistema, manteniéndose sin modificación la compensación de recursos personales, tales como las capacidades físicas y mentales (Queralt et al., 20I4). Una gran mayoría de estudiantes con diversidad funcional requiere apoyos permanentes o por extensos periodos e incluso en diferentes etapas de su ciclo formativo, para progresar en el mundo escolar, a pesar de las expectativas de una "rehabilitación" definitiva, que sirve como argumento para retirar subsidios, beneficios, etc. La discriminación positiva intenta no afectar al mérito de manera de conservar la contribución futura de los postulantes para los fines legítimos de una institución.

Fijar las posiciones en la escuela por medio de derechos facilitaría una movilidad por mérito equilibrada en la escuela (Dubet, 20I2). Por supuesto, no se trata de entregarle menos a los más capaces para contrarrestar la balanza, sino de dotar de conocimientos básicos, mínimos y elementales a todos los alumnos en contextos de 
mixtura y pedagogías individualizadas. Igualar por leyes no ha garantizado el ejercicio de sus derechos en términos de oportunidades, porque la discriminación subsiste aún en ausencia de barreras o prohibiciones explícitas. Prácticas no explícitas de exclusión, como tener derecho a estudiar sin instalaciones educativas accesibles, resignados al trato social recibido y en ausencia de un tratamiento diferenciado formal para evaluar los esfuerzos en materia de rendimiento escolar, ejemplifica el límite de esta justicia. Tal como lo ha señalado Dubet, fijar las posiciones favorece a quienes ya cuentan con una posición establecida, perpetuando el estatus social históricamente condicionado de algunos grupos sociales. Asignarles un estatus de grupo no ha servido más que para constatar el problema específico.

\section{La justa medida de la capacidad}

Los estudiantes con requerimientos de apoyo adicional conforman un grupo heterogéneo en cuanto a las posibilidades de desarrollo de capacidades y funcionamientos. $\mathrm{La}$ aproximación a las capacidades reconoce esta diversidad y se obliga a considerar estos elementos constitutivos como indicador de justicia. Sin desconocer la importancia de ambas propuestas para el análisis de las políticas públicas de inclusión y las prácticas pedagógicas, la conformación de capacidades no está libre de complejidades para la implementación en el mundo escolar.

La posición de los individuos no es tan fácil de determinar, ya que las personas con diversidad funcional desarrollan habilidades en forma variable y existen múltiples experiencias que pueden tener respecto de un set de capacidades. El análisis espectral vertical y horizontal, realizado por Christopher Reddle (20I4) demuestra que el ranking parcial utilizado por Sen, aunque logra establecer si una competencia es más preferible que otra, no puede definir el grado en que las competencias son preferibles.
Asimismo, la lista de capacidades centrales establecidas por Nussbaum no es capaz de considerar las variaciones sociales que obstaculizan la capacidad para situar personas arriba o abajo del umbral.

La exigencia fundamental sobre justicia social para Martha Nussbaum (2OI2) es "que los ciudadanos y ciudadanas estén situados por encima del umbral mínimo amplio (y específico) de capacidad en todas y cada una de las diez áreas" (Ibíd: 56). En la escuela los estudiantes con requerimientos de apoyo adicional transitorios o permanentes presentan capacidades disarmónicas y no todas ellas son inhabilitantes. Por ejemplo, un estudiante que presenta movilidad restringida puede tener amplias capacidades de imaginación. En la lógica de Nussbaum, este estudiante con diferencias estructurales siempre se encontraría bajo el umbral y no cumpliría con sus requerimientos para llevar una vida auténticamente humana.

Si se aceptan las capacidades centrales propuestas por Nussbaum se debe trabajar sin descanso para que todos los niños con discapacidades "tengan las mismas capacidades que las personas «normales»" (Ibíd: 44). Aunque el umbral puede variar dada la historia y sus circunstancias, se espera que a partir de este umbral mínimo las sociedades logren incrementar sus expectativas. La dignidad en la escuela se logra cuando al final del proceso todos y cada uno de los estudiantes reciben una educación adecuada que incluye "alfabetización, formación matemática y científica básica, aunque en modo alguno se agota en ello" (2007: 88). La lista de capacidades precisadas por Nussbaum está muy cerca de las connotaciones de normalidad descritas por la Clasificación internacional del Funcionamiento, de la Discapacidad y de la Salud. Es decir, condicionadas a lo que una persona es capaz de hacer en un ambiente estandarizado (CIF, 200I). Igualar por capacidades descansa sobre una representación armónica y homogénea de un conjunto de funcionamientos valiosos, desanclados de posibilidades personales y contextuales reales de desarrollo. Lahire Bernard (2004) recuerda que no todos los actores 
se ajustan al molde. Vivimos experiencias variadas, diferentes y a veces contradictorias en contextos sociales múltiples y heterogéneos. La "norma especie" acuñada por Nussbaum que pretende escapar del conformismo, con justificada razón, fuerza a la diferencia a un estado de dignidad que no es otra que la pensada desde la normalidad para lograr la adaptación al mundo que los rodea. La retórica de la filósofa, aún cuando se esfuerza por incluir a estos individuos en el diseño de los principios que rigen a la sociedad, sigue supeditando la membresía a un proceso de transformación que los hará dignos. La moral del cuidado del otro se interesa más por fundamentar la premisa sobre una necesidad universal, que reconocer a un otro concreto con necesidades, motivaciones y capacidades específicas para vivir una vida digna. La naturaleza del vínculo social que garantiza es sólo el reconocimiento de un otro como distinto, donde lo verdadero está fuera de sí mismos, despojándolos de su propia forma de ser y estar en el mundo. Nussbaum renuncia a los bienes plurales y no comparables que sustentan su propuesta, insistiendo en una norma especie donde el esfuerzo mayor de adaptación sigue concentrado en los estudiantes con diversidad funcional.

Si la diferencia es aceptada como una libertad fundamental, los lazos posibles no dependerían sólo de la capacidad de adaptación de los sujetos diversos, sino cardinalmente de un esfuerzo de acomodación de la sociedad frente a la diversidad, sus propias necesidades, intereses y expectativas. De este modo, la diferencia se libera del sentido utilitarista que han potenciado las políticas de compensación y rehabilitación, para convertirse por sí misma en valor. No basta reconocer la pluralidad de los criterios de justicia, hay que admitir la pluralidad de funcionamientos que las personas pueden llegar a realizar, así como valorar los progresos relativos. Estas capacidades potencialmente diferenciadas y funcionamientos estructuralmente diferentes (físicos, afectivos, intelectuales, relacionales, emocionales, etc.), emplazan la urgencia de considerar las capacidades humanas como un concepto más amplio, flexible y relativo a la diversidad.
En términos generales, la teoría plantea igualar por medios y/o capacidades, al inicio o final del itinerario formativo. Pero el vacío mayor se encuentra en el corazón de los procesos educativos. Si a la igualdad se le piensa como un continuo de posibilidades y no sólo como un conjunto de oportunidades, aquella que se logra durante el trayecto no ha sido discutida suficientemente. Durante el proceso educativo el núcleo central del debate tiene relación con la idea de que la igualdad debe producirse en la diferencia. En este plano somos iguales si aprendemos, aún cuando existan variaciones individuales sociales, culturales, afectivas y/o cognitivas. Sin embargo, los lazos sociales que tiene un estudiante con su entorno son los que generan tanto posibilidades de desarrollo como límites a sus realizaciones. El progreso de los estudiantes depende del respeto a estas diferencias, al despliegue sistemático de sus potencialidades en términos de realización de sus necesidades, aspiraciones e intereses y a la valoración justa de los avances obtenidos. El encuadre no es fácil de hacer dado que los sujetos imaginados por la educación similar a la filosofía política, son potencialmente iguales. En menor medida diversos.

La relación problemática entre el trato equitativo y preferencial se traslada a la experiencia escolar con un conflicto adicional -la ponderación de las semejanzas y diferenciasdentro de los procesos educativos. La igualdad durante el proceso necesita la consideración de una justicia de rango medio que evalúe estos bienes sociales en el día a día de las interacciones socioeducativas. En el mundo escolar es posible observar dos cursos de acción que dan cuenta de las lógicas y mecanismos implicados en la evaluación de ambos aspectos. La primera hace referencia a los procedimientos utilizados para "elegir" a los beneficiarios, y la segunda se relaciona con los movilizados para “evaluar" los logros alcanzados, luego de la distribución de recursos educativos otorgados. El punto clave, en este momento distributivo, es que el trato igualitario, al no incorporar el reconocimiento de la diferencia en la valoración de sus facultades y esfuerzos, genera un trato injusto en los espacios microeducativos. Durante 
el proceso educativo lo que está en cuestión es la justa medida de la capacidad.

\section{La justa medida del acceso}

Para acceder al sistema regular de educación y recibir los beneficios programados, el programa dispone de mecanismos de categorización de los potenciales beneficiarios, conformados por dispositivos (métodos, técnicas e instrumentos valorados) de verificación de las diferencias respecto al promedio (edad, intelecto, rendimiento académico, etc.), que permiten a los sujetos demostrar una condición de desventaja. Llevar a cabo una identificación adecuada y oportuna permitiría alcanzar el máximo potencial de desarrollo, que es el objetivo de interés de la política.

De acuerdo con la revisión el decreto I70/2009, la evaluación diagnóstica debe ser de carácter integral. La etapa de acceso muestra que el componente de identificación se orienta fundamentalmente a una detección médica y administrativa, cuya función prioritaria es la petición de subvención escolar, más que dirigirse al progreso curricular de los y las estudiantes, aunque así lo declare la política. Si bien el decreto contempla evaluaciones complementarias, como las psicopedagógicas, antecedentes escolares y familiares, lo importante de esta evaluación es que "muestre evidencia del cumplimiento de criterios de especificidad y de exclusión de co-morbilidad y determinación del cumplimiento de los criterios diagnósticos" a partir de instrumentos con normas estandarizadas. Conocer con certeza desviaciones, remanentes y coeficientes convierte a los estudiantes en sujetos elegibles y beneficiarios de la política de integración.

Sostendré que, a pesar del consenso técnico sobre la necesidad de considerar la discapacidad como un constructo médico y social, las perspectivas técnico/ normativas son insuficientes para comprender la experiencia de las personas con diversidad funcional y satisfacer las demandas de justicia en instituciones integradoras.

\section{Modelos mentales de la normalidad}

Las representaciones oficiales se basan en un estereotipo de "normalidad" donde la igualdad se consigue relegando o disociando la diferencia. La postergación de la diferencia es el comienzo de una cadena de discriminaciones y una barrera fundamental para la condición de posibilidad de participación en las restantes esferas distributivas. En breve, lo que privilegia la norma son los rasgos asociados a lo "normal", que se acompañan de una expectativa sobre idoneidad, discernimiento y comportamiento, que se codifica como lo "estándar, promedio, esperado”, en menor medida aceptación. Contrariamente, lo diferente se comprende como una situación de inferioridad que se codifica como lo "patológico, no típico, anormal”, que requiere ser modificado para cumplir con las expectativas sociales establecidas.

La revisión histórica evidencia que la situación persiste a través del tiempo. Al alero del surgimiento de la estadística, el término normalidad se configura a principios de la Edad Media para consignar la reunión en un mismo individuo de toda cualidad física y moral. Constituida la pauta de la normalidad, en adelante la tarea del Estado fue disminuir al máximo posible las desviaciones del promedio mediante una serie de procedimientos dirigidos a fiscalizar y regular el proceso de normalización de los sujetos (Davis, 2009). En esta forma, se constituye un campo de discapacidad como figura de excepción a la norma (Cúpich, 2009) que se mantiene hasta hoy en día.

Los mecanismos utilizados para "elegir" a los estudiantes, como condición de membresía en el sistema regular de educación, son evidencia de un ordenamiento de la normalidad que frena constantemente el respeto por la diferencia, y con ello la posibilidad real de acceder a un espacio educativo que otorgue garantías de seguridad, reconocimiento y realizaciones futuras. Estos estereotipos sociales, vehiculizados por las políticas, alimentados (intencionalmente o no) en el seno de las organizaciones, trazan una frontera simbólica 
que mantiene a los estudiantes "integrados" paradójicamente en zonas excluyentes dentro de sistemas educativos ficticiamente inclusivos.

\section{Insensibilidad al estigma}

La conversión de lo diverso en "no normal" e inaceptable por su "dis-ferencia" hace que las categorías oficiales sean altamente insensibles al estigma. Los estudiantes, cuando narran su experiencia, se describen como: enfermos, anormales, con problemas o diferentes.

Durante toda su trayectoria son expuestos a reiteradas evaluaciones médicas, psicológicas y neurológicas entre otras muchas que, lejos de ser un elemento de contención básica u orientación técnica, son reinterpretados como abusos de poder. La asignación de "términos clínicos”, asociados a una condición definida como patológica, tiene como consecuencia la estigmatización en todos los espacios institucionales formativos.

El discurso oficial sobre la "discapacidad" ha logrado establecer no sólo un modo general de identificación, sino también un grado de distinción al interior del grupo estigmatizado. Así, limítrofes, leves, severos y moderados son resignificados, en el lenguaje de los estudiantes, como "los enfermos de verdad", que son aquellos "mongólicos, súper retrasados, más guagüitas, más chiflados, los que les cuesta más”, que en vista de sus mayores necesidades de apoyo adicional, reciben un trato visiblemente más brutal que el vivido por los protagonistas de estos relatos.

Bajo la categoría “discapacidad” las semánticas oficiales imponen sistemas nominales y virtuales, que vulneran su derecho a elegir la manera de cómo quieren ser vistos y llamados. Lo que se pierde en la clasificación es el derecho humano a ser diferente y hacer efectiva su libertad de autorrepresentación (Sen, 2004). Lo que se niega es la capacidad transformadora del sujeto dentro del ciclo de la política y lo relega a un papel de mero observador (Ribeiro, I999) que oculta su condición de sujetos sociales. Así pues, el concepto discapacidad de acuerdo con
Soledad Arnau (2003) "se ha convertido en el elemento constitutivo de la condición de ser" de las personas que funcionan diferente: "cuerpo y mentes defectuosos", "actores débiles”, "ciudadanos invisibles o de segunda categoría". Una especie de "discapacitación sinecdótica" (Díaz, 20IO: I30), donde se confunde la parte con el todo, asumiendo un funcionamiento global de carácter deficiente en las distintas esferas de la vida social.

\section{Identidades eclipsadas}

La gramática de la normalidad pone en juego la constitución de la identidad de los estudiantes. La identificación obliga a una ruptura y distanciamiento con aquellos "más enfermitos que uno", para mirarse a sí mismo desde un otro lugar que le resulta valioso y del cual se está separado, "la normalidad". Desde aquí, busca apropiarse "somos gentes normales", abandonando un "no lugar" que le recuerda las consecuencias de ser estructural o potencialmente diverso. Ser igual le obliga a ser normal, pero su intuición moral le demanda reconocer su diferencia y exigir el respeto de la misma. El imperativo de conversión para moldearse a la norma resquebraja sus expectativas, puesto que constata diariamente que el ajuste es parcial y lo somete a un conflicto incesante y perverso, debilitándose infaliblemente el ideal inclusivo. "Quiero ser igual pero soy diferente, quiero que me traten igual, pero no puedo hacer las mismas cosas que los demás hacen, si soy diferente por qué me piden lo mismo", expresan la ambivalencia del yo estigmatizado.

Ser igual en la experiencia desigual no le propone una aceptación de sí o cubrir la necesidad de ser uno. Paradójicamente le invita a una renuncia y le traza nuevos desafíos. Incluirse se vislumbra como medio de corrección de limitaciones para alcanzar la normalidad, más que una experiencia de aprendizaje. Así también, una vía para lograr un grado de aceptabilidad y participación en el mundo social, por lo tanto, un proyecto futuro de igualdad. Las representaciones socioculturales dominantes de 
la discapacidad indican a los estudiantes que son iguales a cualquier otro, pero que en realidad no lo son, por las diferencias que presentan. Alcanzar la normalidad, es "incorporar el punto de vista de los normales y saber que según esta posición se está descalificado" (Goffman, I963). En esta asentada zona de contradicciones éticas, fluyen sentimientos de "impotencia, molestia, dolor, tristeza, estrés, rabia”, que son los costos que se deben pagar para gozar de los privilegios que los "otros" poseen, nunca se sabe hasta cuándo. A fin de cuentas, el esfuerzo se hace "ya que el hecho de ser considerado normal trae grandes gratificaciones” (Ibíd: 99).

\section{Discriminación en razón de la diferencia}

La identificación institucional tiene consecuencias en las interacciones socioeducativas. "Ser discapacitado" 5 , es la marca de distinción fundamental que define el trato recibido y la zona donde deben ubicarse. "Ser discapacitado" es constituirse como referente contraidentificatorio para los otros, en un contexto donde "lo normal" se reconoce como valioso para lograr el éxito. Identificados como "enfermos", desde la entrada son instituidos como lo no deseado, rechazado y muchas veces lo amenazante. Se les trata diferente, porque un otro "está contra ellos, les tiene mala, los pasa a llevar, les tiene miedo o les niega sus derechos". Un otro que activamente lo ve como una barrera para aprender y se constituye en una amenaza para una competencia justa. Un otro que lo invisibiliza, no lo toma en cuenta, lo niega por ser diferente. Un otro que no lo respeta como ser humano y no lo reconoce como igual. La discriminación es la vivencia fundamental a partir de la cual es puesto en cuestión el principio de igualdad y con ello la inclusión como medio para alcanzarla.

El trato social diferenciado no se vincula con una especial atención a las necesidades que se tienen para lograr una mejor integración. La discriminación en ningún caso responde

5. Transcribo, fielmente, las expresiones utilizadas por los estudiantes. a una acción positiva que medie entre las circunstancias que rodean a los estudiantes y las exigencias del medio en que se inserta. Muy por el contrario, la experiencia de discriminación en sentido negativo, en todos los casos declina como maltrato físico y psicológico al que fueron expuestos en razón de su diversidad, en distintos momentos de su trayectoria escolar. De forma explícita, la experiencia de maltrato significó golpes, sobrenombres, garabatos, molestarlos, intimidarlos, cuestionar su permanencia en la escuela, enrostrar su lentitud y falta de comprensión de las materias. De manera más soterrada, el maltrato se expresó también en dejarlos a un lado, tratarlos diferentes, no hablarles, no preguntarles o negarse a incluirlos en actividades extraescolares provocando su aislamiento. La indiferencia y el silencio son parte del nuevo rostro del fenómeno de discriminación, y no ha pasado desapercibido por los estudiantes pese a sus supuestas "limitaciones comprensivas". Una de las estudiantes lo expresa de manera transparente "a los diferentes se les humilla", a los otros "los tratan como reyes” (A).

Para cumplir con las expectativas, los estudiantes omiten en todos los casos las situaciones de violencia que han vivido en distintas etapas de su vida. Estas son las memorias de las que hay que deshacerse para "no ser derrotado", "salir adelante", "ser independiente" y "empezar a ser yo". Victimas y culpables frente a la imposibilidad de interiorizar las normas, minusvalorados por remitirse a los estereotipos negativos impuestos por los demás, impotentes frente a la arbitrariedad, despojados de una historia común, son las huellas que se reúnen detrás del profundo deseo de ser sujeto de oportunidades, derechos, consideración y respeto.

La perspectiva de las necesidades que se tengan de las personas con discapacidad, sean hechos brutos o institucionales, no puede desvincularse de los cursos de acción diseñados en los espacios educativos, y menos aún de la experiencia vital de los sujetos a los que se destina. La categoría discapacidad engloba en un sólo concepto "restricciones, deficiencias, limitaciones". Sobre 
este escenario la identificación se conduce hacia una acción estigmatizante, más que a una identificación que orienta el proceso de enseñanza -aprendizajes para progresar en el currículo-. La justa medida del acceso, no logra evitar el daño en este grupo de estudiantes, contribuyendo incluso a la minusvaloración de los mismos.

\section{La justa medida del progreso}

Redlle (20I4) ha demostrado que evaluar cómo una persona se desempeña respecto de una capacidad es más difícil que fijar un nivel de bienestar. ¿Cuáles son las capacidades más valoradas en la escuela? Gran parte de esta definición en la actualidad depende del currículo escolar. Coherentemente con la postura liberal, la educación ha sido pensada como un set de técnicas instruccionales, que buscan estandarizar las conductas, ritmos y tipos de aprendizajes de nuestros estudiantes. Bajo la idea de la igualdad como equidad, distribuir conocimientos por igual hace igualitaria a la escuela y aprender lo mismo es un indicador de justicia educativa. Michel Walzer (I993: 2I4) lo ejemplifica bien, "la meta del maestro que enseña a leer no es proporcionar igualdad de oportunidades sino lograr iguales resultados”. Así, las diferencias son postergadas para cumplir los propósitos y el plan de estudios, acordados socialmente. Como señala Jacobo Cúpich (2008: 234-235), "el dominio del sistema de producción exige que el desempeño se encuentre siempre sometido a pruebas", obligando a las personas a deshacerse de su humanidad.

La etapa de progreso está movilizada por el objetivo político de modificar todos aquellos recursos, espacios, metodologías o procedimientos, con el fin de no fallar en el currículo. Se vincula a la aprobación en los distintos cursos y/o a la superación del déficit, constituyéndose en el momento de demostrar que se aprendió. Los instrumentos de evaluación revisados dan cuenta de los avances, pero a la hora de establecer el tránsito de un nivel a otro, estos esfuerzos son subestimados en la decisión final. El ajuste de metas no es suficiente, porque la teoría del máximo potencial de desarrollo, ahora asociada a "resultados", exige a los estudiantes con diversidad funcional rendir igual que sus compañeros, sin requerimientos adicionales. No existe un procedimiento oficial de cómo valorar los esfuerzos de los estudiantes con diversidad funcional, siendo el fallo último un juicio sesgado y desregulado del progreso.

Para los estudiantes que presentan diversidad funcional, el talento es lo que les permitirá tener éxito en el ámbito escolar. Aquí por mucho esfuerzo que se haga, la idoneidad es lo valorado, por medio de la calificación periódica que permitirá transitar de un nivel educativo a otro. Los estudiantes experimentan continuamente la contradicción entre el esfuerzo realizado y la probabilidad real del exilio, sobre todo en el nivel secundario, donde el sistema de competencia vía calificaciones y estandarización del progreso se alimenta y fortalece. Es decir, se valora la capacidad para lograr un estándar común educativo, sin consideración a la diversidad de perfiles de los estudiantes o esfuerzo, situando los logros de los menos favorecidos en un nivel inferior de logros obtenidos por los grupos más favorecidos. Lo implícito en la teoría de la legislación, más a allá de la lógica igualitaria que la impulsa, es que la ventaja de personas con diversidad funcional se juzga independiente de las condiciones de partida y el esfuerzo realizado.

$\mathrm{Al}$ respecto Olof Page (2013) sostiene que el problema no es la valoración del mérito en sí mismo, sino el procedimiento de comparación del mérito como medida de distribución de ventajas y desventajas en la escuela. La tesis central que defiende es que en los casos sobre desigualdades mixtas (capacidades y responsabilidad), la igualdad de oportunidades no es satisfecha y las desigualdades posteriores no son moralmente aceptables. El ejercicio de Page evidencia la ausencia de criterios o no equivalencia (si existen), que permitan evaluar la justicia en término de mérito y la necesidad de considerar ambos efectos al momento de evaluar la justicia de dicha desigualdad.

Autores como John Roemer (I998), oponiéndose a las concepciones meritocráticas 
que atribuyen los resultados de las personas exclusivamente al ámbito de la responsabilidad personal, han planteado que si este mérito es atribuible a las circunstancias personales de los individuos, entonces no es un mérito real, ya que se ve influenciado por las condiciones iniciales que cada individuo ha tenido que enfrentar. A su juicio, la igualdad de oportunidades prevalece en una situación en donde la distribución de un resultado es independiente de las circunstancias. Por lo tanto, juzgar el esfuerzo de una persona sólo sería justo si se compara con el de aquellas en circunstancias similares.

Siguiendo su razonamiento, si el objetivo de interés de la política de inclusión es alcanzar el máximo potencial de los estudiantes con discapacidad, lo que está en juego en esta proposición es la capacidad para transformar los recursos y oportunidades ofertadas en resultados escolares. Sin embargo, esta capacidad se logra en distintos grados de efectividad o eficacia dependiendo de las características del individuo, el contexto social en el que desenvuelven y las oportunidades ofrecidas por las prácticas pedagógicas. ¿Cuál es la justa medida del progreso? En la actualidad, esta medida se dirige a establecer un valor absoluto que, mediante pruebas estandarizadas, creditaje o calificaciones, permita comparar los logros obtenidos por grupos distintos, sin consideración a las circunstancias no controlables, como lo son las características individuales de los estudiantes (capacidad intelectual, el tipo de discapacidad) y el contexto social que lo rodea (situación socioeconómica, las expectativas docentes, cultura familiar entre otros). La teoría que circula en la arena de la implementación, es una teoría de cómo estandarizar el aprendizaje, que de acuerdo a recientes estudios es cada vez menos pertinente (Murillo e Hidalgo, 20I 5 ). Esta es la justa medida del progreso, que moviliza los programas de inclusión educativa en Chile.

\section{Respuestas sociológicas a la problemática educativa}

\section{Desestabilizar las identidades}

La respuesta ofrecida por Nancy Fraser (I997) a este tipo de dilemas no es una acción afirmativa a la injusticia que mantiene el estatus quo reevaluando la identidad de los discapacitados, como lo ha hecho la CIF en sus revisiones o como lo proponen las distintas regulaciones en los casos estudiados "sin afectar el marco general que lo origina”. Es decir, a partir de un contenido sustantivo propio que la define, el cual se va refinando en las modificaciones políticamente acordadas, sin cambiar la estructura profunda que la contiene. La discapacidad existe en sí y por sí misma y sólo necesita un reconocimiento adicional.

Contrariamente, lo que propone Fraser es una "solución transformativa" (Ibíd: I9). Es decir, una acción que implica deconstruir la dicotomía normal/no normal, desestabilizando las identidades. La formula es desplazarse desde los resultados finales hacia los procesos que los generan y conducirse a un cambio estructural. Deconstruir la discapacidad como el "correlato construido y devaluado" de la diversidad considera que ambas nociones normal/no normal, son reificaciones de un funcionamiento general y que cada una se define únicamente en virtud de la otra.

El objetivo no es solidificar la identidad del discapacitado, sino desarmar el binomio normal/ anormal con el fin de desestabilizar todas las identidades discapacitadas fijas. El punto no es que las diferencias desaparezcan para lograr una identidad humana única y universal, sino proponer "un ámbito individual de diferencias múltiples, no binarias, fluidas, cambiantes" (Ibíd: 20). Para Fraser, con esta solución transformativa se "elevaría la autoestima de los miembros de los grupos irrespetados y cambiaría la imagen que todos los miembros de la sociedad tienen de sí mismos" (Ibíd: I9). 


\section{Nivelar los puntos sociales de partida}

John Roemer (I998), propone nivelar los puntos sociales de partida, cosa que la simple prohibición de discriminar por estigmas y prejuicios no hace. Para ello construye un modelo que analiza el peso del esfuerzo y las circunstancias en la formación individual. Se trata de identificar un número acotado, observable y no manipulable de circunstancias relevantes y diferenciales de los individuos, de las cuales no son responsables y afectan a su capacidad para alcanzar o tener acceso a la ventaja que buscan (cociente intelectual, nivel socioeconómico, necesidad educativa especial). El paso que sigue es distribuir a los individuos al interior de estos grupos y definir medidas de esfuerzo por centil ( $\mathrm{n}^{\circ}$ de años escolarizados, asistencia) de manera de comparar tipos de grupos similares, estableciendo el esfuerzo intertípico relativo.

Si el modelo funciona, la solución sería entonces llegar a un acuerdo sobre un conjunto de medidas de esfuerzo, que dependen de una cadena de discusiones sobre los costos sociales que implica una calificación diferenciada y los contextos en que esta se puede implementar. Evidentemente, este tipo de modelo permitiría mejorar el problema de certificación en la escuela, pero no el tránsito hacia la educación superior o empleo, dónde la selección por competencia es todavía más aguda. Un problema de la propuesta de Roemer es que depende de la disposición de los actores sociales a ceder parte de sus privilegios en aras de la construcción de una sociedad más justa. Esta es también la esperanza de los estudiantes con diversidad funcional, que demandan una valoración distinta de sus esfuerzos en la escuela, siendo medidos con estándares comunes o laxos intentos evaluativos diferenciados, que no se traducen en reales posibilidades de transición, permaneciendo sobreinstitucionalizados a la espera de la justa medida de la capacidad.

\section{A modo de conclusión: ¿qué impide que la promesa se cumpla?}

Los datos recogidos durante el estudio de caso ofrecen una clara evidencia de que las medidas de acceso y progreso, instaladas por las teorías dominantes, legitiman prácticas excluyentes. Tal como se conciben en la actualidad siguen poniendo a los estudiantes con requerimientos de apoyo adicional en desventaja y brindan una oportunidad desigual que dan cuenta de una “injusta medida de la capacidad".

Llamo justa medida de la capacidad a una política evaluativa que, sobre la base de la diferenciación de capacidades pertinentes al ámbito escolar y específicas de las (los) estudiantes, reconoce un nivel real de funcionamiento y a partir de éstas orienta el proceso de enseñanza aprendizaje, en términos del diseño del itinerario formativo y las mediaciones que se requieren para alcanzar el máximo desarrollo posible. Es también una política evaluativa de carácter formal que valora con justicia los esfuerzos realizados por los (las) estudiantes con diversidad funcional, que participan del sistema de educación regular u otro espacio educativo, que libremente haya escogido el (la) estudiante o en su representación la familia, en virtud de su derecho a la libertad de elección, expectativas, requerimientos y preocupaciones.

Esta justa medida es un derecho que se constituye en un reconocimiento de su funcionamiento diverso, favorece una representación subjetiva positiva de sí mismo, de manera de hacer efectiva su libertad de autorrepresentación pero, al mismo tiempo, tiene como fin valorar el esfuerzo de los estudiantes con diversidad funcional en el ámbito escolar, compensando los recursos no controlables para que éstos no se transformen en una barrera que les impida tener un aprovechamiento máximo con autonomía y plenitud de las oportunidades de aprendizaje ofertadas en la escuela y por ello limitar el acceso a otras oportunidades (transitar de 
un nivel a otro, proseguir estudios, insertarse laboralmente).

Conquistar este tipo de justicia implica posicionar la diversidad como principio motor de la política para alcanzar equidad y calidad. Equidad que no se limite a una función subsidiaria, y calidad que no se reduzca al éxito que se tiene en las pruebas estandarizadas.

Esbozamos la posibilidad de una política que redefine sus acciones y expectativas a partir de la experiencia, requerimientos y preocupaciones de los sujetos destinatarios. Es decir, una política que no sólo trabaja para el sujeto, sino que con el sujeto. Una política que se concentra en los requerimientos de apoyo adicional y no en las patologías, concibe la escuela como un espacio de agencia multicultural, superando el gueto del moldeamiento, y valora con justicia los esfuerzos que los estudiantes realizan para progresar en el contexto escolar. 


\section{Referencias bibliográficas}

Ainscow, et al. (2013): "Promoting equity in education". Revista de Investigación en Educación, I I (3): 32-43 (en línea).

$<$ http://webs.uvigo.es/reined/>, acceso I $6 \mathrm{de}$ diciembre de 2015 .

Allport, G. (I954): The nature of prejudice, California: Addison-Wesley Publishing Company.

Araujo, K. (2009): Se acata pero no se cumple. Estudios sobre las normas en América Latina, Santiago: Ediciones LOM.

Araujo, K. (2009a): Habitar lo social, Santiago: Ediciones LOM.

Araujo, K. (2009b): "Configuraciones de sujeto y orientaciones normativas". Psicoperspectivas VIII (2): 248-265 (en línea). <http:// www.psicoperspectivas.cl/index.php/ psicoperspectivas/article/download/60/79>, acceso I 6 de diciembre de 2015.

Araujo, K. (2013): "Interactive Inequalities and Equality in the Social Bond: A Sociological Study of Equality". Working Paper Series, 54. Berlín: desiguALdades.net International Research Network on Interdependent Inequalities in Latin America (en línea). <http:// www.desigualdades.net/Resources/Working Paper/54-WP-Araujo-Online.pdf>, acceso I 6 de diciembre de 2015.

Araujo, K. y Martuccelli, D. (20I0): "La individuación y el trabajo de los individuos". Educação e pesquisa, São Paulo, 36 (núm. especial): 77-9I.

Arnau, M. S. (2003): "Una construcción social de la discapacidad: El Movimiento de Vida Independiente", Universitat Jaume I de Castelló (en línea). <https://www.google.es/url?sa=t\&rct =j\&q=\&esrc=s\&source $=w e b \& c d=I \& c a d=r j a \&$ uact $=8 \&$ ved $=$ oahUKEwiCrdaC99DJAhXJmBo KHbjND 7 CQFgggMAA\&url=http $\%_{3} \mathrm{~A} \%_{2} \mathrm{~F} \%$ 2Fwww.uji.es \% 2Fbin \% 2Fpubl\% 2Fedicions \% 2 Fjif $\%{ }_{2}$ Fhum $\%{ }_{2} \mathrm{~F}_{4}$ 2.pdf\&usg=AFQjCNFud ${ }_{5} \mathrm{~B}$ GmE6 IT $_{7}$ MhRrbEıIuuTit 1 BQ $>$, acceso ro de diciembre de 2015 .
Bernard, L. (2004): El hombre plural. Los resortes de la acción, Barcelona: Ediciones Bellaterra.

CEAS (2003): Estudio a nivel muestral de la calidad del proceso de integración educativa, Santiago de Chile: Ministerio de Educación Chile.

CEPAL (2010): Los censos de 2010 y la salud, Santiago de Chile: Comisión Económica para América Latina y el Caribe.

Chile. Decreto I70, de I4 de mayo de 2009, por el que se fijan normas para determinar los alumnos con necesidades educativas especiales que serán beneficiarios de las subvenciones para educación especial, Biblioteca Nacional del Congreso de Chile, $2 \mathrm{I}$ de abril de $20 \mathrm{~s}$, Ministerio de Educación (en línea). <http:// www.leychile.cl/N? $\mathrm{i}=$ IOI $2570 \& \mathrm{f}=20$ I0-08$25 \& \mathrm{p}=>$, acceso Io de diciembre de 2015.

Chile. Ley 20422, de 3 de febrero de 20IO, por la que se establecen normas sobre igualdad de oportunidades e inclusión social de personas con discapacidad, Biblioteca Nacional del Congreso de Chile, io de febrero de 20 Iо, Ministerio de Planificación (en línea). <http:// www.leychile.cl/N?i= I0 I0903 \& ff=20I I-05$27 \& p=>$, acceso Io de diciembre de 2015 .

Criado de Diego, M. (20I I): "La Igualdad en el constitucionalismo de la diferencia". Revista Derecho del Estado, 26: 7-49.

Cúpich, Z. (2008): "Discapacidad y subjetividad". Revista Latinoamericana de Estudios Educativos, 3-4 (XXXVIII): 233-244.

Cúpich, Z. (2009): "Lo histórico-social como Constituyente de la discapacidad", en Brogna, P. (comp): Visiones y revisiones de la discapacidad. México: Fondo de Cultura Económica.

Davis, L. (2009): "Cómo se construye la normalidad", en Brogna, P. (comp): Visiones y revisiones de la discapacidad. México: Fondo de Cultura Económica.

Díaz, E. (2010): “Ciudadanía, identidad y exclusión social de las personas con 
discapacidad". Política y Sociedad, I (47): I I 5I35.

Díaz, E. (20I I): "Estratificación y desigualdad por motivos de discapacidad". Revista Sociológica de Pensamiento Crítico Intersticios, 5 (I): I $57^{-}$ I70.

Donaldson, S. y Lipsey, M. (2008): "Roles for Theory in Contemporary Evaluation Practice: Developing Practical Knowledge”, Handbook of evaluation. Londres: Sage.

Dubet, F. (2000): "Desigualdades multiplicadas", Educação como exercício de diversidade. Coleção educação para todos, 6. Brasilia: UNESCO, MEC, ANPED.

Dubet, F. (20I2): Repensar la Justicia Social. Contra el mito de la igualdad de oportunidades, Buenos Aires: Siglo XXI editores.

Dworkin, R. (I978): Taking Rights Seriously, Massachusetts: Harvard University Press Cambridge.

Fraser, N. (I997): “¿De la redistribución al reconocimiento? Dilemas en torno a la justicia en una época post socialista”, en Fraser, N.: Iustitia Interrupta: reflexiones críticas desde la posición "postsocialista". Bogotá: Siglo de Hombres Editores.

Fundación Chile (2013): Informe Final de Estudio: Análisis de la implementación de los programas de integración escolar (PIE) en establecimientos que han incorporado estudiantes con necesidades educativas especiales transitorias (NEET), Santiago de Chile: Ministerio de Educación.

Goffman, E. (1963): Estigma. La identidad deteriorada. Buenos Aires-Madrid: Amorrortu Editores.

Honneth, A. (1992): "Integrity and disrespect. Principles of a conception of morality based on the theory of recognition”. Political Theory, 20 (2): I 87-20I. Sage Publications (en línea). $<$ http://www.jstor.org/stable/I9200I>, acceso I 6 de diciembre de 2015.

Jenkins, R. (2008): Social identity. Third Edition, London: Routledge.
Lehmann, D. (2OI2): "Identity, social justice and corporatism. The resilience of republican citizenship", en Sznajder, M. et al.: Shifting Frontiers of Citizenship: The Latin American Experience. Leiden - Boston: Brill.

Loayza, S. (2005): "De indigentes y pobres". Umbrales. Revista de Postgrado en Ciencias del Desarrollo CIDES-UMSA, La Paz: Universidad Mayor de San Andrés.

Ministerio de Desarrollo Social (20I I): Encuesta de Caracterización Socioeconómica Nacional. Discapacidad (CASEN), Santiago de Chile: Gobierno de Chile.

Ministerio de Educación (2004): Informe de Expertos Nueva Perspectiva y Visión de la Educación Especial, Santiago de Chile: Ministerio de Educación.

Ministerio de Educación (2005): Política Nacional de Educación Especial: Nuestro Compromiso con la Diversidad. Santiago de Chile: Ministerio de Educación.

Mora, M. et al. (2005): "Desigualdad Social en América latina: Viejos problemas Nuevos Debates". Cuaderno de Ciencias Sociales I3 I. San Pedro (Costa Rica): Facultad Latinoamericana de Ciencias Sociales (FLACSO).

Murillo, F. e Hidalgo, N. (2015): "Enfoques fundamentales de la evaluación de estudiantes para la justicia social". Revista iberoamericana de Evaluación educativa, 8 (I): 4I-59.

Murillo, J. y Castilla, R. (20I I): "Hacia un Concepto de Justicia Social”. Revista Iberoamericana sobre Calidad, Eficacia y Cambio en Educación, 9 (4).

Nagel, T. (1973): "Equal Treatment and Compensatory Discrimination”. Philosophy and Public Affairs, 4 (2): 348-363 (en línea). <http://www.jstor.org/stable/22650I3>, acceso Io de diciembre de 2015.

Nussbaum, M. (2007): Las Fronteras de la Justicia, Barcelona: Ediciones Paidós Ibérica.

Nussbaum, M. (2012): Crear Capacidades, Barcelona: Ediciones Paidós Ibérica. 
Organización Mundial de la Salud, OMS (200I): Clasificación Internacional del Funcionamiento de la Discapacidad y de la Salud. Versión abreviada, Madrid: Ministerio de Trabajo y Asuntos Sociales. Secretaría de Estado de Servicios Sociales, Familias y Discapacidad. Instituto de Mayores y Servicios Sociales (IMSERSO).

Organización Mundial de la Salud, OMS (20II): Informe Mundial Sobre la Discapacidad. Ginebra: Organización Mundial de la Salud.

Opertti, (2009): “La Educación Inclusiva, perspectiva internacional y retos de futuro", en XV Coloquio de Historia de la Educación - "La Educación Especial y Social del siglo XIX”. Pamplona: Sociedad Española de Historia de la Educación y de la Universidad Pública de Navarra.

Organización de Naciones Unidas, ONU (2010): Para cumplir la promesa: realización de los Objetivos de Desarrollo del Milenio para las personas con discapacidad hasta 2015 y después de esa fecha, ONU (en línea). <http://www. un.org/es/comun/docs/?symbol=A/65/I 73>, acceso Io de diciembre de 2015.

Page, O. (20I3): "Mérito e igualdad de oportunidades". Revista de Ciencias políticas, 33 (2): 533-545.

Pantano, L. (2007): "Personas con discapacidad: hablemos sin eufemismos”. La Fuente. Revista de Psicología y Ciencias Humanas, 33 (X). Córdoba (Argentina).

Pawson, R. (200I): Evidence Based Policy I: In Search of a Method. Londres: ESRC UK Centre for Evidence Based Policy and Practice. Queen Mary. University of London.

Pawson, R. (200Ia): Evidence Based Policy II: The Promise of 'Realist Synthesis. Londres: ESRC UK Centre for Evidence Based Policy and Practice. Queen Mary. University of London.

Pawson, R. (2006): Evidence-bases Policy: A Realist Perspective, Londres: Sage Publications.

Pawson, R. y Tilley, N. (I997): Realistic Evaluation, Londres: Sage Publications

Pérez, L. C. (2003): "Prólogo", en García Alonso, J. V. (Coord): El movimiento de Vida
Independiente: experiencias internacionales. Madrid: Fundación Luis Vives.

Puyol, A. (I999): "Los límites de Igualdad de oportunidades". Leviatán. Revista de Hechose Ideas, 80: 63-84.

Puyol, A. (200I): "La Antropología moral de la igualdad". Isegoría, 24: 223-249.

Queralt et al. (20I4): "La igualdad de recursos de Ronald Dworkin ¿una concepción fallida?” Cuadernos Electrónicos de Filosofía del Derecho. 30: 17-36.

Rawls, J. (2006): Teoría de la Justicia, México: Fondo de Cultura Económica.

Reddle, C. (20I4): Disability and justice. The capabilities approach in practice, Toronto: Lexington Books.

Ribeiro, M. (I999): “Exclusión: problematización del concepto". Revista Educação e Pesquisa, San Pablo, 25 (I): 35-49.

Rodríguez, J. (2006): Un marco teórico para la discriminación. Colección Estudios, 2, México, D.F.: Consejo Nacional para prevenir la Discriminación.

Roemer, J. (I998): “Igualdad de oportunidades”, en III Simposio sobre igualdad y distribución de la renta. Madrid: Fundación Argentaria. Departamento de Economía. Universidad de California, Davis.

Romañach, J. y Palacios, A. (2008): "El modelo de la diversidad. Una nueva visión de la bioética desde la perspectiva de las personas con diversidad funcional (discapacidad)". Intersticios. Revista Sociológica de Pensamiento Crítico, 2 (2) (en línea). <http://www.asoc-ies. org/docs/modelo\% 2odiversidad.pdf $>$, acceso Io de diciembre de 2015 .

Schkolnik, S. (20I0): “América Latina: la medición de la discapacidad a partir de los censos y fuentes alternativas". Los censos de 20 I o y la salud. Informe del Seminario-Taller. CEPAL Serie Seminarios y Conferencias, 59: I79-206. Santiago de Chile.

Sen, A. (1999): Nuevo Examen de la Desigualdad, Madrid: Alianza Editorial. 
Sen, A. (2004): "Discapacidad y Justicia”. Ponencia en la Segunda Conferencia Internacional sobre Discapacidad y Desarrollo Inclusivo. Washington, DC: Banco Mundial.

Shakespeare, T. (2006): Disability Rights and Wrongs. New York: Routledge.

Soto, M. (20I I): "La discapacidad y sus significados notas sobre la (in) justicia”. Revista Política y Cultura, 35: 209-239.

Stang, M. F. (20II): Las personas con Discapacidad en América Latina: del reconocimiento jurídico a la desigualdad real. Santiago de Chile: Centro Latinoamericano y Caribeño de Demografía (CELADE) - División de Población de la CEPAL.

Tajfel, H. (2010): Social identity and intergroup relations, Londres-Nueva York: Cambridge University Press.

Taylor, C. (I992): The Politics of recognition chap, Londres: The Guildford Press.

Toboso, M. y Arnau, M. S. (2008): “La discapacidad dentro del enfoque de capacidades y funcionamientos de Amartya Sen”. Araucaria. Revista iberoamericana de filosofía, política y humanidades, 20 (Segundo Semestre): 64-94.

UMCE (2008): Estudio de la calidad de la Integración Escolar. Santiago de Chile: Ministerio de Educación.
UNESCO (1994): Declaración de Salamanca y Marco de acción para las necesidades educativas especiales, Salamanca: UNESCO (en línea). <https://www.google.es/url?sa=t\&rct=j\& $\mathrm{q}=\&$ esrc $=\mathrm{s} \&$ source $=$ web $\& \mathrm{~cd}=2 \& \mathrm{cad}=\mathrm{rja} \& u \mathrm{uc}$ $\mathrm{t}=8$ \&ved=oahUKEwiZvoq6 $\mathrm{I}-\mathrm{DJAhXEThQKH}$ R7pAKoQFggmMAE\&url=http\% $\%_{3} \mathrm{~A} \%_{2} \mathrm{~F} \%{ }_{2} \mathrm{~F}$ unesdoc.unesco.org \% 2 Fimages $\%$ 2Fooog \% 2 Fo $00984 \% 2$ Fo $9842750 . p d f \& u s g=A F Q j C N F A n e$ iZvoucFkQWw9xjPTa9TJXkg>, acceso ro de diciembre de 2015 .

UNESCO (2009): Realización de los Objetivos de Desarrollo del Milenio para las personas con discapacidad mediante la aplicación del Programa de Acción Mundial para las Personas con Discapacidad y la Convención sobre los derechos de las personas con discapacidad (A/64/I80), Nueva York: UNESCO.

UNICEF (2013): Estado Mundial de la Infancia. Niños y Niñas con Discapacidad, Nueva York: UNICEF.

Walzer, M. (1993): Las Esferas de la Justicia. Una defensa del pluralismo y la igualdad, México: Fondo de Cultura económica.

Young, I. M. (I990): Justice and politics of difference, New Jersey: Princeton University Press. 



\title{
Significados y prácticas de mediación orientada a la inclusión en el contexto mexicano
}

\author{
Meanings and practices of mediation aimed \\ at inclusion in the Mexican context
}

\section{Resumen}

El objetivo de la presente investigación fue contribuir a la comprensión sobre la mediación que realizan los profesionistas ${ }^{\mathrm{T}}$ que inciden en la educación básica en el marco de la inclusión educativa. Se recuperó el discurso y la experiencia de docentes y especialistas en dos escuelas mexicanas a través de entrevistas y observación directa. Mediante el análisis cualitativo, se encontraron diferentes puntos de vista implicados en la mediación inclusiva. Los hallazgos revelaron que entre los agentes de la inclusión existen diferentes puntos de vista sobre su mediación, que difícilmente socializan conocimiento nuevo al respecto y que sus prácticas tienden a reproducir esquemas habituales de actuación en torno a la inclusión. Concluimos que para que la mediación adquiera un carácter incluyente, es necesario que la mediación de los profesionales de la inclusión, adopten un sentido explícitamente educativo que derive de la reflexión colectiva y de acciones concertadas.

\section{Palabras clave}

Mediación, inclusión, significados, profesionistas, educación básica.

\begin{abstract}
The aim of this research is to contribute to the understanding of mediation made by professionals affecting basic education in the context of inclusive education. The discourse and experience of teachers and specialists in two Mexican schools were collected through interviews and direct observation. The qualitative analysis revealed diverse points of view on inclusive mediation. The findings expose that among the agents of inclusion, there are different views on mediation, which arduously socialize new knowledge and that the mediation practices tend to reproduce activity patterns that are commonly used in the context of inclusion. This article concludes that in order to create an inclusive mediation it is necessary to adopt an explicitly educational sense resulting from collective reflection and concerted actions.
\end{abstract}

\section{Keywords}

Mediation, inclusion, meanings, professionals, basic education.

\section{Úrsula Palos Toscano \\ <ursulapalos@hotmail.com>}

Universidad de Colima y secretaria de Educación Pública de Guadalajara, Jalisco (México)

\section{María Luisa Avalos Latorre <marilupsi@hotmail.com>}

Universidad Michoacana de San Nicolás de Hidalgo y CUTonalá Universidad de Guadalajara (México)

\section{Roberto Montes Delgado} <mondel@hotmail.com>

Universidad de Colima (México)
Para citar:

Palos, U. et al. (20I 5): "Significados y prácticas de mediación orientada a la inclusión en el contexto mexicano", Revista Española de Discapacidad, $3(2)$ : 79-97.

Doi: <http://dx.doi.org/I0.5569/23405 I04.03.02.05>

Fecha de recepción: 08 -04-20I 5 Fecha de aceptación: 20-I I-2OI 5 


\section{Introducción}

En la actualidad la inclusión educativa es un tema de interés mundial. En el ámbito internacional se ha logrado consenso en la definición planteada por la Unesco (Unesco, 2007: 4) en torno a garantizar oportunidades equivalentes de aprendizaje, a niños y niñas con necesidades educativas especiales, independientemente de sus antecedentes sociales y culturales y de sus diferencias en las habilidades y capacidades, de tal manera que las instituciones educativas proporcionen ambientes con oportunidades reales de aprendizaje promoviendo la participación y la inclusión. Hoy en día, existen diversos estudios que dan cuenta de este fenómeno desde sus diferentes dimensiones y sus actores. El interés de nuestro trabajo, se centró en describir los significados y prácticas que desarrollan profesionistas involucrados en mediar la inclusión educativa de estudiantes en condición vulnerable o con discapacidad.

Con relación a esto, López (2009) comparó la atención que se ofrecía en los alumnos con discapacidades graves y permanentes en los seis países de la Unión Europea que presentaban mayores índices de inclusión educativa (Italia, Grecia, Portugal, Noruega, Chipre e Islandia). Entre otros hallazgos, el autor observó que la concepción respecto a los alumnos dependía del déficit que presentaba el alumno, considera que es preciso clarificar y profundizar una concepción más uniforme, unívoca y completa que comprenda la totalidad de las necesidades educativas especiales y la globalidad de cada una de ellas, a fin de conseguir que esta visión se generalice en toda la comunidad educativa $\mathrm{y}$, en último término, en toda la sociedad.

También afirma que sólo desde una concepción más humana y pedagógica de los alumnos con Necesidades Educativas Especiales (N.E.E.) pueden generarse las actitudes que permitan alcanzar el objetivo de una educación de calidad, equitativa y para "todos y cada uno".

Torres (20II) afirma que las prácticas educativas dependen en gran medida del significado y de la valoración que se tengan de una serie de dimensiones esenciales como el individuo, la sociedad, la cultura y de cómo se relacionan entre sí. Considera indispensable un proceso de rearme ideológico y conceptual de los planteamientos de la inclusión escolar, ya que las reformas de los sistemas educativos en todo el mundo en torno a la formación de los profesores, se perciben como procesos inacabados que nos muestran grandes distancias entre los discursos teóricos, las medidas legislativas y las prácticas denunciables.

Por su parte, Glazzard (20I I) examinó las barreras a la inclusión en una escuela primaria en el norte de Inglaterra, para ello entrevistó a docentes y auxiliares de enseñanza. Sus hallazgos indicaron una variedad de prácticas y actitudes hacia la inclusión, lo cual impactaba directamente en su práctica educativa.

Asimismo, consideraron que la falta de recursos monetarios y didácticos eran elementos clave para las barreras de la inclusión.

Por otro lado, Padilla (20I I), mediante una investigación cuantitativa, describió la percepción de los docentes sobre su apertura y preparación para brindar una atención adecuada a estudiantes con discapacidad. Encontró que de los 367 docentes participantes, menos de un tercio de ellos se sentían capaces de responder a estos alumnos, siendo la discapacidad física aquella con la cual se sentían más familiarizados. La respuesta que los docentes ofrecían respecto a cada una de las discapacidades fue diversa y de diferentes magnitudes y, por tanto, resulta discriminatoria; debido posiblemente, al nivel de preparación que se tiene, a las experiencias y las vivencias personales.

Montesinos (2012) reflexiona en torno a la concepción sobre inclusión por parte de los actores educativos, considera que el uso del concepto se ha naturalizado a tal punto que pareciera innecesario explicar qué se quiere decir con ello cuando se le invoca como ejes orientadores de políticas y prácticas educativas y sociales. El concepto comúnmente, integra el sentido común, razón por la cual tiende a obviarse su significado, así como a confundirse 
con otros, lo cual trae como consecuencia una aplicabilidad en el ámbito educativo bastante cuestionable.

Garnique et al. (2012), desde una perspectiva cualitativa de las representaciones sociales, identificaron las construcciones simbólicas que los docentes, directivos y supervisores de educación básica, tenían sobre la inclusión. Los resultados sugieren que dichas representaciones guiaban sus actitudes, valores y comportamientos dentro del aula. Consideran que el maestro colaborador se siente con muchas limitaciones, que tiene una percepción de carencia, producto de la falta de información y de capacitación, al no saber cómo brindar atención, al reconocer que la bibliografía le marca lo ideal pero que esto no coincide con su práctica, al percibir una falta de trabajo colaborativo entre los actores educativos puesto que las reacciones interpersonales se mueven en un umbral de rechazo y/o resistencia, lo cual impide el trabajo conjunto entre ellos y en beneficio de los niños, que son la razón del trabajo educativo.

Mediante un ensayo teórico, Ossa et al. (20I4) analizaron el proceso de inclusión de niños y niñas con discapacidad en Chile. Argumentan que la cultura escolar presenta características que incidirían en el nivel de aceptación y efectividad de la inclusión educativa. Consideran que la percepción de la cultura en la organización escolar, y el manejo de los factores que la componen, tendrían influencia en la apreciación de la inclusión escolar. Aspectos como la cultura y organización del establecimiento influirían en la toma de decisiones y de procedimientos que resultan definitorios en el éxito del proceso de inclusión escolar, por ejemplo, la significación de los espacios de comunicación y reconocimiento para fomentar un clima de convivencia solidario y estimulante, lo cual incidiría directa y positivamente en la aceptación de las personas. Tal como podemos observar, existen trabajos que abordan las construcciones docentes sin embargo, son escasos los que las relacionan a la inclusión educativa y a su participación en ésta. Los reportes que predominan son análisis y propuestas teóricas, y sólo algunos de éstos aportan evidencia empírica sobre el tema, aunque generalmente abordándolo desde una perspectiva cuantitativa. En la investigación que presentamos, nuestro interés por la inclusión, se centra en uno de sus determinantes y éste es la mediación que docentes y especialistas realizan para garantizar condiciones de equidad respecto a oportunidades de aprendizaje entre el alumnado, por ser un proceso que consideramos de gran relevancia en tanto hace posible la participación de todos, incluso la de los alumnos en condición vulnerable o de discapacidad.

Pese que la mediación desempeña un papel importante en la construcción autónoma de conocimiento, este proceso escasamente ha sido vinculado a la educación de las personas en condición vulnerable o con discapacidad. Sin embargo, resulta un tema obligado si se considera que hoy en día, en el contexto mundial, existe mayor consciencia respecto a la importancia de reconocer, respetar e incluir a todas las personas a distintos ámbitos del acontecer humano.

Entre los distintos ámbitos de inclusión, el de la educación constituye uno de los más importantes ya que en los últimos años el conocimiento ha llegado a ser considerado como el único capital humano que, por su carácter universal e inalienable, representa la posibilidad de colocarnos a todos en igualdad de condiciones, afirmándose con esto que acceder al conocimiento, además de legítimo derecho, es indicador evidente de equidad e inclusión social. En ese sentido y, partiendo de trabajos como los de Ainscow et al. (2009), Blanco (20II), Carvalho (2008), o la propia Secretaria de Educación en México (20II), podemos asumir que la mediación de los especialistas tiene que ver con impulsar y hacer efectivo el derecho a una educación de calidad y para todos, aún por encima de la condición personal de los distintos estudiantes.

Como se sabe, en su acepción más genérica, la noción de mediación remite a la movilización y empleo de herramientas técnicas, psicológicas (Vigotsky, 1995) y primordialmente, a las 
culturales o simbólicas, lo que implica formas específicas de interacción social (Werstch, 200I), orientadas a ampliar las capacidades humanas y facilitar al individuo tanto la comprensión como la acción deliberada y autónoma sobre su entorno.

De acuerdo con Martínez (I994), mediar implica ayudar a quien aprende a estructurar sus experiencias, ampliar lo que percibe, lo que conoce y comprende, a partir de la gestión de acciones y recursos diferenciados, sobre todo, a través de interacciones sociales orientadas a la construcción intersubjetiva en torno a aquellos aspectos que interesa aprender.

En el presente trabajo la mediación y su relevancia son abordadas por la función que ésta suele llegar a tener no solo en los procesos de construcción autónoma en torno al conocimiento, sino además, en los procesos de inclusión a las escuelas, debido a que las cualidades flexibles y heurísticas de la mediación aseguran el intercambio subjetivo, que hace posible el establecimiento de nexos simbólicos entre las distintas formas de pensamiento individual y las realidades físicas o sociales que todos aspiramos a conocer o aprender.

En función de lo anterior, asumimos que el hacer efectiva la inclusión educativa, implica que además de activar los procesos psicológicos para la construcción autónoma de conocimiento y propiciar la intersubjetividad que facilite la reconceptualización o el aprendizaje entre los alumnos, la mediación del especialista tendría que incitar la construcción compartida de significados en torno a la erradicación o minimización de aquellas barreras que en distintos escenarios y situaciones educativas, obstaculizan el encuentro entre los objetos por conocer y los estudiantes con discapacidad.

A propósito del intercambio subjetivo, Newman et al. (I998), señalan al aprendizaje o cambio cognitivo como el efecto lógico de lo que acontece cuando un profesor enseña y un alumno aprende, a la vez que nos recuerdan la presencia de elementos intelectuales, afectivos y comportamentales entre los rasgos que le definen $\mathrm{y}$, a la vez, condicionan.
Justo por ello, la mediación puesta al servicio de la inclusión educativa se constituye en un problema digno de análisis, sobre todo si consideramos quién es el alumno a incluir, a qué se le incluye, qué implica incluirlo y cómo habría que mediar para lograrlo. Especialmente frente a los prejuicios, actitudes y expectativas docentes que en ciertos espacios aún condicionan las interacciones que se producen con relación a este grupo de estudiantes, limitando de manera importante sus oportunidades para participar y beneficiarse de situaciones de aprendizaje.

Otro problema son las construcciones, como las de mediación, que subyacen a la práctica de los docentes y especialistas en las escuelas, y que según Palos et al. (2OI4) no tiene mucho que ver con la dócil adopción de ideas creadas desde la teoría o en el discurso institucional, aunque tampoco con ideas surgidas solo desde el mundo interior o la lógica individual de los especialistas. Su verdadero sentido se relaciona más con los significados que se negocian en la serie de interacciones que surgen en la actividad compartida y coordinada entre ellos, a partir de lo que comunalmente han valorado como favorable y pertinente para facilitar los procesos educativos e incluyentes.

Asimismo, los conceptos sobre la inclusión o la discapacidad suponen un proceso de elaboración de sentido, donde los significados otorgados a los hechos y experiencias son construidos socialmente en el consenso, cobrando validez o relevancia principalmente en función de la red de relaciones que su vivencia impone (Gergen, 20I0).

En este sentido, el interés de esta investigación está centrado en el descubrimiento de los puntos de vista e interpretaciones de los actores asumidos en sus prácticas de mediación inclusiva, por lo que el objetivo de esta investigación fue analizar los significados que docentes y especialistas elaboran y comparten sobre los procesos de mediación de la inclusión educativa en instituciones de educación básica en un contexto mexicano. 


\section{Metodología}

\subsection{Participantes}

Los criterios de selección de los participantes no estuvieron regidos por la representatividad. Prevalecieron, en cambio, criterios de relevancia y potencial informativo, de manera que el criterio inicial de la muestra tuvo un carácter tentativo, siendo el proceso recursivo de análisis lo que posteriormente influyó en su gradual adecuación y suficiencia. Finalmente, después de alcanzar la saturación teórica, la muestra quedó configurada por 6 docentes y 8 especialistas (psicólogos, maestros de comunicación y maestros en problemas de aprendizaje).

\subsection{Diseño}

El estudio se basó en un paradigma interpretativo y cualitativo, dada la naturaleza social y subjetiva que se asumió en la recuperación de la experiencia de los participantes. Se aplicaron elementos de la teoría fundamentada con la finalidad de lograr esa apreciación íntima de la mediación para descubrir los rasgos definitorios, a partir de la interacción directa con referentes empíricos que las dinámicas en las escuelas aportaron y con la mayor independencia posible de lo que el discurso institucional o teórico han planteado ya respecto a la misma. Esto posibilitó el conocimiento a profundidad de las condiciones que afectaban la intervención de este grupo de profesores y especialistas, aunque por otra parte, implicó renunciar a todo intento de generalización.

\subsection{Técnicas de obtención de información}

Se recurrió básicamente a las técnicas de entrevista y de observación. Las entrevistas empleadas en el trabajo tuvieron un carácter informal y siguieron del modelo de una conversación entre iguales. El entrevistador fungió como recurso central en la captación de la información. La guía que se utilizó se desarrolló de manera gradual y paulatina, en buena medida a partir de interrogantes que en la observación precedente se iban generando, esta guía no quedó establecida como formato fijo, lo que permitió plantear preguntas temáticas, no directivas y centradas en conocer aspectos que no podían ser observados directamente.

La observación que se efectuó fue del tipo participante que involucró la interacción social entre el investigador y los informantes, durante la cual se recogieron datos de modo sistemático y no intrusivo a través de la relación cercana e inmediata con los informantes. A través de ambas técnicas se recuperó lo siguiente: a) el discurso que daba cuenta de lo que se piensa y se comparte en los centros escolares, b) las actividades e interacciones que dan forma a ese discurso y lo objetivan en las aulas y c) las formas habituales de organizarse o participar en torno a estos.

\subsection{Escenario}

La indagación se llevó a cabo en las escuelas de incidencia de los participantes. La primera escuela fue de Educación Preescolar en la cual se ofrecen servicios educativos a niños entre 3 a 5 años. La segunda escuela fue de Educación Primaria en la cual se brinda educación a niños de 6 a I I años de edad.

Las entrevistas se realizaron en un aula equipada con mesas y sillas. Por otro lado, las observaciones que nos permitieron objetivar los discursos, acceder a las formas de interacción y las prácticas de mediación se realizaron en el contexto del aula destinada para la atención especial de cada una de las escuelas participantes (equipada con mesas, sillas, computadora, pintarrón ${ }^{2}$ y material didáctico diverso), en las aulas regulares de clase y en los escenarios destinados para la actualización y reflexión compartida entre los docentes.

2. México: pizarra (nota del editor). 


\subsection{Procedimiento}

Inicialmente, se llevó a cabo una aproximación a los actores, a partir de la incursión con ellos en el ejercicio retrospectivo y auto-valorativo que año con año realizan sobre sus proyectos de trabajo para identificar las áreas susceptibles de mejora. Asimismo, se recuperó información importante que posteriormente se tradujo en referentes, tanto para el diseño del estudio como para la negociación de entrada a las escuelas.

La entrada al campo, inicialmente implicó el consentimiento informado de los participantes y se asignaron claves para respetar y asegurar a todos su anonimato. Se recurrió primero a la observación, alternando las visitas en ambas escuelas. Ésta se centró en las actitudes, consignas, eventos y los recursos aportados por los actores, así como la respuesta de los alumnos, etc. Las entrevistas, en cambio, se aplicaron al considerar que se habían generado condiciones para la aceptación y confianza.

Tuvieron el formato antes descrito e implicaron la interacción cara a cara con los entrevistados, mientras los informantes describieron lo que sucedía, lo que pensaban, sus creencias, percepciones e incluso los sentimientos que experimentaban al respecto.

\subsection{Reducción de la información}

En apego al abordaje metodológico elegido, la siguiente etapa en el proceso se centró básicamente en la revisión de la información obtenida y partió de los textos derivados en la transcripción de entrevistas y registros de observación. Dicha revisión nos permitió concretar el primer trabajo de segmentación, partiendo primero de la lectura vertical de cada uno, en la forma más inductiva posible, con el propósito de localizar y describir los incidentes a los que remitían.

En el caso de la entrevistas, las preguntas que se formularon se ajustaron de acuerdo al tipo de participante, pero conservando el sentido de las mismas. Su lectura permitió el diseño de una matriz que ayudó a recuperar las construcciones de los participantes respecto a: I) Las situaciones que debían resolver en lo cotidiano, 2) Las dificultades que los alumnos enfrentaban, 3) Lo que pensaban de la inclusión, 4) Las acciones que valoraron como favorables para su inclusión, 5) Los rasgos que creyeron deseables en su intervención, 6) Lo que podrían esperar de los alumnos y 7) Los aspectos en que advertirían sus progresos e inclusión.

Una segunda matriz, basada en las interacciones observadas, permitió concentrar datos de las actuaciones de los participantes respecto a: I) Los criterios de selección de los alumnos, 2) Las tareas que proponían para sostener el trabajo del aula, 3) Las interacciones con que apoyaban el aprendizaje y aseguraban la participación, 4) El tipo de lenguaje utilizado con el alumno, 5) Los recursos y referentes que garantizaban la comprensión, 6) Los actores a quienes involucra y cómo negocian su participación y 7) La influencia que tienen en el aprendizaje y en la participación de los alumnos.

Los datos contenidos en las matrices facilitaron la posterior lectura horizontal de los textos y el acceso ágil y oportuno al material empírico. La información derivada de las entrevistas junto con la de los registros se concentró en una tercera matriz que permitió recuperar las citas emergentes en relación a los aspectos explorados (Ver Tabla I).

El trabajo de reducción de la información obtenida produjo como resultado un catálogo con 20 códigos que después de ser analizados permitieron identificar algunos de sus rasgos esenciales, ordenarlos, relacionarlos y formular conceptos más abstractos que en etapas posteriores del análisis dieron origen a las siguientes categorías:

- El concepto de inclusión.

- El sentido que orientan su mediación.

- Estrategias concretas de mediación.

- Las formas de organizar las prácticas de mediación.

- Los procesos incluyentes

- Las interacciones y las formas de participación. 


\begin{tabular}{|c|c|}
\hline Aspectos explorados & Referentes encontrados \\
\hline $\begin{array}{l}\text { Situaciones en que } \\
\text { intervienen para facilitar la } \\
\text { inclusión }\end{array}$ & $\begin{array}{l}\text { Atención a las demandas de profesores. Evaluación inicial al alumno. } \\
\text { Adaptación e instrucción de ciertos contenidos. Abordaje de procesos socio- } \\
\text { afectivos. Orientación/sugerencias a padres y maestros. Diseño de propuestas } \\
\text { adaptadas. }\end{array}$ \\
\hline Actividades que realizan & $\begin{array}{l}\text { Observación al desempeño de los alumnos. Aplicación de pruebas } \\
\text { psicopedagógicas. Entrevistas con padres y maestros. Programas para el } \\
\text { desarrollo de lenguaje. Resolución de problemas de conducta. Monitoreo de } \\
\text { actividades en clase. Talleres de orientación con padres o maestros. Diseño de } \\
\text { programas para apoyo en casa. Elaboración y presentación de informes. }\end{array}$ \\
\hline Quiénes se involucran & $\begin{array}{l}\text { Descripciones respecto a quienes conforman los equipos. Referencias a } \\
\text { quienes colaboran y participan. Participar en interacciones del aula y la } \\
\text { escuela. Interacciones entre integrantes de los colectivos. }\end{array}$ \\
\hline Cómo se organizan & $\begin{array}{l}\text { Percepción de ejes que articulan la actividad conjunta. Descripciones sobre cómo } \\
\text { organizan las actividades. Desarrollo de acciones habituales. Oportunidades de } \\
\text { colaboración y consenso. Elección de escenarios en que actúan. }\end{array}$ \\
\hline Sus interpretaciones & $\begin{array}{l}\text { El sentido que otorgan a la inclusión. Orientaciones respecto al sentido } \\
\text { de su mediación. Apreciaciones sobre el alumno. Atributos deseables en } \\
\text { su mediación. Aspectos en que visualiza la inclusión. Improvisación sobre } \\
\text { objetivos, acciones y recursos. Expectativas de logro respecto al alumno. } \\
\text { Sobrevaloración de procesos intra-mentales al aprender. Concepciones } \\
\text { organicistas sobre la discapacidad. }\end{array}$ \\
\hline Rasgos de su mediación & $\begin{array}{l}\text { Naturaleza de las tareas que propone. Descripciones de la intencionalidad } \\
\text { de sus acciones. Descripción de relaciones entre éstas y contenidos. } \\
\text { Descripciones de atributos deseables en su mediación. Formas de interacción } \\
\text { verbal y cognitiva con el alumno. Códigos y referentes que establece y } \\
\text { comparte con otros. Personalización y flexibilización de interacciones, } \\
\text { estrategias o recursos. }\end{array}$ \\
\hline Actitudes y vivencias & $\begin{array}{l}\text { Percepción del apoyo. Percepción de cómo recibe a los alumnos. Disposición } \\
\text { a involucrarse en acciones comunes. Afirmaciones sobre su rol y el de otros en } \\
\text { el proceso. }\end{array}$ \\
\hline Efectos de su mediación & $\begin{array}{l}\text { Cambios producidos en ambiente del aula y la escuela. El desempeño } \\
\text { observado en el alumno. La participación del alumno. Dinámicas de interacción. }\end{array}$ \\
\hline
\end{tabular}

Fuente: Elaboración propia.

\section{Descripción de los hallazgos}

\subsection{El caso del preescolar}

\subsubsection{El concepto de inclusión: "Que los niños sean aceptados en las escuelas"}

Aunque individualmente los actores han logrado distintos niveles de comprensión respecto a la inclusión, entre los significados que en mayor medida comparten destacan aquellos cuyos contenidos remiten al compromiso de promover la aceptación y asegurar la permanencia de los alumnos en las escuelas. Coinciden al pensar que la mediación que contribuiría a ello tiene que ver con facilitar el desarrollo de destrezas en atención individual. Para la mayor parte de los actores, la inclusión educativa tenía que ver con concretar "el derecho que tienen los niños de estar en la escuela”, o bien, generar la posibilidad de "insertar a los niños con alguna discapacidad a la escuela regular”. 
“...es un proceso en el que los niños son aceptados en la escuela regular a través de que los papás buscan ese espacio para que sus hijos sean... sean recibidos y atendidos pero que sean incluidos ¿verdad? que se les tome en cuenta de acuerdo a sus capacidades...” (Entrevista EUI).

También hubo especialistas que individualmente asociaron la inclusión en las escuelas con la posibilidad de que los alumnos aprendieran, reconociendo a las escuelas y sus dinámicas como elementos susceptibles de transformación y mejora a través de sus propias intervenciones, pero solo excepcionalmente se arriesgaron a probar formas de actuación distintas a las habituales.

En consonancia con ello, al interior de la escuela los actores suelen a promover ideas en torno al propósito de su tarea, asociadas a la aceptación y socialización como el compromiso central de su trabajo, o bien en otras ocasiones al compromiso más elemental que incluir implicaba, “...no nomás es que este dentro del salón y que ande dando vueltas o que no haga nada...es que trabaje y vaya al ritmo de sus compañeros, va a trabajar, a lo mejor él aprende de manera diferente y no va a lograr los contenidos, pero que tenga cambios...", con la expectativa en mente de que el desarrollo de los alumnos solo era posible en ciertas áreas de la personalidad.

\subsubsection{El sentido en que orientan su mediación: "Desarrollar destrezas en atención individual"}

Los participantes de este centro escolar aluden a su mediación como un conjunto de estrategias orientadas al desarrollo de habilidades y destrezas especificas, procesos socio-afectivos, estimulación sensorial, destrezas comunicativas y el desarrollo de la atención o la regulación de la conducta para que los alumnos con N.E.E. logren responder a las demandas en las aulas.

Sus respuestas constituyen un proceso cuyo inicio parte de la solicitud de apoyo por parte de los docentes regulares para los alumnos que han sido identificados con un nivel de desempeño inferior al del resto del grupo. A partir de esta demanda, los especialistas entran al grupo, a observar y "constatar que en verdad los alumnos presentan ritmos diferentes para aprender", o "que sus formas de interacción afectan la dinámica del aula" y aunque observan a todos, enfatizan la atención en aquellos "alumnos con discapacidad intelectual, problemas de expresión y/o comprensión del lenguaje y problemas de conducta" que son los que les "toca [ba] atender".

La atención suele ofrecerse "de acuerdo a las necesidades", lo que propicia "un proceso de depuración" mediante los primeros ajustes curriculares "conforme marcan las orientaciones generales” para la operación del servicio, de manera que primero "se brinda una serie de orientaciones a la maestra para que esos alumnos logren superar la dificultad reportada". En los casos cuando la dificultad de los alumnos persistía, especialistas y profesores coincidían al afirmar que, "ya como en octubre, empezamos con la evaluación psicopedagógica si es necesario, donde se entrevista al papá, se entrevista a los maestros, se aplican pruebas, se hace un diagnóstico y bueno, una serie de cosas que hablan de nuestra intervención”.

$$
\begin{aligned}
& \text { “...a partir de eso, pues ya fueron..., heee..., } \\
& \text { citas con la mamá y el papá, para ver si } \\
& \text { aceptaban una valoración medica, en eso están } \\
& \text { todavía, porque no..., no se ha concretado } \\
& \text { que es lo que realmente tiene el niño..., si } \\
& \text { nada más un trastorno de déficit de atención, } \\
& \text { o realmente trae algún rasgo de autismo o de } \\
& \text { asperger...” (Entrevista } \mathrm{MR}_{3} \text { ). }
\end{aligned}
$$

Lo que sigue en el proceso, según afirman, depende en mayor medida de la dificultad identificada pero generalmente queda asentado en la propuesta curricular adaptada donde especifican quién y cómo "apoyan con los niños y sus padres dándoles estrategias para el trabajo en casa y la atención con ellos, también a nosotros [los maestros] nos apoyan con estrategias".

\footnotetext{
“...Te dicen "mira puedes emplear estas estrategias” y ya tu aplicas unas en tu salón
} 
otras se las das a los padres... o cuando ya de plano la cosa es muy complicada, ellas te reciben a los niños, trabajan con ellos, los evalúan hablan con sus padres o los atienden aquí...Reciben casos de NEE...” (Entrevista MR2).

\subsubsection{Estrategias concretas de mediación: "Estimulación especial de los aspectos a la baja"}

Las estrategias para mediar la inclusión se produjeron básicamente en escenarios destinados para el apoyo especial, aunque en menor medida también se apreciaron actividades programadas por los especialistas al interior de las aulas regulares. Lo más común fue que los alumnos a incluir recibieran el apoyo especial mediante actividades y recursos que los habilitaran para responder de manera más efectiva a las demandas de sus salones de clase. Las consignas propuestas para el trabajo en las aulas de apoyo se produjeron a manera de entrenamiento o estimulación específica en torno a la dimensión de la personalidad que los especialistas, educadoras u otros actores reportaron afectada o con menor grado de desarrollo.

PA. "Vamos a pasar harina de aquí para acá, diez veces". (Diez puñitos).

O. El niño acata la consigna a la vez que verbaliza los números correctamente.

Ao. "Ya esta, Ah que lico, ahora lo vamos a vaciar, con agüita".

O. La harina quedó distribuida en dos recipientes, uno de ellos, la mamá le ha aplicado agua.

PA. "Tienes que hacerlo con la mano izquierda diez veces, en lo seco y luego en lo mojado.

Otra vez ¿dónde está el seco?, ¿dónde está el mojado?".

PA. "D... D... otra vez, aquí, Aquí en el mojado, cómo se siente eso"

Ao. . “iLico!!” (Rico).

PA. "Muy bien ahora, vamos a trabajar con la mano derecha. Estamos trabajando con la mano... derecha".

Intervención en aula de apoyo.
Acciones como éstas generalmente se promovieron y coordinaron por el especialista a cargo, se orientaron con base en lo que conocía y consideraba pertinente para el alumno, e influidas por supuestos respecto a lo que subyacían a la condición del alumno. La mayor parte de las veces, las actividades propuestas se desarrollaron con relativa independencia a las del salón de clase. Otras estrategias consistieron en la orientación o consultoría con los padres de familia.

EC. "Oye al final de del taller se me acercó la mamá de $\mathrm{NN}$, y me dice que tiene un trastorno obsesivo compulsivo (TOC), le digo que yo no le puedo atender en ese sentido, pero que sí debe revisar eso. Yo creo que debemos decirle a PS ¿podemos hacerle una cita con la Sra.?” (Registro intercambio entre especialistas EUI).

Finalmente, otra estrategia que emplearon para facilitar los procesos de inclusión, fue la asesoría a docentes, que básicamente se empleó por los actores para la actualización y capacitación de los docentes, lo que no siempre lograba ser considerado por las educadoras como una estrategia de apoyo directo al alumno.

“...una capacitación pero como te diré... en la marcha, ver cómo lo hace la psicóloga o pedagoga en el aula,... no solo la asesoría como cuestión teórica, sino que realmente el equipo te acompañe, no solo que te asesore..." (Entrevista MR2).

\subsubsection{Las formas de organizar las prácticas de mediación: "el flujograma de atención y los expedientes de carrera"}

Pese a que las actividades de los docentes y especialistas en pocas ocasiones llegaban a conjuntarse, existieron aspectos en que optaron por conciliar la organización. Sus prácticas fueron las etapas y "productos" señalados en el flujograma de atención que los especialistas compartían entre sí, el cual formaba parte del manual operativo de los servicios de educación especial. 
“...para favorecer la inclusión, es como si tuvieras que cubrir en términos de temporalidad las acciones que nos son establecidas y esto implica que nos atrevamos sin ser sistemáticos...” (Experiencia Narrada EUo).

Por otra parte, debieron ajustarse a los criterios estadísticos ya que, según señalaron, cada especialista debía atender en promedio 20 alumnos en el total de escuelas que incidían. Así también, debían privilegiar la atención en el caso de aquellos alumnos que encontraran en condición de discapacidad, y/o aptitudes sobresalientes, lo que en cierta forma, imponía la necesidad de tomar acuerdos básicos como equipo o en su relación con las educadoras, disciplinas que se desarrollaban a manera de:

PA. “Aquí está la estadística con los alumnos que quedaron del ciclo pasado y las que han ido reportando las educadoras".

EC. "Oye pero son 42 en total".

PA. "Sí, pero no todos son tuyos, sólo los del lenguaje".

EC. Sí pero...de todos modos eso rebasa los

20.

PA. “Oigan, ¿cómo ven si vamos subrayando los que sí y los que no, para irlos poniendo en la (RA)?” .

Interacción especialistas Reg. EUI.

Básicamente las reuniones informativas mensuales de actualización y reflexión compartida entre los docentes y especialistas, se consideraron como sesiones de planeación y una forma para organizar su trabajo. Durante estas reuniones, cada uno de los servicios planeaba los contenidos a desarrollar ya fuera conforme a consignas institucionales o en caso de los especialistas, conforme a temáticas que ellos identificaban como necesidad más relevante.

3.1.5. El efecto sobre los procesos incluyentes: "Apoyos que escasamente contribuyen a mejorar el desempeño en el aula"

Las estrategias de mediación que se propusieron para fomentar la autonomía y mejorar el desempeño del alumno en al aula, la mayor parte de las veces parecen descontextualizadas respecto a las situaciones de clase, de manera que los recursos ofrecidos para resolver la dificultad no siempre contribuyen para que el alumno logre responder a las demandas en clase, lo que refuerza el escepticismo y apatía entre los docentes respecto a las ventajas de contar con apoyo especializado.

... [Falta de actualización] "Esto implica que nos atrevamos sin ser sistemáticos, sin saber lo que ocurre con el alumno en sus diferentes contextos, sin tener el dominio de los contenidos curriculares, sin conocer como aprenden los alumnos a quedarnos en el plano de dar sugerencias..." (Experiencia relatada EPA).

“...Están encargadas de proponer, pero no de resolver. Me gustaría más tener herramientas en conjunto, me gustaría verlas en acción en el aula, trabajar con ellas en directo...” (Entrevista MR 2).

En los salones de clase el alumno en condición de vulnerabilidad, muestra dificultad para seguir la secuencia y el ritmo de la actividad, Algunos alumnos en clase refieren dificultad para comprender de qué trata la actividad y lo que se espera que ellos logren. Por otra parte, cuando los alumnos participaron en clase casi siempre lo hicieron en solitario y en tareas o actividades distintas al resto de sus compañeros. Sus participaciones en clase no alcanzan a reflejar las habilidades que desarrolló en el aula de apoyo.

PA. "Se supone que con esta atención el niño debe mejorar, para que aprenda a pasar de una actividad a otra sin que haya mucha dispersión".

MR. "Sí, pero ya no se trata solo de que sostenga la atención, sino de ver que le sirva, tratar de que se meta en la actividad".

PA. "Recuerda que esto es un proceso, lo primero es captar su atención y luego lograr que permanezca y ya después se verá que le sirva”.

(Registro de Asesoría entre especialista y docente $\mathrm{MR}_{3}$ ). 


\subsubsection{Las interacciones y las formas participación: "El abordaje disciplinar de los procesos educativos e incluyentes"}

En el desarrollo de las acciones antes descritas la participación activa correspondía principalmente a los integrantes del equipo de apoyo, aunque decir de ellos mismos, "los docentes crean un ambiente de confianza, respeto, y armonía, se muestran con disposición al trabajo conjunto con los especialistas”. Además, en las interacciones observadas mostraron ser receptivos a la diversidad en sus aulas, pero no necesariamente conscientes de su compromiso con ello.

"Yo me dediqué con más énfasis, a observarlo un promedio de, dos semanas o tres, lo canalicé".

(Intercambio informal con docente $\mathrm{MR}_{3}$ ).

Quienes participaron de la atención, configuraron un equipo itinerante de especialistas que brindaba apoyo a cuatro escuelas a la vez, solo quien fungía como especialista en problemas de aprendizaje sostenía presencia y relación constante con el centro escolar, el resto de los integrantes alternaban sus participaciones con las de otras escuelas y otros agentes educativos.

Estas dinámicas de participación además de propiciar inconsistencias e interferencias en las acciones, llegaron a influir negativamente en el ánimo y disposición del resto de los actores debido a que, por un lado, los profesores experimentaban sólo como prescripciones los intermitentes apoyos recibidos y, por otra parte, los especialistas tendían a sentirse rebasados por la cantidad y el tipo de demandas.

"Ellas hacen un trabajo... que les lleva todo el año, evalúan, entrevistan y vuelven a transcribir pero no hay apoyo que se refleje en el aula...” (Entrevista MR2).

"Haría falta seguimiento...o tiempo... sobre todo de nosotros que somos el equipo itinerante ¿verdad? siento que es mejor un equipo completo en cada escuela...o tal vez dos... ¿pero cuatro? como que... siento que sólo damos como flashazos ¿verdad?” (Entrevista EPS2).

Pese a que los especialistas tendían a experimentar mayor compromiso que los docentes con la tarea inclusiva, no siempre participaron de las experiencias educativas previstas en clase, optando por intervenciones más afines a su ámbito disciplinar con relativa independencia de las acciones del resto de los actores.

PS. "Hoy vamos a trabajar con las narrativas de las vidas de los niños... Bueno, los que ya tenemos las narrativas de las vidas de los niños, quienes no, vamos a hacer un ejercicio breve en el que... les contaremos a manera de cuento la historia de sus vidas...".

PS. "Vamos a necesitar que vayamos a por nuestros niños al salón, que se traigan la silla de su niño, y ya que estemos aquí, los vamos a poner frente a nosotros y primero vamos a mirarnos, recuerden, no se vale usar palabras, de lo que se trata es de que aprendamos a mirarnos"

(Interacción en aula de apoyo: trabajo grupal con padres/ en torno a la relación maternoinfantil o "maternaje". EPS2).

Otros espacios de interacción entre los actores fueron las reuniones de actualización y reflexión compartida entre los docentes, en los que debían abordar los aspectos que se les presentaban como conflictivos en relación a la tarea educativa, en este caso, se previeron espacios para la participación de los especialistas quienes participaron básicamente mediante la exposición de temas relativos a las discapacidades y sugerencias para su abordaje en el aula. Estas interacciones difícilmente constituyeron alguna forma de trabajo en colegiado. 


\subsection{El caso de la escuela primaria}

\subsubsection{El concepto de inclusión: "Darles la oportunidad a los alumnos que están en desventaja para que aprendan"}

Conforme los participantes de la primaria expresaron, la tarea incluyente revestía diversos sentidos: mientras que para unos especialistas la tarea consiste en promover aprendizajes mediante propuestas educativas adaptadas de acuerdo a las necesidades de los alumnos, para muchos de ellos la aceptación y socialización seguía siendo el compromiso de su trabajo. "Como [en el caso de] A... saber que puede aprender, que no solamente va a estar ahí sentadita socializando, sino que puede dentro de sus recursos demostrar que está aprendiendo..." (Entrevista EPAI).

“...al lograr la socialización está aprendiendo... a lo mejor no tanto contenido, pero sí está aprendiendo habilidades para la vida, lo que se le vaya a enfrentar, o sea la socialización nos da mucha apertura... mucho conocimiento, o sea... a comparación de un niño que... que no está escolarizado..." (Entrevista EPSI).

Sólo excepcionalmente uno de los especialistas piensa que incluir significa "asumir con el maestro lo que nos toca hacer en la escuela" por el alumno, ayudar a los niños a que se sientan como los que no tienen necesidades, "es ponerlo junto a los otros y ayudarle a que descubra que en ese lugar hay cosas que él puede hacer como lo hacen los demás, sólo o con ayuda y que si necesita ayuda enseñarlo a pedirla”.

Pudimos observar la tendencia a pensar en la discapacidad y lo diverso como una condición de vulnerabilidad y frente al caso de los alumnos en dicha condición, algunos docentes mostraron la inclinación a asumir que su desarrollo sólo era posible en determinadas dimensiones de la personalidad.

“...entonces son niños que necesitan a una persona, quizá una educación individualizada mas dedicada a ellos, y este... quiero pensar que... eso, lo que tiene está en todas las áreas, no solo puedo decir en cuestión de aprendizaje, nuestras debilidades son los niños que traen problemas familiares, tenemos..." (Entrevista MRP2).

Tanto los profesores como los especialistas asumieron el apoyo pedagógico como una práctica exclusiva de los especialistas que podía y debía producirse de manera alterna en las escuelas, a fin de propiciar la respuesta adaptativa del alumno en condiciones de vulnerabilidad y conseguir así la participación de éste por lo menos en algunos de los eventos del aula y la escuela.

“...me gustaría que el grupo de USAER 3 manejara a los niños que tienen problemas en determinadas horas...” (Entrevista MRP2).

La mayor parte de las interpretaciones desarrolladas y expresadas por los participantes, evidenciaron el predominio de la construcción subjetiva e individual influida por nociones o elementos formativos previos, ajenas a la socialización e intercambio, que escasamente influyeron en la percepción que habitualmente los profesores tenían acerca del apoyo especializado en las escuelas.

3.2.2. El sentido en que orientan su mediación: "Adaptar contenidos y tareas alternas en clase y el aula especial"

Para los especialistas que inciden en primaria, la respuesta frente a la diversidad tuvo que ver más con adaptar recursos, actividades y contenidos para los alumnos con necesidades educativas especiales a fin de acercarlos al aprendizaje. Conforme señalaron, durante el apoyo que ofrecían en las escuelas los especialistas debían recibir demandas de los profesores, observar la actividad del alumno en las aulas y aplicar pruebas psicopedagógicas, orientar a padres

3. USAER, en el contexto mexicano son las Unidades de Servicio de Apoyo a la Educación Regular y que en el presente manuscrito referimos como las aulas de apoyo. 
y asesorar a los profesores a quienes sugerían ajustes a los contenidos y las actividades de acuerdo a las dificultades que identificaban en los alumnos, según refirieron.

“...lo que hacemos es monitorear, apoyar al niño en el salón, en esos casos hay un cierto recelo, porque entonces el docente dice, claro, sí puede aprender pero porque tu estas ahí pegadita, en esos casos lo que se hace es dotar al docente de otras estrategias, adecuar los materiales, adecuarle los libros o dejarle claro al docente que si en su jornada diaria, los niños van a trabajar cinco actividades, el niño, solo trabaje tres, que otro compañero trabaje como monitor, tenerlo cerca, evitar distractores, todo esto ha funcionado muy bien, así el docente no se siente solo, no siempre funciona pero sí la mayoría de las veces..." (Entrevista EPAI).

Se identificó una mayor preocupación por acercarlos a los contenidos curriculares mediante acciones paralelas en el aula de apoyo, pues a decir de los especialistas en primaria "no ha existido la apertura para permitirles intervenir en el aula regular" lo que, por otra parte, refuerza en ellos la tendencia a intervenir desde el aula especial en torno a determinadas dimensiones del desarrollo de los alumnos.

"No, aquí no hemos tenido la apertura para intervenir en el aula regular...” (Entrevista EC2).

En el aula de apoyo el trabajo que los especialistas decidían hacer se determinaba dependiendo de cada niño "ya sea de manera individual o sub grupal, ya va a depender el trabajo pues que se realiza, pero aparte se le está dando constantemente información a la maestra, generalmente de manera bimestral: esto se ha estado trabajando en el aula especial".

\subsubsection{Estrategias concretas de mediación: "Individualización de actividades, recursos e instrucción de contenidos"}

En la primaria casi siempre se trabajaban en el aula de apoyo aquellos contenidos que en la clase y en dinámica del aula el alumno no logró dominar. El maestro solicitaba al especialista que apoyara al alumno, de manera que algunas actividades del salón de clase eran retomadas mediante consignas simplificadas o bien, se trabajaba en el desarrollo de habilidades que especialistas y docentes consideran que podrían llevarle a alcanzar el nivel de aprendizaje esperado. Las actividades, como las interacciones implicadas en la estrategia, focalizaban la atención del especialista sobre el alumno afectado por la dificultad, generalmente no involucraban la participación de éste ni con sus pares ni con sus docentes.

EC. "Vamos a buscar en esta ilustración todas la imágenes que empiezan la letra que nos va diciendo el monito, si nos equivocamos, el mismo nos va diciendo, si acertamos pues nos va a felicitar, con esta flechita puedes ir escogiendo y señalando".

EC. "A ver con T. Tú me vas a ir diciendo de estas imágenes cual empieza con $\mathrm{T}$ ”.

Aa. "Tele".

EC. "Muy bien, entonces dale click aquí".

OB. Aa. Acciona el mouse de la PC y acierta.

EC. "Muy bien ahora con Ra, ¿Cuál empieza con Ra?".

Aa. "Radio".

EC. “¿Dónde está?, a ver dale click. Ahora, ¿sí escuchaste con qué? es K".

Aa. "Carta".

EC. "A ver no. Prueba con esta...".

Registro de intervención en Aula de Apoyo

EC.

Las consignas presentadas reflejaban mayor cercanía a contenidos curriculares, aunque en la pretensión por adaptarlas a necesidades específicas de los alumnos, tendían a ser simplificados o a adoptar una intención educativa a veces distinta de la que se producía en las aulas regulares. En el desarrollo de estas actividades, las interacciones de los especialistas tenían un carácter instruccional, directivo y afectivamente cálido.

PA. "Muy bien entonces fíjate bien: El, La, Los. Las" (dice, mostrándole los artículos en unas tarjetitas). 
Ao. "El, La, Los, Las" (repite los artículos que la especialista le ha mostrado).

PA. "No te lo digo para que te lo aprendas de memoria, sino para que sepas cuántos hay". PA. "Aquí te voy a dejar los cuatro para que escojas y veas cual debe ir".

PA. "El perico come semillas. Fíjate bien, ¿cual es que debes de escoger?".

Ob. El niño elige uno de los artículos entre los que la especialista le ha entregado. (EL).

PA. "Muy bien, ahora escríbelo".

Ob. Al tratar de escribir la oración el niño insiste con otros artículos que no corresponden al sustantivo, la maestra, opta por retirar los que no corresponden para evitar que se confunda y logre escribir la oración sin tratar de copiar otros y prestando más atención a lo que ella le dice.

PA. "Ella hace énfasis en el sonido de las silabas para que el niño comprenda lo que debe escribir".

Ao. “¡Ay qué hueva!”.

PA. “Ay, No digas eso, qué es eso, yo no sé que eso".

Registro de intervención aula de apoyo PA.

En otros casos la mediación de los especialistas se tradujo en una forma de asesoría o consultoría clínica con los padres de familia, los docentes y algunos alumnos.

PF. "Bueno... pero si... ya lo hemos estado llevando a su consulta, pero nos dijo el "paido" que si aprenden, que no hay escuelas especiales para ellos... no es para tanto, que si pues... deben tomar su medicamento y se controlan, a estos niños no hay que llevarlos a la escuela especial".

D. "Sí es cierto, pero la medicina no actúa en automático también hay algo que desde la casa debe hacerse, se necesita estructura y orden". PS. "Sí, por eso es muy importante que cuando se lleve las actividades a casa, se les dé cumplimiento, que ustedes vean que $\mathrm{AB}$ no sienta que por no venir ya... lo quitaron del problema y ya, porque entonces, eso para él es como un premio. Se trata de que se levante por la mañana y haga las actividades como si tuviera su jornada de clase...porque si no, pues ahí se va a estar en sus juegos, frente a la televisión y mientras nadie le diga nada... así va a seguir".

Registro interacción EUI.

Los profesionistas en la primaria no consideraban como recurso de mediación los espacios y el tiempo destinado institucionalmente a la actualización y capacitación. Cuando participaban de ello, lo hicieron por separado. Pese a que los contenidos previstos por los equipos de supervisión para cada ciclo escolar, tenían que ver básicamente con aspectos teórico-metodológicos de una reforma educativa que, como ya hemos visto, les era común e implicaba transformaciones para ambas modalidades de servicio (especial y regular), solo uno de nuestros informantes expresó interés por incidir con y para los docentes en ese sentido.

\subsubsection{Las formas de organizar las prácticas de mediación: "Dispositivos alternos que no demandan colaboración"}

Los profesionistas señalaron que las acciones a desarrollar se definen en función de las consignas institucionales consideradas como prioridad en cada ciclo escolar, de manera que para los profesores lo prioritario era contribuir al desarrollo de competencias (cognitivas, formativas y tecnológicas) mediante el abordaje de temas transversales a todas las asignaturas, en tanto que para los especialistas lo prioritario era garantizar que los alumnos en condición de vulnerabilidad se beneficiaran de eso mismo. Para conseguirlo, especialistas y profesores solían a hacerlo desde sus propios espacios.

“...como que la estructura de educación regular no está trabajando de manera coordinada con educación especial...si se conjuntaran... o la educación especial fuera parte de la educación regular, si ustedes pertenecieran a la misma zona escolar o al mismo sector, obviamente, con su especialización pero que pertenecieran a la misma estructura y que no tuvieran sus propios directivos en otra estructura paralela... creo que eso ayudaría...” (Entrevista DR). 
El apoyo especial a los alumnos básicamente se producía en paralelo, no propiciaba la colaboración y por tanto no implicaba el consenso y la organización anticipada de acciones en conjunto, aunque la intención, afirmaron los especialistas, era trabajar de manera "interdisciplinaria".

En función de ello, la planeación en todo caso se hacía necesaria solo al interior del equipo, donde el eje articulador descansaba en el especialista en problemas de aprendizaje por ser quien tenía mayor contacto y disponía de mayor tiempo en la escuela, de manera que los otros integrantes tendían a organizar sus actividades a partir de las prioridades que éste señalaba, basándose en las necesidades y demandas identificadas con los profesores al interior de las aulas y escuelas.

Las formas en que organizaron sus prácticas, la mayor parte de las veces, privilegiaron acciones de carácter correctivo y emergente debido principalmente a que los especialistas disponían de tiempos y oportunidades escasos para discutir y negociar propósitos, prioridades y estrategias de intervención entre el equipo y los profesores o entre ellos mismos.

“...hemos luchado por revisarlo en los consejos técnicos...porque se hagan reuniones en donde se pueda revisar sobre estos casos colegiadamente, e inclusive para invitar a expertos que nos ofrezcan información o deriven estrategias pero desgraciadamente tenemos resistencias...tenemos resistencias por la misma estructura educativa, nosotros por ejemplo, tenemos una limitante en cuanto al tiempo para pasar información así básica en los consejos técnicos..." (Entrevista DR2).

La manera en que los profesionistas se organizaban para responder y participar ante lo diverso, reflejaba un escaso nivel de consciencia respecto al compromiso que tenían en común y respecto a la relevancia de unificar sus esfuerzos para realizarla, además de la mínima disposición hacia la previsión conjunta en cuanto a tiempos, espacios, roles y actividades necesarias para colaborar y apoyarse entre sí.

\subsubsection{Los efectos sobre procesos incluyentes: "Apoyos que marginan y postergan el logro y la participación"}

Estas particulares formas de proceder por parte de los especialistas escasamente contribuyeron a transformar las dinámicas en el contexto de sus escuelas, en primer término, la atención a la diversidad en muchos casos fue considerada como una cuestión de elección, de manera que algunos profesores en la primaria creyeron que tenían la opción de aceptar o rechazar a los alumnos en condición de vulnerabilidad, particularmente a aquellos que presentaban alguna condición de discapacidad y que, involucrarse o no hacerlo, comprometerse o no con sus aprendizajes, dependía más bien de los intereses promocionales de cada uno.

MR (Paty). "No yo lo que digo, (de presentar los dos) es por asegurar el puntaje".

PA. "Las personas que te reciben los documentos en carrera, como te digo, no te van a evaluar ellas, lo que lo asegura es el trabajo que vayamos haciendo a lo largo del ciclo".

MR (Nn). "Por eso es que si ustedes lo avalan ya no hay vuelta atrás ¿verdad?”.

DR. "Ustedes ya saben cómo estamos con esto de los tiempos ¿verdad?, pero la intención de las maestras ${ }^{4}$ es apoyar el trabajo para que ustedes tengan los puntos de carrera, porque se lo merecen, ya con el simple hecho de recibir a los niños y atenderlos en el salón..." (Registro de Interacción EUI).

En el caso de los alumnos, las actividades o contenidos tuvieron un efecto marginal pues según los especialistas nos comparten "hay contenidos que es mejor recortar porque momentáneamente no les resultaban funcionales a los niños". Por ejemplo: la escritura en números romanos o chinos, y aunque estos aspectos como sean retomados en la evaluación, sólo son considerados a manera de ensayo, "el grado de exigencia es menor para ellos, lo cual ha quedado asentado en sus propuestas curriculares". Otras ocasiones, sus estrategias

4. De USAER. 
terminaron por adquirir un carácter claramente excluyente.

“...la maestra ya no sabe qué hacer y optamos primero por recortar la jornada, para que asistiera solo cuando puede estar tranquilo y también para mantener el orden dentro del salón. Pero debido a esto último... por eso se pensó que el niño nada más viniera los jueves, ese día que viene darle las actividades a los padres de familia para que las trabajen en casa, que el niño... eso sí, que acuda a las evaluaciones y...bueno se trata de no afectarlo en sus calificaciones para que no vaya a tener problemas más adelante...” (Interacción entre agentes educativos y familias).

Por otra parte, en los salones de clase, los docentes optaron por asignar a los alumnos en condición de vulnerabilidad tareas distintas a las del resto de los alumnos. Solían ser evaluados en momentos, espacios y bajo criterios distintos.

MR. “Ahora sí, pueden empezar el examen, en silencio, es un examen... a los que les faltó, esperen un momento, fueron a traernos unas copias".

Ob. Alrededor de las diez, la especialista pasa al aula de clases a recoger a Adán y Aranza para aplicarles a ellos en lo individual la evaluación. En una interacción más directa, la especialista en PA. es quien aplica para ellos la evaluación con menos reactivos o aportando pistas a su realización (Interacción en aula regular EU2).

$\mathrm{Al}$ igual que la mayor parte de las actividades de apoyo, las evaluaciones a los alumnos eran aplicadas por los especialistas en el aula de apoyo, debido a que en el salón de clase regular estos alumnos no logran avanzar al ritmo de los demás y porque los docentes no disponían de oportunidad y tiempo para centrarse sólo en su ejecución.

\subsubsection{Las interacciones y las formas de participación: "Ausencia de implicación y compromiso que inhibe condiciones de receptividad"}

En el compromiso de incluir a los alumnos quienes más se involucraban eran los especialistas. La mayor parte de los profesores, bajo el argumento de no contar con capacitación para ello, solían delegar en el especialista la responsabilidad por los aprendizajes de los alumnos a incluir de manera que, en la organización y previsión de sus actividades, generalmente no consideraban o preveían los ajustes para éstos. De ahí que la participación de estos alumnos en tareas académicas solía postergarse hasta que dichos ajustes fueran asumidos por el equipo de apoyo a partir de lo que sus integrantes consideraban pertinente.

“...tenemos la maestra especialista en lenguaje, la psicóloga y la maestra de éste...se de... que si sabe de esto... este son las únicas que están aquí para... resolver este tipo de situaciones, pero cuando no están tenemos que canalizarlos...”.

“...el maestro sabe que hay USAER y también quiere que la USAER asuma la responsabilidad de la intervención...” (Entrevista DP2).

“...que los del equipo estén dentro del salón, acompañando a los niños y ayudándolos, que les dejen su cuaderno aparte en el que ellos [los alumnos a incluir] tienen que trabajar, eso sí sería mucha ayuda...” (Entrevista MRP2-3).

En el plano individual, algunos profesionistas admitieron la necesidad de involucrarse o colaborar juntos en el proceso, pero ya en las dinámicas grupales que se producían al interior de las escuelas, la mayor parte de los profesores mostraban pasividad, apatía y hasta renuencia en algunos casos.

“...hay otros que desde que les decimos te vas a encargar de tal grupo donde está fulanito... te dicen cruz, cruz, o sea... no yo... es... por favor cámbiame no...” (Entrevista DRP2). 
Conforme logramos apreciar en sus interacciones, los profesores que se involucraron con las necesidades especiales de los alumnos fueron pocos, quizá porque buena parte de ellos tendían a experimentar como falta de apoyo aquellas acciones de los especialistas que no coincidían con sus expectativas del servicio. Los especialistas percibieron como renuencia la ausencia de respuesta frente a lo que los docentes no lograban comprender, a pesar de que profesores y especialistas participaban de procesos semejantes de actualización.

"Yo no sé lo que la USAER haga, a veces me doy cuenta que les mandan un recadito a los papás para trabajar con ellos, o decirles no sé qué (...) Ahora como le digo uno casi ni las ve, además a cada rato las cambian, la que más da la cara es esta niña la de PA, pero con las otras, casi ni sabe uno cuando vienen o que harán, eso es lo que le puedo decir..." (Entrevista MPR 3).

Pese a ello, los actores escasamente mostraron iniciativas para el intercambio, la expresión y gestión de conflictos que les permitiera establecer consenso y colaboración, aunque algunos especialistas y docentes en lo individual si consideraban la sensibilización y la socialización como una de las tareas pendientes en las escuelas.

"La sensibilización es básica, no podemos pensar en una reunión de dos horas con los docentes y que de ahí ya la inclusión se dé mágicamente, hay que hacer una sensibilización constante, hay que involucrar más al docente, hacerle saber de la planeación conjunta, interviniendo más en su evaluación y... no interviniendo como tal, sino que se haga un trabajo conjunto" (Entrevista EPAI).

Cuando los apoyos fluyeron del especialista hacia los profesores, éstos parecían interpretarlos más como prescripciones distantes a sus demandas, de manera que solían desconocer qué, cómo y porqué se ofrecía al alumno una determinada propuesta de atención.

“... pues esperaría que los niños, si traen problemas no avanzan dentro de un grupo, uno no puede tener tiempo, o me dedico al niño que necesita esa ayuda, a ese apoyo, o me dedico a los 30 que tengo, que están necesitando de mí, que tienen las mismas necesidades, quisiera quizás, que se...que fuera una persona a mi grupo, que observara, que me ayudara, que se lo trajera en un momento...” (Entrevista MRI).

\section{Reflexiones finales}

Las interpretaciones de los participantes recuperadas de los hallazgos permiten comprender que los significados desarrollados en este contexto respecto a la inclusión y las formas de operarla, presentan distintos matices. Atrae especialmente la atención el hecho de que, al interior de ambas escuelas, el compromiso por propiciar el aprendizaje y erradicar la segregación, predomine en mayor medida, actuaciones y esfuerzos individuales, en contraste a lo que se propone desde las premisas incluyentes o los modelos de enseñanza mediacional.

Estas formas de intervención al interior de las escuelas, representan una invitación abierta a reflexionar en torno a la interpretación que especialistas y docentes han hecho respecto al fin último de la inclusión educativa, el sentido en que habrían de orientar su mediación y de los aspectos que habrían de privilegiarse en términos de aprendizaje y participación. Desde la evidencia que los datos aportan, los esfuerzos y participaciones que despliegan no siempre han podido concretarse en acciones que conduzcan en la dirección que idealmente han sido planteadas.

Los rasgos que caracterizan a los procesos incluyentes en las escuelas han sido objeto de análisis a través de investigaciones y trabajos realizados en otros contextos (INCLUDED, 2OII) a partir de los cuales se ha demostrado ya el efecto positivo que se logra, el tomar acuerdos y orientar las acciones en una misma 
dirección. En este sentido, resulta de gran ayuda la creación de espacios y el establecimiento de relaciones plurales entre los actores, donde se analicen las situaciones y prácticas.

Mediar en las escuelas para que la inclusión suceda implica que los involucrados en el proceso vuelvan la mirada sobre lo que hacen, reconozcan en ello las situaciones que les problematizan, e identifiquen en sus dinámicas de interacción y participación elementos que les impulsen a fortalecerse como comunidades incluyentes.

Es importante desarrollar primero, conceptos que como equipo les lleven a aclarar que justo por tratarse de la inclusión al ámbito del conocimiento (y no otro) lo que habría que mediar es el aprendizaje a lo largo de la vida. En este proceso, la construcción colaborativa de un nuevo sentido, la participación activa de todos y la horizontalidad son aspectos por demás importantes. Desde las distintas funciones que cada uno de los actores desempeña habrá conocimientos, destrezas, valores, y actitudes que podrían aportar para construir significados compartidos respecto a los rasgos deseables en esa mediación que contribuiría a garantizar la inclusión. Lo relevante en este caso, como Flecha (20I3) señala, es aprender conjuntamente unos de otros, en un espacio formativo informal, donde la clave de éxito descansa en lograr acuerdo respecto a lo que representa un beneficio común a todos.

Es importante configurar escenarios propicios para el aprendizaje en común donde cada uno de los agentes de mediación se reconoce a sí mismo como un aprendiz (Taylor et al., 2012) y contribuye al aprendizaje permanente mediante la apropiación participativa de conceptos, de métodos, de procedimientos y de herramientas que contrarresten la reproducción irreflexiva de inercias y, conforme estos autores nos muestran, contribuyan a producir y hacerse de mayor conocimiento, modificar actitudes y hacerse de técnicas renovadas.

Es necesario reconocer que la mediación del especialista habrá de operar en dos planos y que implica comprometer la participación activa desde dos distintas posiciones. Por un lado habría que comprometer las acciones con el apoyo pedagógico personal y ajustado que promueva el logro de aprendizajes significativo de los alumnos pero, por otra parte, habría que acompañar y colaborar activamente en la cogeneración de condiciones que garanticen que se produzca la equidad y participación plena con otros.

Lo anterior significa que los agentes educativos a la vez que realizan la función mediadora frente a sus estudiantes, participen simultáneamente como aprendices activos, que se involucren de manera activa y responsable en acompañamiento a colegas y pares. En este sentido, es importante que predominen los intereses colectivos sobre los individuales y se genere un clima de apoyo mutuo.

Una última condición es que los integrantes de la comunidad escolar se reconozcan y asuman como tales y que al completar los procesos participen en un ejercicio metacognitivo y traten de generar condiciones que propicien la reflexión sobre las acciones que desarrollan, recuperar y analizar sus prácticas, contrastarlas con las que se producen al exterior desde otros espacios, beneficiarse con los aportes de la teoría o fortalecerlas a partir de su análisis y contraste con experiencias reportadas en la investigación reciente. 


\section{Referencias bibliográficas}

Ainscow, M. et al. (2009): "Promoviendo la equidad en educación”. Revista de Investigación en Educación, I I (3): 44-56.

Blanco, G. (20I I): "La inclusión educativa en América Latina y el Caribe". Revista CEE Participación Educativa, I 8: 46-59.

Carvalho, E. (2008): "Políticas de la educación especial”. Revista Internacional de Psicología y Educación, IO (I): I 5-28.

Flecha, R. (2013): Caminando hacia una educación más justa: Políticas de inclusión. Madrid: Encuentro Educared 2012-2013 (en linea).

Garnique, C. et al. (2012): "Educación básica e inclusión: un estudio de representaciones sociales”. Magis. Revista Internacional de Investigación en Educación, 4 (9): 577-593.

Gergen, K. (2010): Talks about Social Construccionism (en línea). <http://www. taosinstitute.net/theoretical-background>, acceso 20 de Octubre de 2015.

Glazzard, J. (20II): "Perceptions of the barriers to effective inclusion in one primary school: voices of teachers and teaching assistants". British Journal of Learning Support, 26 (2): 56-63.

INCLUDED (20I I): Actuaciones de éxito en las escuelas europeas. Madrid: Instituto de Formación del Profesorado, Investigación e Innovación Educativa (IFIIE). Ministerio de Educación.

López, T. (2009): "La inclusión educativa de los alumnos con discapacidades graves y permanentes en la Unión Europea”. RELIEVE, I 5 (I): I-2O.

Martínez, J. M. (I994): La mediación en el proceso de aprendizaje. Madrid: Bruño.

Montesinos, M. (20I2): "Claves para pensar la diversidad cultural y la inclusión educativa”. Educación, Lenguaje y Sociedad, 9 (9): 20I$2 \mathrm{I} 8$.
Newman, D. et al. (1998): La zona de construcción del conocimiento. Ministerio de educación y cultura. Madrid: Ediciones Morata.

Ossa, C. et al. (2014): "Cultura y liderazgo escolar: factores claves para el desarrollo de la inclusión educativa". Revista Electrónica Actualidades Investigativas en Educación, I4 (3): I-23.

Padilla, M. (20II): "Inclusión educativa de personas con discapacidad". Revista Colombiana de Psiquiatría, 40 (4): 670-699.

Palos, U. et al. (2014): "Referentes teóricos en un estudio sobre significados y prácticas de mediación desde la educación especial”. Revista Intercontinental de Psicología y Educación, I6 (I): 95-II 5 .

Secretaría de Educación Pública, SEP (20I I): Modelo de Atención de los servicios de educación especial. México: SEP.

Taylor, M. et al. (2012): Handbook for facilitators. Learning to learn in practice. Vilnius (Lithuania): Firidias. Learning to Learn Project European Network UNIQUE.

Torres, G. (20I I): "Psique: La inclusión educativa, la necesidad de transformación ante nuevas realidades". Boletín Científico Sapiens Research, I (I): I I-I 5 .

Unesco (2007): Taller internacional sobre inclusión educativa América Latina - Regiones cono sur $y$ andina (en línea). <http://www.ibe.unesco. org/fileadamin/user_upload/COPs/News_ documents/2007/0709BuenosAires/Actividad_ prep_ES.pdf $>$, acceso 20 de agosto de 2015 .

Vigotsky, L. (1995): Funciones psíquicas superiores (Vol. III), Madrid: Visor.

Wertsch, J. (200I). Vygotsky y la función social de la mente, Barcelona: Paidós. 



\section{TRIBUNAS}

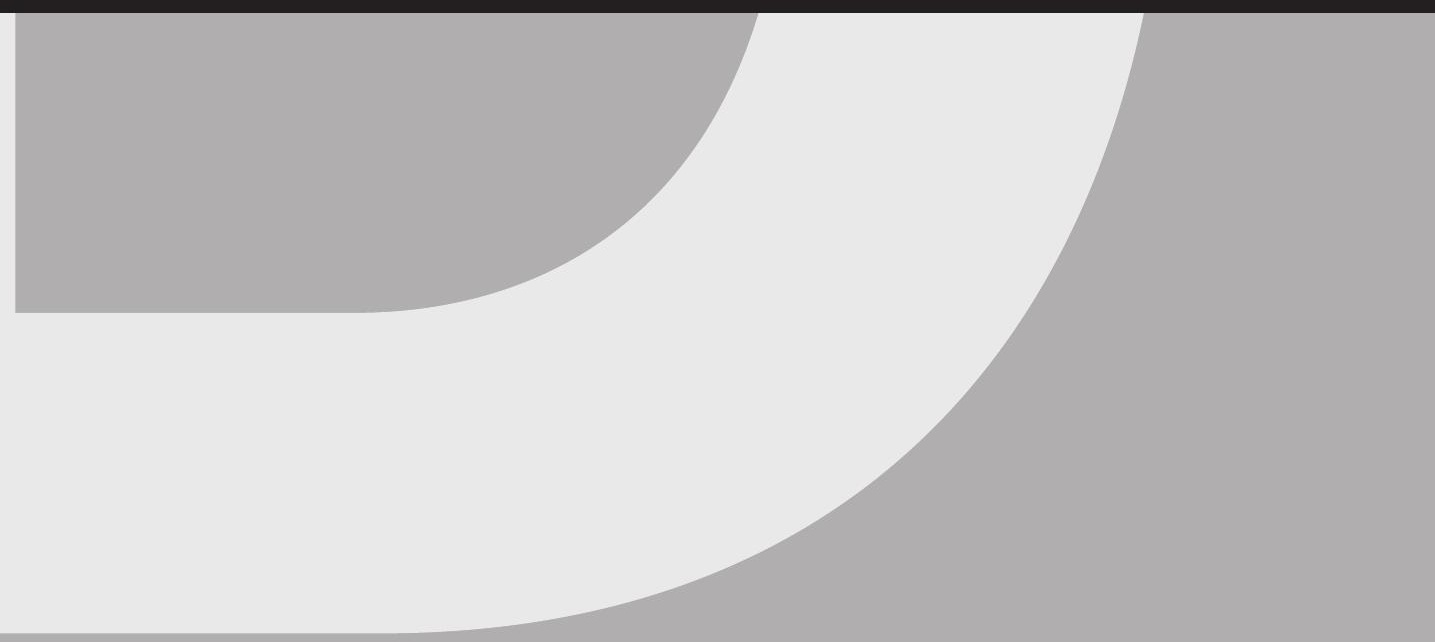



Personas con Trastorno del Espectro del Autismo con necesidades intensas y generalizadas de apoyo: estrategias para mejorar su calidad de vida

\section{People with autism spectrum disorder with the need for intense and widespread support: strategies to improve their quality of life}

\section{Palabras clave}

TEA, necesidades intensas y generalizadas de apoyo, estrategias, calidad de vida.

\section{Keywords}

ASD, needs for intense and widespread support, strategies, quality of life.

\section{Introducción}

Los Trastornos del Espectro del Autismo (TEA) son trastornos complejos con base biológica, que afectan al desarrollo del sistema nervioso y al funcionamiento cerebral, especialmente en relación al procesamiento de la información que proviene de los estímulos sociales (Rutter, 20II). Se trata por tanto de una discapacidad permanente del desarrollo que, "si bien a menudo se asocia con discapacidad intelectual, tiene entidad propia y unas características específicas” (Cuesta, 2013: 176). Ahora bien, es necesario tener en cuenta la amplia heterogeneidad que caracteriza a los TEA en relación a sus manifestaciones clínicas, y a los procesos cognitivos, habilidades personales (comunicativas, sociales, adaptativas, etc.), intereses, etc. de las personas que los presentan.

La mejora continua de la calidad de vida constituye una condición necesaria para un desarrollo pleno y satisfactorio de cualquier persona. Es por lo tanto un factor esencial a considerar en los apoyos y servicios que desarrollan las organizaciones vinculadas a las personas con TEA. En este sentido, proporcionar herramientas para
Ruth Vidriales Fernández <ruth.vidriales@autismo.org.es>

Confederación Autismo España. Licenciada en Psicología y responsable del área de asesoramiento técnico de Autismo España desde 2005

\section{José Luis Cuesta Gómez} <jlcgomez@ubu.es>

Universidad de Burgos

\section{Marta Plaza Sanz}

<marta.plaza@autismo.org.es>

Confederación Autismo España

\section{Cristina Hernández Layna}

<cristina.hernandez@autismo.org. es>

Confederación Autismo España

Para citar:

Vidriales, R. et al. (2015): "Personas con Trastorno del Espectro del Autismo con necesidades intensas y generalizadas de apoyo: estrategias para mejorar su calidad de vida", Revista Española de Discapacidad, 3 (2): IOI-II5.

Doi: <http://dx.doi.org/IO.5569/23405 I04.03.02.06> 
realizar adaptaciones e interpretaciones de las diferentes prácticas de intervención y apoyo de manera que se orienten hacia el logro de metas y objetivos personales, es clave para promover la participación de las personas como agentes activos de sus vidas y disfrutar de manera plena y satisfactoria de una calidad de vida óptima (OMS, 2OII).

Sin embargo, hasta el momento, los avances para incorporar los intereses y preferencias individuales de las personas con TEA que presentan necesidades intensas y generalizadas de apoyo han sido limitados y constituyen un reto difícil de abordar. En primer lugar, existen dificultades significativas para el desarrollo de los procesos de consulta, debido en parte a las propias características cognitivas y comunicativas de la persona y también a la ausencia o escaso desarrollo de facilitadores o recursos que promuevan la superación de las barreras existentes. Así, muchas de las personas con TEA que presentan necesidades intensas de apoyo no disponen de sistemas funcionales de comunicación o los emplean de manera restringida. Esto hace que en muchas ocasiones se asuma, erróneamente, que la persona no tiene nada que opinar respecto a su calidad de vida (Involve me, 20II).

El segundo motivo a señalar es el escaso desarrollo de estrategias e instrumentos dirigidos a la evaluación y el consenso en la comunidad profesional en relación a los procedimientos a seguir. De esta manera es posible afirmar que incluir la perspectiva de las personas que forman parte de este colectivo, y así poder considerarla en la toma de decisiones significativas sobre su calidad de vida, es todavía un reto pendiente de resolver (Renty y Roeyers, 2006).

En este sentido, y con la finalidad de contribuir a este ámbito de desarrollo, Autismo España ${ }^{\mathrm{I}}$ inició en 20 I I un proyecto que pretendía profundizar

I. Es una confederación de ámbito estatal que representa a 74 entidades de acción social promovidas por familiares de personas con TEA. El trabajo que se desarrolla es por y para las personas con TEA en la promoción del ejercicio efectivo de sus derechos y en el fortalecimiento del movimiento asociativo del autismo en España. en los elementos relevantes para la calidad de vida de las personas con TEA y en los procesos que las entidades vinculadas al colectivo pueden desarrollar para fomentarla de manera efectiva. A continuación se presentan los resultados de una de las líneas de desarrollo de dicho proyecto, dirigido especialmente a las personas con TEA con mayores necesidades de apoyo en las organizaciones. Éste ha sido desarrollado por una red de profesionales expertos vinculados a las entidades de Autismo España y ha contado con la participación de las propias personas con TEA que reciben apoyos en las mismas.

El trabajo que se describe a continuación tiene dos objetivos. El primero se dirige a facilitar la participación de las personas con TEA con necesidades intensas de apoyo, en los procesos de consulta sobre aspectos significativos para su calidad de vida y también en la toma de decisiones sobre la misma. Este objetivo se relaciona con la promoción de buenas prácticas derivadas de la experiencia, la ética y el consenso profesional. En segundo lugar, se pretende suscitar la reflexión de los y las agentes implicados en los procesos de evaluación y consulta a las personas con TEA, concernientes a los procesos de participación y a la mejora de sus propias prácticas profesionales.

Todas las voces han de ser escuchadas

En un marco de avance en el ejercicio efectivo de los derechos humanos, coherente con el reconocimiento de los mismos en tratados internacionales ${ }^{2}$, una de las principales preocupaciones de las entidades vinculadas a las personas con TEA debe dirigirse a garantizar su derecho a ser consultadas, escuchadas y a que sus preferencias e intereses guíen todos los procesos de toma de decisiones sobre sus vidas.

2. En concreto nos referimos a la Convención Internacional de Derechos de las Personas con Discapacidad aprobada por la Asamblea General de las Naciones Unidas el I 3 de diciembre de 2006. 
Así, las prácticas profesionales y la dinámica de funcionamiento de las organizaciones que facilitan apoyos para el colectivo, han de orientarse necesariamente a fomentar iniciativas que hagan efectivo este derecho, promoviendo de manera activa su inclusión social, su participación ciudadana, y en definitiva su calidad de vida.

En términos generales, la apuesta de evaluar y mejorar los apoyos teniendo en cuenta en el mayor grado posible la perspectiva de las personas con TEA (Whemeyer y Schalock, 200I), constituye un instrumento esencial para lograr estos objetivos, y mejorar su desarrollo personal, aprendizaje e inclusión social. Para conseguirlo, resulta fundamental orientar las prácticas organizacionales y profesionales hacia el logro de metas personales significativas y diferenciadas para cada persona con TEA.

Como se ha comentado anteriormente, las propias características nucleares de los TEA (Plimley, 2007) y otros factores asociados, como la presencia de discapacidad intelectual o dificultades significativas de comunicación, hacen especialmente complejo y difícil estos procesos de recogida de información sobre sus preferencias y percepciones. Sin embargo, tal y como se pone de manifiesto en este trabajo, es posible el desarrollo o mejora de herramientas y procedimientos de actuación que favorezcan la inclusión del punto de vista y las necesidades de la persona con TEA en los procesos de toma de decisiones sobre sus vidas.

Para ello es necesario que el proceso de evaluación y consulta se realice de manera sistemática, integral y centrada en las necesidades de la persona. Asimismo, es imprescindible la implicación de las redes personales de apoyo que resultan significativas para su vida, como familiares y profesionales, $\mathrm{u}$ otras que puedan resultar relevantes (Schalock et al., 2009). En este sentido, es necesario el establecimiento de un procedimiento unificado que integre todos los puntos de vista y la implementación de una metodología que faciliten el proceso. Estas herramientas y las estrategias diseñadas para su desarrollo se describirán a continuación.

\section{Aproximaciones metodológicas}

Tal y como se ha expuesto con anterioridad, el contenido de este proyecto responde a la necesidad de impulsar estrategias que den voz a las personas con TEA que encuentran mayores dificultades en los procesos de participación y consulta sobre aspectos significativos de sus vidas. Este es el objetivo que ha articulado todo el proceso de trabajo y que ha orientado las decisiones metodológicas sobre el mismo.

En este sentido, la necesidad de consultar y evaluar la calidad de vida implica tener en cuenta las necesidades de todas las personas, independientemente de su desarrollo o características cognitivas y de las barreras que se puedan anticipar en el proceso de consulta.

En el momento de iniciarse este proyecto no se contaba con instrumentos estandarizados que evaluaran la percepción de la calidad de vida de las personas con TEA específicamente, si bien recientemente se ha diseñado la Escala San Martín para personas con discapacidades significativas (Verdugo et al. 20I4). Por esta razón, y debido a la necesidad de tomar un referente común para el desarrollo de las actuaciones, se optó por la aplicación de tres cuestionarios validados que sirvieran como referencia, teniéndose en cuenta diferentes grupos de edad. Las herramientas fueron:

- Cuestionario de evaluación de la calidad de vida en la infancia, CCVI (Sabeh, N. et al., 2009) $)^{3}$

- Cuestionario de evaluación de la calidad de vida de alumnos adolescentes, CCVA (Gómez-Vela, M. y Verdugo, M. A., 2009) ${ }^{4}$

- Cuestionario mapa de importancia y satisfacción, ISMAP5

\footnotetext{
3. Dirigido a niños y niñas en edades comprendidas entre los 8 a II años.

4. Dirigido a adolescentes en edades comprendidas entre los I 2 a I 8 años, tanto si tienen necesidades educativas especiales como si no.

5. Dirigido a personas adultas, a partir de los I 8 años.
} 
El objetivo de utilizar estos instrumentos no era el propio análisis de los datos que pudieran recogerse de su aplicación, sino que sobre estos cuestionarios se propusieran las adaptaciones que se considerasen oportunas para favorecer la comprensión por parte de la persona de las preguntas sobre su calidad de vida y su participación en el proceso. Para ello, se solicitó a los y las profesionales que recogieran información cualitativa en un protocolo común denominado "descripción de los procedimientos de entrevista/aplicación del cuestionario" de manera que fuera posible identificar las adaptaciones que generaban en el proceso de administración.

Uno de los pilares fundamentales del estudio ha sido el desarrollo en base a un enfoque de aprendizaje y con una metodología participativa. Por ello, el protocolo fue diseñado por la Red de Calidad de Vida de Autismo España, integrada por I 3 organizaciones y I 59 profesionales, y posteriormente validado por un equipo de personas expertas ajenas a la Red.

Para la aplicación del cuestionario se hizo una selección de la muestra no probabilística en las entidades participantes, considerando la representación de la heterogeneidad que caracteriza a los TEA.

Para la selección de las personas con TEA participantes en la administración del protocolo se tuvieron en cuenta dos aspectos. Por un lado, se consideraron las características de comunicación y lenguaje, incorporando tanto a personas que presentaran habilidades lingüísticas fluidas como a otras que emplearan sistemas alternativos o aumentativos de comunicación. Por otro lado, relacionado con el funcionamiento intelectual, se contó tanto con la participación de personas con TEA que presentaban una discapacidad intelectual asociada como sin ella.

Asimismo, se consideró la cuestión de sexo de manera proporcionada a como se representa en el colectivo ( 4 hombres por I mujer). Así, el total de la muestra estuvo compuesta por 45 personas con TEA (34 hombres y I I mujeres).
La distribución por grupos de edades ${ }^{6}$ se desagrega de la siguiente manera:

- Infancia (6-I2 años): 7 niños y 4 niñas

- Adolescencia (I 3 -I7 años): 9 chicos y 3 chicas

- Adultez (más de I 8 años): I 8 hombres y 4 mujeres

\section{La construcción de una herramienta para favorecer la evaluación de la calidad de vida de las personas con TEA}

El proceso para el consenso de la metodología y herramientas que pueden contribuir a favorecer la participación de las personas con TEA en los procesos de evaluación sobre su calidad de vida se desarrolló en varias fases. A continuación se presenta un desarrollo de las mismas y de las acciones realizadas en cada una de ellas.

Tal y como se ha indicado anteriormente, la aplicación del protocolo tenía como finalidad la recogida de información sobre distintos aspectos del procedimiento empleado para fomentar la participación de la persona con TEA en la evaluación de su calidad de vida: adaptaciones en el tiempo y espacio de administración, apoyos a la comunicación, motivación, etc.

Una vez que concluyó la administración y se codificó la información obtenida, se procedió al análisis de los contenidos aportados, identificando y definiendo categorías y validando las mismas.

Estas categorías recogen recomendaciones unificadas en cuatro instrumentos. En ellos se identifican las principales barreras que surgen en los procesos de participación así como los elementos que pueden facilitarlos, y también se hacen recomendaciones para la evaluación de la calidad de vida de la persona con TEA.

6. Las edades están comprendidas entre los 6 hasta los 45 años. No se ha podido optar a la selección de la muestra en proceso de envejecimiento. 


\begin{tabular}{|c|c|}
\hline \multicolumn{2}{|c|}{ PROCESO DE CONSTRUCCIÓN DE LA HERRAMIENTA } \\
\hline FASES & ACCIONES REALIZADAS \\
\hline 1. RECOGIDA DE DATOS & $\begin{array}{l}\text { - Adapatación de los cuestionarios } \\
\text { - Completar los protocolos iniciales }\end{array}$ \\
\hline $\begin{array}{l}\text { 2. ORGANIZACIÓN DE LA } \\
\text { INFORMACIÓN }\end{array}$ & - Clasificación y ordenación de la información \\
\hline 3. ANÁLISIS DE LA INFORMACIÓN & $\begin{array}{l}\text { - Análisis cualitativo de la información } \\
\text { - Transcripciones de la información recogida a través de los } \\
\text { protocolos a una base de datos } \\
\text { - Organización de la información en categorías de primer y } \\
\text { segundo orden }\end{array}$ \\
\hline $\begin{array}{l}\text { 4. VALIDACIÓN DE LAS CATEGORÍAS } \\
\text { DE PRIMER Y SEGUNDO ORDEN }\end{array}$ & $\begin{array}{l}\text { Reunión presencial de doce personas expertas para validar } \\
\text { la información organizada en categorías de primer y segundo } \\
\text { orden }\end{array}$ \\
\hline 5. REVISIÓN DE LAS CATEGORÍAS & $\begin{array}{l}\text { - Realización de las modificaciones sugeridas por el grupo de } \\
\text { personas expertas } \\
\text { - Creación de un único archivo llamado "adaptaciones } \\
\text { generales" } \\
\text { - Creación de una dimensión denominada "procedimiento } \\
\text { indirecto" }\end{array}$ \\
\hline 6. REVALIDACIÓN DE LAS CATEGORÍAS & $\begin{array}{l}\text { - Validación a través de la técnica Delphi el archivo } \\
\text { "adaptaciones generales" por el grupo de personas expertas } \\
\text { - Organización de la información en tres dimensiones: } \\
\text { evaluación directa, barreras encontradas en el procedimiento } \\
\text { de evaluación y procedimiento indirecto }\end{array}$ \\
\hline 7. RESULTADOS & $\begin{array}{l}\text { - Valoración del grado de importancia de cada recomendación } \\
\text { o ítem por el grupo de personas expertas } \\
\text { - Organización de la información de acuerdo a tres grados de } \\
\text { importancia } \\
\text { - Mejorar la redacción de los ítems } \\
\text { - Creación de dimensiones: evaluación directa, evaluación } \\
\text { indirecta, facilitadores para el desarrollo de la evaluación y las } \\
\text { barreras para la participación de la persona en la evaluación }\end{array}$ \\
\hline
\end{tabular}

Fuente: elaboración propia.

Los cuatro instrumentos elaborados son:

- Procedimiento para la evaluación directa de la calidad de vida (realizada cuando la persona con TEA participa en alguna medida en el proceso de evaluación con los apoyos que requiera para ello).

- Procedimiento para la evaluación indirecta de la calidad de vida (realizada cuando la participación de la persona con TEA no resulta posible y es necesario desarrollar procedimientos alternativos para garantizar la inclusión de su percepción personal).
- Facilitadores para el desarrollo de la evaluación.

- Barreras para la participación de la persona en la evaluación.

Asimismo, en el caso de los procedimientos directos e indirectos de evaluación, se priorizó la relevancia de las estrategias a desarrollar, distinguiéndose entre imprescindible, necesaria y conveniente.

En cuanto a los facilitadores y las barreras, se diferenciaron en base al nivel de interferencia 
o apoyo que podrían proporcionar, distinguiéndose entre muy significativa, significativa y moderada.

\section{Descripción de los procedimientos de evaluación y consulta a las personas con TEA}

Una de las principales premisas antes de poner en marcha cualquier proceso de consulta o evaluación es que es necesario movilizar todos los recursos y herramientas disponibles para involucrar activamente a la persona con TEA en el mismo, procurando favorecer su participación como primer objetivo independientemente de sus características personales o de la intensidad de sus necesidades.

Una vez que se ha intentado sin éxito, o se han agotado las opciones y recursos para favorecer la participación, es cuando puede resultar recomendable optar por el procedimiento indirecto de evaluación. En ningún caso éste debería plantearse como primera opción de manera automática, ya que los protocolos elaborados no recogen ni agotan las posibles adaptaciones que se puedan generar con el objetivo de favorecer la participación de la persona con TEA. El ejercicio de innovación y desarrollo de nuevas estrategias siempre puede resultar enriquecedor para la práctica profesional, por lo que se recomienda su incorporación como buena práctica interna en cualquier organización que pretenda mejorar la calidad de vida de las personas a las que facilita apoyos.

\section{Procedimiento de evaluación directa}

A continuación se detallan los distintos elementos que han de guiar el proceso de participación de la persona con TEA.

En primer lugar, resulta recomendable el desarrollo de actuaciones para generar aprendizajes previos a la consulta y para establecer las condiciones (ambientales, temporales, personales...) óptimas para su realización. En este sentido, se incorporan recomendaciones sobre la persona/s más adecuadas para llevar a cabo la evaluación, el lugar o el momento más apropiado para su desarrollo.

En segundo lugar, la evaluación de la calidad de vida ha de considerar distintos aspectos antes de cumplimentar el instrumento de recogida de información, durante el propio proceso y de manera posterior a su finalización. Por último, puede ser necesaria la adaptación de los propios materiales a utilizar. Estos elementos se recogen de manera gráfica a continuación. 
Figura 1. Procedimiento directo. Acciones previas a la evaluación

\section{ACCIONES PREVIAS A LA EVALUACIÓN}

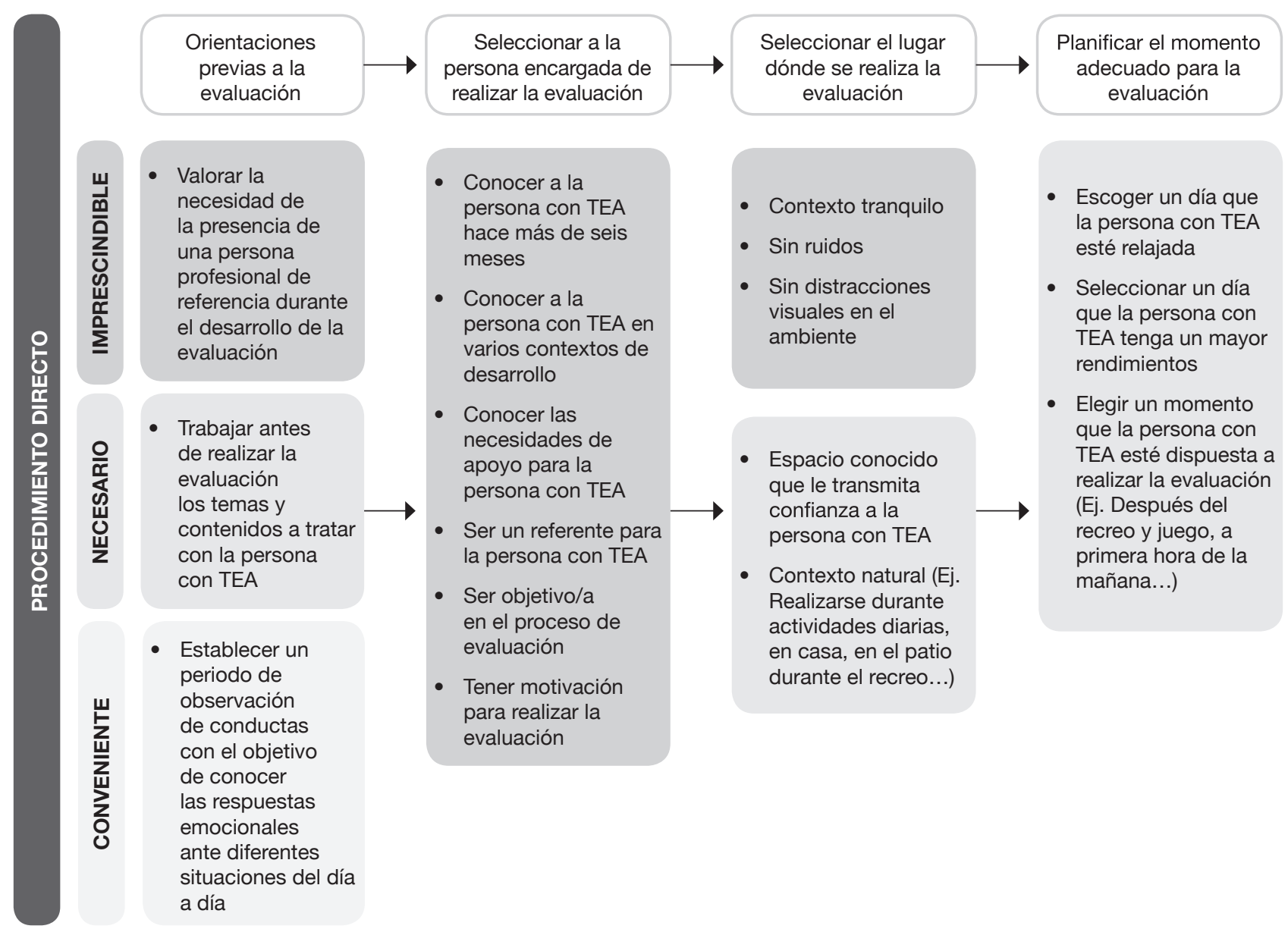

Fuente: elaboración propia. 
Figura 2. Procedimiento directo. Procedimiento de evaluación

\section{PROCEDIMIENTO DE EVALUACIÓN}

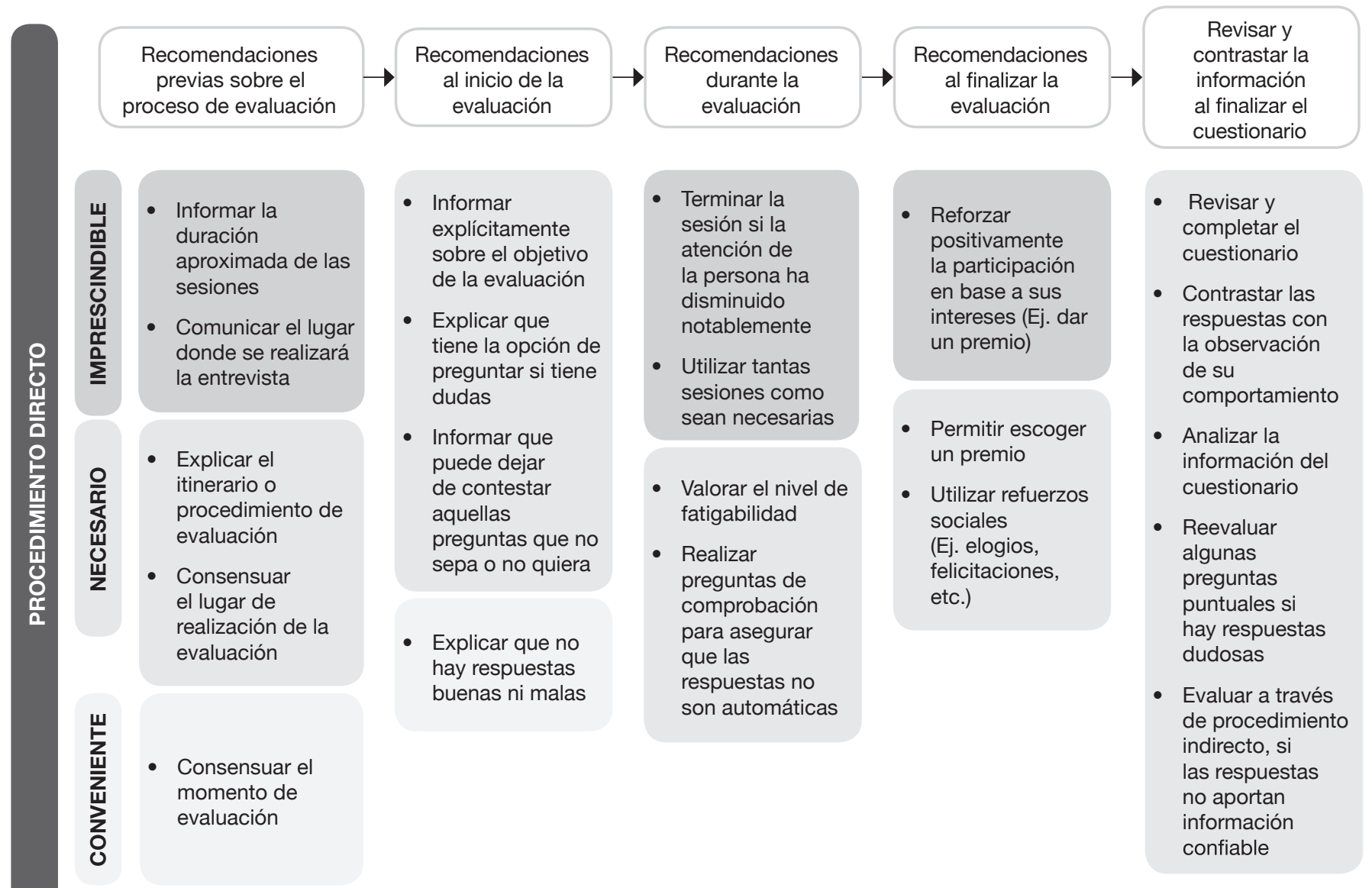

Fuente: elaboración propia. 


\section{MATERIALES DE EVALUACIÓN}

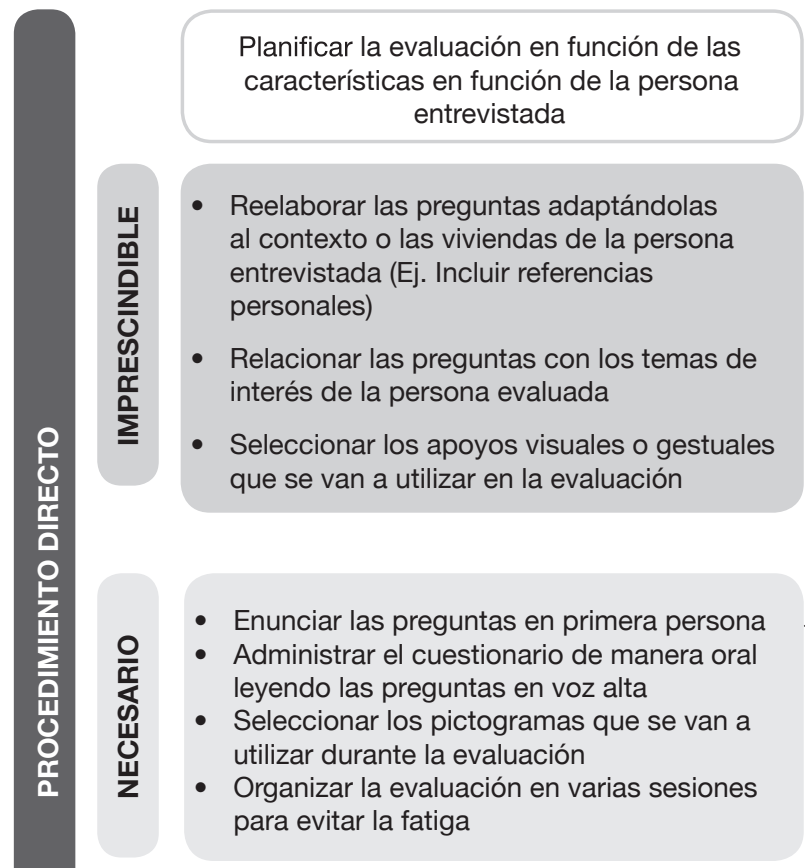

\section{CONVENIENTE}

Fuente: elaboración propia.
Adaptar los materiales al nivel de comprensión de la persona entrevistada

- Reelaborar las preguntas, en caso de necesidad, a su nivel de comprensión simplificando el enunciado

- Adaptar la terminología al nivel de comprensión de la persona

- Realizar preguntas complementarias y aclaratorias sobre la información solicitada

- Preparar sinónimos de las palabras de díficil comprensión

- Incluir ejemplos de situaciones reales y concretas

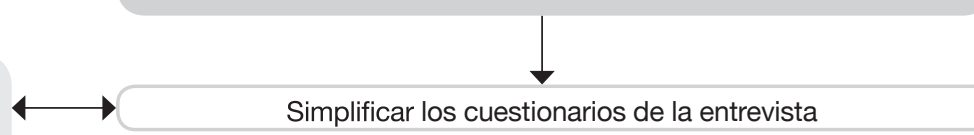

- Reducir las opciones de respuesta

- Simplificar el enunciado de las preguntas ( Ej. Elaborar preguntas cerradas)

- Sustituir las frases de difícil comprensión por otras más sencillas

- Agrupar ítems con la misma temática

Simplificar los cuestionarios de la entrevista

- Incluir claves visuales en el formato (Ej. Hacer más colorido el cuestionario)

- Espaciar las preguntas para facilitar la visualización del contenido

Desarrollar procedimientos que aumenten la fiabilidad de la información

- Incluir preguntas de comprobación

- Elaborar un registro de observación para constatar las preguntas del cuestionario con una evaluación complementaria si las respuestas son dudosas

- Cambiar a positivo las preguntas formuladas en negativo para evitar la tendencia a agradar

- Cambiar el orden de preguntas para evitar respuestas automáticas 


\section{Figura 4. Procedimiento directo. Uso de apoyos}

\section{USO DE APOYOS}

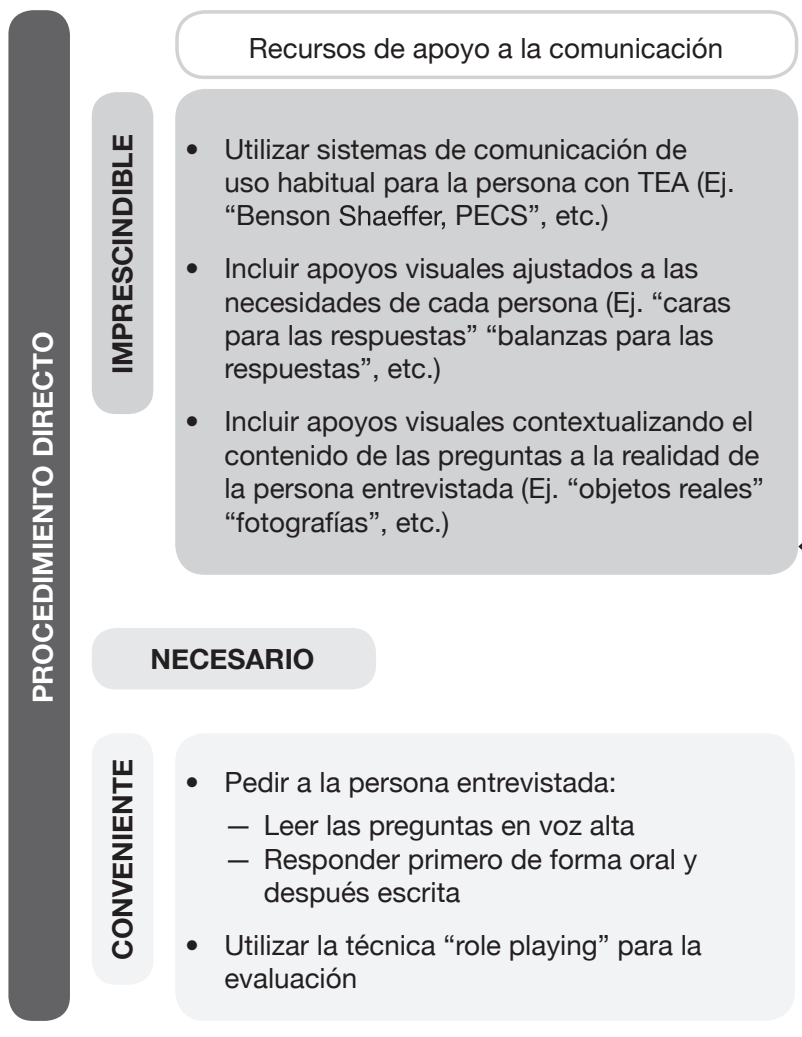

\section{Intensidad de los apoyos}

- Ajustar los apoyos a las necesidades de la persona

- Utilizar apoyos continuos o intermitentes para mantener la motivación durante toda la evaluación (Ej. ayuda o adaptación de todas las preguntas, explicación de ciertos ítems etc.)

\section{$\longleftrightarrow$ Reforzadores positivos}

- Utilizar reforzadores sociales de su actitud, predisposición y respuesta (Ej. pasar la prueba como si fuera un concurso)

- Utilizar reforzadores secundarios (Ej. Pedir lo que quiera en la cafetería

- Resaltar la importancia de la prueba

Fuente: elaboración propia. 


\section{Procedimientos de evaluación indirecta}

Hace referencia a las estrategias alternativas de recogida de información que pueden emplearse de manera sistematizada cuando la participación de la persona con TEA no resulta posible por cualquier circunstancia (barreras ambientales, personales, etc.). Este protocolo recoge recomendaciones en relación a la observación directa del comportamiento de la persona, el contraste de los datos por parte de otros/as informantes, la realización de entrevistas a familiares o a personas de referencia, etc. Es necesario insistir en que este procedimiento deberá emplearse únicamente cuando se hayan agotado todos los medios para llevar a cabo una evaluación directa. Del mismo modo, podrá aplicarse para completar algunas lagunas de la evaluación y, contrastar, siempre que sea posible, la evaluación directa de calidad de vida en la que haya participado la persona con TEA.

\section{Figura 5. Procedimiento indirecto. Procedimiento general de evaluación}

\section{PROCEDIMIENTO GENERAL DE EVALUACIÓN}

\section{IMPRESCINDIBLE}

- Evaluar las señales que informan de emociones positivas y negativas de la persona

\section{NECESARIO}

- Plantear una evaluación objetiva a través de personas informantes externas

- Al finalizar el proceso de evaluación, recoger las respuestas de todas las personas informantes y ponerlas en común

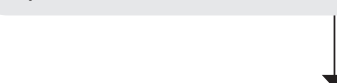

Estrategias de recogida y análisis de la información

\section{NECESARIO}

- Seleccionar ítems que puedan ser observables en el entorno familiar a través de conductas o emociones

- Revisar que la documentación contenga la información actualizada y continuada de la persona

- Utilizar un registro de observación para la familia y el personal profesional de referencia

\section{CONVENIENTE}

- Realizar una entrevista a una persona familiar que la conozca bien
Requisitos mínimos de las personas informantes

\section{IMPRESCINDIBLE}

- Conocer bien a la persona

- Responder poníendose en el lugar de la persona

- Manifestar objetividad al completar la evaluación y responder las preguntas

- La persona que evalúia manifiesta objetividad al analizar los datos

\section{NECESARIO}

- Ser significativa/referente para la persona

\section{CONVENIENTE}

- Ser un grupo heterogéneo y multidisciplinar (Ej. Personal trabajador del centro y familia)

Fuente: elaboración propia. 


\section{Barreras que dificultan la participación de la persona con TEA en la evaluación}

Definidas como dificultades observadas durante el proceso de consulta y recogida de información sobre la calidad de vida de la persona con TEA, que impiden o interfieren significativamente en el mismo de manera que no resulta posible obtener datos relevantes sobre el contenido de la evaluación.

Los elementos identificados como barreras se detallan a continuación.

Figura 6. Barreras relacionadas con la participación de la persona

\section{CAPACIDADES COGNITIVAS}

\section{MUY SIGNIFICATIVA}

- Dificultad para la comprensión de la pregunta

- Dificultad para comprender términos mentalistas (desear, pensar, etc.)

- Dificultades de metacognición (conocimiento y regulación de sus propios procesos cognitivos)

- No tiene conciencia sobre sus propias necesidades

\section{SIGNIFICATIVA}

- No comprende la finalidad de la evaluación

- No tiene experiencia de valorar conceptos complejos

- Necesidad de aclaración de conceptos

- Dificultades:

- Comprender términos abstractos

- Comprender conceptos que implican temporalidad

- Mantener la atención y la concentración

- Comprender preguntas relacionadas con el futuro

- Comprender situaciones no habituales

\section{COMUNICACIÓN E INTERACCIÓN SOCIAL}

\section{SIGNIFICATIVA}

- No tiene lenguaje oral

- Dificultad para la expresión oral

- Las respuestas dadas son difíciles de valorar

- Dificultad para opinar sobre sí mismo/a

- No puede comunicar emociones respecto a conceptos amplios y complejos

\section{MODERADA}

- No posee un lenguaje funcional

- Dificultad para participar en interacciones basadas solamente en la comunicación verbal

- Dificultad para mantener una interacción prolongada y basada en el lenguaje

- Expresiones de signos gestuales limitados

- Tendencia a agradar con sus respuesta

Fuente: elaboración propia.

\section{MOTIVACIÓN}

\section{SIGNIFICATIVA}

- Las rutinas son más importantes que sus gustos (dificulta la valoración)

- Muestra reducido interés por la escasa comprensión del cuestionario

- Tendencia a responder automáticamente

\section{MODERADA}

- Escasa motivación para realizar la evaluación

- Pérdida de motivación por el extenso contenido del cuestionario

- Oponerse a responder sobre temas personales

- Tardar en dar la respuesta a temas que no le interesa

- Las temáticas del cuestionario no son de su interés 
Facilitadores para el desarrollo de la evaluación

Incorpora los elementos de apoyo que pueden resultar más relevantes para promover la participación en el desarrollo de la evaluación o proceso de consulta y contrarrestar las barreras anteriormente identificadas. Se relacionan especialmente con el contenido de las cuestiones o preguntas a formular, el formato de la información solicitada o los apoyos que se pueden proporcionar en las distintas fases del proceso.

\section{Figura 7. Facilitadores de la evaluación}

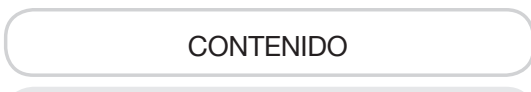

\section{SIGNIFICATIVA}

- Adaptar el cuestionario a las características de la persona

- Garantizar la comprensión de las preguntas del cuestionario

\section{MODERADA}

- Incluir ejemplos personales de su vida cotidiana

- Preparar a la persona para trasmitir emociones durante la realización de la entrevista

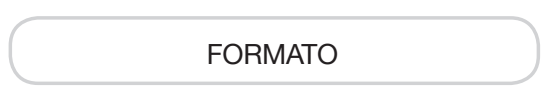

\section{MUY SIGNIFICATIVA}

- Modificar las preguntas para que sean de fácil comprensión

- Facilitar y simplificar las opciones de respuesta del cuestionario

\section{SIGNIFICATIVA}

- Adaptar el formato del cuestionario a las habilidades comunicativas de la persona

- El cuestionario no debe ser muy extenso

- La presentación del cuestionario debe ser amigable

\section{MODERADA}

- Ordenar las respuestas para que no conteste de manera automática

\section{APOYOS FACILITADOS}

\section{SIGNIFICATIVA}

- Facilitar apoyos que permitan la comprensión de la pregunta

- Prestar atención a los ejemplos para evitar asociar la respuesta a éstos y no al contenido general de la pregunta

- Intentar que los pictogramas hagan referencia a conceptos abstractos

Fuente: elaboración propia. 


\section{Conclusiones sobre la inclusión de la perspectiva de las personas con TEA en la toma de decisiones sobre sus vidas}

En la actualidad, la incorporación de las percepciones de las personas con TEA, y en concreto, de aquellas que presentan mayores necesidades de apoyo, constituyen un reto pendiente para las y los profesionales que se encuentran vinculados a este colectivo y que procuran con sus actuaciones promover su calidad de vida y el logro de metas personales y significativas para cada una de estas personas.

Ahora bien, contar con la perspectiva específica de la persona con TEA para planificar y definir un plan sobre su calidad de vida a largo plazo, detectando las principales áreas de mejora y aquellas que tienen mayor incidencia en el alcance de sus objetivos, es un requisito imprescindible para avanzar en su desarrollo personal, inclusión y participación social, así como para garantizar el disfrute de sus derechos fundamentales.

No obstante, la heterogeneidad de los TEA es enorme, lo que hace que las necesidades de apoyo de las personas con este tipo de trastornos también sean muy variables. Esta circunstancia hace que resulte fundamental el establecimiento de un rango amplio de apoyos que favorezcan la participación directa de la persona o que puedan incorporar de la manera más objetiva posible su perspectiva en el proceso de consulta y toma de decisiones.

Con esta finalidad y gracias a la experiencia y bagaje de las organizaciones participantes y de los y las profesionales que facilitan apoyos directos a las personas con TEA que han contribuido al estudio ha sido posible el desarrollo de una sistemática que favorece desde el inicio de la elaboración de los planes individualizados de apoyo la participación de la persona con TEA y la inclusión de su perspectiva en los mismos.

En este artículo se han explicado los procedimientos contrastados desde el apoyo directo a las personas con TEA y consensuados en base a la experiencia y el conocimiento experto. El objetivo fundamental es que resulten de utilidad a las organizaciones y a sus profesionales en el impulso de sistemas que promuevan la participación de personas con necesidades intensas de apoyo en la consulta y toma de decisiones sobre sus vidas.

Este es un aspecto que no sólo redunda en el reconocimiento de los derechos y capacidades de las personas para ser agentes activos en sus vidas, sino que promueve el desarrollo de las organizaciones y de los apoyos que éstas facilitan en base al reconocimiento efectivo de los derechos y la dignidad de las personas con mayores necesidades de apoyo, y a las buenas prácticas que transforman y enriquecen el desarrollo organizacional.

En este sentido, la iniciativa que ha dado lugar a las anteriores recomendaciones ha fomentado la reflexión de los y las profesionales participantes y de las entidades a las que éstos/as se encuentran vinculados. Estos instrumentos se derivan de una práctica colaborativa, orientada a la mejora global y continuada de la calidad de las intervenciones y los apoyos que las distintas organizaciones desarrollan.

Por último, para las organizaciones implica un cambio profundo en la concepción sobre los procesos de participación de las personas con TEA en todos los aspectos que les conciernen y que repercuten en su calidad de vida, desde la evaluación de la misma a la planificación de actuaciones destinadas a favorecerla. De esta manera, no sólo se reconoce el derecho a la participación sino que se contribuye a hacerlo efectivo de una manera real. 
Cuesta, J. L. (2013): “Aplicación de la técnica Delphi en el proceso de validación de un instrumento para la evaluación de la calidad de vida en centros para personas con trastornos del espectro autista". Revista Qurriculum, 26: I 35 -I 60

Gómez-Vela, M. y Verdugo, M. A. (2009): Cuestionario de evaluación de la Calidad de Vida de Alumnos Adolescentes, Madrid: CEPE.

Involve me (20II): Practical guide. How to involve people with profound and multiple learning disabilities (PMLD) in decision-making and consultation (en línea). <https://www.mencap. org.uk/sites/default/files/documents/Involve \% 20 $\mathrm{Me} \%$ 2opractical\% 2oguide_full\% 2oversion. pdf $>$, acceso I 7 de diciembre de 2015 .

Organización de Naciones Unidas (2006): Convención Internacional sobre los Derechos de las Personas con Discapacidad (en línea). $<$ http://www.un.org/esa/socdev/enable/ documents/tccconvs.pdf $>$, acceso I 7 de diciembre de 2015 .

Organización Mundial de la Salud (20I I): Informe Mundial sobre la Discapacidad (en línea). <http://whqlibdoc.who.int/hq/20 I I/WHO_ NMH_VIP_I I.03_spa.pdf?ua $=$ I $>$, acceso I7 de diciembre de 2015.

Patterson, R. (2OI2): Strategies to incorporate the voices of people with significant disabilities in UCEDD information gathering and operations (en línea) <http://www.aucd.org/docs/urc/ AUCD_StrategiesReport_Final.pdf>, acceso I7 de diciembre de 2015 .

Plimley, L.A. (2007): “A review of quality of life issues and people with autism spectrum disorders". British Journal of Learning Disabilities, 35 (4): 205-2I3.
Renty, J. O. y Roeyers, H. (2006): “Quality of life in high-functioning adults with autism spectrum disorder: The predictive value of disability and support characteristics”. Autism, IO (5): 5 I I -524 .

Rutter, M. (20II): "Progress in Understanding Autism: 2007-2010”. Journal Autism Development Disorder, 4I: 395-404.

Sabeh, N. et al. (2009): Cuestionario de evaluación de la Calidad de Vida en la Infancia, Madrid: CEPE.

Schalock, R. I. y Verdugo, M. A. (2007): “El concepto de calidad de vida en los servicios y apoyos para personas con discapacidad intelectual". Revista Española sobre Discapacidad Intelectual. 38 (4): 2I-36 (en línea). <http://www.feaps.org/archivo/centrodocumental/doc_download/293-el-concepto-decalidad-de-vida-en-los-servicios-y-apoyos-parapersonas-con-discapacidad-intelectual.html>, acceso 7 de diciembre de 2015 .

Schalock, R. et al. (2009): Quality of life for People with Intellectual and other Developmental Disabilities, Washington: American Association on Intellectual and Developmental Disabilities.

The council on quality and leadership (I997): Importance and satisfaction map. EEUU.

Verdugo, M. A. et al. (2014): Escala San Martín para personas con discapacidades significativas. Santander: Fundación Obra San Martín, INICO (en línea). <http://sid.usal.es/idocs/ escala-san-martin.zip $>$, acceso 7 de diciembre de 2015 .

Wehmeyer, M. y Schalock, R. (200I): "Selfdetermination and quality of life: Implications for special education services and supports". Focus on Exceptional Children, 33 (8): I-I6. 



\section{Modelos, pseudomodelos y "burbujas terapéuticas" en Atención Temprana}

\section{Models, pseudomodels and "therapeutic bubbles" in Early Intervention}

\section{Palabras clave}

Atención Temprana, modelo, calidad, socio sanitario

\section{Keywords}

Early intervention, model, quality, socio-sanitary.

\section{Antecedentes}

La publicación en el año 2000 del Libro Blanco de Atención Temprana (Federación Estatal de Asociaciones de Profesionales de Atención Temprana, 2000) marca la fecha a partir de la cual podemos discriminar entre lo que es Atención Temprana y lo que no lo es. Han pasado quince años y todavía nos encontramos con iniciativas, técnicas y estrategias que pretenden representar un nuevo modelo o un nuevo paradigma, cuando sin embargo no reúnen todos los requisitos que ya se definieron en su día en el Libro Blanco.

Aunque la tradición asociativa autonómica de los profesionales de la Atención Temprana se remonta a la década de los ochenta, el nacimiento de la Federación Estatal de Asociaciones Autonómicas de Profesionales de Atención Temprana (GAT) se puede fechar en Madrid en noviembre de I995 en el transcurso de una jornada interdisciplinar, cuando un grupo de profesionales de varias Comunidades Autónomas decidió elaborar un primer Libro Blanco sobre la Atención Temprana en España. La repercusión alcanzada por los distintos trabajos y estudios realizados por el GAT ha sido muy amplia. Así, el Libro
Juan Carlos Belda Oriola <beldhern@gmail.com>

Conselleria de Sanidad de la Generalitat Valenciana. Psicólogo Especialista en Psicología Clínica. Presidente de AVAP y GAT
Para citar:

Belda, J. C. (2015): “Modelos, pseudomodelos y 'burbujas terapéuticas' en Atención Temprana", Revista Española de Discapacidad, 3 (2): II7-I 24

Doi: <http://dx.doi.org/I0.5569/23405 I04.03.02.07> 
Blanco sobre la Atención Temprana desde su publicación en el año 2000 se ha consolidado como un referente necesario en los distintos desarrollos legislativos y normativos que sobre la Atención Temprana se han realizado en las distintas Comunidades Autónomas. Las Recomendaciones Técnicas sobre la Atención Temprana, el estudio sobre la Realidad de la Atención Temprana, la Guía del Desarrollo y la Primera Noticia son a su vez referentes teóricoprácticos para todos los profesionales ya sean del ámbito sanitario, de servicios sociales o educativos. La Clasificación Diagnóstica para la Atención Temprana en su afán de convertirse en lenguaje común y holístico ya se está utilizando en distintas Comunidades Autónomas.

A continuación se presenta la Tabla I sobre la evolución de la Atención Temprana en España, desde la década de los setenta hasta nuestros días. Incluye la evolución de los términos utilizados, el objetivo de la intervención, la población diana y la denominación dada a los centros.

\section{Modelo definido en el Libro Blanco de Atención Temprana}

Cuando hablamos de Modelo de Atención Temprana nos referimos a un modelo que reúne toda una serie de requisitos que vienen sintetizados en la definición y en los principios básicos recogidos en el Libro Blanco de la Atención Temprana. Así tenemos que:

La Atención Temprana viene definida como "el conjunto de intervenciones, dirigidas a la población infantil de cero a seis años, a la familia y al entorno, que tienen por objetivo dar respuesta lo más pronto posible a las necesidades transitorias o permanentes que presentan los niños con trastornos en su desarrollo o que tienen riesgo de padecerlos. Estas intervenciones, que deben considerar la globalidad del niño, han de ser planificadas por un equipo de profesionales de orientación interdisciplinar o transdisciplinar”.

Los principios básicos enunciados en el mismo libro blanco, y que han servido de base a los

\begin{tabular}{|c|c|c|c|c|}
\hline $\begin{array}{l}\text { Estimulación } \\
\text { Precoz }\end{array}$ & $\begin{array}{l}\text { Intervención } \\
\text { Temprana }\end{array}$ & $\begin{array}{l}\text { Atención } \\
\text { Temprana }\end{array}$ & $\begin{array}{c}\text { Atención Temprana } \\
\text { de calidad }\end{array}$ & $\begin{array}{c}\text { AT } \\
\text { Sociosanitaria }\end{array}$ \\
\hline $70-80$ & $80-90$ & $90-00$ & $00-10$ & $10-$ \\
\hline Niño & Niño-Familia & $\begin{array}{l}\text { Niño-Familia- } \\
\text { Entornos naturales }\end{array}$ & $\begin{array}{c}\text { Niño-Familia- } \\
\text { Entornos -Sociedad }\end{array}$ & $\begin{array}{l}\text { Centrada en las } \\
\text { personas }\end{array}$ \\
\hline $\begin{array}{l}\text { Minusvalías } \\
(0-2)(0-6)\end{array}$ & $\begin{array}{c}\text { Minusvalías (0-6) } \\
\text { Riesgo }\end{array}$ & $\begin{array}{l}\text { Población general } \\
\qquad(0-6)\end{array}$ & $\begin{array}{c}\text { Derecho Universal } \\
(0-6)\end{array}$ & Derecho Universal \\
\hline Prevención $3^{a}$ & Prevención $2^{a}$ y $3^{a}$ & $\begin{array}{l}\text { Prevención } \\
1^{\mathrm{a}}, 2^{\mathrm{a}} \text { y } 3^{\mathrm{a}}\end{array}$ & $\begin{array}{l}\text { Prevención } \\
1^{\mathrm{a}}, 2^{\mathrm{a}} \text { y } 3^{\mathrm{a}}\end{array}$ & $\begin{array}{l}\text { Prevención } \\
1^{\mathrm{a}}, 2^{\mathrm{a}} \text { y } 3^{\mathrm{a}}\end{array}$ \\
\hline $\begin{array}{l}\text { Unidades de } \\
\text { Estimulación } \\
\text { precoz }\end{array}$ & $\begin{array}{l}\text { Servicios de } \\
\text { Intervención } \\
\text { Temprana }\end{array}$ & $\begin{array}{c}\text { Centros de } \\
\text { Atención Temprana }\end{array}$ & CDIATs & CDIATs \\
\hline
\end{tabular}

Fuente: Elaboración propia. 
distintos desarrollos legislativos que se han realizado en distintas comunidades autónomas, son:

- El Diálogo, la Integración y la Participación.

La integración familiar, escolar y comunitaria de cualquier niño implica el respeto a su condición de sujeto activo. La Atención Temprana debe facilitar el conocimiento social del niño y el acceso a su forma de comunicar y expresar sus deseos, promoviendo modelos de crianza, educativos y relacionales coherentes y estables, basados en actitudes de dialogo y en la aceptación de los modos alternativos de ser.

- $\quad$ La Gratuidad, la Universalidad, la Igualdad de Oportunidades y la Responsabilidad Pública.

La Atención Temprana actúa para la prevención y, en su caso, evitando y compensando los riesgos, facilitando la igualdad de oportunidades en el acceso a los distintos contextos de la vida social, la incorporación a una familia donde ser amado, la convivencia y socialización en una escuela abierta a todos los niños, además del diseño del hábitat comunitario de una forma comprensiva hacia la diferencia. La Atención Temprana ha de constituirse en un servicio público, universal, de provisión gratuita para todos los niños y familias que lo precisen.

- La Interdisciplinariedad y la Alta Cualificación Profesional.

La preparación de los profesionales ha de implicar tanto la formación en una disciplina específica como en un marco conceptual común a todas ellas que debe tener su propio espacio de desarrollo a través de la reflexión y el trabajo en equipo. Un marco común definido en cuatro áreas: desarrollo psicomotor infantil, psicosociología de la dinámica familiar, conocimiento de la realidad (recursos y características comunitarias) y una formación y experiencia suficientes sobre el trabajo en equipo. Sin olvidar la importancia de la formación continua y supervisada.

- La Coordinación.

La coordinación ha de realizarse a tres niveles. El primero entre los servicios sanitarios, sociales y educativos que atienden a la población infantil y a sus familias. De forma que, las familias y sus hijos, reciban una orientación común y no contradictoria entre los diversos profesionales. Incluyendo la continuidad de los servicios. El segundo y tercer nivel hacen referencia a la coordinación entre las administraciones autonómicas y estatales.

- La Descentralización.

Implica el establecimiento de un sistema organizado en torno a las necesidades de la familia, en su proximidad, incluyendo la prestación de servicios a domicilio, así como la inserción en las redes de atención primaria de salud y de servicios sociales, en el entorno de las escuelas infantiles y en la vecindad de la familia.

- La Sectorización.

Consiste en delimitar el campo de actuación de los servicios para garantizar una correlación equilibrada entre proximidad y conocimiento de la comunidad y el hábitat, funcionalidad y calidad operativa de los equipos y volumen suficiente de la demanda a efectos de facilitar la inclusión de todo tipo de servicios sanitarios, educativos o sociales en el área de referencia que se constituya.

\section{Pseudomodelos y "burbujas terapéuticas"}

Si el Modelo de Atención Temprana viene definido por el cumplimiento de los requisitos marcados en el Libro Blanco de Atención Temprana, por pseudomodelos entenderemos 
aquellas intervenciones o abordajes parciales y que no reúnen todos estos requisitos. En muchos casos nos encontramos con métodos, técnicas o estrategias cuyos autores autodenominan como modelos, pero que evidentemente suelen obedecer a un afán de protagonismo y que constituyen acercamientos parciales. Representan aportaciones interesantes que sirven como herramientas específicas para cierto tipo de situaciones concretas que se pueden encontrar dentro de la amplia gama de situaciones dentro de la Atención Temprana.

Entre los pseudomodelos más usuales, señalar por ejemplo la corriente que pretende reducir la edad de intervención a cero-dos o cero-tres años, los centros que atienden solo a niños con una determinada patología en contra del carácter generalista defendido por el conjunto de profesionales, el tipo de organización administrativa que a nivel autonómico centraliza el diagnostico para el acceso a la Atención Temprana o cuando se pretende que la única estrategia eficiente sea la atención a domicilio.

A continuación se incluye la Tabla 2 que nos permite discriminar si el conjunto de intervenciones se puede considerar como Modelo o, por el contrario, al incumplir algún requisito, se trata de un pseudomodelo.

Tabla 2. Identificación de pseudomodelos en Atención Temprana

\begin{tabular}{|l|l|l|}
\hline Principios & SI & NO \\
\hline Edad: 0-6 años & & \\
\hline Diálogo, Integración y Participación & & \\
\hline $\begin{array}{l}\text { Gratuidad, Universalidad e Igualdad } \\
\text { de Oportunidades. } \\
\text { Responsabilidad Pública }\end{array}$ & & \\
\hline $\begin{array}{l}\text { Interdisciplinariedad y Alta } \\
\text { Cualificación Profesional }\end{array}$ & & \\
\hline Coordinación & & \\
\hline Descentralización & & \\
\hline Sectorización & & \\
\hline
\end{tabular}

Fuente: Elaboración propia.
Las "burbujas terapéuticas” o métodos milagrosos, como veníamos denominándolos y que por desgracia siguen de rabiosa actualidad, a pesar de su reincidencia histórica nos obligan a su constante repudio mediante la información clara y sincera a los padres o posibles "clientes". Incluimos la hoja de ruta establecida en el artículo "La Atención Temprana Infantil y su praxis" (Belda, 20I4: I95-20I) y añadimos un último paso para cuando no se cumplen las expectativas y se entra en el fracaso y el silencio.

\section{Tabla 3. Hoja de ruta de las "burbujas} terapéuticas"

\begin{tabular}{|c|c|}
\hline \multicolumn{2}{|r|}{ Hoja de ruta de las "burbujas terapéuticas" } \\
\hline $1^{\circ}$ & $\begin{array}{l}\text { "Situación de partida": existencia de } \\
\text { una enfermedad, trastorno o patología } \\
\text { que produzca una situación de grave } \\
\text { discapacidad. Posible situación de duelo no } \\
\text { resuelto por los padres. }\end{array}$ \\
\hline $2^{\circ}$ & $\begin{array}{l}\text { "Promesa de sanación": se asegura que si } \\
\text { se siguen totalmente las prescripciones el } \\
\text { niño podrá superar todas sus dificultades y } \\
\text { normalizarse en un futuro. }\end{array}$ \\
\hline $3^{\circ}$ & $\begin{array}{l}\text { "Descalificación”: se menosprecian los } \\
\text { anteriores diagnósticos y pronósticos, } \\
\text { sobre todo, los realizados por los servicios } \\
\text { públicos de salud. Se llega a descalificar a } \\
\text { estos profesionales alegando desmotivación, } \\
\text { incompetencia o falta de actualización } \\
\text { profesional. }\end{array}$ \\
\hline $4^{\circ}$ & $\begin{array}{l}\text { "Tratamiento intensivo": el tratamiento implica } \\
\text { un gran esfuerzo porque hay que superar un } \\
\text { hándicap, que ha sido mal atendido hasta } \\
\text { que han acudido a esta clínica. Suele consistir } \\
\text { en innumerables sesiones de movilizaciones } \\
\text { físicas, intensos controles sanitarios, } \\
\text { dietéticos, compensatorios, etc. }\end{array}$ \\
\hline $5^{\circ}$ & $\begin{array}{l}\text { "Lucro para la empresa": el coste del } \\
\text { tratamiento "milagro" supera la capacidad } \\
\text { económica de la mayoría de las familias que } \\
\text { invierten todo su patrimonio. A veces los } \\
\text { padres se ven obligados organizar actividades } \\
\text { benéficas para financiarlos. Otra estrategia } \\
\text { consiste en que los responsables del método } \\
\text { becan parcialmente algunos tratamientos } \\
\text { de algunas familias que se dedican al } \\
\text { "apostolado" vendiendo a otras familias las } \\
\text { "virtudes" de éste o aquel método. Sea como } \\
\text { fuere los beneficios económicos de estos } \\
\text { profesionales son enormes a cambio de exigir } \\
\text { un esfuerzo en tiempo, dedicación y dinero } \\
\text { que suele terminar por desestructurar a las } \\
\text { familias. }\end{array}$ \\
\hline
\end{tabular}


"Fracaso y silencio": Al final algunas familias desertan desesperadas y otras que no ven mejoría renuncian avergonzadas y culpabilizadas por no haber conseguido la mejoría deseada en sus hijos.

Fuente: Belda, 20I4: I95-20I.

\section{La gestión de calidad asegura la Atención Temprana}

Si disponemos de un Modelo de Atención temprana consensuado y con proyección legislativa, nos queda pendiente elaborar un instrumento que nos garantice la calidad en su aplicación práctica. Estamos hablando de una Certificación de Calidad específica de la Atención Temprana y para ello proponemos utilizar como base la Guía de Estándares de Calidad en Atención Temprana.

Esta Guía de Estándares tiene su origen en el programa INTER, impulsado y financiado por el IMSERSO (I999-200I), que permitió desarrollar un sistema de formación basado en el intercambio de conocimientos y experiencias de personas pertenecientes a distintas organizaciones.

De este modo, se podía conocer mejor las diferentes iniciativas de cada Comunidad Autónoma, identificar proyectos eficaces y buenas prácticas, darlas a conocer y generalizarlas a través de normas técnicas o legislativas. Pretende actuar como recurso e impulso para empezar a crear una cultura de autoevaluación y evaluación externa en el ámbito de la Atención Temprana en toda España.

En este sentido, los estándares no se plantean como un sistema cerrado de exigencias sino como un catálogo de factores de calidad abiertos a la aportación de distintos agentes.
Éste es un principio de trabajo imprescindible para compaginar la diversidad y participación de múltiples entidades y administraciones con la regulación coherente de unas prestaciones básicas. De esta manera, la Guía podrá servir a diversos objetivos:

- Generar una cultura de criterios de calidad que permitan contrastar las prácticas profesionales.

- Disponer de distintos núcleos de evaluación de los procedimientos y de los resultados en el nivel comunitario, familiar o del niño.

- Introducir a los promotores y profesionales en la cultura de gestión de procedimientos y servicios en el ámbito de la Atención Temprana.

- Ofrecer la oportunidad de mostrar que el trabajo que se realiza es útil y eficaz para sus destinatarios y patrocinadores.

- Servir como estímulo a la iniciativa de cambio, formación e investigación.

- Proporcionar coherencia y colaboración entre iniciativas de distinta procedencia o responsabilidad.

- Facilitar a las familias una fórmula de identificación y participación en los procesos clave.

- En el formulario de estándares se identifican cinco niveles: comunidad, familia, infancia, centro y programa de Atención Temprana. En cada uno de estos niveles se identifican los estándares e indicadores que vamos a utilizar para contrastar el trabajo del centro o servicio.

La Guía de Estándares está formada por cinco niveles, estándares e indicadores (Tabla 4).

Con los indicadores podemos comparar y contrastar nuestra práctica profesional, valorando en qué medida el programa se adecua a los estándares apuntados. Los estándares nos 


\begin{tabular}{l}
\hline Tabla 4. Guía de Estándares de Calidad en Atención Temprana \\
\begin{tabular}{|l|c|c|}
\hline NIVEL & N DE ESTÁNDARES & N $^{\circ}$ DE INDICADORES \\
\hline Comunidad & 8 & 25 \\
\hline Familia & 9 & 40 \\
\hline Infancia & 5 & 21 \\
\hline Centro & 11 & 42 \\
\hline Programa de A. T. & 4 & 19 \\
\hline Total & $\mathbf{3 7}$ & $\mathbf{1 4 7}$ \\
\hline
\end{tabular}
\end{tabular}

Fuente: Ponte, 2004.

permiten, por tanto, valorar los programas, pero pueden y deben utilizarse como mecanismos o instrumentos de mejora y homologación de las acciones de los centros. En este sentido, constituyen una ayuda que permite prevenir errores en el diseño y desarrollo de programas, puesto que su elaboración parte de la identificación de acciones que son consideradas por los profesionales como aceptables y recogen las mejores acciones actuales.

El nivel I denominado Comunidad incluye el Programa de redes sociales e institucionales, con el objetivo de integrar el Programa de Atención Temprana (PAT) en las redes comunitarias de programas y servicios. El nivel 2 denominado Familia incluye el Programa de recursos para la familia, con el objetivo de facilitar a la familia los medios y reformas contextuales que precisen para atender a sus nuevas necesidades. El nivel 3 denominado Infancia incluye el Programa de igualdad de oportunidades, con el objetivo de proteger los derechos del niño asegurando la valoración objetiva y los medios que precisa para su desarrollo y necesidades. El nivel 4 denominado Centro incluye el Programa del Centro de Desarrollo Infantil y Atención Temprana, con el objetivo de disponer en el Centro de una adecuada estructura y organización de sus unidades. El nivel 5 denominado Programa de Atención Temprana incluye el Programa de evaluación con el objetivo de realizar el Control de la funcionalidad del programa.
Esta distribución en cinco niveles nos lleva a tener en consideración al niño, a la familia y a los profesionales. Entre los profesionales hemos de considerar a aquellos situados en los entornos naturales: hospitales, centros de salud, escuelas infantiles, etc. También a los profesionales propios de los Centros de Desarrollo Infantil y Atención Temprana (CDIATs), y también a los profesionales y/o responsables de la comunidad, es decir, políticos locales y autonómicos y responsables técnicos de los departamentos administrativos, consejerías, etc. Con lo cual podemos afirmar que el Modelo de Atención Temprana es un Modelo Centrado en las Personas.

\section{La Atención Temprana en el espacio sociosanitario}

La dificultad de la ubicación (dependencia administrativa) de la Atención Temprana en España ha venido dada por factores relacionados con su aparición y desarrollo desde sus inicios en la Unidades de Rehabilitación, en los Centros del IMSERSO, en las iniciativas de las Asociaciones de Padres, etc., y con una financiación mayoritariamente asociada a Servicios Sociales, cuando tiene un encaje perfecto en el ámbito sanitario si nos acogemos a los contenidos de la Ley General de Sanidad de 
25 de abril de I986. La asignación de tareas a las Áreas de Salud y su estructuración en Zonas Básicas de Salud constituyen la demarcación idónea para la sectorización de los Centros de Desarrollo Infantil y atención temprana (CDIATs) como Servicios Especializados de Apoyo a la Atención Primaria de Salud. Por las características de cuidado y promoción de la salud, la Atención Temprana debe formar parte de la cartera de servicios de la sanidad española y también estar relacionada con los servicios sociales y educativos ya que por sus necesidades los niños comparten atención en estos otros dos ámbitos.

El espacio socio-sanitario se define como la actuación simultanea del sistema de salud y del sistema social prestando unos servicios a las personas que tengan efectos sinérgicos. No ha de estar constituido por servicios o recursos que conformen una red paralela. El reto planteado consiste en integrar la atención social y sanitaria en España en un único sistema y la estrategia con la que se viene trabajando se basa en cinco ejes:

- El perfil de las personas con necesidades de atención socio-sanitaria.

- La cartera y el catálogo de servicios sociosanitarios y dispositivos de atención.

- Los requisitos básicos y comunes que deben cumplir estos dispositivos (con el establecimiento de un sistema común de autorización y acreditación en todo el territorio nacional, con criterios homogéneos).

- Los instrumentos de coordinación.

- Los sistemas de información.

Esta Federación GAT de alguna forma ha venido perfilando y desarrollando estos ejes al definir la población diana en niños de cero a seis años con trastornos en el desarrollo (o riesgos de padecerlos) y sus familias en entornos naturales; definiendo el modo de actuación con principios básicos, incidiendo en la interdisciplinariedad y la coordinación, y explicitando el proceso de detección, derivación, diagnóstico, intervención y valoración con una línea abierta en busca del instrumento de acreditación específico para la Atención Temprana, y desarrollando la Organización Diagnóstica para la Atención Temprana (ODAT) como base de datos y lenguaje común entre los distintos profesionales.

\section{La Atención Temprana: un modelo centrado en las personas}

Tomando como base los documentos elaborados por el GAT (LBAT, RTAT, ESRATE, ODAT...), la Guía de Estándares de Calidad en Atención Temprana y la Ley General de Sanidad de I 986 estaremos en condiciones de elaborar un Modelo Global para la Atención Temprana del futuro, enfatizando dos directrices:

- La necesidad de centrar el conjunto de intervenciones en las personas, entendido como las atenciones al niño, la familia, los profesionales de los entornos naturales (escuela infantil, centro de salud, centro hospitalario, etc.), los profesionales que forman los CDIATs, y los profesionales y políticos responsables de sanidad, servicios sociales y educación implicados en el tramo de edad de cero a seis años.

- La incardinación definitiva de la Atención Temprana como derecho universal en el espacio sociosanitario como servicio de apoyo a la atención primaria de salud y con relación (administrativa, financiera, etc.) con servicios sociales y coordinación con los servicios educativos. 


\section{Referencias bibliográficas}

Belda, J. C. (20I4): "La Atención Temprana Infantil y su praxis”. Revista Española de Discapacidad, 2 (I): I95-20I.

Belda, J. C. y Casbas, I. (20I3): "Saber lo que no hay que hacer en Atención Temprana”. Desenvolupament infantil i atenció precoç: revista de l'Associació catalana d'atenció precoç, 34: 5 .

EDIS (2000): Necesidades, demandas y situación de las familias con menores (0-6 años) discapacitados. Madrid: IMSERSO.

GAT (2000): Libro Blanco de la Atención Temprana. Madrid: Real Patronato de Prevención y Atención a Personas con Minusvalía.

GAT (2004) (2008) (2012): Organización Diagnóstica para la Atención Temprana. Madrid: Real Patronato sobre Discapacidad.
GAT (2005): Recomendaciones Técnicas para el desarrollo de la Atención Temprana. Madrid: Real Patronato sobre Discapacidad.

GAT (20I0): La realidad actual de los recursos de Atención Temprana en el ámbito estatal. Madrid: Real patronato sobre Discapacidad.

España. Ley I4/1986, de 25 de abril. General de Sanidad, Boletín Oficial del Estado, 29 de abril de I986, núm. Io2.

Pérez-López, J. y Brito, A. G. (2004): “Evaluación y pruebas de evaluación infantil aplicadas a la atención temprana". En Buceta, M.J. et al. Manual de Atención Temprana (2004). Madrid: Ediciones Pirámide.

Ponte, J. et al. (2004): Guía de Estándares de Calidad en Atención Temprana. Madrid: IMSERSO. 


\section{Arte y salud social. Programas de participación sociocultural para personas con diversidad funcional}

\author{
Art and social health. Sociocultural program \\ participation for people with funcional \\ diversity
}

\section{Palabras clave}

Salud social, diversidad funcional, participación social, integración activa, museo arte contemporáneo, acción social.

\section{Keywords}

Social health, functional diversity, social participation, active integration, contemporary art museum, social action.

\section{Contextualización}

El ocio es uno de los derechos humanos fundamentales, que favorece el desarrollo de las personas, y del que nadie debiera ser privado por razones de discapacidad, género, orientación sexual, edad, raza, religión, creencia, salud, condición económica o cualquier otra circunstancia personal o social.

El ocio es signo de calidad de vida y bienestar, e implica una mejora a nivel individual y social. Entre las condiciones que influyen en la calidad de vida de las personas destaca el tipo y grado de participación en actividades sociales. Y esta participación social depende de la propia conducta de la persona, pero también de la oferta disponible desde la comunidad.

Entre los principales ámbitos en los que se manifiesta el ocio están: la cultura, el turismo, el deporte y la recreación (Universidad de Deusto, 20I4). Desde esta perspectiva, el EUCREA (Comité Europeo para el Arte y la Creatividad de las Personas con Discapacidad), establece en su título fundacional que el arte es un derecho básico de toda la humanidad, un bien universal del que todos podemos y debemos disfrutar, y uno

\section{María Martínez Lemos} <accionsocial@adaptasocial.com>

Coordinadora del Departamento de Acción Social del MAC, Museo de Arte Contemponáneo Gas Natural Fenosa

\section{Jesús Rodríguez López}

<jesus@asocparticipa.org>

Psicólogo Clínico, Asesor Técnico del Departamento de Acción Social del MAC, Museo de Arte Contemporáneo Gas Natural Fenosa

Para citar:

Martinez, M. y Rodríguez, J. (20I 5 ): "Arte y salud social. Programas de participación sociocultural para personas con diversidad funcional", Revista Española de Discapacidad, 3 (2): I25-I3I.

Doi: <http://dx.doi.org/IO.5569/23405 I04.03.02.08> 
de los mejores instrumentos de integración y mejora de toda la población (EUCREA España, I989).

Ya en I 853, A. Coon desarrolló la primera experiencia registrada de exploración táctil de piezas por personas con ceguera (Axel y Levent, 2003: 45). Desde entonces, se han llevado a cabo multitud de experiencias relacionadas con el acceso y experimentación de personas con discapacidad en actividades artísticas.

En 1976 el Museo Metropolitano de Nueva York crea el Servicio para los visitantes minusválidos. Su acogida impulsa el "Programa de Educación Museológica para Deficientes Psíquicos" coordinado por Charles K. Steiner y un equipo de docentes de la Universidad de Yale (Salmen, I998: 9I).

Dichos programas suponen una concepción global del arte como vehículo de incorporación y participación de todos los ciudadanos; al tiempo que incorporan una visión del museo como actor en continuo diálogo con la sociedad en la que se integra.

Sensible a esta realidad y compartiendo los principios que la inspiran, el Museo de Arte Contemporáneo Gas Natural Fenosa (MAC), pone en marcha en 2005 el Programa de Participación Social a través del Arte Contemporáneo (PPSAC). Este programa tiene como objetivo ofrecer una alternativa de ocio saludable a personas con diversidad funcional, mejorando su nivel de participación y ajuste social y, por tanto, su calidad de vida. (Rodríguez et al., 201 2: 22).

Cuatro años después, y con el objetivo de ampliar el número de beneficiarios e incluir a entidades del ámbito provincial de A Coruña, se inicia un convenio de colaboración con la Diputación de A Coruña. Esto hace posible que las entidades de afectados distantes geográficamente del MAC, puedan participar de su oferta de actividades a través de una modalidad en la que el personal del departamento de Acción Social se desplaza a las entidades.

\section{La acción social desde un museo de arte contemporáneo}

La acción social en el MAC se lleva a cabo desde el departamento de Acción Social, que trata de responder adecuadamente a una triple necesidad:

- Ofrecer actividades socioculturales adaptadas a las necesidades y características de una parte de la población.

- Incorporar una perspectiva inclusiva en todas las iniciativas llevadas a cabo por el Museo, al mismo tiempo que contribuir a utilizar el arte como una alternativa de ocio saludable.

- Desarrollar actividades que contribuyan a mejorar los niveles de participación, ajuste social y apoyo social percibido, entrenar las habilidades cognitivas, de relación y de inclusión social.

Todo ello para contribuir a mejorar los niveles de salud (física, psicológica, social y relacional) y, por tanto, la calidad de vida de las personas (niños y adultos) con diversidad funcional (personas con alteraciones físicas, psíquicas o sensoriales) o en situación de riesgo social.

Para gestionar las actividades dirigidas a poblaciones especiales, se estructuran diferentes programas de intervención relacionados con diferentes objetivos de salud y que se reflejan en la Tabla I.

De este modo, si el arte puede contribuir a mejorar los niveles de ajuste y apoyo social, las capacidades cognitivas básicas y facilitar la integración social de las personas afectadas por diversidad funcional, entonces el arte contribuirá a mejorar la salud de las personas. Esa concepción global de la salud, incluyendo salud física, psicológica, emocional y social, es la que promueven los programas del Departamento de Acción Social del MAC. Porque la salud 


Tabla 1. Programas de intervención y sus objetivos de salud.
\begin{tabular}{|l|l|}
\hline Programa & Objetivo de salud \\
\hline $\begin{array}{l}\text { Programa de Participación Social } \\
\text { a través del Arte Contemporáneo } \\
\text { (PPSAC) }\end{array}$ & $\begin{array}{l}\text { Mejorar los niveles de ajuste social de los participantes: } \\
\text { psicomotricidad, orientación espacio-temporal, conocimiento } \\
\text { de la actualidad, manejo de medios de comunicación y nuevas } \\
\text { tecnologías, trabajo en equipo y colaboración, cuidado del medio } \\
\text { ambiente, identificación y expresión de emociones y pensamiento } \\
\text { creativo. }\end{array}$ \\
\hline $\begin{array}{l}\text { Programa provincial de participación } \\
\text { social/ programa de alcance }\end{array}$ & $\begin{array}{l}\text { Incrementar los niveles de participación y ajuste social de las } \\
\text { personas afectadas por diversidad funcional y que pertenezcan a } \\
\text { entidades ubicadas en el entorno rural de la provincia de A Coruña. }\end{array}$ \\
\hline Programa Acompañ@rte & $\begin{array}{l}\text { Contribuir a mejorar los niveles de apoyo social percibido de los } \\
\text { participantes; no estar, ni sentirse solos. Formar parte de un grupo } \\
\text { de apoyo social. }\end{array}$ \\
\hline Programa Lembrart & $\begin{array}{l}\text { Entrenar las habilidades cognitivas básicas en población mayor o } \\
\text { con deterioro cognitivo leve: memoria, atención, concentración, } \\
\text { orientación espacio-temporal, pensamiento abstracto... }\end{array}$ \\
\hline Actividades de integración social & $\begin{array}{l}\text { Sensibilizar e instaurar comportamientos que favorezcan la inclusión } \\
\text { social de personas afectadas por diversidad funcional. }\end{array}$ \\
\hline
\end{tabular}

Fuente: elaboración propia

social se concreta en las circunstancias que condicionan el bienestar de una persona; $y$ dependen de la disponibilidad de recursos y las posibilidades de acceso a ellos.

Esa es la motivación de nuestras actuaciones: ofertar más a los que tienen menos. Acercar los recursos a quienes tienen menor disponibilidad por razones sociales, económicas o derivadas de su estado de salud.

\section{Programas de participación social a través del arte del MAC}

Desde el departamento de Acción Social se diseñan, desarrollan, gestionan y evalúan los siguientes programas:

\subsection{Programa de Participación Social a través del Arte Contemporáneo (PPSAC)}

El PPSAC es un programa sociocultural especialmente concebido para fomentar la participación y la inclusión social a través del arte de las personas con diversidad funcional.

Sus objetivos son experimentar activamente el Arte Contemporáneo para aumentar el nivel de conocimiento y participación en actividades de ocio saludable y contribuir a mejorar la calidad de vida de los participantes.

Está dirigido a niños y adultos con diversidad funcional: discapacidad intelectual y/o sensorial, Trastorno del Espectro Autista, deterioro cognitivo leve y enfermedad mental.

Las actuaciones y actividades de este programa son básicamente talleres didácticos en el Museo a partir de las exposiciones temporales. Los contenidos se centran en aspectos de ajuste social: psicomotricidad, orientación espacio temporal, manejo de emociones, interacción social... El lugar de desarrollo es el aula de Acción Social del MAC y resto de instalaciones del museo, incluidas las propias Salas de Exposición.

Las actividades se articulan en torno a cuatro pilares fundamentales: enfoque relacional, 
carácter lúdico creativo, vinculación con las obras de las exposiciones temporales del MAC y fomento de la participación en la oferta sociocultural del propio museo (cursos de formación, conciertos, tertulias literarias, inauguraciones, conferencias...).

\subsection{Programa provincial de participación social. Programa de alcance}

Esta modalidad supone el desplazamiento del equipo del departamento de Acción Social a las entidades de afectados de la provincia para la realización de talleres en las propias entidades. Esto permite que los usuarios más severamente afectados, o aquellas entidades ubicadas en zonas periféricas, participen activamente de las actividades.

El Programa de Alcance tiene un doble objetivo:

- Incorporar al programa a aquellos usuarios con dificultad para desplazarse.

- Integrar el arte en su cotidianeidad mediante el desarrollo de sesiones en las entidades.

Está dirigido a equipamientos del entorno rural (escuelas de educación especial, hospitales, asociaciones de afectados, centros de día, unidades de rehabilitación...).

El lugar de desarrollo son las propias instalaciones de los equipamientos que atienden a personas con diversidad funcional en la provincia de A Coruña. Este programa está cofinanciado por la Diputación de A Coruña.

\subsection{Acompañ@rte}

Este programa es un espacio de encuentro para personas que, por problemas de salud mental, problemática socio-familiar, edad, y/o circunstancias vitales se encuentran en situación de soledad y aislamiento social. Se parte de la constatación clínica de que disponer de una buena red social de apoyo constituye uno de los principales factores de protección frente al riesgo de padecer problemas socio sanitarios.

Sus objetivos específicos son:

- Incrementar sus niveles de participación social y las relaciones interpersonales.

- Crear una red social de referencia, para mejorar el apoyo social percibido y la calidad de vida de los participantes.

Los usuarios son derivados de las Unidades de Salud Mental de la Sanidad Pública y de los dispositivos de Servicios Sociales del entorno. Son personas en situación de aislamiento social derivado de problemas clínicos (enfermedad mental) u otras situaciones vitales.

El lugar de desarrollo es el aula de Acción Social del MAC y resto de instalaciones del museo, incluidas las propias Salas de Exposición.

\subsection{Lembrart, Programa de entrenamiento de la memoria y otras capacidades cognitivas}

Es un programa de Participación Social en actividades artísticas y creativas, específicamente diseñado para la estimulación de las habilidades cognitivas básicas (memoria, atención, concentración, orientación espacio temporal y conocimiento de la actualidad) en personas mayores y con inicio de deterioro cognitivo.

Sus objetivos son:

- Experimentar activamente el arte como instrumento de rehabilitación y entrenamiento de las capacidades cognitivas básicas.

- Mejorar el rendimiento cognitivo global de los participantes.

Está dirigido a personas mayores de 50 años; que se puedan beneficiar de un programa de entrenamiento específico de sus capacidades cognitivas, con independencia de tener algún tipo de deterioro o patología. Los usuarios de 
este programa han sido derivados de los Centros Cívicos cercanos al MAC.

El lugar de desarrollo es el aula de Acción Social del MAC y resto de instalaciones del museo, incluidas las propias Salas de Exposición.

\subsection{Integración activa}

Esta línea de acción desarrolla actividades específicamente diseñadas para grupos mixtos: adultos y niños afectados, con grupos de adultos y niños no afectados. Su objetivo es estimular la incorporación a actividades de creación en las que participan centros educativos ordinarios y centros de educación especial o centros de afectados.

Son actividades de este programa: conciertos, talleres de música, sesiones de dramatización, sesiones de percusión corporal, actividades con los alumnos de la Universidad de A Coruña, sesiones con los trabajadores de diferentes empresas, rutas culturales por el MAC y juegos artísticos.

El lugar de desarrollo es el aula de Acción Social del MAC y resto de instalaciones del museo, incluidas las propias Salas de Exposición.

El equipo técnico del departamento de Acción Social del MAC (dirigido por Carmen Fernández Rivera) que diseñó los programas está constituido por personal especializado en el ámbito sociosanitario y los desarrolla en colaboración con la consultoría Adaptasocial, la Asociación Participa para la Inclusión Social, y la Diputación de A Coruña (en el programa de ámbito provincial).

\section{Valoración de resultados}

La evaluación de los programas abarca una doble vertiente. Por una parte, proporcionar experiencias enriquecedoras a los participantes en un medio seguro, estimulante e inexcusablemente adaptado a sus capacidades. Por otra, evidenciar una coherencia entre los objetivos de los programas y el resultado obtenido.

En este contexto, evaluar significa: reflexionar en cuanto al diseño, al proceso desarrollado por los participantes y al contexto social y espacial de los programas.

Para llevar a cabo la evaluación se utilizan dos instrumentos (en forma de documentos) fundamentales. Uno de ellos lo cubren los técnicos al término de cada sesión de visita y actividad.

En ese formato se registrarán: el grupo de participantes, el módulo de actividades propuestas, las incidencias y sus observaciones en relación con la sesión. El otro es un cuestionario de satisfacción entregado a los usuarios, y acompañantes/responsables de cada grupo de visitantes. El cuestionario presenta para su valoración una serie de ítems que proporcionarán información sobre los aspectos de organización y gestión del programa y medios dispuestos para su desarrollo. Todos los datos obtenidos se vuelcan para su tratamiento estadístico y, posteriormente, se elabora un Informe Semestral de Impacto.

Los resultados de las valoraciones reflejan un alto nivel de satisfacción respecto de la participación: un 8,56 sobre ıo. En relación con la contribución a mejorar los niveles de participación social, el $93 \%$ de los responsables y técnicos de las entidades participantes registran una influencia directa y atribuible al programa.

Desde el inicio de actividades en el año 2005 , más de I 50 equipamientos y entidades y un total de 23.700 participantes se han beneficiado de las actividades de Acción Social del MAC.

En el pasado año 20I4, el número de participantes fue de $5 \cdot 778$, distribuidos de la siguiente forma: 
- Programa de Participación Social a través del Arte Contemporáneo: 2.0I 8 participantes.

- Programa Provincial de Participación Social: 2.55 I participantes.

- Acompañ@rte: 375 participantes.

- Lembrart: 548 participantes.

- Integración Activa: 286 participantes.

\section{Conclusiones}

Partiendo de la idea sencilla de tender un "puente sin peaje”, desde el departamento de Acción
Social del MAC somos conscientes de que la mayor situación de marginación la proporciona la carencia de recursos. Por ello, y en colaboración con las Unidades de Atención Social, en los últimos años se han incorporado participantes en situación de exclusión social por motivos fundamentalmente económicos. De esta forma, hemos extendido las actividades a personas no afectadas, pero en situaciones vitales complejas. Porque entendemos que, desde la idea de ocio como derecho fundamental, no podíamos dejarles fuera de un programa voluntario y gratuito. $\mathrm{Y}$ esa es la intención de la actividad del departamento, incrementar la calidad de vida de los participantes a través de actividades relacionadas con el arte contemporáneo, y colaborar en la mejora de su salud social. 


\section{Referencias bibliográficas}

Axel, E., y Levent, N. (2003): Art beyond sight. New York: AFB Press.

Cátedra Ocio y Discapacidad (20I4): Manifiesto por un ocio inclusivo. Instituto de Estudios de Ocio, Facultad de Ciencias Sociales y Humanas, Universidad de Deusto, Bilbao (en línea). $<$ http://avifes.org/wp-content/uploads/201 5/o7/ Manifiesto-Ocio-castellano.pdf>, acceso 7 de diciembre de 2015 .

EUCREA España (I989): Acta Fundacional (en línea). <http://www.eucrea-international.org/ fr/eucrea_international.php $>$, acceso $7 \mathrm{de}$ diciembre de 2015 .

Rodriguez, J. et al. (20I2): Programa de participación social a través del arte contemporáneo para personas con diversidad funcional. Museo de Arte Contemporáneo Gas Natural Fenosa (MAC) de A Coruña.

Salmen, J. (1998): Everyone's welcome: The Americans with Disabilities Act and Museums. Washington, DC: Smithsonian Institution. 



\section{La sordera: una oportunidad para descubrir la música}

\section{Deafness: an opportunity to discover music}

\section{Palabras clave}

Música, sordera, persona Sorda, sonido, vibración, silencio.

\section{Keywords}

Music, deafness, Deaf person, sound, vibration, silence.
El aire vibrante golpeó las membranas del tímpano de Lord Edward; el sincronizado martillo, el yunque y el estribo se pusieron en movimiento

hasta sacudir la membrana de la ventana oval y producir una historia infinitesimal en el fluido del laberinto. Las terminaciones vellosas del nervio auditivo se agitaron como olas en un mar alborotado; un gran número de oscuros milagros se produjeron en el cerebro, y Lord Edwar susurro extasiado “¡Bach!”. Sonrió con placer, le brillaron los ojos.

(Aldous Huxley, citado en Swanwick, 2000).

La música, como lo muestra el epígrafe que da inicio al presente ensayo, ha sido típicamente entendida como un fenómeno acústico, íntimamente relacionado con los componentes estructurales del sistema auditivo y sin los cuales resulta impensable que se pueda percibir. Dado esto, las experiencias musicales han sido concebidas para las personas oyentes y no para las personas Sordas ${ }^{\mathrm{I}}$, quizá porque resulta desconcertante tan siquiera imaginar como una persona que no puede

I. "Sordo" (con mayúscula) que se refiere a una persona que no oye, que utiliza una lengua de signos como primera lengua y además, se identifica a sí misma con otras personas Sordas (Estrada, 2008: 8).

\section{Liliana Elizabeth Otero \\ Caicedo \\ <leoteroc@unal.edu.co>}

Universidad de Nariño, Colombia

Para citar:

Otero, L. (2OI 5): "La sordera: una oportunidad para descubrir la música", Revista Española de Discapacidad, 3 (2): I33-I37.

Doi: <http://dx.doi.org/I0.5569/23405104.03.02.09> 
escuchar el sonido pueda vivenciarlas de una forma genuina y diferente. Lo que se pretende en este escrito es sostener que la música va más allá de la sensación que se percibe en el oído y que es definida como sonido, razón por la cual la sordera no se constituye en un impedimento para poder percibirla.

Ingenuamente se presume que el sonido se refiere al material acústico que llega al sistema auditivo y por lo tanto una persona Sorda no podría escucharlo. No obstante, quienes se convencen de esta idea, olvidan que el sonido es una vibración originada de un cuerpo y difundida mediante ondas. Éste presenta, según Gustems (2006) cuatro cualidades: a) el timbre, que permite distinguir los sonidos de las voces y diferentes instrumentos musicales; b) la intensidad, que indica la fuerza del sonido, si es fuerte o débil; c) la duración, que está asociada con el tiempo que determina los ritmos musicales, y d) la altura, que posibilita la distinción entre sonidos graves y agudos. Al igual que el sonido, la música tiene elementos estructurantes como: a) el ritmo, que es una combinación de sonidos según sus duraciones; b) la armonía, en la cual se combinan los sonidos de forma simultánea, y c) la melodía, formada por combinaciones de sonidos según sus alturas (notas) con un ritmo determinado. Como podrá notarlo el lector, estos elementos musicales están estrechamente relacionados con las cualidades del sonido, en otras palabras, tienen como base la vibración, por lo cual la música no requiere únicamente de la audición para ser percibida.

Teniendo en cuenta lo anterior, no es desacertado pensar que una persona Sorda pueda realizar una apreciación musical con todo su cuerpo, ya que el sonido al ser una vibración que tiene la virtud de cristalizarse en la piel, trasciende la mera sensación auditiva. Para sustentar lo anterior, Infante (2005) afirma que en el silencio, la persona Sorda siente las vibraciones internas, por lo que el sonido de la música puede hacer que su cuerpo vibre contantemente, como si alguien le tocara delicada y profundamente, o como si alguien estuviera dentro del cuerpo golpeando el estómago, intestinos, pulmones y hasta los huesos.
Es relevante mencionar en este punto una investigación realizada por Yennari (20IO) quien retoma diferentes estudios en los cuales se plantea que las personas Sordas presentan dificultades en la percepción del timbre, la altura, reconocimiento de la melodía y que el único aspecto de la música que parece ser percibido adecuadamente, como las personas oyentes, es el ritmo. Al respecto, caben dos cuestionamientos acuciantes. En primer lugar, pareciese que el hecho de que una persona Sorda perciba el ritmo es un aspecto insulso. Sin embargo, según Maneveau (I993) el ritmo por sí solo ya es música, pues éste organiza la dimensión misma de la música y se constituye en un elemento esencial en ella. Lo que se puede decir al respecto es que el ritmo es un elemento substancial de la música y no un simple agregado, lo que demuestra que si una persona Sorda puede percibir el ritmo, indiscutiblemente está también percibiendo la música, y que además, puede hacerlo con todo su cuerpo.

En segundo lugar, la investigación ya relacionada y otra realizada por Gordon, Hopyan y Papsin (20II) son una pequeña muestra de que los estudios que se realizan en torno a la música y a las personas Sordas, usualmente hacen comparaciones entre personas oyentes con audición "normal” y personas Sordas, en las que obviamente se afirma que estas últimas no pueden percibir la música como lo hacen los oyentes. Lo que se objeta al respecto es ¿por qué se espera que las personas Sordas escuchen igual que los oyentes?, ¿acaso sólo existe una manera de escuchar y sentir la música?, ¿por qué es necesario comparar la experiencia musical de una persona Sorda con la de una persona oyente y querer normalizarla con diferentes tecnologías como el implante coclear?, ¿se puede decir que hay una manera buena o mala, normal o anormal, de experimentar la música?

Desde el punto de vista de quien escribe este ensayo, y con base en lo que se ha expuesto hasta el momento, una persona Sorda puede disfrutar plenamente de la música desde sus capacidades, sin requerir de audífonos o implantes cocleares que pretenden encajar la música en una ideología normalizadora que 
la circunscribe. Además, si se deconstruyeran estos paradigmas para crear posibilidades inverosímiles, como el hecho de que la música pueda ser escuchada sin necesidad de que el sonido sea percibido por el aparato auditivo, se comprendería gracias a las personas Sordas que en este arte no existen barreras y que no hay maneras buenas o malas en las que la música pueda ser percibida. Simplemente diferentes.

Siendo coherente con el planteamiento anterior y partiendo de la premisa de que las personas Sordas pueden vivenciar de manera diferente la música, no es posible que ésta sea reducida a una combinación de elementos musicales, ejecuciones prodigiosas, composiciones perfectas, representantes memorables, géneros o modas. El poder de la música radica en la fuerza que tiene para despertar el deseo de compartir sentimientos, prácticas, concepciones del mundo y significados que las personas construyen y los interpelan en la interacción. En otras palabras, la música posibilita la construcción de escenarios diversos que producen sentidos articulados con los ámbitos social, económico, político y cultural de cada sociedad, en la medida en que ofrece una experiencia con un profundo componente vivencial que involucra distintas dimensiones del ser (Carballo, 2006; Cabello y Hormigos, 2004; Díaz y Flores, 2009; Díaz, 2010; Samper, 20Io). Por lo tanto, la música, desde esta perspectiva, es mucho más que un fenómeno acústico, es un pasaje vivo-emocional-relacional a través del cual se pueden crear espacios en donde la sordera no sea un impedimento para que las personas puedan crear y re-crear sentidos en la interacción. Además, no cabe la menor duda de que la música puede convertirse en el pretexto perfecto para la creación de escenarios que favorezcan la inclusión social y cultural de las personas Sordas en entornos que tradicionalmente sólo han sido contemplados para las personas oyentes, desconociendo que con adaptaciones pertinentes, la música es un arte que le pertenece a todos, sin ninguna excepción.

Cabe aclarar que, al hablar de adaptaciones pertinentes, se hace referencia a los ajustes que se realizarían a los contextos musicales con el objetivo de brindar a las personas Sordas la accesibilidad para participar de la experiencia musical. Al respecto, Peter y Wills (2000) afirman que un niño Sordo puede experimentar la música sintiendo las vibraciones, por lo que para favorecer dicha experiencia es necesario contar con instrumentos con grandes cajas de resonancia cuyas vibraciones se puedan sentir, utilizar aquellos instrumentos que produzcan sonidos muy agudos o graves y un suelo de madera o de un material conductor, con el fin de que se experimente una sensación de vibración muy aumentada. Estos autores también mencionan que se puede experimentar la música mediante el refuerzo de un estimulo visual (un instrumento coloreado de forma llamativa), lo cual tiene concordancia con la perspectiva de Alonso (20I I) quien plantea que los sonidos poseen un determinado color e incluso propone que es posible establecer una correspondencia entre el color y el timbre de los instrumentos o voces. Podría pensarse entonces en la utilización de proyectores de luz que vayan de la mano con el ritmo, que muestren los matices presentes en la música y sean la metáfora de las sensaciones que producen los instrumentos. Finalmente, seria imprescindible que las letras de canciones sean traducidas a Lengua de Signos por un intérprete que encarne de manera prodigiosa la intención de la canción.

Contrariamente a lo que podría pensar el lector con lo mencionado anteriormente, no se trata de encajar a las personas Sordas en el mundo de los oyentes, sino de comprender que no existe tal cosa, es decir, que el mundo de los oyentes y los Sordos es el mismo y que ambos están inmersos en una cultura que los define y que son parte de la construcción de la misma. Además, no se trata de que las personas Sordas experimenten la música de la misma manera que las personas oyentes, sino de desvelar que existen otras formas de percibir la música, igualmente válidas y dignificantes, lo que demuestra que los escenarios musicales y la educación musical deben contemplarse para las personas Sordas, ya que según Lubet (2009) la participación en experiencias musicales es un derecho de los seres humanos. 
Por lo tanto, de lo que se trata es de una cuestión de justicia pues, como lo plantea Nussbaum (2007), la sociedad debe ofrecer las condiciones necesarias para que ciertas capacidades, como las que poseen las personas Sordas en relación a la música, puedan desarrollarse en escenarios de elección, es decir, que se ofrezcan las adaptaciones para que estas personas elijan o no participar en el disfrute de ésta experiencia, enfatizando en que lo importante es que se confiera esta opción.

Así, las personas Sordas, no tendrían que adaptar sus preferencias, como consecuencia de un contexto con condiciones injustas, a lo que la comunidad oyente piensa que pueden alcanzar y a lo que su sociedad les dice que es una meta adecuada para alguien como ellos. Por lo tanto, lo que se pretende es propiciar la inclusión, entendida como la igualdad de oportunidades, por medio del encuentro de dos comunidades lingüísticas diferentes en donde se compartan las distintas maneras de vivenciar la música y por ende de comprender el mundo, posibilitando la redefinición de paradigmas excluyentes en torno a la comunidad sorda y la consecución de la trasformación social. Sin duda, en esto radica el auténtico valor de la música. 


\section{Referencias bibliográficas}

Alonso, A. (20I I): El Color de Los Sonidos. Madrid: Editorial Visión Libros.

Cabello, A. y Hormigos, J. (2004): “La construcción de la identidad juvenil a través de la música”. Revista Española de Sociología, 4:259-270.

Carballo, P. (2006): "La música como práctica significante en los colectivos juveniles". Revista de Ciencias Sociales. Universidad de Costa Rica, (III-IV): II3-I I 4 .

Díaz, J. y Flores, E. (2009): "La respuesta emocional a la música: atribución de términos de la emoción a segmentos musicales”. Salud Mental, 32 (I): 2I-34.

Díaz, J. (20I0): “Música, lenguaje y emoción: una aproximación cerebral”. Salud mental, 33 (6): 543-55I.

Estrada, B. (2008): Salud mental: Depresión y sordera. Monterrey: Editorial Universidad Autónoma de Nuevo León.

Gordon, A. et al. (20I I): "Identifying emotions in music through electrical hearing in deaf children using cochlear implants”. Cochlear Implants International, I 2 (I): 2I-26.

Gustems, J. (2006): Atlas básico de música. Editorial Parramón.
Infante, M. (2005): Sordera: Mitos y realidades. San José (Costa Rica): Editorial Universidad de Costa Rica.

Lubet, A. (2009): "Disability, music education and the epistemology of interdisciplinarity". International Journal of Qualitative Studies in Education, 22 (I): I I9-I32.

Maneveau, G. (I993): Música y educación. Madrid: Ediciones Rialp.

Nussbaum, M. (2007): Las fronteras de la justicia. Barcelona: Editorial Paidós.

Peter, M. y Wills, P. (2000): Música para todos. Desarrollo de la música en el currículo de alumnos con necesidades educativas especiales. Madrid: Ediciones AKAL.

Samper, A. (2010): "La apreciación musical en edades juveniles: territorios, identidad y sentido". Cuadernos de música, artes visuales y artes escénicas, 5 (2): 29-42.

Swanwick, K. (2000): Música, Pensamiento y Educación. Madrid: Ediciones Morata.

Yennari, M. (20IO): "Beginnings of song in young deaf children using cochlear implants: the song they move, the song they feel, the song they share". Music Education Research, I 2 (3): 28 I-297. 



\section{ASPAYM Córdoba a fondo}

\section{ASPAYM Cordoba in detail}

\section{Palabras clave}

Lesión medular, discapacidad, discapacidad física, diversidad funcional, integración social, Córdoba, ASPAYM Córdoba.

\section{Keywords}

Spinal cord, disability, physical disability, functional diversity, social integration, Córdoba, ASPAYM Córdoba.
La Asociación de Personas con Lesión Medular y Gran Discapacidad Física de Córdoba - ASPAYM (en adelante ASPAYM Córdoba) es una asociación de personas con lesión medular y gran discapacidad física que nace en 2008 como ALMA y cambia su nombre en 2012 para unirse a la Federación Nacional ASPAYM.

La lesión medular es la pérdida o alteración de la movilidad, de la sensibilidad o del sistema nervioso autónomo, ocasionada por un trastorno de las estructuras nerviosas alojadas en el canal medular. Dependiendo de la localización del daño, podrá afectar a órganos pélvicos, extremidades inferiores, tronco y abdomen y extremidades superiores, provocando desde dificultades leves en la movilidad, hasta paraplejia o tetraplejia.

El objetivo de la asociación es mejorar la calidad de vida de todas las personas con movilidad reducida, promoviendo su desarrollo integral y trabajando por la integración social y laboral.

Durante el año 20 I 5 se ha llevado a cabo el Proyecto "ASPAYM Córdoba a fondo", realizando entrevistas a varios de los socios de ASPAYM Córdoba para conocer la realidad de estas personas que han sufrido situaciones difíciles y dolorosas,

\section{Esther Carrasco Rivero}

<aspaymcordoba.ts@gmail.com>

Asociación ASPAYM Córdoba. Psicóloga en Asociación ASPAYM Córdoba (España)
Para citar:

Carrasco, E. (20I 5): “ASPAYM Córdoba a fondo", Revista Española de Discapacidad, 3 (2): I39-I43.

Doi: <http://dx.doi.org/IO.5569/23405IO4.03.02.IO> 
tanto que han hecho cambiar su forma de ver y afrontar la vida. La finalidad es ofrecer sus historias a la población general para aumentar la conciencia social sobre estas lesiones y facilitar la inclusión social, psicológica y laboral de los afectados. Éste es el resultado:

Hace 44 años sufre un accidente de tráfico, recuerda el día perfectamente, tenía 20 años recién cumplidos:

"El I9 de octubre de I970, estaba trabajando canalizando un arroyo en Marchena, aún no había amanecido, iba en mi moto por la carretera de Palma del Río a Écija. Venían tres camiones de frente con las luces encendidas y no vi el carro tumbado en mi carril".

Se rompió las vértebras cervicales, y durante el traslado hasta Sevilla, improvisado por personas de a pie, sufrió más daños y fue muy doloroso. Tuvo momentos de pérdida de consciencia pero lo recuerda casi todo. Los daños que sufre le dejan con tetraplejia.

"Cuando volví a casa ponía buena cara a los demás, pero quería morirme, no veía salida. ¿Qué voy a hacer en esta vida si no sirvo para nada?, ¿quién me va a querer? Nadie creía que yo sirviera para algo, antes tenía éxito con las mujeres y ahora no quería arriesgarme a que me rechazaran, así que no intentaba nada, ni siquiera hablaba con ninguna".

Este es Salvador, uno de nuestros socios. Nos cuenta su historia con tanto realismo que parece que podemos ver su vida pasar. Hechos innegables, ilusiones perdidas, momentos duros, y luego... la luz de nuevo.

"El psiquiatra insistía en que 'todos servimos para algo', y que 'hay personas en silla de ruedas que valen más que muchos de los que andan'. A partir de ahí comencé a estudiar y eso me animó. Luego me ocupé de las tierras de mi padre y junto a mis hermanos, compramos más tierras y vivimos de ello".

También se atrevió con el amor, su asignatura pendiente:
"Hasta que no vi en un viaje gente como yo que había conseguido tener pareja, no me atreví a intentarlo". Años después se casó y se encuentra feliz y realizado. "Mantengo una lucha permanente, en cuanto pasa el invierno no paro en casa, quiero viajar en verano todo el tiempo que se pueda. Salgo mucho, hablo con la gente, me informo sobre el campo y voy cambiando los cultivos".

Escribió un libro y tiene otro en mente.

Rafa sufre un accidente cuando realiza una zambullida en San Sebastián, donde se encuentra trabajando como policía nacional. Reconoce que estaba en su mejor momento. "Lo tenía todo, era joven, tenía coche, moto", y allí era donde quería quedarse a vivir y trabajar, "me gusta mucho la montaña, el norte de España y mi trabajo lo hacía por vocación”.

Despierta en el hospital desorientado, con un arco en la cabeza y el cuerpo lleno de tubos. "La situación me resultaba absurda”. Se produjo una lesión medular en $\mathrm{C}_{6}-\mathrm{C}_{7}$, no tiene sensibilidad ni musculatura ninguna desde el pecho hacia abajo. Tampoco en antebrazos y manos. Le practicaron una operación para tensar el tendón en la mano derecha y poder usarla como pinza para coger cosas.

Tras 20 días en la UCI, y casi nueve meses en planta, se replantea su vida:

"Fueron momentos duros pero pensé que es una nueva vida, un nuevo reto, que tenía que partir de cero".

Pasó momentos muy duros, lo considera "una oportunidad obligada para ver, sentir y vivir otro tipo de vida". "Encuentras gente muy especial, vives cosas que te enriquecen como persona, sientes que las cosas no podían ser de otra forma".

“Todos los días vas aprendiendo, más de errores que otra cosa". Aprende cada día cosas que no le pueden enseñar en ningún sitio. "Los amigos no sabían que hacer conmigo al principio, yo era 


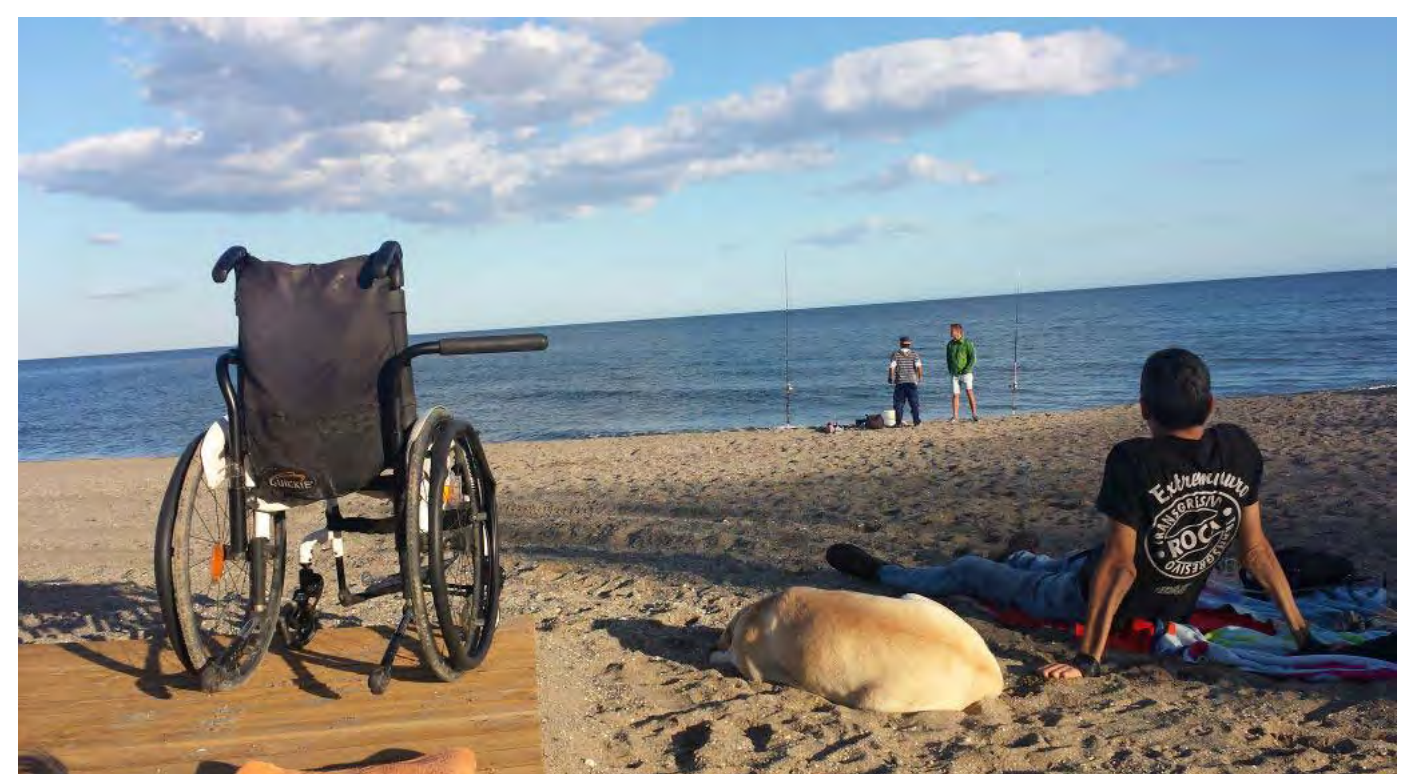

Nuestro compañero Rafael disfrutando de un día de playa.

el que los movía a todos y montaba los peroles cuando venía a Córdoba”.

"Yo antes vivía al límite: montaña, deportes, motos... ahora considero que vivo más al límite".

Y se refiere a vivir desde su silla de ruedas, en la que tiene muy poca movilidad y estabilidad, y puede caerse en cualquier momento. Y vive solo.

Lola sufrió un accidente de tráfico cuando derrapó la furgoneta de trabajo en el puerto de montaña de Despeñaperros: "noté un crack y no podía levantarme; pedía a Dios que no me muriera en aquella carretera tan fría”.

Conducía su novio, quien más tarde sería su marido: "se sentía culpable al principio, yo le dije que esto iba a ser muy duro y si quería podía dejar la relación; él me dijo que no se iba a ir de mi lado".

"Me di cuenta inmediatamente que eso era lo que tocaba y tenía que afrontarlo. Los dos primeros meses estuve aguantando con actitud positiva, queriendo mejorar pronto para hacer cosas. Luego reventé y me arroparon muy bien. Soy muy positiva, creo que es mejor así, la negatividad no te deja avanzar".

Recuerda que su estancia en el Hospital Nacional de Parapléjicos de Toledo fue muy buena, aprendió a manejar la silla y a valerse por sí misma. "Siempre he sido muy autónoma. Había mucho compañerismo y lo llevas bien, todos van en silla de ruedas”. Allí se sacó el carnet de conducir y se decidió a alquilar un piso junto a su novio al volver a Córdoba.

Se casó y tuvo dos hijos. Hace todo en su casa: compra, cocina, limpia... "hasta donde me llega el brazo". Y en la calle: traslada a los niños en su coche al colegio, a las actividades, a las citas con los amigos. Hace todo lo que quiere, y se considera feliz. También realiza charlas de prevención de accidentes de tráfico junto a ASPAYM Córdoba.

"Todavía me sorprendo de las cosas que puedo hacer, me supero cada día. Soy feliz. Esto es muy duro y te cuesta cada día, pero me quedo con el SÍ”. 


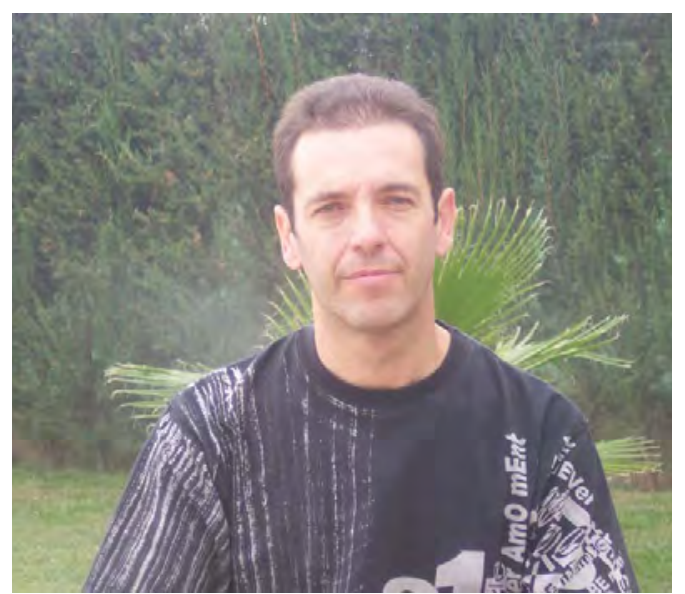

Manuel en uno de sus paseos.

En r996, Manuel llevaba una vida normalizada, con mujer y dos hijos de 2 y 4 años. Un día, mientras trabajaba como vigilante de seguridad, recibió tres disparos en un atraco a un banco. Sufrió una lesión medular, además de perforación en algunos órganos internos. "Supe que algo pasaba porque no me sentía las piernas".

Tras tres meses en la UCI, en los que surgieron muchas complicaciones, le trasladan al Hospital Nacional de Parapléjicos de Toledo, donde permanece un año.

"Allí es donde me encuentro con mi discapacidad cara a cara", la mayoría de los pacientes son parapléjicos y van en silla de ruedas, como él. Acompañado de su mujer, que pasa todo el día con él en el hospital, aprende a usar la silla y a realizar tareas básicas de la vida diaria; sin embargo refiere: "no lo aceptaba, no quería quedarme en una silla de ruedas para siempre, y aún no lo acepto”.

Acude a rehabilitación al Hospital Reina Sofía y posteriormente al Hospital San Juan de Dios. Sin embargo, su ánimo no mejora, continúa sintiéndose "triste, sin ganas de nada", afectándole a su día a día y a la relación con su familia: "no quería salir ni saber de los niños".

Su mujer ha estado siempre tratando de empujarle a hacer cosas y Manuel ha ido mejorando muy lentamente: "iba arrancándolo a la fuerza poco a poco".

Los hijos han jugado un papel fundamental, lo que les ha mantenido en un camino estable. Su hija, al contar con sólo dos años cuando ocurrió el accidente, siempre le ha conocido así y no ha tenido que aceptar el cambio, incluso quería realizar todas las tareas de cuidado, hasta llevar la silla. Sin embargo, su hijo, que tenía cuatro años, sí lo vivió con más complejidad y tardó en normalizar la situación. Hasta que no pasó la adolescencia no lo aceptó del todo.

Disfrutan de salidas de ocio frecuentes con familia y amigos, gustan de dar paseos, tomar una cerveza en una terraza, hacer peroles camperos y, sobre todo, pasar el verano en la playa.

Alfonso, socio y deportista, también tiene una gran historia:

“A los I 8 años sufrí un accidente de moto provocado por un coche que giró a la izquierda mientras yo adelantaba”. Estuve r 6 meses en hospitales: dos y medio en el Virgen del Rocío y el resto en San Juan de Dios, unidad de lesión medular. Muy buenos profesionales, sobre todo el monitor de silla de ruedas, me hacía caerme para que aprendiera a levantarme, no tenía piedad, y eso me ayudó mucho”.

El primer recuerdo tras el accidente fue muy duro:

"No se lo deseo ni a mi peor enemigo: darte cuenta de que no mueves las piernas, que no puedes hacer las cosas por ti mismo, que dependes de los sanitarios, de tu madre. Pero si te vienes abajo, ¿qué clase de vida vas a tener?”.

"No he echado muchas cuentas a mis limitaciones, he mirado hacia adelante; no me sirve mirar atrás y ver personas peor que yo, no puede ser una satisfacción, es una estupidez. Si miras atrás y ves que estás mejor que hace años, sí te sientes satisfecho de verdad". 


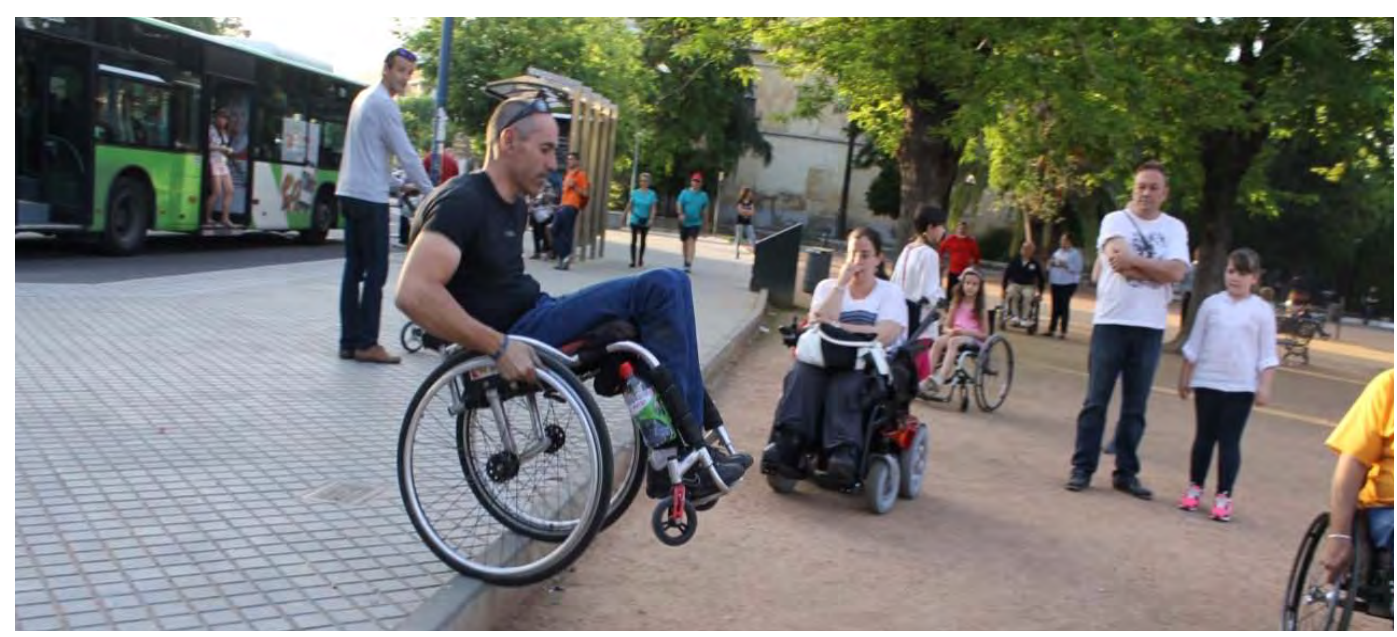

Nuestro deportista Alfonso realizando una exhibición de silla de ruedas para ASPAYM Córdoba.

"Mi padre tenía sentimientos de culpa por haberme comprado la moto. Yo nunca he pensado que tuviera la culpa, al contrario, hizo mi sueño realidad". "Mi madre me acompañó en todo momento. Lo malo es que yo tenía que ser fuerte para que mi madre no sufriera, no me ha permitido desahogarme".

Tiene mujer y dos niñas y hacen una vida normalizada como cualquier familia.

“Las niñas me decían: 'Papá, ¿cuándo te vas a levantar?’, ellas se acostumbran rápidamente, diferencian bien enfermedad de discapacidad".

Trabaja como formador de prevención vial:

"Me llena el trabajo que estoy realizando porque transmitir mi problema puede hacer que los chavales no pasen por esto $y$ concienciar a los infractores de lo que puede ocurrir".

Reconoce que “se pasa” con el deporte:

"Me he volcado demasiado, realizo deporte a diario, soy semiprofesional. Llevo siete años compitiendo, y cinco años subiendo al podio del Campeonato de España. Hay pocos patrocinadores y muchos gastos. Todo esto es tiempo que le quito a la familia, soy consciente de ello y me apena, pero es mi trabajo y mi satisfacción".

Esto son sólo algunos ejemplos de lo que podemos encontrar en ASPAYM Córdoba, personas con increíbles historias reales, vidas llenas de vida y días para afrontar lo que haga falta. Vidas que se han truncado por accidentes de tráfico, atracos o caídas, pero que han luchado por seguir adelante y que, gracias a los avances médicos y la atención apropiada, pero sobre todo a sus familiares y amigos, han tenido una segunda oportunidad.

También hay enfermedades que provocan lesiones medulares que se van agravando, algunas más lentas, otras rápidamente, y cuyas consecuencias son siempre las mismas: la dificultad para vivir de forma autónoma.

Por todos lados vemos que hay muchas más personas así, que encuentran continuamente complicaciones para desplazarse por casa, por la calle, para realizar las tareas diarias, para relacionarse con los demás o para trabajar, y desde ASPAYM Córdoba luchamos para reducir los riesgos de sufrir nuevos accidentes y que toda la sociedad tome conciencia y colabore para facilitar la integración y la igualdad de todos, porque son nuestros vecinos, nuestros amigos... nuestros iguales. 



\section{RESEÑAS}





\section{Los beneficios de la inclusión social de las personas con discapacidad Gregorio Rodríguez, Julia Montserrat Codorniu y Vicente Marbán (2015) Madrid: Grupo Editorial Cinca}

\author{
SIIS Centro de Documentación y Estudios \\ $<$ documentacion@siis.net> \\ Fundación Eguía-Careaga
}

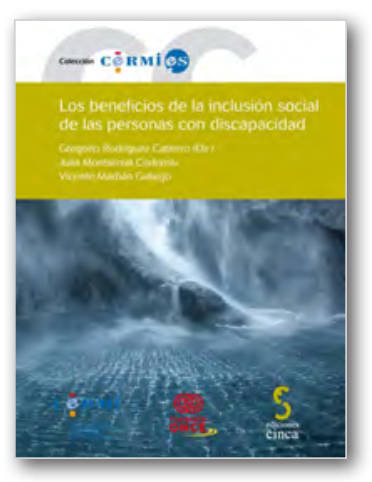

El presente estudio se enmarca dentro de la colección Cermi.es, que recopila obras, estudios e informes con el fin de conocer y analizar aspectos de la discapacidad o proponer vías de acción política que mejoren las condiciones de vida o ciudadanía de las personas con discapacidad y sus familias.

Desde esta perspectiva, Los beneficios de la inclusión social de las personas con discapacidad pretende aportar evidencias de que efectivamente las políticas de discapacidad son una inversión y, de manera particular, las dirigidas a la inclusión laboral y la mejora educativa. Más allá de implicaciones legales y normativas, los autores defienden que la inclusión tiene beneficios para toda la sociedad, monetarios y no monetarios, directos $\mathrm{e}$ indirectos.

Prologado por el presidente de la ONCE, Miguel Carballeda, este trabajo innovador se enmarca en el contexto de la Estrategia Española sobre Discapacidad 20I2-2020, que tiene como objetivo general promover el acceso al empleo, elevar el nivel educativo y facilitar el acceso a los diferentes lugares de la vida de las personas con discapacidad. En línea con esos objetivos, que también forman parte de la Estrategia Europea de Discapacidad 2010-2020, el presente estudio analiza el efecto de las políticas activas de empleo en la reducción de la pobreza y generación de retornos positivos, el papel de la educación como inversión social tanto para la persona con discapacidad como para el conjunto de la sociedad y el papel clave de la accesibilidad para garantizar la eficiencia y efectividad de esas políticas de empleo y de educación en la vida cotidiana de las personas con discapacidad.

El objetivo fundamental del trabajo es evidenciar que las políticas de discapacidad se constituyen como una inversión que genera importantes beneficios (tanto económicos y sociales como individuales y colectivos), en especial las dirigidas a la inclusión laboral y la mejora formativa. El enfoque del estudio se basa en la perspectiva de derechos, tomado de la Convención de la ONU sobre los Derechos de las Personas con Discapacidad, la Estrategia Europea 2020, la Estrategia Europea de Discapacidad y la Estrategia Española sobre Discapacidad 20I2-2020. Entre los objetivos de todos estos textos normativos figura el desarrollo de la educación, la formación continua, el acceso al empleo y una calidad de vida que garantice la dignidad de las personas. De ahí que los tres ámbitos de inclusión utilizados para valorar las políticas de discapacidad sean, precisamente, el empleo y la formación ocupacional, la educación reglada y la accesibilidad.
Para demostrar la eficacia y rentabilidad de las políticas sociales de inclusión laboral, el libro describe los avances normativos en materia de discapacidad desde la puesta en marcha de la Ley I3/I982 de Integración Social de los Minusválidos (LISMI), sus efectos en las políticas públicas de empleo y los resultados que en la vida de las personas con discapacidad han tenido, medido a través de un conjunto de indicadores de inclusión social, entre los que destacan diversos indicadores en relación con la actividad y el empleo, la renta (incluyendo datos estadísticos relativos a las diferencias salariales entre personas con y sin discapacidad) e indicadores de cohesión social, como la tasa de riesgo de pobreza y la concentración de rentas de las personas con discapacidad.

Del análisis de los indicadores propuestos para la valoración de las políticas activas de empleo dirigidas a personas con discapacidad podemos deducir que las citadas políticas ayudan a reducir el riesgo de pobreza y generan entornos positivos, por lo que deben ser consideradas como una inversión del Estado.

Revista Española de Discapacidad, 3 (2): I47-I 49 . 
Si bien el libro explica que se trata de una inversión que tiene un coste en incentivos a la contratación de aproximadamente 957 millones de euros al año, también se nos advierte de que los beneficios que genera ascienden a 2.I 54 millones de euros, lo cual supone una tasa de retorno de 2,25 euros por euro invertido. Ese retorno alcanza los 3,94 euros por euro si incluimos en la ecuación los beneficios indirectos derivados del incremento del bienestar en la persona con discapacidad, su familia y su entorno. El análisis de los datos aportados en el estudio nos lleva a deducir que, a mayor inversión en este ámbito, mayores serán los beneficios sociales.

En lo que respecta a la inclusión educativa, el estudio hace un repaso de la literatura existente sobre los beneficios económicos y no económicos de la educación de las personas con discapacidad y analiza la relación entre formación y empleo del colectivo, valorando los costes y beneficios salariales de los distintos niveles educativos.

$\mathrm{Al}$ igual que ocurre con las políticas sociales de inclusión laboral, la inversión realizada en políticas de inclusión educativa también genera beneficios tanto a nivel individual como en el conjunto de la sociedad. El texto advierte al lector de que, en España, la educación inclusiva se ha desarrollado con importantes logros pero también con grandes déficits. La experiencia en nuestro país, según ilustra el libro, demuestra que la rentabilidad no sólo depende de los recursos invertidos sino también de la organización educativa, de los compromisos institucionales y profesionales y de un clima social favorable a la educación inclusiva.

Los datos aportados en el trabajo extraídos del informe de la OCDE sobre la educación en España (MECD, 20I4) tienen en cuenta factores como la permanencia en el sistema educativo y el nivel de formación alcanzado. Una evidencia destaca sobre las demás: mayor nivel formativo implica mayor remuneración. En este sentido, al margen de si la inversión se realiza en educación secundaria o universitaria, o si los beneficiarios son personas con discapacidad moderada o severa, la tasa de retorno de cualquier inversión educativa de las analizadas en el marco de este estudio es positiva y, además de los monetarios, los autores también señalan beneficios como la mejora en salud y el aumento en la esperanza de vida a nivel individual o una mayor cohesión social desde un punto de vista colectivo.

Si bien en los ámbitos de empleo y educación el presente trabajo aporta datos y estadísticas concretas con los que analizar la efectividad de las políticas inclusivas a través de la inversión y los beneficios económicos y sociales de las mismas, en lo que respecta a la accesibilidad la recopilación de información cuantitativa resulta más complicada. En este caso, la publicación se centra en la valoración de algunos estudios y planes sobre accesibilidad en el entorno urbano, el transporte o la comunicación para constatar que, si bien todos ellos insisten en los beneficios económicos de la eliminación de barreras que frenan el acceso a la empresa, no existe una sistematización metodológica suficiente para la medición coste-beneficio de la inversión en accesibilidad universal. Se explica en el texto que se trata de un campo metodológicamente complejo y un reto todavía no resuelto, a pesar de existir algunas estrategias metodológicas que pueden ser de relativa utilidad. Según se advierte, para mejorar las políticas y seguimiento de la inclusión social desde la perspectiva de la accesibilidad, es clave fomentar la medición y analizar los costes y beneficios desde el primer momento en que se desarrollan los proyectos.

Conviene especificar que la accesibilidad al puesto de trabajo viene planteada en el estudio desde una perspectiva integral que comienza en el momento en el que la persona sale de su vivienda y discurre como un elemento transversal a todos los ámbitos (transporte, comunicación) del proceso de accesibilidad al y en el puesto de trabajo.

Entre sus conclusiones principales, el estudio constata las evidencias empíricas de que los beneficios son siempre superiores a los costes cuando se aplican programas de inserción laboral y formación ocupacional en el colectivo de personas con discapacidad, si bien las 
diferentes situaciones de empleabilidad producen tipos o modalidades de inserción con un mayor o menor beneficio económico y social.

Igualmente, el libro muestra cómo la promoción educativa proporciona un valor añadido superior a los costes efectuados. Uno de los elementos clave para aumentar el bienestar de las personas con discapacidad es su participación laboral, junto con su nivel retributivo. La evidencia empírica muestra una alta correlación entre educación y salarios. Concretamente, el libro aporta como dato relevante que, en el caso de las personas con discapacidad, las que cuentan con estudios universitarios ganan casi un $40 \%$ más que aquellas con estudios secundarios y un $72 \%$ más respecto a las que tienen estudios primarios.

Ante estas evidencias, la accesibilidad juega un papel clave en la eficacia de las políticas públicas dirigidas a fomentar la inclusión educativa y laboral de las personas con discapacidad. Y es que, según se advierte, es necesario que la accesibilidad esté presente en el diseño y aplicación de políticas dirigidas al colectivo, como marco favorecedor de las acciones de inclusión social y laboral y, para conseguirlo, es imprescindible sistematizar su medición para conocer el impacto de la misma en la inclusión social de las personas con discapacidad y en el conjunto de la sociedad. 



\title{
Discapacidad y políticas públicas. La experiencia real de los jóvenes con discapacidad en España

\author{
Amparo Cano, Eduardo Díaz, Susana Rodríguez, \\ Mario Toboso y Miguel A. V. Ferreira (2015)
} \\ Madrid: Los Libros de la Catarata
}

\author{
SIIS Centro de Documentación y Estudios \\ <documentacion@siis.net> \\ Fundación Eguía-Careaga
}

Esta publicación muestra los principales resultados del proyecto Quali-TYDES (Qualitative Tracking of Young Disabled People in European States) en España.

Se trata de una iniciativa enmarcada en el programa de la European Science Foundation (ESF), que trata de recopilar y analizar información acerca de la efectividad de las políticas públicas dirigidas a las personas con discapacidad nacidas en los años ochenta en cuatro países: España, Irlanda, Austria y República Checa.

\section{Discapacidad y politicas públicas se} centra en analizar en qué medida los nuevos avances en las políticas públicas a nivel nacional y europeo están repercutiendo en la vida de las personas jóvenes con discapacidad en España.

Para llevar a cabo la investigación, tanto en el caso español como en los demás países estudiados, se empleó una metodología fundamentalmente cualitativa, basada tanto en historias de vida (que ahondan en la experiencia y las aspiraciones de los propios jóvenes con discapacidad) como en el análisis crítico de la legislación vigente. El objetivo del proyecto Quali-TYDES a nivel internacional es comparar los regímenes político-jurídicos nacionales sobre discapacidad, en especial en la educación y en el empleo, y los posibles efectos de esa normativa en el bienestar social de los jóvenes con discapacidad.

Esta publicación profundiza en el estudio realizado en España y se centra en el impacto que en el colectivo de jóvenes con discapacidad ha tenido la aplicación de las distintas normas legales que, dirigidas a este colectivo, se han implantado desde la Ley I3/I 982 de Integración Social de los Minusválidos (LISMI) hasta la actualidad, fundamentalmente en los ámbitos de educación, empleo, promoción de la autonomía personal y atención a la dependencia.

De este modo, Discapacidad y políticas públicas complementa los datos estadísticos existentes, dotando a la información disponible de un nuevo enfoque en el que la experiencia, voz y expectativas de las personas con discapacidad son tenidas en cuenta en el diseño y ejecución de las políticas públicas relativas a la discapacidad.

Ya desde la introducción el libro nos advierte de que, al menos en el caso de España, las transformaciones en la legislación sobre discapacidad no siempre han supuesto para las personas con discapacidad un cambio sustancial en su calidad de vida ni en sus expectativas de futuro. Además, las políticas públicas nacionales no han tenido en cuenta las necesidades específicas derivadas de la condición corporal singular que poseen las personas con discapacidad. El resultado es que el colectivo cuenta con especiales dificultades de acceso a la plena participación en la vida social, a la inclusión real y, en definitiva, a la igualdad.

En la primera parte del libro se hace un repaso a la discapacidad como fenómeno social desde una perspectiva histórica. Seguidamente se realiza un análisis global de la evolución de las políticas de discapacidad en España, especialmente en el contexto de la construcción del sistema público de servicios sociales, que se inició durante la década de los ochenta del siglo pasado. Además, se resalta la importancia de algunas de las leyesmarco que han regulado los derechos de las personas con discapacidad en nuestro país, desde la citada LISMI hasta la actual Ley General de Derechos de las Personas con Discapacidad y de su Inclusión Social, pasando por la Ley de Igualdad de Oportunidades, no Discriminación

Revista Española de Discapacidad, 3 (2): I 5 I-I 53. 
y Accesibilidad Universal de las Personas con Discapacidad (LIONDAU); la Ley de Promoción de la Autonomía Personal y Atención a las personas en situación de dependencia; la Ley 49/2007 por la que se establecía el régimen de infracciones y sanciones en materia de igualdad de oportunidades, no discriminación $y$ accesibilidad universal de las personas con discapacidad y la Ley 26/20 I I de Adaptación Normativa a la Convención Internacional sobre los Derechos de las Personas con Discapacidad. En el plano internacional, se destaca la Convención sobre los Derechos de las Personas con Discapacidad de Naciones Unidas, que entró en vigor en España en mayo de 2008.

El segundo capítulo, uno de los centrales del trabajo, profundiza en las políticas públicas sobre discapacidad en España desde 1982 hasta 2013 , un período en el que tiene lugar una paulatina transición desde un enfoque de actuación sustentado en parámetros médicos hacia el reconocimiento de derechos.

Las políticas de educación, empleo o las relativas a la autonomía personal y atención de la dependencia son desgranadas en este capítulo, resaltando las potencialidades y limitaciones de las principales normas en estos tres ámbitos a la par que se presentan algunos resultados de la aplicación de dichas políticas. Tras el análisis de estas tres áreas de las políticas de discapacidad, el texto realiza un análisis crítico del impacto de esa normativa en las personas con discapacidad y propone la reflexión en torno a los motivos por los cuáles los avances legislativos en materia de discapacidad no siempre tienen un impacto trascendente en la vida de las personas a las que se dirigen.

Con el fin de aproximarnos a la relación entre las políticas públicas y la experiencia vital de los jóvenes con discapacidad, la investigación parte de historias concretas, dando voz a sus protagonistas y reconstruyendo la experiencia que supone vivir en el mundo actual siendo una persona (joven) con discapacidad.

La selección de los entrevistados, todos jóvenes nacidos en la década de I980, tiene en cuenta distintos factores. Para obtener un marco lo más amplio posible de experiencias diversas se buscó una representatividad social (no estadística) que permitiera la obtención de distintas posiciones discursivas. De este modo, se consideraron variables como el género, la posición social, el lugar de residencia, el nivel educativo, el tipo y grado de discapacidad y el momento en la que ésta se produce, en relación con la situación vital de la persona.

El análisis de las entrevistas realizadas a jóvenes con discapacidad nos presenta diferentes habitus de la discapacidad que se ven influidos no sólo por la misma sino también por la posición social de partida de dichos jóvenes. El análisis se presenta desde las propias palabras de los entrevistados, a través de los que conocemos sus formas de afrontar la condición o "etiqueta" de persona con discapacidad y sus trayectorias vitales, dentro de los contextos sociales, familiares y económicos en los que las personas se insertan, así como de las estructuras sociales en las que se enmarcan sus prácticas cotidianas.

Como conclusión, los autores hacen un breve balance de la situación de las personas con discapacidad en nuestro país, relacionándola con los avances normativos en materia de discapacidad de las últimas décadas y argumentando que, en base a los datos aportados por la investigación, las políticas públicas sobre discapacidad distan aún de ser efectivas para lograr una equiparación en las condiciones vitales del colectivo en relación con las personas sin discapacidad.

Aunque en el ámbito legislativo el avance ha sido notable en los últimos 30 años, las experiencias vitales indican que el alcance de las políticas públicas ha sido limitado y los obstáculos en el acceso a la educación, al empleo, a la vivienda y a la independencia personal y económica sitúan a estas personas en una posición de vulnerabilidad que puede ser mayor dependiendo de la condición socioeconómica de cada persona, afectando de distinta manera en función del género, la posición social, la educación o el tipo de discapacidad, entre otras cuestiones. 
Esta situación se deriva en parte de una persistencia de estereotipos sociales vinculados con la discapacidad. Como advierte el texto, si bien en algunos aspectos como la supresión de barreras arquitectónicas en los espacios públicos parecen haberse registrado significativos avances, las barreras mentales en torno a las personas con discapacidad persisten en nuestra sociedad a pesar de la normativa dirigida a conseguir una mayor integración.
Para los autores de la publicación es necesario reivindicar el valor de la diversidad e impulsar una participación de las personas con discapacidad como sujetos de pleno derecho, para que los avances legislativos y las políticas públicas dirigidas al colectivo tengan un impacto real y efectivo en sus destinatarios. 



\section{BREVES RESEÑAS BIOGRÁFICAS}



Francisco Alcantud Marín es catedrático de Psicología Evolutiva y de la Educación y director del Centro Universitario de Diagnostico y Atención Temprana de la Universitat de València.

Yurena Alonso Esteban es doctora en Psicología y técnico superior de apoyo a la investigación de la Unidad de Investigación Acceso del Departamento de Psicología Evolutiva y de la Educación de la Universidad de Valencia.

María Luisa Avalos Latorre es licenciada en psicología, maestra en Ciencias del Comportamiento con énfasis en Análisis de la Conducta y Doctorado en Psicología. Actualmente, desarrolla Estancia Posdoctoral en el Doctorado Interinstitucional en Psicología en la Universidad Michoacana de San Nicolás de Hidalgo. Candidata a Investigadora Nacional por el CONACYT. Docente en la licenciatura de Médico Cirujano y Partero en CUTonalá de la Universidad de Guadalajara en Jalisco (México), docente en la Maestría en Ciencias de la Salud en el Trabajo en el CUCS y tutor en el Doctorado Interinstitucional en Psicología. Diseñadora y coordinadora de talleres y cursos presenciales y virtuales relacionados con estilos de crianza, violencia de pareja y estrategias terapéuticas cognitivo conductuales para psicólogos. Es miembro fundador del Sistema Mexicano de Investigación en Psicología y de la Red Mexicana de Investigación en Psicología Educativa (REMIPE). Secretaria del Consejo Académico del Doctorado Interinstitucional en Psicología en la Universidad de Guadalajara.
Juan Carlos Belda Oriola es psicólogo especialista en Psicología Clínica. Trabajó desde 1982 en Atención Temprana y Salud Mental Infantil. En la actualidad es personal estatutario de la Conselleria de Sanidad de la Comunidad Valenciana. Desde I982 pertenece a Asociaciones relacionadas con la Discapacidad. Asimismo, es socio promotor y fundador de la Asociación Valenciana de Atención Temprana, donde ha desempeñado los cargos de secretario, vicepresidente y presidente. Presidente de la Federación Estatal de Asociaciones de Profesionales de Atención Temprana (G.A.T.), ha publicado libros y artículos sobre Atención Temprana y Psicología.

Esther Carrasco Rivero es psicóloga de la Asociación ASPAYM Córdoba. Licenciada en Psicología por la Universidad de Granada, máster en Psicología Clínica y de la Salud por ADEIT y la Universidad de Valencia, y monitora sociocultural. Acumula experiencia como psicóloga en diferentes asociaciones y entidades sobre diversidad funcional, acogimiento familiar, violencia de género, alcoholismo y otras dependencias, colectivos de tercera edad, de la mujer, educativos y juveniles. 
José Luis Cuesta Gómez es profesor y doctor en Ciencias de la Educación por la Universidad de Burgos. Licenciado en Pedagogía Terapéutica por la Universidad Pontificia de Salamanca. Entre sus líneas principales de investigación destacan el autismo y calidad de vida, la calidad de servicios para personas con discapacidad y las necesidades de las personas con TEA a lo largo del ciclo vital. Presidente de la Asociación Española de Profesionales del Autismo (AETAPI).

Jesús Armando Delgado Meza es docente investigador perteneciente al grupo UDIPSI de la Corporación Universitaria de Investigación y Desarrollo -UDI de Colombia.

Ignacio Haya SALmón es doctor en Educación por la Universidad de Cantabria. Su actividad investigadora se centra en el estudio de los procesos de inclusión y exclusión social y educativa. De manera más concreta, ha participado en distintos proyectos de investigación del plan nacional que tienen como objetivo identificar las barreras y ayudas que diferentes colectivos en situación de riesgo de exclusión socioeducativa identifican en sus trayectorias vitales. Fruto de esos trabajos cuenta con diversas publicaciones en revistas nacionales e internacionales como Revista de Educación o British Journal of Learning Disabilities, entre otras. Actualmente imparte docencia en la Facultad de Educación en asignaturas vinculas con la atención a la diversidad y la inclusión educativa.

Cristina Hernández Layna es técnica de investigación del área de Asesoramiento y Orientación TEA de la Confederación Autismo España.
Susana Lázaro Visa es doctora en Psicología por la Universidad de Salamanca. Su interés investigador se centra en la promoción del bienestar en población en situación de vulnerabilidad, abordando el estudio de factores protectores y participando en el diseño de diferentes programas de intervención que han sido publicados en la editorial Pirámide. Actualmente desarrolla su actividad docente e investigadora en la Universidad de Cantabria donde imparte distintas materias relacionadas con el desarrollo adolescente y los contextos de riesgo.

María Martínez Lemos es coordinadora del Departamento de Acción Social del MAC, Museo de Arte Contemponáneo Gas Natural Fenosa de A Coruña.

Roberto Montes Delgado es doctor en Psicología de la Salud por la Universidad Michoacana de San Nicolás de Hidalgo, perteneciente al Programa Nacional de Posgrados de Calidad (PNPC) del CONACYT. Profesor e Investigador de Tiempo Completo con perfil PROMEP. Línea de investigación: "Calidad de vida y psicoeducación para el autocontrol de enfermedades crónicas no transmisibles". Ha participado en la publicación de artículos científicos, libros y capítulos de libro. También ha asesorado más de 30 tesis de licenciatura y maestría. Cuenta con I9 años de trabajo en escenarios educativos y de salud comunitaria en las ciudades de Colima y Veracruz. Actualmente es coordinador del Doctorado Interinstitucional en Psicología en la Universidad de Colima (México), coordinador del Programa Psicoeducativo para el Autocontrol de la Diabetes Mellitus tipo 2 en Personas Adultas (PROPAD) en la facultad de psicología, y líder del cuerpo académico UCOLCA-68 psicología social: identidad, socialización y cultura. 
Liliana Elizabeth Otero Caicedo es psicóloga, especialista en Pedagogía de la Creatividad, magister en Discapacidad e Inclusión Social de la Universidad Nacional de Colombia. En la actualidad es docente de la Licenciatura de Artes Visual de la Universidad de Nariño y orientadora de la Fundación Luna Arte. Su recorrido académico y artístico se fundamenta en la emocionalidad y sensibilidad ante las vivencias cotidianas de personas que viven diferentes situaciones de discapacidad, las cuales se materializan en fotografías, escrituras y pinturas enmarcadas en las metodologías artísticas y, principalmente, en la investigación basada en las artes visuales.

Úrsula Palos Toscano es licenciada, maestra y doctora en Psicología. Cursa la Estancia Posdoctoral en el Doctorado Interinstitucional en Psicología en la Universidad de Colima. Es Psicóloga Especialista en el nivel de Educación Especial de la Secretaria de Educación Pública de Guadalajara, en Jalisco (México). Docente en la licenciatura de Psicología Clínica en el Centro Mexicano de Programación Neurolinguística, tutor en el Doctorado Interinstitucional en Psicología con sede en la Universidad de Colima, México. Ha participado en foros nacionales e internacionales con la presentación de propuestas derivadas del trabajo de investigación y vinculadas al desarrollo de competencias cognitivas, la mediación de éstas y sobre la inclusión escolar: Diseñadora y coordinadora de talleres y cursos sobre Disciplina en el Aula, Competencias Docentes e Inclusión Educativa. Ha publicado artículos sobre Educación e Investigación educativa, y es coautora de textos como: Desarrollo de competencias cognitivas en preescolar: experiencias y propuestas, Narraciones Docentes Editados por ITESO en 2008 y 2009 respectivamente.
Marta Plaza Sanz es técnica de investigación del área de Asesoramiento y Orientación TEA de la Confederación Autismo España.

Darío Rico Bañón es Doctor en Psicología y Coordinador de Centro Universitario de Diagnostico y Atención Temprana.

Jesús Rodríguez López es psicólogo clínico, asesor técnico del Departamento de Acción Social del MAC, Museo de Arte Contemporáneo Gas Natural Fenosa de A Coruña.

Susana Rojas Pernia es doctora por la Universidad Autónoma de Barcelona. Actualmente trabaja como profesora e investigadora en la Universidad de Cantabria donde imparte distintas asignaturas en el marco de la Educación Inclusiva. Sus principales intereses de investigación se centran en la Autodeterminación de las personas con discapacidad intelectual y en los Procesos de Inclusión y Exclusión Educativa. Ha participado en diferentes proyectos de investigación competitivos y es autora de artículos publicados en revistas nacionales e internacionales como Revista de Educación o Journal of Inclusive Education.

\footnotetext{
El SiIS Centro de Documentación y Estudios, perteneciente a la Fundación Eguía-Careaga, es una institución sin ánimo de lucro dedicada desde 1972 a actividades de documentación e investigación en el ámbito del bienestar social. Especializada inicialmente en el ámbito de la discapacidad intelectual, dispone hoy día de uno de los fondos más importantes de Europa sobre políticas y servicios sociales en general. A través de un convenio con el Real Patronato sobre Discapacidad, desde 1979 gestiona el Centro Español de Documentación sobre Discapacidad.
} 
Ana María Valenzuela Rabi es docente universitaria, asesora de diseño curricular e investigadora con formación en métodos cualitativos en la Universidad Santiago de Chile..
Ruth VidRiales FernándeZ es licenciada en Psicología y responsable del área de Asesoramiento y Orientación TEA de la Confederación Autismo España desde 2005. 


\section{Extracto de las normas de presentación de originales}

La Revista Española de Discapacidad (REDIS) es un espacio abierto a la publicación de artículos por parte de profesionales, investigadores, representantes institucionales y de todas aquellas personas interesadas que trabajan e investigan en el campo de la discapacidad, desde una perspectiva multidisciplinar.

Los artículos deben ser inéditos y estar relacionados con los objetivos de la revista (proporcionar un marco para la reflexión y el análisis en materia de discapacidad desde distintas áreas y disciplinas científicas y producir conocimiento teórico y aplicado en materia de discapacidad).

Una vez recibidos, los artículos serán sometidos a un proceso de revisión anónima por pares, por parte de especialistas externos a la revista, que son invitados a participar en el proceso de revisión contando con el aval del Consejo de Redacción. Desde el punto de vista formal los manuscritos deberán cumplir las siguientes pautas:

- El texto del manuscrito propuesto debe contar con una extensión máxima de $\mathbf{1 0 . 0 0 0}$ palabras, excluyendo título, resúmenes, palabras clave y bibliografía (con interlineado 1,15 en letra Arial 11, sin justificar el texto y sin sangrías al comienzo).

- Los trabajos irán precedidos del título en español y en inglés; nombre de autor/a o autores; su adscripción institucional y su dirección email de contacto; un breve resumen de entre 100 y 150 palabras, que tendrá una versión en español y otra en inglés (abstract), de idéntico contenido; y palabras clave (entre 4 y 8) en español con su correspondiente traducción en inglés (keywords); también deberán ir acompañados por una breve reseña biográfica de cada autor/a (no más de 150 palabras por cada persona).

- Las notas irán a pie de página. Las referencias bibliográficas de los artículos seguirán las normas ISO 690/2010. Para más detalle, véanse las directrices para autores.

Los interesados e interesadas podrán mandar los manuscritos originales a través de la aplicación informática destinada a tal efecto o por correo electrónico <redis@cedd.net>.

Una vez aceptados los artículos para su publicación, la dirección de la revista se reserva el derecho a modificar el título y epígrafes de los textos, así como de realizar las correcciones de estilo que se estimen convenientes, de acuerdo con las normas de estilo de la revista.

Para ver nuestros últimos números, haz click aquí.

Para más información:

Teléfono: +34 9174524 46/47

http://www.cedd.net/redis 

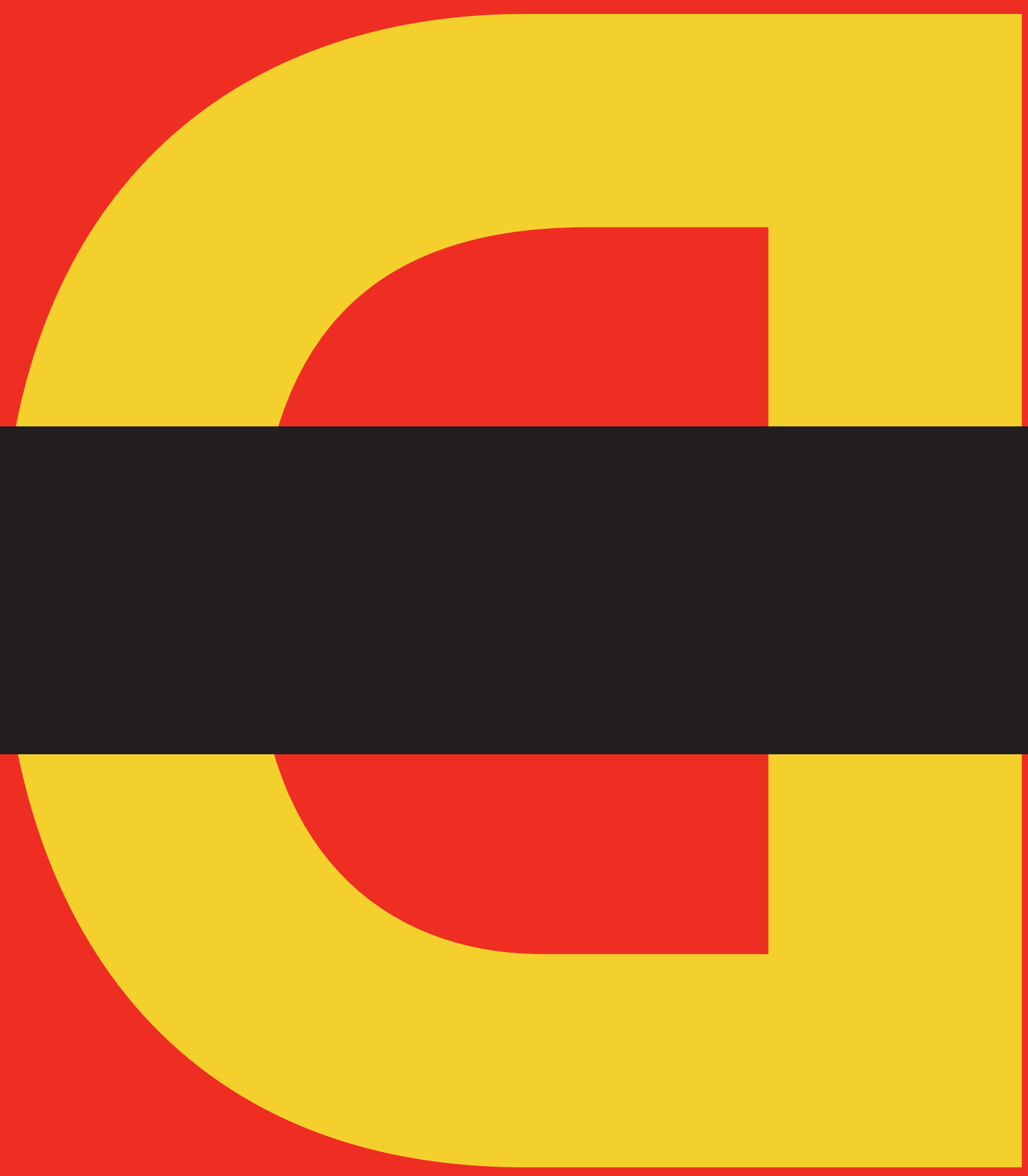

10 